ALEXANDER ALVAREZ ROSARIO

\title{
ANÁLISE ESTATÍSTICA MULTIVARIADA PARA RECONHECIMENTO DE PADRÕES EM ENSAIOS NÃO DESTRUTIVOS MAGNÉTICOS
}

Dissertação apresentada á Escola Politécnica da Universidade de São Paulo para obtenção do título de Mestre em Engenharia 
ALEXANDER ALVAREZ ROSARIO

\title{
ANÁLISE ESTATÍSTICA MULTIVARIADA PARA RECONHECIMENTO DE PADRÕES EM ENSAIOS NÃO DESTRUTIVOS MAGNÉTICOS
}

\author{
Dissertação apresentada á Escola \\ Politécnica da Universidade de São Paulo \\ para obtenção do título de Mestre em \\ Engenharia \\ Área de concentração: \\ Projeto e fabricação \\ Orientador: \\ Prof. Dr. Linilson Rodrigues Padovese
}

São Paulo

2011 
Este exemplar foi revisado e alterado em relação à versão original, sob responsabilidade única do autor e com a anuência de seu orientador.

São Paulo, de março de 2011.

Assinatura do autor

Assinatura do orientador

FICHA CATALOGRÁFICA

Alvarez Rosário, Alexander

Análise estatística multivariada para reconhecimento de padrões em ensaios não destrutivos magnéticos / A. Alvarez Rosário. -- ed.rev. -- São Paulo, 2011.

$147 \mathrm{p}$.

Dissertação (Mestrado) - Escola Politécnica da Universidade de São Paulo. Departamento de Engenharia Mecânica.

1. Ensaios não destrutivos 2. Reconhecimento de padrões 3. Análise multivariada 4. Análise discriminante I. Universidade de São Paulo. Escola Politécnica. Departamento de Engenharia Mecânica II. t. 


\section{DEDICATÓRIA}

A minha amada mãe, Yorman, quem constantemente me motiva e desde sempre tem se sacrificado pela minha formação.

A memória do meu amado pai, Gonzalo, quem vive por sempre no meu coração.

A meu querido filho, Nicolas, motivo de muitas alegrias e retos.

A meus irmãos Darleds, Carlos, John e Jeimmy.

A Jaqueline, o meu amor e inspiração. 


\section{AGRADECIMENTOS}

A DEUS, por me permitir viver e realizar este outro dos seus planos.

Ao meu irmão, John, quem fez possível esta grande experiência para mim no Brasil.

Ao Prof. Dr. Linilson Rodrigues Padovese, pela oportunidade oferecida, pela amizade e pelo apoio e pela confiança depositada em mim.

À CNPq, pela concessão da bolsa e pelo apoio financeiro, o que possibilito a minha permanência no Brasil e dessa forma, conseguir realizar meus estudos de mestrado.

Aos professores jurados da qualificação, Dr. João Eduardo Ferreira e Dr. Antonio Domingues dos Santos pelos seus valiosos aportes para alcançar os objetivos do projeto.

Aos colegas do Laboratório LADIN, Dr. Julio Capó, Dr. José Benitez, Dr. Carlos Shiniti, Manuel Caldas, Ana e especialmente ao Dr. Fredy Franco e Manuel Alberteris pelas conversas, sugestões e a grande amizade.

A os meus amigos colombianos Ediguer F, Adriana G, German, Loer F, Miguel M, German R, Natalia L, Dairo M, Olga P, Mario G, John C. e a todos aqueles que me ajudaram e fizeram a minha estância no Brasil mais agradável.

E a todas as outras pessoas que direta ou indiretamente colaboraram com a realização desta dissertação, meu agradecimento. 


\section{RESUMO}

Neste trabalho se estuda a aplicação de técnicas de estatística multivariada para reconhecimento de padrões em sinais de ensaios não destrutivos $(E N D)$ magnéticos, baseados no Ruído Magnético de Barkhausen $(R M B)$. O reconhecimento de padrões pode ser feito de forma não supervisionada com a técnica multivariada de Análise de Agrupamentos, conglomerados ou "Clusters" que definem grupos segundo critérios de similaridade. Já para reconhecimento supervisionado a Análise Discriminante procura classificar amostras novas em grupos conhecidos, a-priori, usando para este propósito uma regra de classificação criada a partir desses grupos de amostras conhecidos.

Foram utilizados dois casos de deteç̧ão e classificação utilizando $R M B$. O RMB é um fenômeno magnético gerado por abruptas mudanças na magnetização de materiais ferromagnéticos quando submetidos a campos magnéticos variáveis. Essas mudanças estão relacionadas com a microestrutura do material, presença e distribuição de tensões elásticas (tensão e compressão).

No primeiro caso de estudo procura-se identificar arames quebrados em risers, através da medição de tensão mecânica. No segundo caso procura-se classificar diferentes tratamentos térmicos em Aço AISI 420. Para a análise de integridade estrutural de risers foi feita a redução da dimensionalidade dos dados via Análise de Componentes Principais e posteriormente Análise de Agrupamentos. Já para o problema de classificação de amostras de aço foi usada a técnica de Análise Discriminante Linear de Fisher e a Quadrática. Os resultados das análises mostraram que as técnicas de Estatísticas Multivariadas proporcionam ferramentas muito adequadas para aumentar a eficiência da inspeção na área de END Magnéticos em geral e $R M B$ em particular.

Palavras chave:

Ensaios não destrutivos magnético, Reconhecimento de padrões, Análise multivariada, Análise discriminante. 


\begin{abstract}
The present work deals with application of multivariate statistic techniques for pattern recognition in signals from Non-Destructive Essays (NDE), based on the Magnetic Barkhausen Noise (MBN). Pattern recognition can be done in a nonsupervised way by Cluster Analysis defining similarity criteria. On the other hand, for supervised recognition, Discriminant Analysis looks for classifying new samples in known groups, a priori, by means of classification rules created for these known sample groups.

Two detection and classification cases were studied by MBN.

The MBN is a magnetic phenomenon generated by sudden changes in magnetization of ferromagnetic materials, when these materials are subjected to variable magnetic fields. These changes are related to material microstructure as well as to the presence of elastic stresses (tension and compression).

In the first studied case, the present study searches identifying broken wires in risers through measurements of mechanical strain. In the second case, the study classifies different thermal treatments in AISI 420 steel samples. Regarding the analysis of structural integrity of risers, firstly the reduction of data dimensionality was obtained via Analysis of Main Components and, later, Cluster Analysis was performed. Concerning the classification problem of steel samples, the Fisher Linear Discriminant Analysis and the Quadratic Analysis were used. Analysis results showed that Multivariate Statistic Techniques give rise to tools very appropriated for increasing the efficiency of inspection both in the Magnetic NDE area in general, and MBN in particular.
\end{abstract}

Keywords:

Non-destructive testing, Pattern Recognition, Multivariate analysis, Discriminant analysis. 


\section{LISTA DE FIGURAS}

FIGURA 1 - FASES PARA AVALIAÇÃO DA QUALIDADE DOS DADOS SEGUNDO HAIR (HAIR ET AL., 1999)

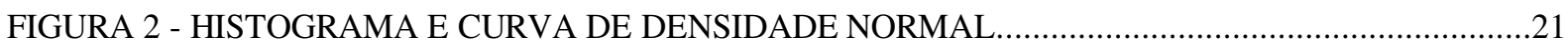

FIGURA 3 - GRÁFICO DE DISPERSÃO DE DADOS PARA UMA AMOSTRA NORMAL ...........................22

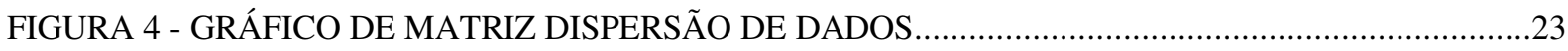

FIGURA 5 - DIAGRAMA DE CAIXAS E FUNÇÃO DENSIDADE DE PROBABILIDADE...........................24

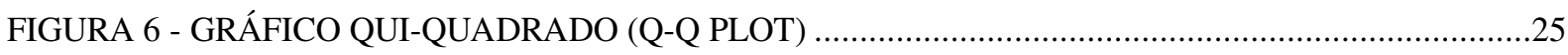

FIGURA 7 - COMPONENTES PRINCIPAIS $C P_{1}$ E $C P_{2}$ OBTIDOS PARA UM CONJUNTO DE DADOS

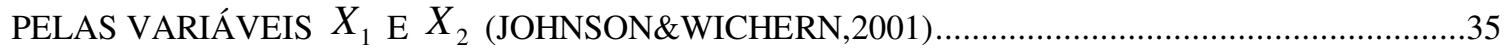

FIGURA 8 - SCREE-PLOT PARA UM CONJUNTO DE 12 COMPONENTES PRINCIPAIS [CRAN.R]........36

FIGURA 9 - ESQUEMA DE ARMAZENAMENTO DE DISTÂNCIAS NUMA MATRIZ $4 \times 4$,

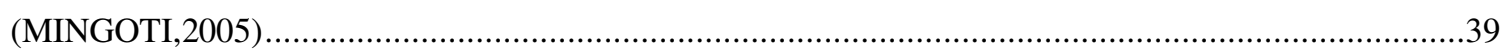

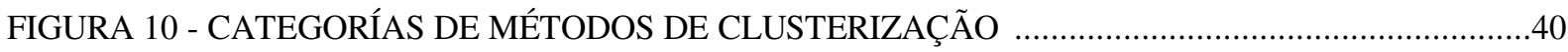

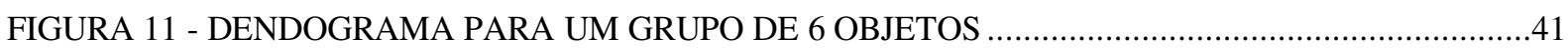

FIGURA 12 - DISCRIMINAÇÃO DE DUAS POPULAÇÕES NORMAIS. FUNÇÃO DISCRIMINANTE DE

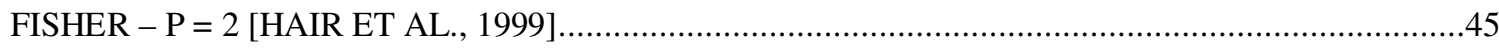

FIGURA 13 - ILUSTRAÇÃO DA CLASSIFICAÇÃO DE DUAS POPULAÇÕES NORMAIS COM MESMA

VARIABILIDADE E UMA VARIÁVEL DISCRIMINANTE (SUELI, 2005).........................................46

FIGURA 14 - EXPERIMENTO FEITO POR HEINRICH BARKHAUSEN, (FRANCO,2010)........................49

FIGURA 15 - ESQUEMA DE MOVIMENTAÇÃO DE PAREDES DE DOMÍNIO NA CURVA DE

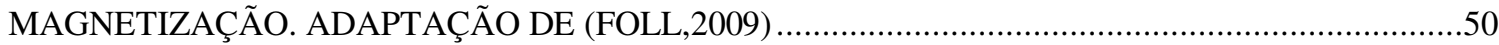

FIGURA 16 - CURVA DE MAGNETIZAÇÃO PARA UMA LIGA FE-SI 3\% (CHIH,1986).............................50

FIGURA 17 - REORIENTAÇÃO DE DOMÍNIOS PRODUZIDA POR TENSÃO MECÂNICA

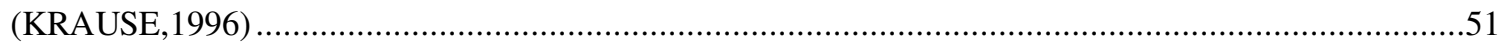

FIGURA 18 - EXEMPLO DO ENVELOPE DO SINAL RMB (FRANCO,2010) …...........................................54

FIGURA 19 - REPRESENTAÇÃO GRÁFICA DE UM EVENTO BARKHAUSEN ……….............................56

FIGURA 20 ESQUEMA DA AMOSTRA E DIREÇÃO DOS CARREGAMENTOS ….......................................

FIGURA 21 - MONTAGEM FINAL DA AMOSTRA E EQUIPAMENTO DE MEDIÇÃO................................58

FIGURA 22 - CONFIGURAÇÃO TÍPICA DE UM DUTO FLEXÍVEL DO TIPO UNBOUNDED

(MARTINS, 2008)

FIGURA 23 - EQUIPAMENTO DE MEDIÇÕES DO RUÍDO MAGNÉTICO DE BARKHAUSEN,

BARKTECH.

FIGURA 24 - FOTOGRAFIA DE SONDA RMB PARA ENSAIOS DE FLEXÃO (FRANCO,2010)

FIGURA 25 - ESQUEMA DO POSICIONAMENTO DAS SONDAS DE LEITURA PARA O RISER, CORTE

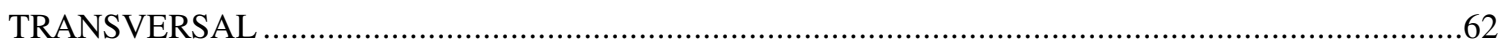

FIGURA 26 - MONTAGEM DO SISTEMA DE EXCITAÇÃO, LEITURA E AMOSTRA ................................62 
FIGURA 27 - SINAL RMB TÍPICO (LINHA AZUL) MEDIDO NO RISER E SINAL DE EXCITAÇÃO (LINHA VERMELHA)

FIGURA 28 - APLICATIVO BARKFLEX, SOFTWARE DE AQUISIÇÃO DE SINAIS RMB .63

FIGURA 29 - FLUXOGRAMA DOS MÉTODOS EMPREGADOS PARA A ANÁLISE DOS SINAIS RMB PARA O RISER.

FIGURA 30 - DIAGRAMA DE BLOCOS DOS PASSOS PARA IDENTIFICAÇÃO E TRATAMENTO DOS VALORES DISCREPANTES

FIGURA 31 - DIAGRAMA DE CAIXAS (BOX-PLOT) PARA A O PARÂMETRO $R M B_{r m s}$ QUANDO O CARREGAMENTO APLICADO É 80 TONELADAS

FIGURA 32 - DIAGRAMA DE CAIXAS (BOX-PLOT) PARA A O PARÂMETRO $R M B_{r m s}$ QUANDO O CARREGAMENTO APLICADO É 150 TONELADAS

FIGURA 33 - DIAGRAMA DE CAIXAS (BOX-PLOT) PARA A O PARÂMETRO $R M B_{r m s}$ QUANDO O CARREGAMENTO APLICADO É 220 TONELADAS

FIGURA 34 - GRÁFICO DE CAIXA PARA A VARIÁVEL $R M B_{r m s}$, DO SENSOR NÚMERO 28 ,

QUANDO O CARREGAMENTO É DE 80 TONELADAS.

FIGURA 35 - GRÁFICO $Q-Q N O R M A L$, PARA A VARIÁVEL $R M B_{r m s}$, DO SENSOR NÚMERO 28 , QUANDO O CARREGAMENTO É DE 80 TONELADAS.

FIGURA 36 - GRÁFICO DO SINAL RMB, PARA AS OBSERVAÇÕES NÚMERO 18 E 20, E COMPARAÇÃO COMO UM SINAL PADRÃO. SINAL ARQUIVO NO. 18 (A), SINAL ARQUIVO NO. 20 (B), SINAL DE REFERÊNCIA (C)

FIGURA 37 - COMPARATIVO DOS ESPECTROGRAMAS DE UM SINAL PADRÃO (A), E OS SINAIS DOS ARQUIVOS NÚMERO 18 (B) E 20 (C), RESPONSÁVEIS PELOS VALORES DISCREPANTES DO SENSOR NÚMERO 28, QUANDO O CARREGAMENTO É DE 80 TONELADAS.

FIGURA 38 - GRÁFICOS DE DISPERSÃO ENTRE AS VARIÁVEIS AMPLITUDE DE PICO, ENERGIA, NÚMERO DE EVENTOS, POSIÇÃO DO PICO E RMS PARA O CARREGAMENTO DE 80 TONELADAS.

FIGURA 39 - GRÁFICOS DE DISPERSÃO BIVARIADO PARA OS PARÂMETROS RMS E ENERGIA, QUANDO O CARREGAMENTO É DE 80 TONELADAS (AMPLIAÇÃO DO QUADRANTE VERMELHO NA FIGURA 38).

FIGURA 40 - GRÁFICO QUI-QUADRADO (Q-Q PLOT) DAS DISTÂNCIAS $D_{J}^{2}$ PARA OS PARÂMETROS DO SINAL RMB, DOS 37 SENSORES E OS TRÊS CARREGAMENTOS DE 80, 150 E 220 TONELADAS .78

FIGURA 41 - SCREE-PLOT DAS 5 PRIMEIRAS COMPONENTES PRINCIPAIS ……...............................84

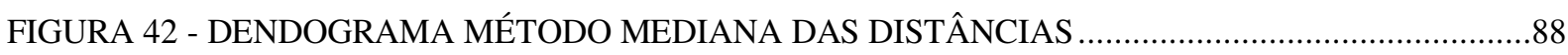

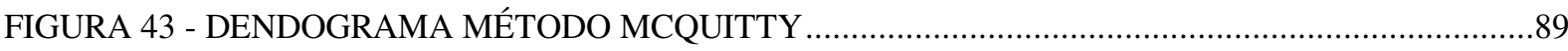

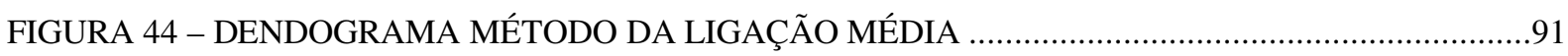
FIGURA 45 CARACTERÍSTICAS DIMENSIONAIS DAS AMOSTRAS DE AÇO (A), AMOSTRAS ANTES DO TRATAMENTO TÉRMICO. 
FIGURA 46 - CARACTERÍSTICAS MECÂNICAS X TEMPERATURA REVENIMENTO, TOMADO DE FAVORIT (FAVORIT, 2010)

FIGURA 47 - COMPORTAMENTO DA MACRO E MICRODUREZA PARA AS AMOSTRAS DE AÇO AISI 420, SEGUNDO O TRATAMENTO DE TÊMPERA E/OU REVENIDO EMPREGADA.........................98

FIGURA 48 - FOTOGRAFIA DE SONDA $R M B$ PARA ENSAIOS DE FLEXÃO (FRANCO,2010) ................98 FIGURA 49 - FLUXOGRAMA DOS MÉTODOS EMPREGADOS PARA A ANÁLISE DOS SINAIS RMB

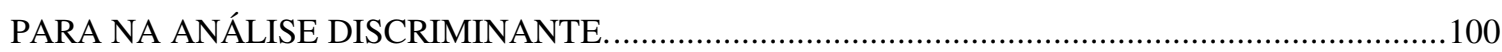

FIGURA 50 - SINAL RMB TÍPICA PARA AS AMOSTRAS T00 (A), T01 (B) E T14 (C)...........................101

FIGURA 51 - - SINAL RMB TÍPICA PARA AS AMOSTRAS T10 (A), T11 (B) E T12 (C).........................102

FIGURA 52 - SINAL RMB TÍPICA PARA AS AMOSTRAS T13 …......................................................102

FIGURA 53 - PARÂMETROS RMS, ENERGIA E NUMERO DE EVENTOS DO SINAL RMB VS.

MACRODUREZA DO MATERIAL, SEGUNDO TRATAMENTO TÉRMICO. 103

FIGURA 54 - PARÂMETROS APICO E PPICO DO SINAL RMB VS. MACRODUREZA DO MATERIAL, SEGUNDO TRATAMENTO TÉRMICO. .104

FIGURA 55 - FUNÇÕES DE DENSIDADE DE PROBABILIDADE PARA O PARÂMETRO RMS DOS SINAIS RMB, SEGUNDO O TIPO DE TRATAMENTO TÉRMICO. .108

FIGURA 56 - FUNÇÕES DE DENSIDADE DE PROBABILIDADE PARA O PARÂMETRO ENERGIA DOS SINAIS RMB, SEGUNDO O TIPO DE TRATAMENTO TÉRMICO .108

FIGURA 57 - FUNÇÕES DE DENSIDADE DE PROBABILIDADE PARA O PARÂMETRO NÚMERO DE EVENTOS DOS SINAIS RMB, SEGUNDO O TIPO DE TRATAMENTO TÉRMICO. 109

FIGURA 58 - FUNÇÕES DE DENSIDADE DE PROBABILIDADE PARA O PARÂMETRO AMPLITUDE DO PICO DO ENVELOPE DOS SINAIS RMB, SEGUNDO O TIPO DE TRATAMENTO TÉRMICO.

FIGURA 59 - FUNÇÕES DE DENSIDADE DE PROBABILIDADE PARA O PARÂMETRO POSIÇÃO DO PICO DO ENVELOPE DOS SINAIS RMB, SEGUNDO O TIPO DE TRATAMENTO TÉRMICO......110 FIGURA 60 - DIAGRAMAS DE DISPERSÃO MULTIVARIADO V1 (RMS), V2 (ENERGIA), V3 (NÚMERO DE EVENTOS), V4 (ALTURA DO PICO) E V5 (POSIÇÃO DO PICO).

FIGURA 61 - PROCESSO DE LEITURA DE ARQUIVOS POR UM SENSOR, SEGUNDO O PLANEJAMENTO EXPERIMENTAL DO RISER (OS VALORES DE 80, 150 E 220 CORRESPONDEM COM OS NÍVEIS DE CARREGAMENTO APLICADOS) 


\section{LISTA DE TABELAS}

TABELA 1 - DESENHO EXPERIMENTAL DE MEDIÇÕES

TABELA 2 - VALORES DOS PARÂMETROS CALCULADOS DO SINAL RMB - CARREGAMENTO DE

80 TONELADAS

TABELA 3 - VALORES DOS PARÂMETROS CALCULADOS DO SINAL RMB - CARREGAMENTO DE

150 TONELADAS.

TABELA 4 - VALORES DOS PARÂMETROS CALCULADOS DO SINAL RMB - CARREGAMENTO DE

220 TONELADAS.

TABELA 5 - RESUMO DE VALORES DISCREPANTES SEGUNDO CARREGAMENTO. . .70

TABELA 6 - NÚMERO DE VALORES DISCREPANTES EM FUNÇÃO DO SENSOR, PARA

CARREGAMENTO DE 80 TONELADAS

TABELA 7 - NÚMERO DE VALORES DISCREPANTES EM FUNÇÃO DO SENSOR, PARA

CARREGAMENTO DE 150 TONELADAS

TABELA 8 - NÚMERO DE VALORES DISCREPANTES EM FUNÇÃO DO SENSOR, PARA

CARREGAMENTO DE 220 TONELADAS

TABELA 9 - DISTÂNCIAS DE MAHALANOBIS D2J, DA MATRIZ DE DADOS PADRONIZADOS, PARA

CARREGAMENTO DE 80 TONELADAS.

TABELA 10 - VALORES PADRONIZADOS DOS PARÂMETROS CALCULADOS DO SINAL RMB -

CARREGAMENTO DE 80T. .79

TABELA 11 - VALORES PADRONIZADOS DOS PARÂMETROS CALCULADOS DO SINAL RMB -

CARREGAMENTO DE 150T. .80

TABELA 12 - VALORES PADRONIZADOS DOS PARÂMETROS CALCULADOS DO SINAL RMB -

CARREGAMENTO DE 220T.

TABELA 13 - VALORES DA MATRIZ DE COVARIÂNCIAS S DOS VALORES PADRONIZADOS DOS

PARÂMETROS DO SINAL RMB.

TABELA 14 - FATORES DE CARGA DAS PRIMEIRAS CINCO (5) COMPONENTES PRINCIPAIS PARA

TODOS OS PARÂMETROS CONSIDERADOS NA ANÁLISE. .85

TABELA 15 - CORRELAÇÃO COFENÉTICA DOS RESULTADOS DOS AGRUPAMENTOS......................86

TABELA 16 - CORRELAÇÃO COFENÉTICA DOS RESULTADOS DOS AGRUPAMENTOS.....................90

TABELA 17 - COMPARAÇÃO DOS RESULTADOS OBTIDOS COM MÉTODOS MCQUITTY (M1) E,

LIGAÇÃO DA MEDIANA (M2), RESPEITO À INSPEÇÃO VISUAL..................................................92

TABELA 18 - COMPOSIÇÃO QUÍMICA DO AÇO 420 CONFORME NORMA AISI ..................................94

TABELA 19 - RESULTADOS DA ANÁLISE DE ESPECTROMETRIA DE EMISSÃO ÓPTICA..................94

TABELA 20 - CODIFICAÇÃO DE AMOSTRAS E TRATAMENTOS TÉRMICOS APLICADOS ................95

TABELA 21 - MACRO E MICRODUREZAS DAS MEDIDAS NAS AMOSTRAS DE AÇO AISI 420.........97

TABELA 22 - DESENHO EXPERIMENTAL DAS MEDIÇÕES …….........................................................99

TABELA 23 - NUMERO DE OBSERVAÇÕES DO BANCO DE DADOS PARA ANÁLISE 
TABELA 24 - VALORES MÉDIOS DOS PARÂMETROS CALCULADOS DO SINAL RMB SEGUNDO TRATAMENTO TÉRMICO

TABELA 25 - CORRELAÇÕES ENTRE OS PARÂMETROS DO SINAL RMB E AS MEDIÇÕES DE MACRO-DUREZA MICRO-DUREZA 104

TABELA 26 - MÉDIAS DAS VARIÁVEIS E NÚMERO DAS OBSERVAÇÕES SEGUNDO GRUPO DE TRATAMENTO TÉRMICO. .105

TABELA 27 - TABELA DE TESTE DE HIPÓTESE DE IGUALDADE DOS VETORES DE MÉDIAS (CÁLCULOS ANOVA) 106

TABELA 28 - TESTE DE HOTELLING PARA DIFERENÇA DE MÉDIAS ENTRE GRUPOS 107

TABELA 29 - TESTES PARA HOMOGENEIDADE DAS MATRIZES DE COVARIÂNCIAS DOS GRUPOS DE TRATAMENTOS TÉRMICOS. 110

TABELA 30 - DISTÂNCIA DE MAHALANOBIS 112

TABELA 31 - TABELA DE CLASSIFICAÇÃO TIPO PLUG-IN ANÁLISE LINEAR DE FISHER SEGUNDO TRATAMENTOS TÉRMICOS.

TABELA 32 - TABELA DE CLASSIFICAÇÃO DE VALIDAÇÃO CRUZADA .113

TABELA 33 - DISTÂNCIA DE MAHALANOBIS 113

TABELA 34 - TABELA DE CLASSIFICAÇÃO TIPO PLUG-IN ANÁLISE LINEAR DE FISHER SEGUNDO TRATAMENTOS TÉRMICOS

TABELA 35 - TABELA DE CLASSIFICAÇÃO DE VALIDAÇÃO CRUZADA .114

TABELA 36 - COMPARAÇÃO DOS ERROS DE CLASSIFICAÇÃO SEGUNDO O MODELO LINEAR DE FISHER E O MODELO QUADRÁTICO.

TABELA 37 - VALORES MÉDIOS DOS PARÂMETROS PARA O SENSOR NO. 1 (CARREGAMENTO $80 \mathrm{~T})$.

TABELA 38 - CÁLCULO DOS PARÂMETROS DO SINAL RMB PARA O SENSOR NO. 1 (CARREGAMENTO 80T) 


\section{SUMARIO}

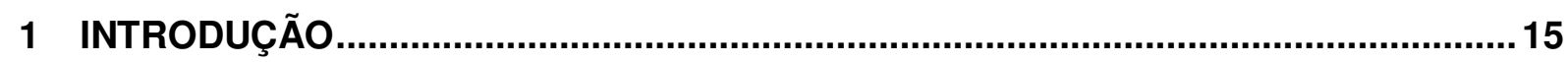

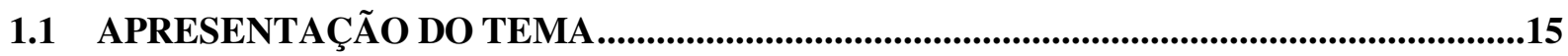

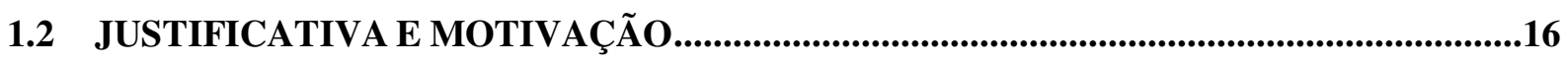

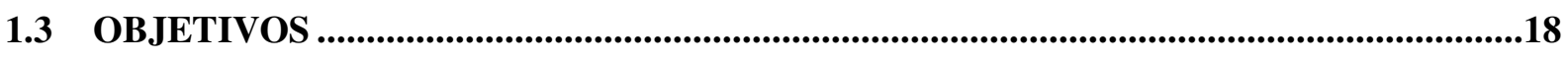

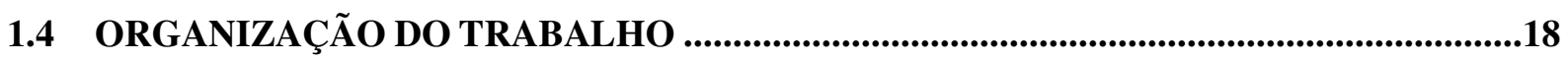

2 ANÁLISE UNIVARIADO E MULTIVARIADO DA QUALIDADE DOS DADOS ..............20

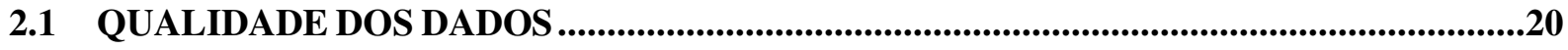

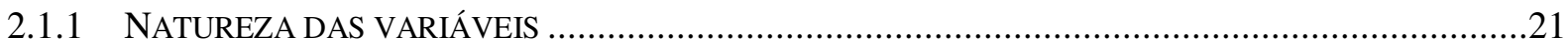

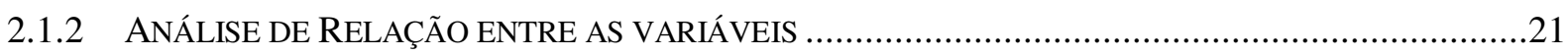

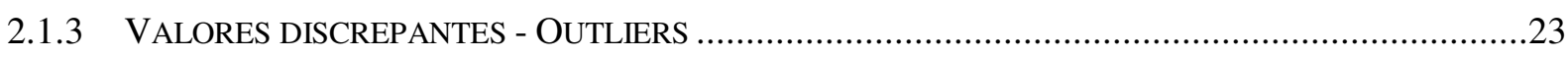

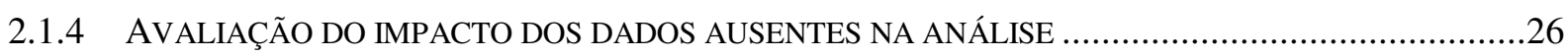

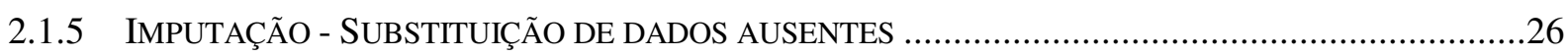

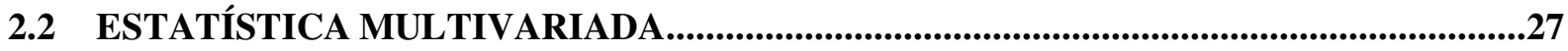

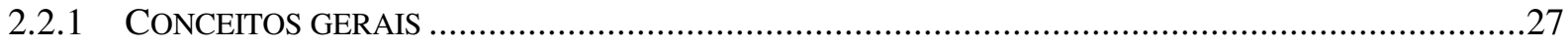

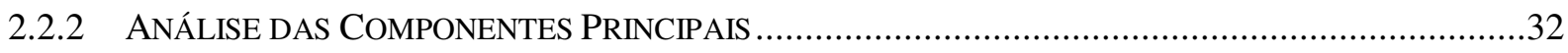

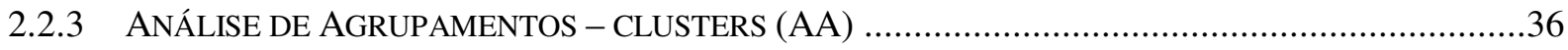

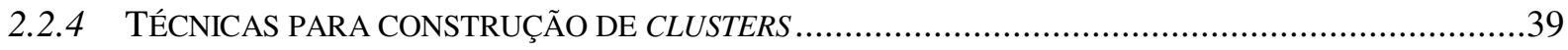

2.2.5 QUALIDADE DO RESULTADO DO AGRUPAMENTO - CORRELAÇão COFENÉTICA .......................44

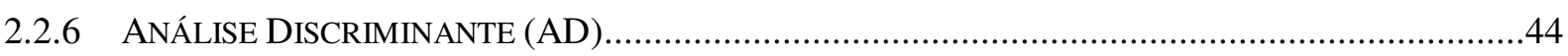

3 RUÍDO MAGNÉTICO DE BARKHAUSEN - RMB................................................... 49

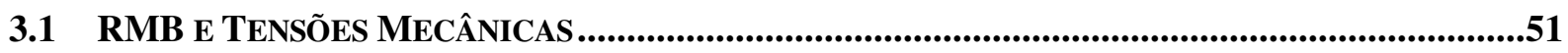

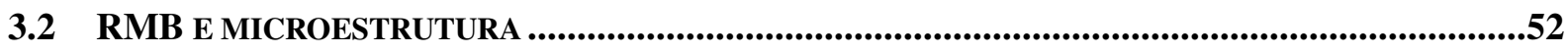

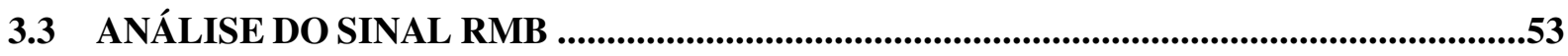

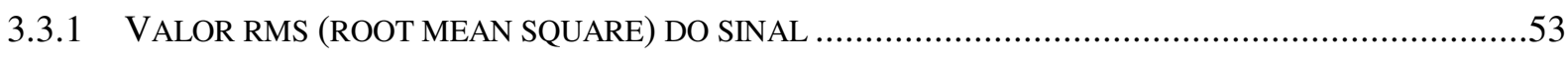

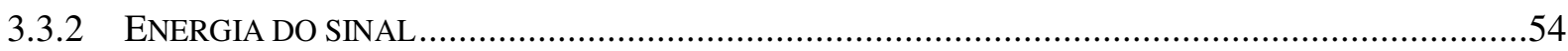

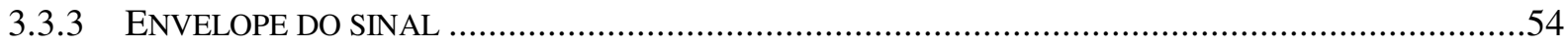

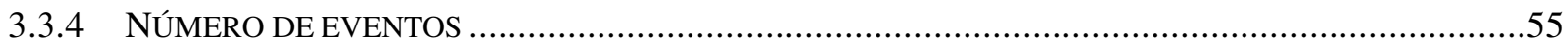

3.3.5 ANÁLISE DO SINAL DE RMB NO DOMÍNIO DA FREQUÊNCIA - ESPECTRO DO SINAL .....................56 


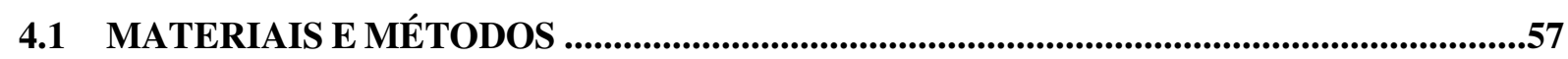

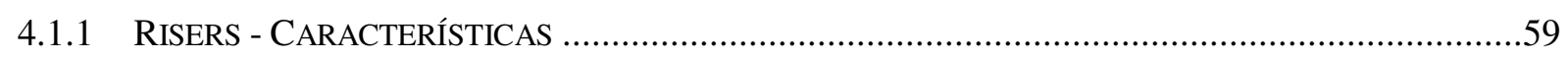

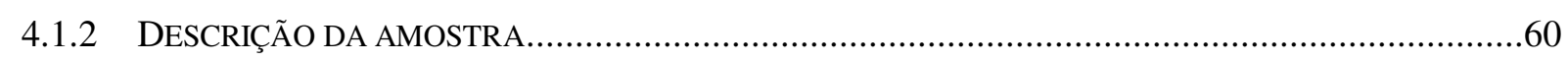

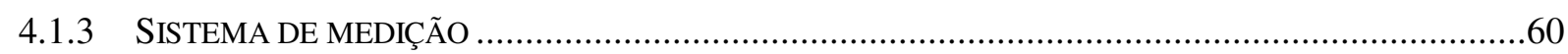

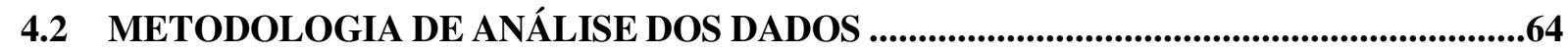

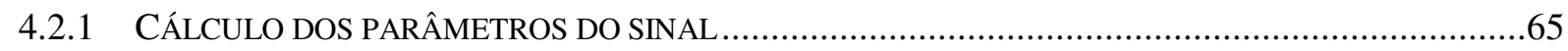

4.2.2 IDENTIFICAÇÃO E TRATAMENTO DOS VALORES DISCREPANTES …........................................68

4.2.3 IDENTIFICAÇÃO DOS SINAIS RESPONSÁVEIS PELOS VALORES DISCREPANTES .........................71

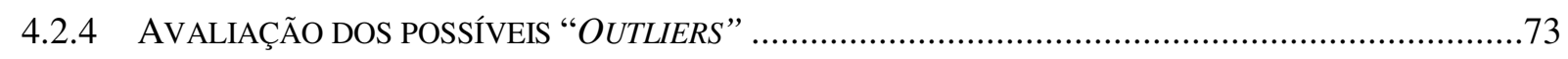

4.2.5 IDENTIFICAÇÃO DE VALORES DISCREPANTES BIVARIADOS E MULTIVARIADOS ........................76

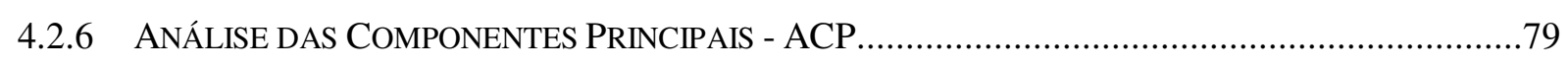

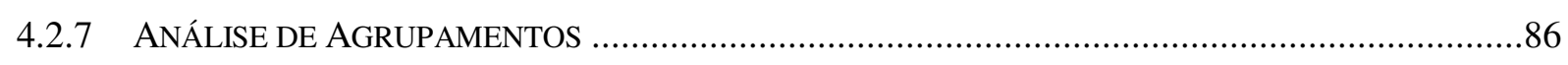

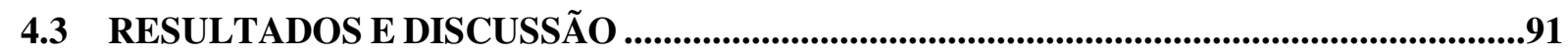

5 CASO II - CLASSIFICAÇÃO DE TRATAMENTOS TÉRMICOS ..................................93

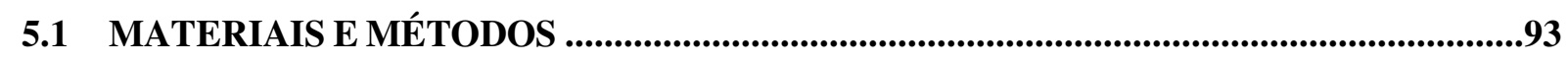

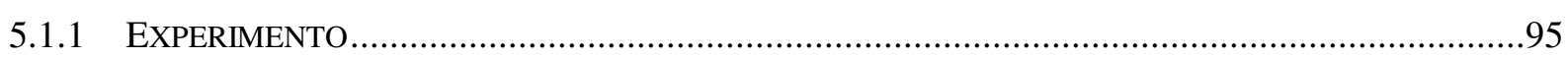

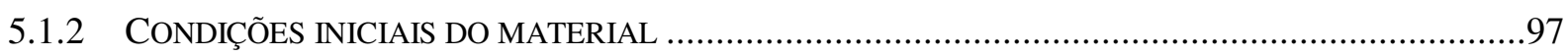

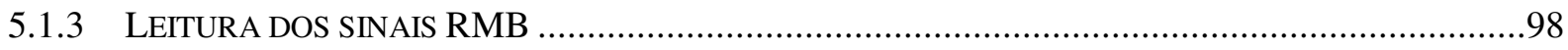

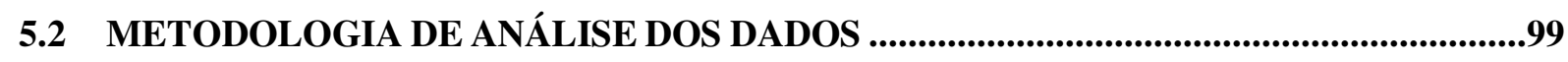

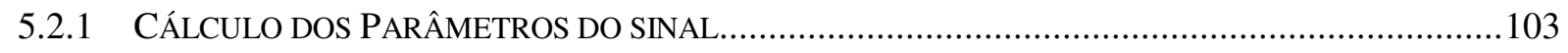

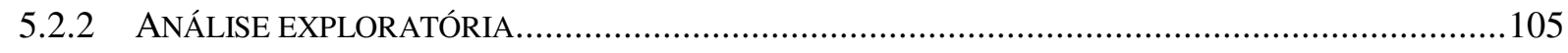

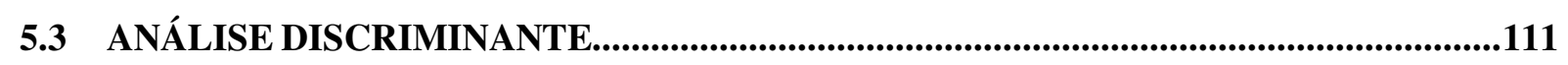

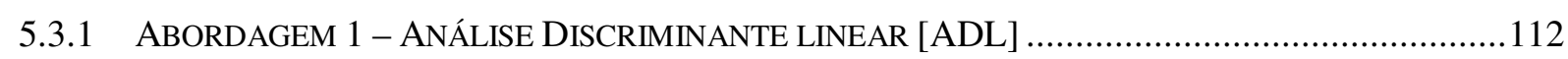

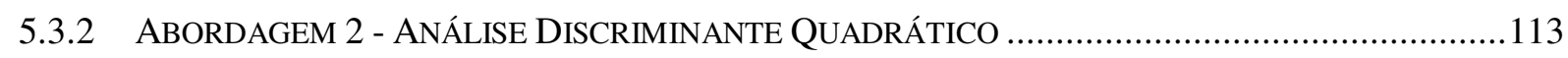

5.4 RESULTADOS E DISCUSSÃO ...............................................................................................114

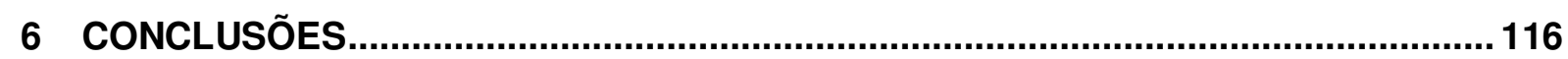

6.1 CASO I: INTEGRIDADE ESTRUTURAL DE RISER .................................................116

6.2 CASO II: ClaSSIFICAÇÃO DE TRATAMENTOS TÉRMICOS..............................................116

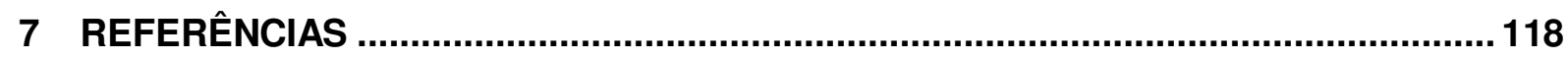




\section{INTRODUÇÃO}

\subsection{APRESENTAÇÃO DO TEMA}

Desde a década dos anos oitenta, o estudo do fenômeno conhecido como Ruído Magnético de Barkhausen ou $(R M B)$, assim como suas possíveis aplicações industriais, tem recebido um interesse crescente por parte dos grupos de pesquisa devido ao seu potencial como técnica de Ensaio Não Destrutivo (END).

$E N D$ baseado no $R M B$, contudo, é uma técnica que não está padronizada pelo fato de requerer pessoal com grande conhecimento das características mecânicas do material, assim como do fenômeno estudado, além da interpretação do sinal de $R M B$ e sua correlação com estes.

O sinal de $R M B$ contêm informações sobre o estado do material e, portanto, a escolha apropriada dos métodos para extrair e analisar essas informações e relacioná-las com o fenômeno de interesse é de particular importância.

Uma grande quantidade de métodos têm sido desenvolvidos e aplicados para este propósito, como por exemplo, análise de dados no tempo e no domínio da frequência (PIOTROWSKI,2008) (PADOVESE,2009), cálculo de parâmetros matemáticos e estatísticos (SAWADA,1952) (JILES,2000), transformadas wavelets (MAASS,2000) (PADOVESE, 2009) (FARIAS,2005), teoria do caos (TSUCHIDA,2002), análise do espectro (FRANCO,2010) e diversas técnicas de estatística multivariada. No entanto, técnicas estatísticas que tratam do problema da classificação ou agrupamento de amostras baseadas no RMB têm sido pouco utilizadas ou exploradas (NORMANDO et all.,2010).

$\mathrm{Na}$ área da estatística multivariada existem técnicas de reconhecimento de padrões que podem ser usadas para este propósito. A análise de conglomerados (clusters) é uma técnica de reconhecimento de padrões não supervisada de 
agrupamento de dados em categorias sobre a base da similaridade ou dissimilaridade das características medidas dos seus elementos. A análise discriminante é uma técnica supervisionada de reconhecimento de padrões que aloca um item novo ou uma observação nova no local apropriado (grupo ou categoria) segundo uma regra pré-estabelecida. Por último, a análise de componentes principais é uma técnica que visa a escolha de variáveis que descrevem melhor o conjunto de dados ou, à criação de um novo e menor conjunto de variáveis que consigam descrever a variabilidade do conjunto de dados com a perda mínima de informação.

Neste contexto, o principal objetivo desta dissertação é explorar a possibilidade do uso de alguns parâmetros estatísticos extraídos do sinal RMB como variáveis de entrada para diferentes técnicas estatísticas multivariada, sempre com o objetivo de diferenciar, classificar ou formar grupos que sejam de utilidade para a posterior tomada de decisões por parte do usuário, seja na pesquisa, seja no campo industrial.

\subsection{JUSTIFICATIVA E MOTIVAÇÃO}

Dentre os elementos químicos existentes na atualidade, cerca de $75 \%$ deles podem ser classificados como metais e, dentro destes, aproximadamente a metade é para uso industrial ou comercial de alguma importância. Esses metais são classificados em duas famílias: os ferrosos (conteúdo de ferro acima do 90\%) e não ferrosos (BRADY,2002).

Os materiais ferrosos são amplamente usados na indústria nas formas de ligas, devido às características especiais que são obtidas com a adição de outros elementos. Estes materiais apresentam propriedades que podem ser agrupadas em seis diferentes categorias: mecânicas, elétricas, térmicas, magnéticas, ópticas e de degradação. Para cada uma destas propriedades existem características que podem ser alteradas de acordo com o estímulo aplicado (CALLISTER,2007) conforme as exigências do uso final. Assim, essas características precisam ser controladas 
medidas, monitoradas, quantificadas e avaliadas tanto no momento da produção, quanto na operação.

Dentre estes materiais, o ferro é talvez o metal mais importante e de maior consumo pelo homem, devido às propriedades mecânicas como dureza, ductilidade, resistência à tração, e à relativa facilidade com que estas podem ser alteradas por meio de mudanças em sua composição química ou no processo de fabricação aplicado. Estudos demonstraram que mudanças ocorridas nestas propriedades também promovem alterações nas características magnéticas dos materiais ferromagnéticos, como o RMB emitido durante a magnetização (YANG,2001).

Em materiais ferromagnéticos submetidos a um campo magnético variável, pequenas e bruscas mudanças magnéticas surgem no local da magnetização. Estas mudanças bruscas na magnetização são geralmente associadas com movimentações bruscas das paredes de domínio magnético, de um ponto de ancoragem para outro. As voltagens medidas como uma bobina destes saltos, são conhecidos como o RMB (KRAUSE,1996). O RMB é sensível às mudanças nas características dos materiais, podendo a sua análise ser utilizada como uma ferramenta de grande potencialidade para ensaios não destrutivos (GIRALDO,2007).

A partir do sinal $R M B$ tem sido calculados diversos parâmetros que, segundo seu comportamento, tem sido correlacionados com alguma ou varias características e propriedades do material. Um desses parâmetros, a raiz média quadrática ou RMS, tem sido um dos mais estudados para determinação estados de tensões quanto para aspectos micro-estruturais (O'SULLIVAN et al.,2004) (PEREZ-BENITEZ et al.,2003) (MITRA,1995) (SAQUET,1999). No entanto, a existência de outros parâmetros descritivos do sinal, e a possibilidade de se analisar estes como um conjunto, e não de forma isolada, faz com que a análise multivariada seja uma interessante técnica.

A utilização das técnicas de estatística multivariada na análise dos parâmetros do sinal RMB, como ferramenta prática de controle de qualidade e/ou de classificação de materiais ferromagnéticos, tem sido pouco explorada. Trata-se de uma iniciativa relativamente recente, havendo trabalhos para classificação de amostras idênticas segundo variações na sua dureza (MAASS,2000), detecção de fases de aços nos 
processos de fabricação a altas temperaturas (NORMANDO,2010) e presença de fases ferríticas-perlíticas em amostras de tubos de vasos de pressão a vapor (PADOVESE,2010) e corrosão (EWALD,1994).

Assim, a utilização dos métodos de estatística multivariada pode permitir extrair e analisar um maior número de informações a partir da análise do RMB para o estudo de tensões e alterações microestructurais. Os métodos tradicionais que utilizam como parâmetro de referência o valor RMS do ruído, a distribuição dos pulsos e outros parâmetros do sinal, podem ter limitações pelo enfoque univariado ou bivariado abordado nestas análises.

\subsection{OBJETIVOS}

Desenvolver técnicas de estatística multivariada para detecção e diagnóstico em END magnéticos baseados no RMB.

Analisar bancos de dados se sinais do Ruído Magnético de Barkhausen, provenientes de dois experimentos diferentes (análise de integridade de risers flexíveis, peças de aço submetidas a tratamentos de tempera e revenido), com técnicas de estatística multivariada dos parâmetros calculados do sinal, visando agrupar e/ou classificar, por similaridade dos parâmetros, integridade estrutural (elementos que falharam) e mudanças na microestrutura do material

\subsection{ORGANIZAÇÃO DO TRABALHO}

Os capítulos 2 e 3 contêm a revisão bibliográfica dos métodos estatísticos univariados e multivariados a serem usados no trabalho e do $R M B$, respectivamente.

O capítulo 4 corresponde com os materiais, método, resultados e conclusões da análise de componentes principais e agrupamentos para o banco de dados do riser flexível. 
O capítulo 5 corresponde com os materiais, método, resultados e conclusões da análise discriminante para amostras de aço AISI 420 submetidos a diferentes tratamentos térmicos.

No capítulo 6 são apresentadas as conclusões do trabalho.

No capítulo 7 apresentam-se as referências bibliográficas e, finalmente no capítulo 8 os apêndices e anexos. 


\section{ANÁLISE UNIVARIADO E MULTIVARIADO DA QUALIDADE DOS DADOS}

A seguir são apresentados alguns conceitos de estatística univariada e multivariada, assim como algumas ferramentas gráficas necessárias para avaliar a qualidade dos dados a serem tratados e das técnicas e métodos envolvidos no processamento estatístico da informação.

\subsection{QUALIDADE DOS DADOS}

Uma análise previa dos dados é um passo necessário para garantir a qualidade das análises posteriores e dos resultados finais em qualquer estudo, no entanto, é uma etapa geralmente descuidada pelos analistas ou, que devido à grande quantidade de dados, pode resultar ser uma tarefa complexa. Segundo (HAIR et. al., 1999), a sofisticação analítica dos métodos para assegurar que os dados estejam livres de valores atípicos, ou respostas extremas (outliers) pode muitas vezes rivalizar em complexidade com as próprias técnicas de análise multivariada.

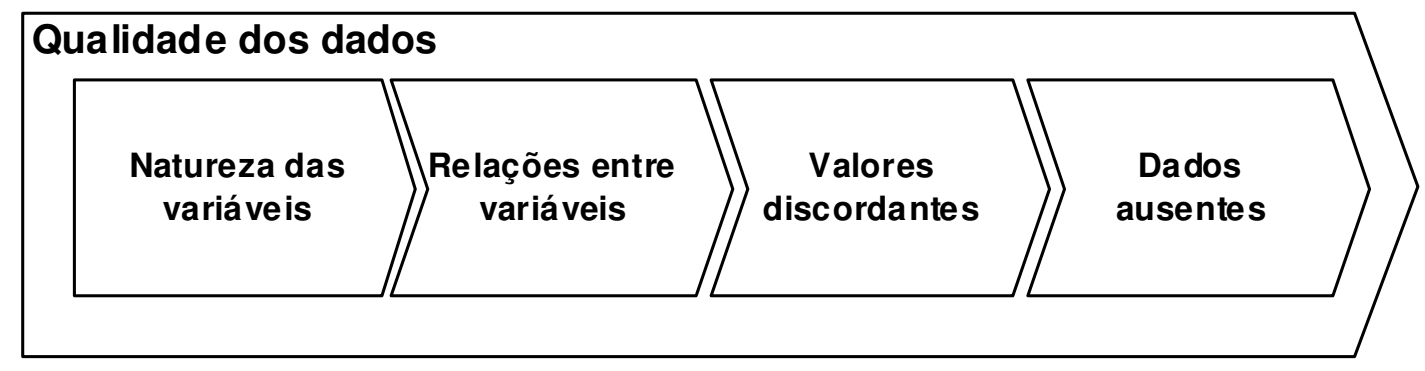

Figura 1 - Fases para avaliação da qualidade dos dados segundo HAIR (HAIR et al., 1999)

Para a avaliação da qualidade dos dados, existem várias técnicas gráficas que proporcionam um conjunto de formas simples, mas completo, de examinar variáveis individuais, as relações existentes com outras variáveis, identificação de valores extremos e dados ausentes. HAIR propõe quatro fases para avaliar a qualidade dos dados, representados no esquema da Figura 1 e descritos a seguir: 


\subsubsection{Natureza das variáveis}

Numa primeira análise gráfica dos dados, procura-se entender a forma da distribuição das variáveis. Isto pode ser feito por meio de um histograma, que é uma representação gráfica dos dados a partir da frequência dos valores em categorias (Figura 2).

\section{Histograma da variável $X$}

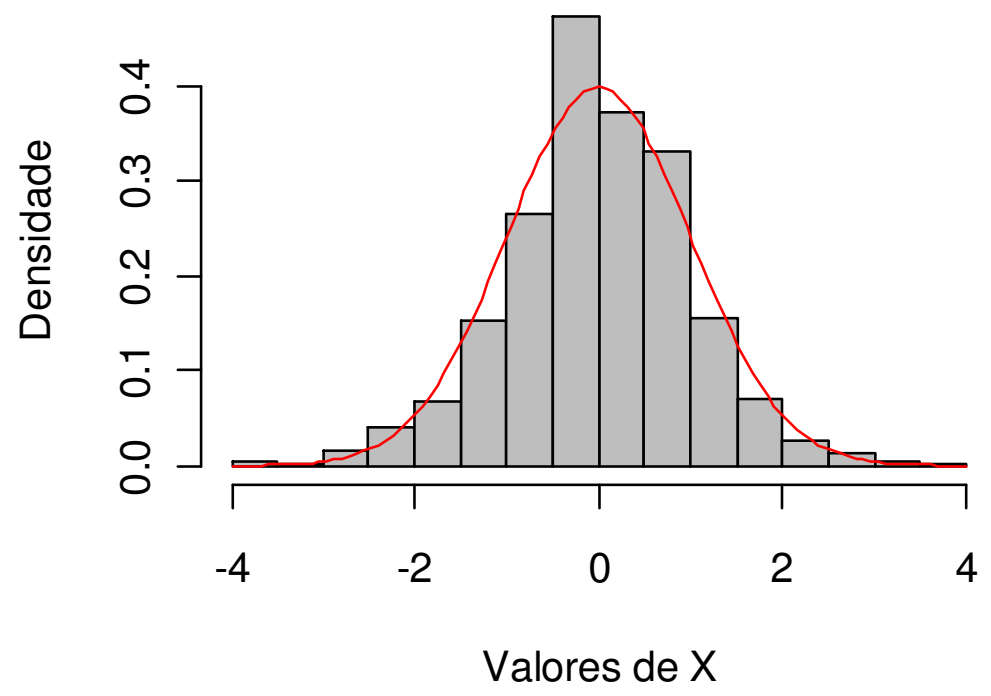

Figura 2 - Histograma e curva de densidade normal

\subsubsection{Análise de Relação entre as variáveis}

Nesta análise, o objetivo é analisar as possíveis relações entre duas ou mais variáveis. O método mais popular é o gráfico de dispersão (scatter-plot), no qual uma das variáveis é apresentada no eixo horizontal e outra no vertical e os pontos do gráfico representam a relação entre as variáveis (Figura 3). Quando os pontos estão organizados ao longo de uma linha reta, tem-se uma relação linear de correlação. Um conjunto de pontos curvados pode indicar uma relação não linear ou, ainda que não existam padrões, só um conjunto de pontos aparentemente sem nenhuma relação. Nesse caso, não há relação entre as variáveis. 


\section{Exemplo de Scatter-plot}

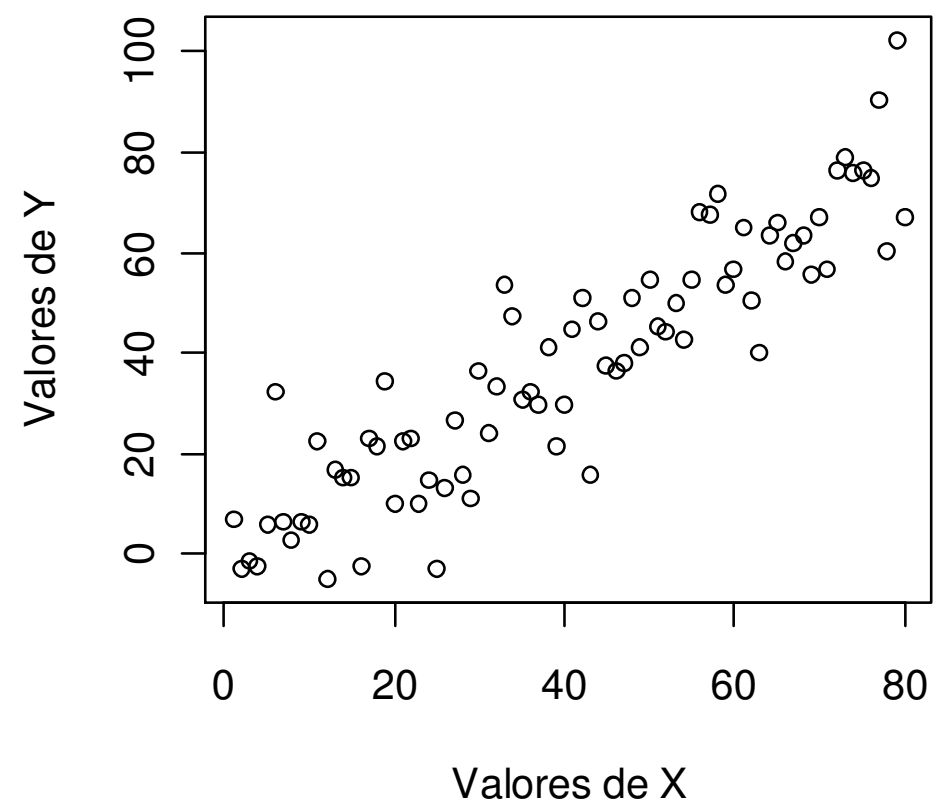

Figura 3 - Gráfico de dispersão de dados para uma amostra normal

Quando há mais de duas variáveis, existe uma adaptação do gráfico anterior, no qual são representadas todas as possíveis combinações em pares de variáveis. Esse gráfico é conhecido como gráfico de matriz de dispersão (Figura 4). Na parte inferior da matriz são apresentados os gráficos de dispersão para cada par de variáveis e, na diagonal, os histogramas de cada variável, assim, podem ser avaliados a natureza (forma da distribuição) e a relação entre variáveis com ajuda de simplesmente um gráfico. 


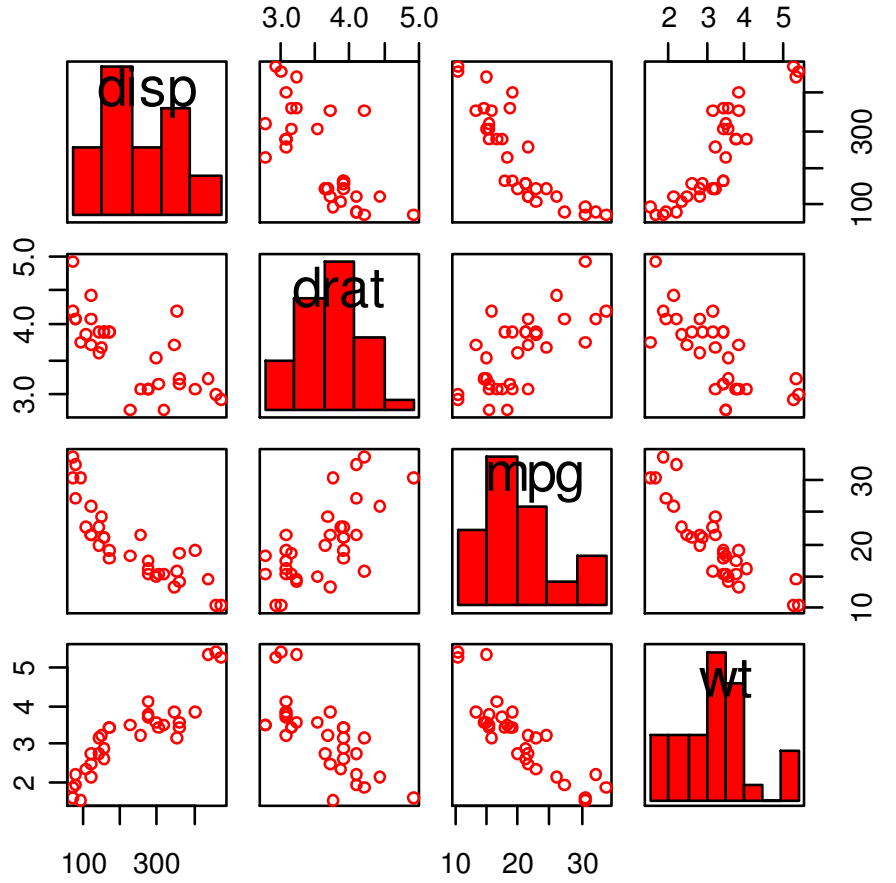

Figura 4 - Gráfico de matriz dispersão de dados ${ }^{1}$

\subsubsection{Valores discrepantes - Outliers}

São valores, ou casos dentro dos dados que, pela sua singularidade podem distorcer as relações sobre uma ou mais das variáveis em estudo. A natureza desses valores pode ser devida a erros na coleta dos dados ou comportamentos estranhos do item que está sendo medido. Assim, é necessário identificar estes valores e analisar cada caso para seu tratamento posterior, seja eliminação, substituição ou permanência do valor no conjunto de dados.

Para a avaliação dos dados na procura de valores discrepantes, JOHNSON (JOHNSON\&WICHERN,2001) recomenda procurar primeiro os casos univariados e bivariados, os quais são os mais simples de analisar e, na maioria dos casos é suficiente para garantir que não há valores discrepantes multivariados. Por última instância, uma avaliação dos outliers multivariados.

\footnotetext{
${ }^{1}$ Feito a partir do banco de dados "mtcars" do software $\mathrm{R}$
} 


\subsubsection{Valores discrepantes univariados}

Uma ferramenta que permite visualizar a presença de valores discrepantes univariados é o gráfico de caixas ou bigodes (boxplot) (Figura 5). Este é uma representação da distribuição dos dados na qual os limites, superior e inferior, marcam os quartis superior e inferior da distribuição dos dados. Assim, o comprimento da caixa é a distância entre o primeiro e terceiro quartil, e contêm o $50 \%$ dos dados centrais da distribuição. A linha do centro indica a posição da mediana e, se está perto do final da caixa é uma indicação de assimetria. Quanto maior é a caixa, maior a extensão das observações. As linhas que se estendem desde a caixa (chamadas de bigodes) representam a distância entre a maior e a menor das observações que estão a menos de um quartil da caixa, representadas pelos valores $Q_{1}-1,5 \times I Q R$ e $Q_{3}-1,5 \times I Q R$ na Figura 5 .

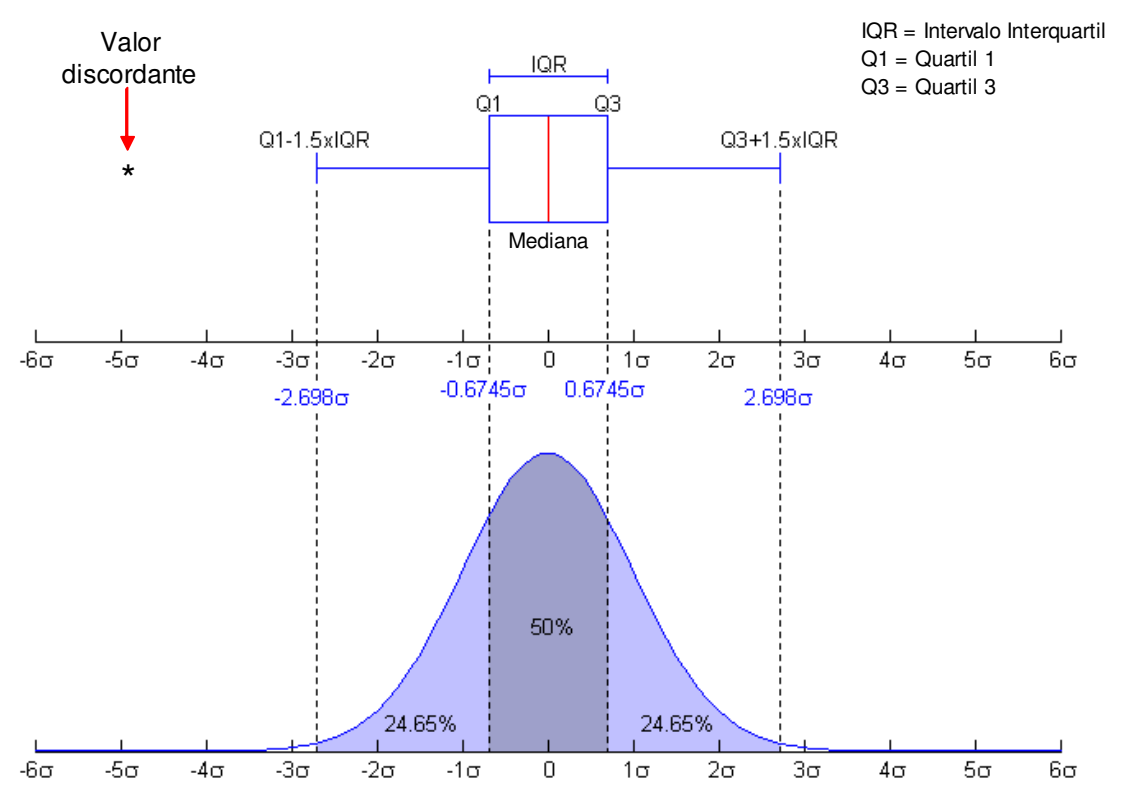

Figura 5 - Diagrama de caixas e função densidade de probabilidade

Os casos atípicos são valores que se situam entre 1,0 e 1,5 quartis fora da caixa, e os valores extremos ou discrepantes (Outliers) são aquelas observações maiores que estão a 1,5 fora dos limites da caixa, como mostrado na mesma figura. 


\subsubsection{Valores discrepantes multivariados}

Para a avaliação de dados discrepantes multivariados é construído o gráfico Quantis-Quantis. Nesse gráfico (Figura 6) são comparados os valores da distância $d_{j}^{2}$ (JOHNSON\&WICHERN,2001), ou distância de Mahalanobis (Equação 1), com as respectivas ordenadas dos percentis da distribuição qui-quadrado.

O gráfico apresenta uma linha reta de $45^{\circ}$ no qual, e quando os dados têm a mesma distribuição de probabilidade, os pontos plotados devem seguir aproximadamente essa linha. Assim os valores mais distantes são considerados como possíveis valores discrepantes multivariados.

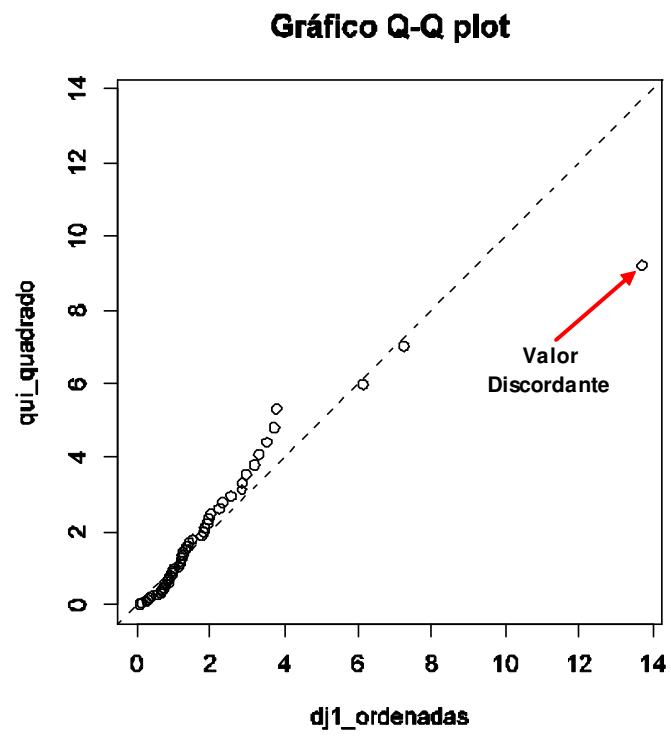

Figura 6 - Gráfico qui-quadrado (Q-Q plot)

A seguir é apresentada a equação da distância de Mahalanobis:

$$
d_{j}^{2}=\left(X_{j}-\bar{X}\right)^{\prime} S_{p \times p}^{-1}\left(X_{j}-\bar{X}\right)
$$

Onde:

$X_{j}=$ valores observados das $p$-variáveis do j-ésimo elemento amostral

$\bar{X}=$ vetor de médias amostrais

$S_{p \times p}^{-1}=$ matriz de covariâncias amostral (Equação (6). 


\subsubsection{Avaliação do impacto dos dados ausentes na análise}

Os dados ausentes são algo habitual na análise multivariada. O objetivo principal do pesquisador é entender as razões subjacentes no dado ausente, para assim escolher a melhor ação para tratar esses dados. As causas que podem levar ao tratamento de dados ausentes podem ser problemas na captura dos dados, ou por terem sido retirados pelo investigador. Assim, segundo o caso, podem ser eliminadas as variáveis com dados ausentes ou substituídas segundo algum modelo estatístico. A seguir são descritas algumas das ações que podem ser tomadas para tratar estes casos:

Fazer uso somente daquelas observações que têm dados completos,

Retirar variáveis e ou casos (elementos amostrais),

Imputação de dados.

Cada um dos métodos citados anteriormente possui vantagens como simplicidade (caso 1), e eficiência (caso 2), no entanto, e devido ao nível de aleatoriedade dos valores ausentes, estes métodos podem gerar valores viciados nos resultados. Já o terceiro caso está relacionado com a estimação dos valores ausentes baseado nos valores válidos das outras variáveis ou casos da amostra. $\mathrm{O}$ objetivo é empregar relações conhecidas que possam ser identificadas nos valores válidos da amostra para auxiliar na estimação dos valores ausentes (HAIR,1999).

\subsubsection{Imputação - Substituição de dados ausentes}

Para substituir efetivamente os dados ausentes, por valores estimados sobre a base da informação existente, há várias opções, desde uma substituição direta dos valores, até processos de estimação baseados nas relações entre as variáveis (HAIR1999). A seguir os métodos mais amplamente utilizados:

Substituição do caso: Neste método, as observações com dados ausentes são substituídas por outras observações não amostrais. 
Substituição pela média: É um dos mais empregados e consiste em substituir os valores ausentes por uma variável cujo valor médio é calculado baseado nas respostas válidas existentes.

Substituição por um valor constante: Consiste em substituir os dados ausentes por um valor constante derivado de fontes externas. A natureza deste método é similar ao método de substituição pela média. Segundo a qualidade do dado imputado, pode ser considerado como de maior validade que a imputação pela média da amostra.

Imputação por regressão: Este método usa a análise de regressão para predizer os valores ausentes de uma variável baseado na relação com outras variáveis no conjunto de dados.

Imputação Múltipla: É uma combinação de dois ou mais métodos para derivar uma estimação composta, geralmente é usado o valor médio de diversas estimações para o dado ausente. A lógica desta aproximação é que seu uso minimiza os problemas específicos relativos com um método simples.

\subsection{ESTATÍSTICA MULTIVARIADA}

A estatística multivariada é um conjunto de métodos estatísticos, utilizados em situações nas quais, diferentes variáveis, são medidas simultaneamente em cada elemento amostral. Os métodos de análise de dados multivariados permitem um estudo global dessas variáveis, colocando em evidência as relações, semelhanças ou diferenças entre elas.

\subsubsection{Conceitos gerais}

Para a análise multivariada, é necessário ter uma base conceitual sobre vetores aleatórios, matrizes de covariâncias e de correlação, bem como dos estimadores mais comuns, dos parâmetros das distribuições univariadas e multivariadas. A seguir 
são apresentadas algumas definições básicas, as quais estão envolvidas nos cálculos desta pesquisa.

Vetor Aleatório. Seja $X$ um vetor contendo $p$ componentes, onde cada componente é uma variável aleatória, isto é , $X$ é uma variável aleatória, $\forall i=1,2,3, \ldots, p$. Então, $X$ é chamado de vetor aleatório e é denotado por:

$$
X=\left[\begin{array}{c}
X_{1} \\
X_{2} \\
\vdots \\
X_{p}
\end{array}\right]
$$

O vetor transposto do vetor aleatório $X$ é denotado por $X^{\prime}=\left[\begin{array}{llll}X_{1} & X_{2} & \cdots & X_{p}\end{array}\right]$

Vetor de médias. Seja $X$ um vetor de médias. O vetor $\mu=E(X)$ é chamado de vetor de médias do vetor $X=\left[\begin{array}{llll}X_{1} & X_{2} & \cdots & X_{p}\end{array}\right\rfloor$, sendo:

$$
\mu=E(X)=\left[\begin{array}{c}
E(X)_{1} \\
E(X)_{2} \\
\vdots \\
E(X)_{P}
\end{array}\right]=\left[\begin{array}{c}
\mu_{1} \\
\mu_{2} \\
\vdots \\
\mu_{P}
\end{array}\right]
$$

Variância. A variância do i-ésimo componente do vetor $X$ é denotada por:

$$
\operatorname{Var}\left(X_{i}\right)=\sigma_{i}^{2}=\sigma_{i i}
$$

O desvio padrão é denotado por $\sqrt{\sigma_{i i}}$ e fornece a informação sobre a disposição dos valores da variável $X_{i}$ em relação a $\mu$, isto é, indica se os valores de $X_{i}$ estão próximos ou distantes da média $\mu_{i}$.

Covariância. A covariância entre os valores da i-ésima e j-ésima variáveis do vetor $X$ é definida por: 


$$
\operatorname{Cov}\left(X_{i}, X_{j}\right)=\sigma_{i j}=E\left[\left(X_{i}-\mu_{i}\right)\left(X_{j}-\mu_{j}\right)\right]
$$

A covariância serve para medir o grau de relacionamento linear entre duas variáveis aleatórias.

Matriz de covariâncias. A matriz de variâncias e covariâncias do vetor aleatório $X$ é denotada por:

$$
S_{p \times p}=\left[\begin{array}{cccc}
\sigma_{11} & \sigma_{12} & \cdots & \sigma_{1 p} \\
\sigma_{21} & \sigma_{22} & \cdots & \sigma_{1 p} \\
\vdots & \vdots & \ddots & \vdots \\
\sigma_{p 1} & \sigma_{p 1} & \cdots & \sigma_{p p}
\end{array}\right]
$$

Correlação. O coeficiente de correlação entre as i-ésima e j-ésima variáveis do vetor $X$ é definido por:

$$
\rho_{i j}=\frac{\sigma_{i j}}{\sqrt{\sigma_{i i} \sigma_{i j}}}=\frac{\sigma_{i j}}{\sigma_{i} \sigma_{j}}
$$

A correlação permite avaliar o grau de relação linear entre duas variáveis quantitativas. Seus valores estão sempre entre os valores de referência -1 e 1 . Assim, quanto mais próximo de 1 , mais indicação se tem de que existe uma relação linear positiva (crescimento) entre as variáveis $X_{i}$ e $X_{j}$; quanto mais próximo de 1, mais indicação se tem da existência de uma relação linear negativa (decrescimento). Uma correlação próxima de zero é uma indicação numérica de uma relação não linear entre as variáveis em questão. Quando se têm muitas variáveis, o procedimento mais comum é guardar os valores de $\rho_{i j}$ em uma matriz chamada de "matriz de correlação" definida a seguir:

Matriz de Correlação. A matriz de correlação do vetor aleatório $X$ é denotada por: 


$$
A_{m, n}=\left[\begin{array}{ccccc}
1 & \rho_{12} & \rho_{13} & \cdots & \rho_{1 p} \\
\rho_{21} & 1 & \rho_{23} & \cdots & \rho_{2 p} \\
\rho_{31} & \rho_{32} & 1 & \cdots & \rho_{3 p} \\
\vdots & \vdots & \vdots & \ddots & \vdots \\
\rho_{p 1} & \rho_{p 2} & \rho_{p 3} & \cdots & 1
\end{array}\right]
$$

\subsubsection{Estatísticas Descritivas - Estimação de parâmetros}

Um grande conjunto de variáveis e observações, para um grupo de amostras é volumoso, esta massa de dados impõe um sério obstáculo para qualquer tentativa de extrair informações visuais pertinentes (JOHNSON\&WICHERN,2001). Desta forma, é necessário usar valores de resumo consigam explicar a informação contida nos dados. Esses valores são conhecidos como estatísticas descritivas, e são parâmetros ou variáveis que oferecem informações tais como posição, variação e associação linear dos dados avaliados. Esses parâmetros calculados são organizados em vetores e matrizes, a partir dos quais são estimadas as matrizes de covariâncias e correlação, as quais são a base para aplicação das técnicas de estatística multivaridada. A definição formal dessas estatísticas, segundo (MINGOTI,2005), são descritas a seguir:

Numa amostra aleatória de tamanho $n$, na qual, para cada elemento amostral que se tenham observado valores de $p$-variáveis aleatórias, tem-se $n$ vetores aleatórios independentes e identicamente distribuídos da seguinte forma:

$$
X_{1}=\left[\begin{array}{l}
X_{11} \\
X_{21} \\
\vdots \\
X_{p 1}
\end{array}\right] X_{2}=\left[\begin{array}{l}
X_{21} \\
X_{22} \\
\vdots \\
X_{p 2}
\end{array}\right] X_{3}=\left[\begin{array}{l}
X_{13} \\
X_{23} \\
\vdots \\
X_{p 3}
\end{array}\right], \ldots, X_{n}=\left[\begin{array}{l}
X_{1 n} \\
X_{2 n} \\
\vdots \\
X_{p n}
\end{array}\right]
$$

O primeiro índice indica a variável e o segundo o elemento amostral. Esses valores são armazenados numa matriz chamada matriz de dados. A informação de 
cada vetor $X_{i}$ é armazenada numa linha dessa matriz e cada coluna representa os dados observados de uma variável. Assim, tem-se uma matriz $n \times p$ denotada por:

$$
X_{n x p}=\left[\begin{array}{cccc}
X_{11} & X_{21} & \cdots & X_{p 1} \\
X_{21} & X_{22} & \cdots & X_{p 2} \\
\vdots & \vdots & \vdots & \vdots \\
X_{1 n} & X_{2 n} & \cdots & X_{p n}
\end{array}\right]
$$

O vetor de médias $\mu$ será estimado pelo vetor de médias amostrais $\bar{X}$, definido por:

$$
\bar{X}=\frac{1}{n}\left[X_{1}+X_{2}+X_{3}+\cdots+X_{n}\right]=\left[\begin{array}{l}
\bar{X}_{1} \\
\bar{X}_{2} \\
\bar{X}_{n}
\end{array}\right]
$$

onde $\bar{X}_{i}$ é a média amostral da i-ésima variável, $i=1,2,3, \ldots, p$. A matriz de covariâncias $\sum_{p x p}$ será estimada pela matriz de covariâncias amostrais $S_{p x p}$ definida por:

$$
S_{p x p}=\left[\begin{array}{cccc}
S_{11} & S_{12} & \cdots & S_{1 p} \\
S_{21} & S_{22} & \cdots & S_{2 p} \\
\vdots & \vdots & \ddots & \vdots \\
S_{p 1} & S_{p 2} & \cdots & S_{p p}
\end{array}\right]
$$

sendo, $S_{i j}=S_{j i}, j \neq i$ e $S_{i i}$ definidos respectivamente por:

$$
S_{i i}=\frac{\sum_{l=1}^{n}\left(X_{i l}-\bar{X}_{i}\right)^{2}}{n-1}
$$

que é a variância amostral da i-ésima variável, 


$$
S_{i i}=\frac{\sum_{l=1}^{n}\left(X_{i l}-\bar{X}_{i}\right)\left(X_{j l}-\overline{X_{j}}\right)}{n-1}
$$

que é a covariância amostral entre a i-ésima e a j-ésiima variáveis. A matriz de correlação teórica $P_{p \times p}$ será estimada pela matriz de correlação amostral $R_{p \times p}$ definida por:

$$
R_{p x p}=\left[\begin{array}{cccc}
R_{11} & R_{12} & \cdots & R_{1 p} \\
R_{21} & R_{22} & \cdots & R_{2 p} \\
\vdots & \vdots & \cdots & \vdots \\
R_{p 1} & R_{p 2} & \cdots & R_{p p}
\end{array}\right]
$$

Onde:

$$
R_{i j}=\frac{S_{i j}}{\sqrt{S_{i i} S_{i j}}}
$$

é o coeficiente de correlação amostral entre as i-ésima e j-ésima variáveis, conhecido como coeficiente de correlação de Pearson (TRIOLA,2005).

\subsubsection{Análise das Componentes Principais}

A técnica denominada de análise de componentes principais tem como objetivo explicar a estrutura de variância e covariância de um vetor aleatório, composto de $p$ variáveis aleatórias, por meio da construção de combinações lineares das variáveis originais. Estas combinações lineares são chamadas de componentes principais, e não são correlacionadas entre si (MINGOTI,2005).

Em geral, o objetivo da $A C P$ é a redução de dados. Essa redução de dados pode ser feita por meio da escolha de um número menor de novas variáveis, construídas a partir das componentes principais, ou seja, a informação contida nas p-variáveis originais é substituída pela informação contida em $k(k<p)$ componentes principais. Outra forma de redução de dados é a escolha, a partir da primeira componente principal, das variáveis com maiores coeficientes em valor absoluto, por serem estes 
os de maior efeito ou influência na componente principal (maior peso). Uma outra variação é escolher as variáveis com os maiores coeficientes em cada uma das componentes principais obtidas.

O cálculo das componentes principais envolve a decomposição da matriz de covariâncias do vetor aleatório de interesse explicado anteriormente e, caso seja feita alguma transformação desde o vetor aleatório, o cálculo deverá ser feito utilizando-se a matriz de correlações, equivalente à matriz de covariâncias do vetor transformado. Uma transformação muito usual é a padronização das variáveis do vetor pelas respectivas médias e desvios padrões, segundo a equação ((17) gerando-se novas variáveis centradas em zero e com variâncias iguais a 1.

$$
z=\frac{(x-\mu)}{\sigma}
$$

\subsubsection{Obtenção das componentes principais}

Cunha (CUNHA,2006) faz uma descrição, baseado em grande parte no trabalho de (JOHNSON\&WICHERN,2001), para a obtenção das componentes principais. (MINGOTI,2005) também faz um trabalho similar diferenciado-se basicamente pela abordagem matricial por ela feita, manipulando direitamente a matriz de covariâncias, discriminando as respectivas matrizes de autovalores e auto-vetores, chegando contudo ao mesmo equacionamento descrito por (CUNHA,2006) como mostrado seguir:

Seja $X_{1}, X_{2}, \ldots, X_{p}$ um conjunto de $\mathrm{m}$ variáveis. As componentes principais $C P_{1}, C P_{2}, \ldots, C P_{p}$ são combinações lineares destas variáveis:

$$
\begin{gathered}
C P_{1}=a_{11} X_{1}+a_{12} X_{2}+\ldots+a_{1 p} X_{p}=a_{1}^{\prime} \mathrm{X} \\
C P_{2}=a_{21} X_{1}+a_{22} X_{2}+\ldots+a_{2 p} X_{p}=a_{2}^{\prime} \mathrm{X} \\
\vdots \\
C P_{1}=a_{p 1} X_{1}+a_{p 2} X_{2}+\ldots+a_{p p} X_{p}=a_{p}^{\prime} \mathrm{X}
\end{gathered}
$$


Onde os coeficientes $a_{i j}$ de cada componente são determinados de forma a maximizar a variância de cada componente. A variância de cada $C P_{i}$ é dada por:

$$
\operatorname{Var}\left(C P_{i}\right)=a_{i}^{\prime} S a_{i}, i=1,2, \ldots, p
$$

Onde $a_{i}^{\prime}$ é a transposta de $a_{i}$, e $S$ é a matriz de covariância.

A primeira componente principal é a combinação linear que maximiza $\operatorname{Var}\left(C P_{1}\right)$. A segunda componente principal é obtida da mesma forma, mas com a restrição de que esta deve ser ortogonal à primeira, ou seja,

$$
\operatorname{Cov}\left(C P_{2}, C P_{1}\right)=0
$$

Onde $\operatorname{Cov}\left(C P_{2}, C P_{1}\right)$ é a covariância entre as combinações lineares independentes entre si.

Assim, a i-ésima componente principal deve maximizar $\operatorname{Var}\left(a_{i} X\right)$ com a restrição de que $\operatorname{Cov}\left(a_{i} X, a_{k} X\right)=0, \forall k<i$. Dessa forma obtêm-se um conjunto de $m$ combinações lineares independentes entre si.

Se $\lambda_{i}, i=1,2, \ldots, p$ é o i-ésimo autovalor associado ao auto-vetor $e_{i}$ da matriz de covariância $S$, pode-se mostrar que a variância da i-ésima componente principal $C P_{I}$ é máxima se $\operatorname{Var}\left(C P_{I}\right)=\lambda_{I}$. As componentes podem então ser escritas na forma:

$$
C P_{I}=e_{i} X=e_{i 1} X_{1}+e_{i 2} X_{2}+\ldots+e_{i p} X_{p}
$$

com

$$
\begin{gathered}
\operatorname{Var}\left(C P_{i}\right)=e_{i}^{\prime} \sum e_{i}=\lambda_{i} \\
\operatorname{Cov}\left(C P_{i}, C P_{k}\right)=e^{\prime}{ }_{i} \sum e_{k}=0, i \neq k
\end{gathered}
$$


Geometricamente, as componentes principais representam uma rotação do eixo das coordenadas originais, na direção da maior variância dos dados, conforme mostra a Figura 7.

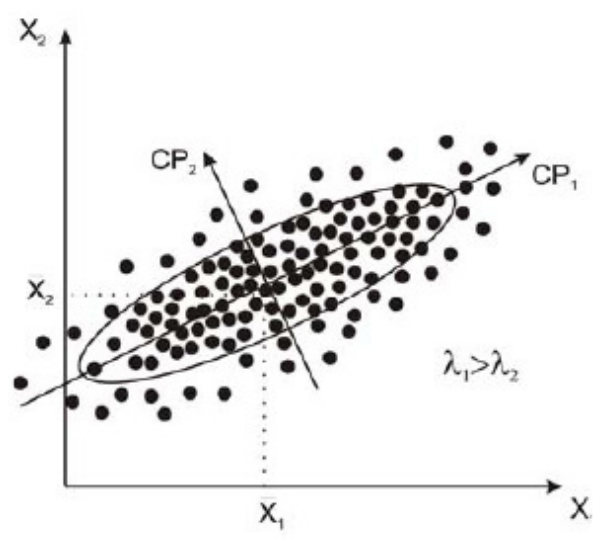

Figura 7 - Componentes principais $C P_{1}$ e $C P_{2}$ obtidos para um conjunto de dados pelas variáveis $X_{1}$ e $X_{2}$ (JOHNSON\&WICHERN,2001)

\subsubsection{Determinação do número de Componentes}

Se $\operatorname{Var}\left(C P_{i}\right)=\lambda_{i}$ é a variância da $i$-ésima componente principal, então a variância total é dada por:

$$
\sum_{i=1}^{p} \operatorname{Var}\left(C P_{i}\right)=\sum_{i=1}^{p} \lambda_{i}
$$

A proporção da variância total devida à k-ésima componente principal pode ser descrita como:

$$
p_{k}=\frac{\operatorname{Var}\left(C P_{k}\right)}{\sum_{i=1}^{p} \operatorname{Var}\left(C P_{I}\right)}=\frac{\lambda_{k}}{\lambda_{1}+\lambda_{2}+\ldots+\lambda_{p}}
$$

Se a maior parte da variância total for devida a um número reduzido de componentes, então as outras componentes podem ser eliminadas sem ter perda relevante de informação. Desta forma, a análise das $p$ variáveis originais se resume à análise de algumas poucas componentes. 
Uma forma gráfica de se determinar o número ideal de componentes principais para análise dos dados é por meio do gráfico scree-plot (Figura 8). Neste gráfico, os autovalores $\lambda_{i}$ aparecem ordenados do maior para o menor no eixo horizontal, e no eixo vertical as respectivas porcentagens da variância total. $O$ número ideal de componentes é dado pelo índice $i$ onde os pontos referentes aos autovalores começam a ficar relativamente pequenos e praticamente constantes.

\section{Exemplo de Scree-plot}

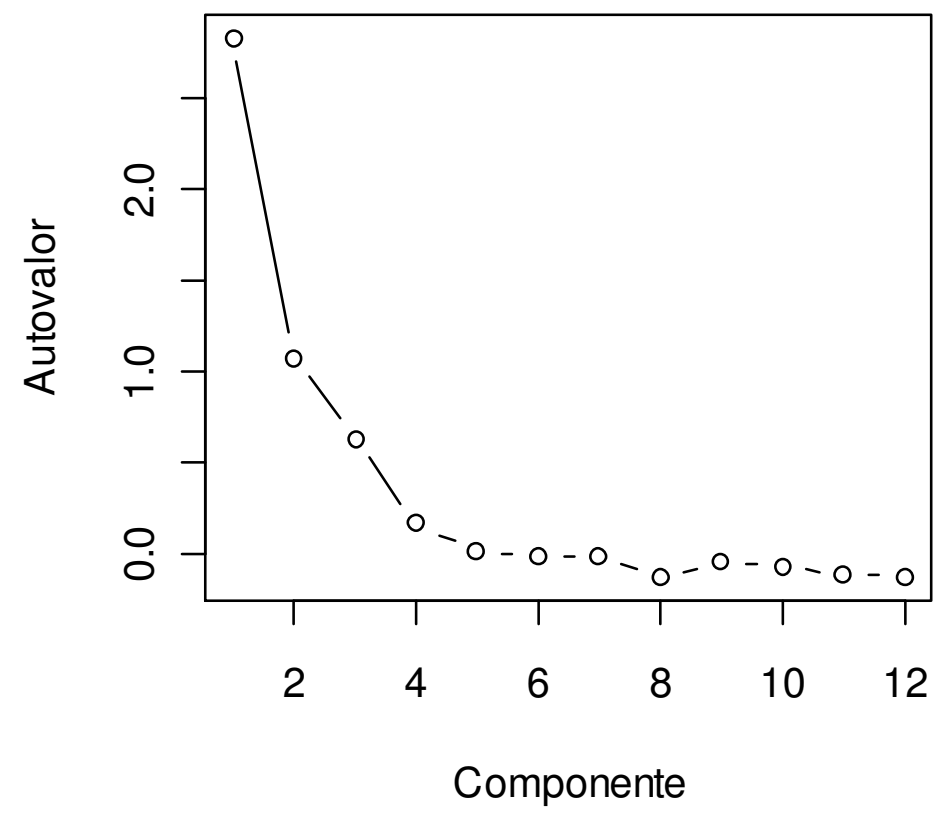

Figura 8 - Scree-plot para um conjunto de 12 componentes principais [cran.r]

\subsubsection{Análise de Agrupamentos - clusters (AA)}

A análise de conglomerados ou clusters é uma técnica que procura construir classificações naturais dos elementos de um conjunto de dados que, de outra forma não poderia ser evidente. $O$ critério básico para qualquer agrupamento é a distância. Os objetos que estejam mais perto um do outro pertenceriam ao mesmo conglomerado ou cluster, e os objetos mais distantes um do outro, pertenceriam a clusters diferentes (MINGOTI,2005) (JOHNSON\&WICHERN,2001). 
Se dispõe de um conjunto de dados constituído de $n$ elementos amostrais, tendose medido $p$-variáveis aleatórias em cada um deles, chamamos de distância entre os elementos ie $k$ a uma medida, a qual indicaremos como $d(i, k)$ que mede o grau de semelhança entre os elementos a partir de uma serie de características.

Existem várias medidas diferentes e cada uma delas produz um determinado tipo de agrupamento (MINGOTI,2005). Essas medidas dependem da natureza das variáveis que estão sendo avaliadas (discretas, contínuas, binárias), escalas de mensuração (nominal, ordinal, intervalos, proporção) (JOHNSON\&WICHERN,2001). A seguir são apresentadas as medidas mais comuns para variáveis quantitativas e que são objeto do presente trabalho.

\subsubsection{Distância Euclidiana}

A distância euclidiana entre dois elementos $X_{l}$ e $X_{k}, l \neq k$ é definida por:

$$
d\left(X_{l}, X_{k}\right)=\left[\left(X_{l}-X_{k}\right)^{\prime}\left(X_{l}-X_{k}\right)\right]^{\frac{1}{2}}=\left[\sum_{i=1}^{p}\left(X_{i l}-X_{i k}\right)^{2}\right]^{\frac{1}{2}}
$$

ou seja, os dois elementos amostrais são comparados em cada variável pertencente ao vetor de observações.

\subsubsection{Distância generalizada ou ponderada}

A distância generalizada ou ponderada entre dois elementos $X_{l}$ e $X_{k} l \neq k$, é definida por:

$$
d\left(X_{l}, X_{k}\right)=\left[\left(X_{l}-X_{k}\right)^{\prime} A\left(X_{l}-X_{k}\right)\right]^{\frac{1}{2}}
$$


onde $A_{p x p}$ é uma matriz de ponderação, positiva definida. Quando a matriz $A_{p x p}$ é a matriz identidade, a distância generalizada é a distância Euclidiana; se $A_{p x p}$ é igual a $S_{p x p}^{-1}$, tem-se a distância de Mahalanobis (MAHALANOBIS,1936) e quando $A_{p x p}=\operatorname{diag}\left(\frac{1}{p}\right)$ tem-se a distância Euclidiana média.

\subsubsection{Distância de Minkowsky}

A distância de Minkowisky entre dois elementos $X_{l}$ e $X_{k}, l \neq k$ é definida por:

$$
d\left(X_{l}, X_{k}\right)=\left[\sum_{i=1}^{p} w_{i}\left|X_{i l}-X_{i k}\right|^{\lambda}\right]^{\frac{1}{\lambda}}
$$

onde $w_{i}$ são os pesos de ponderação para as variáveis. Quando $\lambda=1$, esta distância é conhecida como city-block ou Manhattan, e para $\lambda=2$ tem-se a distância Euclidiana. A métrica de Minkowisky é menos afetada pela presença de valores discrepantes na amostra do que a distância Euclidiana.

As distâncias entre os elementos são armazenadas numa matriz de dimensão $n \times n$, chamada de matriz de distâncias (equação (28), como mostra a Figura 9, na qual $d_{(i, j)}$ representa a distância do elemento amostral $i$ ao elemento amostral $j$.

$$
D_{4 \times 4}=\left[\begin{array}{cccc}
0 & d_{12} & d_{13} & d_{14} \\
d_{21} & 0 & d_{23} & d_{24} \\
d_{31} & d_{32} & 0 & d_{34} \\
d_{41} & d_{42} & d_{43} & 0
\end{array}\right]
$$




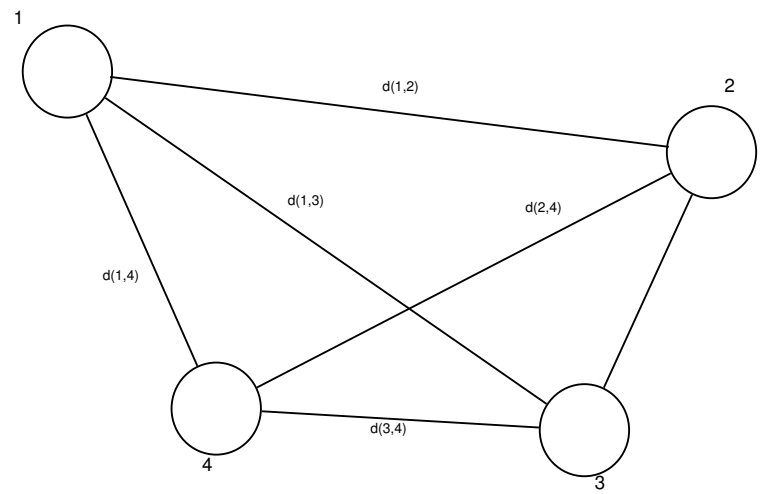

Figura 9 - Esquema de armazenamento de distâncias numa matriz 4×4, (MINGOTI,2005)

\subsubsection{Técnicas para construção de clusters}

Uma vez calculadas as diferentes matrizes de distâncias, explicadas anteriormente, o passo a seguir é escolher a técnica de construção de aglomerados a ser usada, segundo as características dos dados e do objetivo da pesquisa.

Existe na literatura uma grande quantidade de algoritmos de clusterização. De forma geral, diferentes algoritmos devem ser aplicados sobre o banco de dados e, escolhidos os resultados mais adequados, segundo a que se destinam os dados. $\mathrm{Na}$ Figura 10 é representada de forma esquemática, uma classificação dos métodos de clusterização, detalhando os de tipo hierárquico, nos quais está baseado o presente trabalho. 


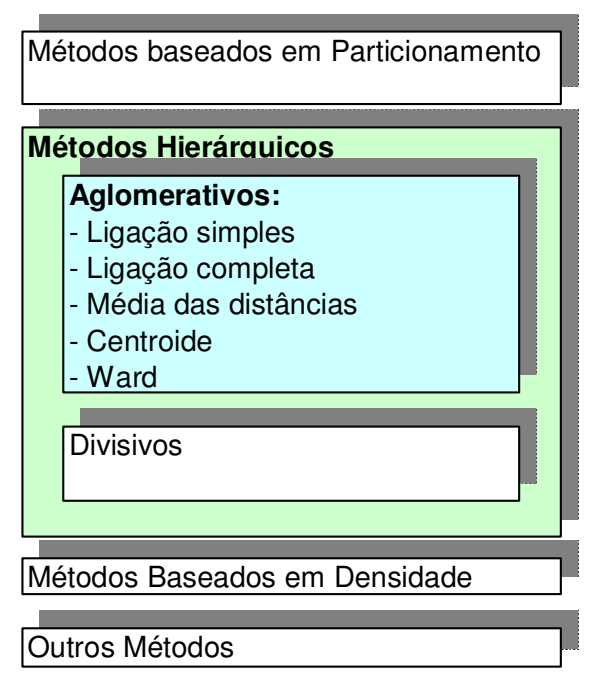

Figura 10 - Categorías de métodos de clusterização ${ }^{2}$

Métodos hierárquicos aglomerativos partem do principio de que no inicio do processo de agrupamento tem-se $n$ conglomerados, ou seja, cada elemento do conjunto de dados observado é considerado como sendo um conglomerado isolado. Em cada passo do algoritmo, os elementos amostrais vão sendo agrupados, formando novos conglomerados até o momento no qual, todos os elementos considerados estão num único grupo.

As agrupações obtidas podem ser visualizadas num gráfico bi-dimensional chamado de Dendrograma ou Dendograma (Figura 11). Este gráfico apresenta as fusões ou divisões (quando empregados métodos divisivos) que tem sido feitas sucessivamente. A escala vertical indica o nível de similaridade (ou dissimilaridade). No eixo horizontal, são marcados os elementos amostrais, numa ordem convenientemente relacionada à história de agrupamento. As linhas verticais, partindo dos elementos amostrais agrupados, têm altura correspondente ao nível em que os elementos foram considerados semelhantes, isto é, a distância do agrupamento ou nível de similaridade (MINGOTI,2005).

2 Adaptação das notas de Aula de Data Mining, da professora Sandra de Amo. Faculdade de Computação, Universidade de Uberlândia. 


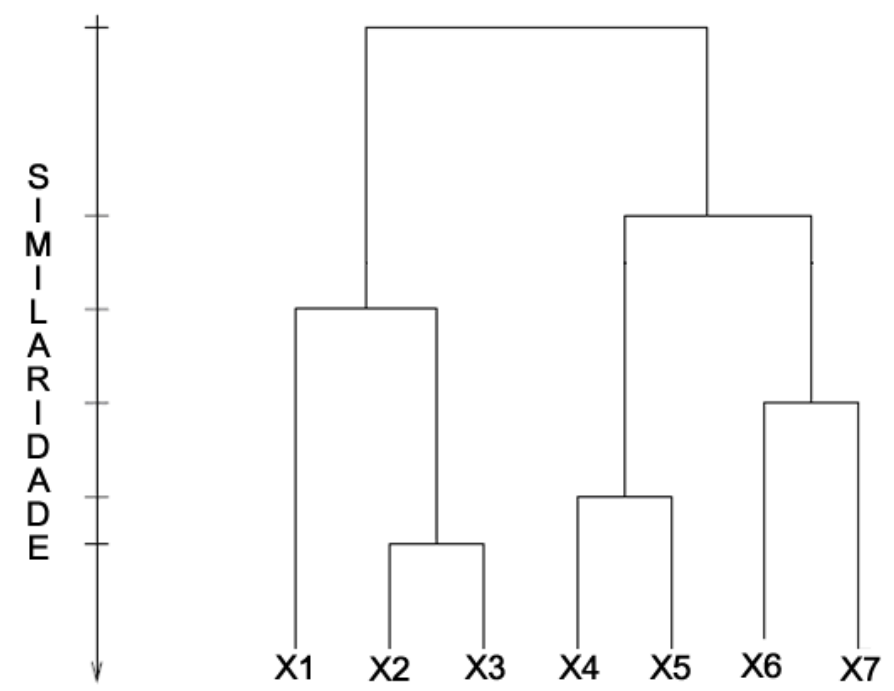

Figura 11 - Dendograma para um grupo de 6 objetos

Um algoritmo que explica a técnica de aglomeramento hierárquico de agrupamento, para $N$ objetos (itens ou variáveis), e descrito em (JOHNSON\&WICHERN,2001), é apresentado a seguir:

1. Começar com $N$ clusters, cada um contendo uma entidade unitária e uma matriz simétrica de distâncias (ou similaridades) $D=d_{i k}$.

2. Procurar a distância da matriz para o par de (clusters) mais próximo. Deixar a distância entre os clusters "mais similares" $U$ e $V$ como $D_{u v}$.

3. Fusionar os clusters $U$ e $V$, re nomear o cluster recentemente formado (UV). Atualizar a matriz de distâncias:

4. Eliminando as filas e colunas correspondentes aos clusters $U$ e $V$, e,

5. Adicionando uma fila e uma coluna, preenchendo as distâncias entre o cluster (UV) e os clusters restantes.

6. Repetir os passos 2 e 3 até $N-1$ vezes. (Todos os elementos estarão num cluster unitário (quando o algoritmo terminar)).

7. Salvar a identidade dos clusters que estão fusionados e os níveis (distâncias ou similaridades) no qual a fusão foi feita.

Este algoritmo é referência necessária para entender a forma de operação das diferentes técnicas de agrupamento que serão expostas a seguir: 


\subsubsection{Método da ligação simples}

Neste método, a similaridade entre dois conglomerados é definida pelos dois elementos mais parecidos entre si (SNEATH,1957). A entrada para o algoritmo pode ser, as distâncias ou similaridades entre um par de objetos. Grupos são formados das entidades individuais por fusão dos vizinhos mais próximos, onde o termo Vizinho mais próximo é referido à menor distância ou à maior similaridade.

Inicialmente, é encontrada a distância em $D=d_{i k}$ e fusionados os correspondentes objetos, por exemplo, U e V, para ter o cluster UV. Para o passo 3 do algoritmo descrito anteriormente, as distâncias entre UV e qualquer outro cluster Wé calculada por:

$$
d_{(U V)} W=\min \left\{d_{U V}, d_{V W}\right\}
$$

Aqui as quantidades $d_{U V}$ e $d_{V W}$ são as distâncias entre o vizinho mais próximo dos clusters $U$ e $V$, e os clusters $V$ e $W$, respectivamente.

\subsubsection{Método da ligação completa}

Neste método, a similaridade entre dois conglomerados é definida pelos elementos que são "menos semelhantes" (SNEATH,1957). O algoritmo é o mesmo usado no método da ligação simples, mas, no passo número 3, a distância empregada para fazer o cálculo de similaridade é definida por:

$$
d_{(U V)} W=\max \left\{d_{U V}, d_{V W}\right\}
$$

\subsubsection{Método da média das distâncias}

O método da média das distâncias trata a distância entre dois conglomerados, como a distância média entre todos os pares de itens, onde um membro de um par pertence a cada conglomerado. Novamente, o algoritmo é o mesmo usado para os 
casos anteriores, mas, a distância empregada para estabelecer a similaridade entre conglomerados é definida por:

$$
d_{(U V)} W=\frac{\sum_{i} \sum_{k} d_{i k}}{N_{(U V)} N_{W}}
$$

\subsubsection{Método do Centróide}

Neste método, a distância entre dois grupos é definida como sendo a distância entre os vetores de médias, também chamados de centróides, dos grupos que estão sendo comparados (MINGOTI,2005). Assim, se $U=\left\{X_{1}, X_{3}, X_{7}\right\}$ e $V=\left\{X_{2}, X_{6}\right\}$, os vetores de médias correspondentes são:

Vetor de médias de $U=\bar{U}=\frac{1}{3}\left[X_{1}+X_{2}+X_{3}\right]$

Vetor de médias de $V=\bar{V}=\frac{1}{2}\left[X_{2}+X_{6}\right]$

e a distância $d_{U V}$ é definida por:

$$
d_{U V}=(\bar{U}-\bar{V})^{\prime}(\bar{U}-\bar{V})
$$

O método do centróide é direto e simples. Para fazer o agrupamento, no entanto, em cada passo é necessário voltar-se aos dados originais para o cálculo da matriz de distâncias, o que exige um tempo computacional maior do que nos anteriores métodos.

\subsubsection{Método de McQuitty}

Este método começa com a hipótese que cada elemento pertencer a um cluster diferente. São fusionados os elementos com o maior grau de similaridade. Neste método, o valor de similaridade é calculado pela equação a seguir: 


$$
d_{J M}=\left[\left(d_{j k}+d_{j l}\right) / 2\right]
$$

\subsubsection{Qualidade do resultado do agrupamento - Correlação Cofenética}

Um procedimento comum para avaliação dos resultados de técnicas hierárquicas de agrupamento é comparar os dados de entrada (Matriz de distâncias), com os dados dos resultados do agrupamento, expressos de forma matricial (Matriz de distâncias ultra-métricas) (HOLGERSSON,1978). Assim, o coeficiente de correlação linear de Pearson, entre os elementos da matriz de distâncias original e a matriz de dados ultra-métrica, é conhecido como Coeficiente de Correlação Cofenética. Assim, um bom resultado do método de agrupamento é aquele que pode reproduzir a matriz de distâncias original (OKSANEN,2010), ou seja, quanto mais perto de 1,0 seja o valor da correlação entre a matriz de distâncias originais e, a matriz de distâncias ultra-métricas, maior é o sucesso da classificação pelo método hierárquico (HOLGERSSON,1978).

\subsubsection{Análise Discriminante (AD)}

A AD é uma técnica estatística que tem a ver com o problema de classificação ou discriminação de elementos em grupos, classes ou populações conhecidas (JOHNSON\&WICHERN,2001). A idéia geral consiste em alocar um indivíduo ou objeto em um dos grupos existentes, através da medição e comparação das características de cada indivíduo $x_{1}, x_{2}, \ldots, x_{p}$.

$A A D$ é um dos modelos de reconhecimento de padrões com enfoque estatístico (JAIN et all.,2000) de tipo supervisionado. Para este caso, dispõe-se de um conjunto de observações multivariadas, para as quais a classe, grupo ou população à qual pertencem é conhecida a - priori. Esse conjunto é conhecido como a amostra ou grupo de treinamento. Baseados na amostra de treinamento, é calculada uma regra de classificação ou classificador, fundamentada na teoria das probabilidades. 


\subsubsection{Análise discriminante linear}

A ADL procura por meio da construção de um modelo matemático linear, construído a partir de um grupo de observações de características em grupos de amostras, provenientes de populações conhecidas (grupo de treinamento), classificar elementos para os quais não é conhecida a população à qual pertence, mas sim os valores das mesmas variáveis do grupo de treinamento.

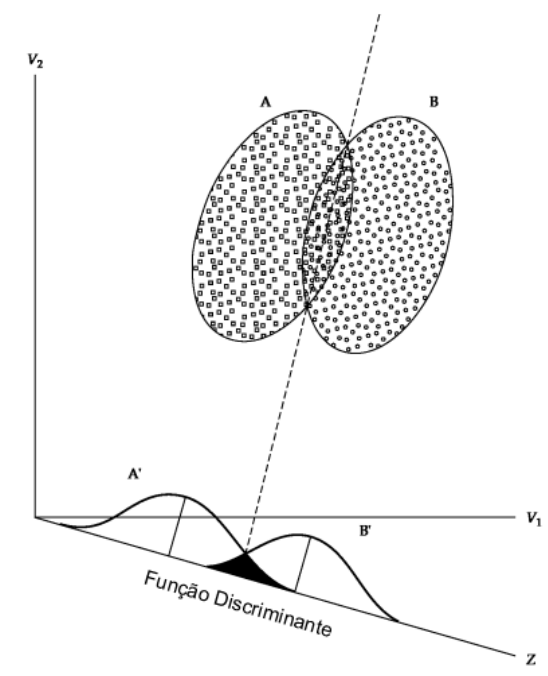

Figura 12 - Discriminação de duas populações normais. Função discriminante de Fisher $p=2$ [HAIR et al., 1999]

Para um melhor entendimento, na Figura 12 é apresentado o caso de duas populações normais bivariadas. Na figura, todos os pontos no diagrama de dispersão são projetados numa linha na direção $Z$, e a direção da linha é modificada até os grupos de amostras ficarem com a máxima separação possível.

Baseados no mesmo caso do exemplo anterior, quando há duas populações normais com igual variabilidade, acontecem os diferentes cenários como os apresentados na Figura 13. Observando-se os gráficos (a)-(d), percebe-se que, se o valor $x$ observado estiver mais próximo do valor $\mu_{1}$, o elemento amostral será classificado como pertencente à população 1 , enquanto que, se o valor de ${ }^{x}$ estiver mais próximo de $\mu_{2}$, ele será classificado como pertencente à população 2. A qualidade da discriminação dependerá do grau de intersecção entre as duas distribuições de probabilidades. Se a variável discriminante é tal que as duas 
distribuições são bem separadas no espaço (Gráfico (a)), o número de classificações incorretas é zero. Para uma pequena intersecção (Gráfico (b)), haverá um pequeno número de erros de classificação. Por outro lado, se a área de intersecção entre as curvas é muito acentuada (Gráficos (c) e (d)), o número de erros tenderá a aumentar, chegando a valores que impossibilitam o uso da função discriminante como regra de classificação.
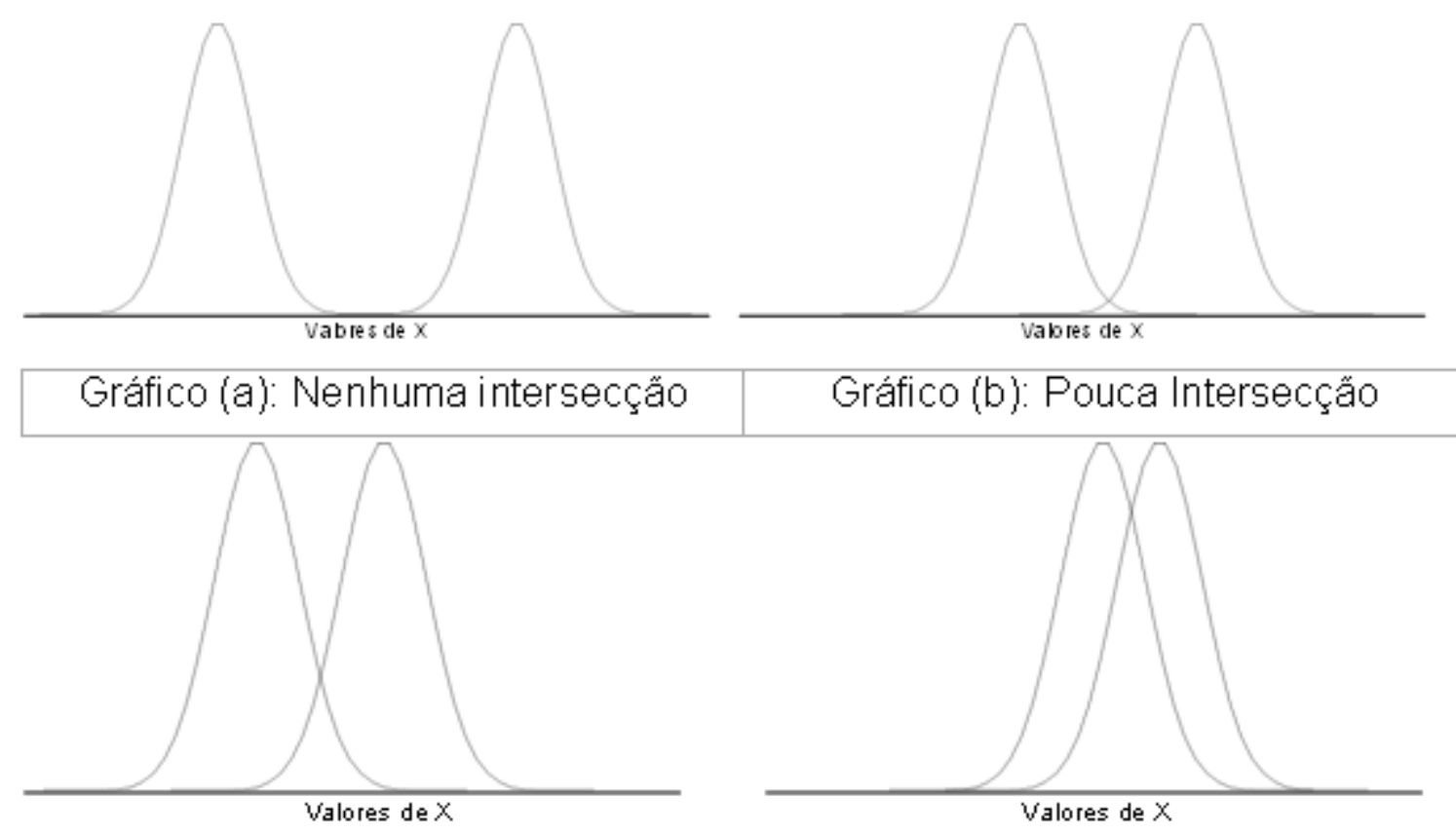

Gráfico (c): Intersecção moderada

Gráfico (b): Grande Intersecçã̃o

Figura 13 - llustração da classificação de duas populações normais com mesma variabilidade e uma variável discriminante (SUELI, 2005)

\subsubsection{Análise discriminante quadrática}

A análise $A D L$ está baseada na hipótese de normalidade $p$-variada e igualdade das matrizes de variâncias populacionais. No entanto, a hipótese de igualdade das matrizes de covariâncias (homocedasticidade) raras vezes é satisfeita (MINGOTI,2005). Nesse caso, optas-se pela análise discriminante quadrática. Porém, é necessário testar as hipóteses de normalidade e de homocedasticidade com o intuito de escolher a análise mais apropriada. A maioria dos softwares tem funções para realizar este tipo de testes, a mais usada é a estatística Lambda de Wilks (AnexoA), que é a estatística padrão usada para denotar a significância 
estatística do poder discriminatório da função discriminante em questão. $O$ valor do teste pode variar de 0,0 a 1,0 considerando-se que, quanto mais próximo de 1,0 menor será o poder discriminatório da função, sendo o contrário verdadeiro (VIEIRA,2009). Podem-se usar outros testes disponíveis na maioria dos softwares como são: Pillai Trace, Hotelling Lawley Trace, Roy Greatest Root, etc. Da mesma forma, estão também disponíveis os testes de Box. M. (Anexo B) e Adj. M (Adjust Pvalues for Multiple Comparisons) para testar a homogeneidade das matrizes de covariâncias..

Mingoti (MINGOTI,2005) recomenda como alternativa mais prática avaliar os dois modelos, linear de Fisher e quadrático, ficando-se no final, com o que resultar em menores proporções de erros de classificação. Caso ambos ofereçam resultados semelhantes e satisfatórios, opta-se pelo modelo linear, uma vez que a matriz de covariâncias teórica estará sendo estimada com um número maior de observações. As considerações para a AD quadrática são descritas no Anexo C.

\subsubsection{Avaliação da qualidade dos resultados}

A qualidade da função discriminante ou regra de classificação é determinada pelo erro de classificação. O objetivo, portanto, é o de construir uma regra de classificação que minimize o número de classificações incorretas, ou seja, o erro de dizer que um elemento amostral pertence a uma população quando, na realidade, ele pertence a outra.

Para o cálculo do erro de classificação há várias alternativas descritas a seguir (JOHNSON\&WICHERN,2001) (MINGOTI,2005):

a) Método de colocação de elementos à parte para classificação (Holdout method): neste método, o conjunto de observações é repartido em duas partes, uma que vai servir como grupo de treinamento para a construção da regra de discriminação e outra que vai ser utilizada para a estimação das probabilidades de classificações incorretas (amostra de validação). 
b) Método Plug-in: neste método, a totalidade das observações é usada para a criação da regra de discriminação e para a estimação dos erros de classificação.

c) Método de validação cruzada ou de Lachenbruch: este procedimento também é conhecido como pseudo-jaknife (Lachenbruc; Michey, 1968) (Ver Anexo D). 


\section{RUÍDO MAGNÉTICO DE BARKHAUSEN - RMB}

Nos materiais ferromagnéticos, na presença de um campo magnético variável no tempo, pequenas e bruscas mudanças surgem no local da magnetização, essas mudanças bruscas na magnetização são geralmente associadas com movimentações bruscas das paredes de domínio de um ponto de ancoragem para outro dentro da microestrutura do material. Este fato foi observado inicialmente pelo professor alemão Heinrich Barkhausen (1919) (DURIN,2000). Ele descobriu que, durante a magnetização de uma barra de ferro, pulsos de tensão elétrica de curta duração são induzidos em uma bobina enrolada em torno da barra. Esses pulsos foram detectados como cliques audíveis em um alto-falante (Figura 14). As voltagens medidas destes saltos são conhecidas como o Ruído Magnético de Barkhausen (KRAUSE,1996).

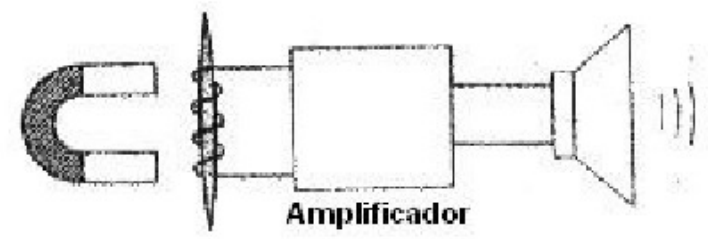

Figura 14 - Experimento feito por Heinrich Barkhausen, (FRANCO,2010)

A maioria dos eventos Barkhausen é produzida pelo movimento irreversível de paredes de domínio de $180^{\circ}$ e acontecem na região de maior inclinação da curva de, magnetização, região $O A B$ da . No avanço do processo de magnetização, outros fatores começam a contribuir, incluindo o movimento de paredes de $90^{\circ}$, rotação de domínios, e, aniquilação de paredes. Assim que o processo se aproxima da saturação magnética, o movimento de paredes desaparece. A Figura 15 mostra a evolução do Ruído Barkhausen na curva de magnetização. 


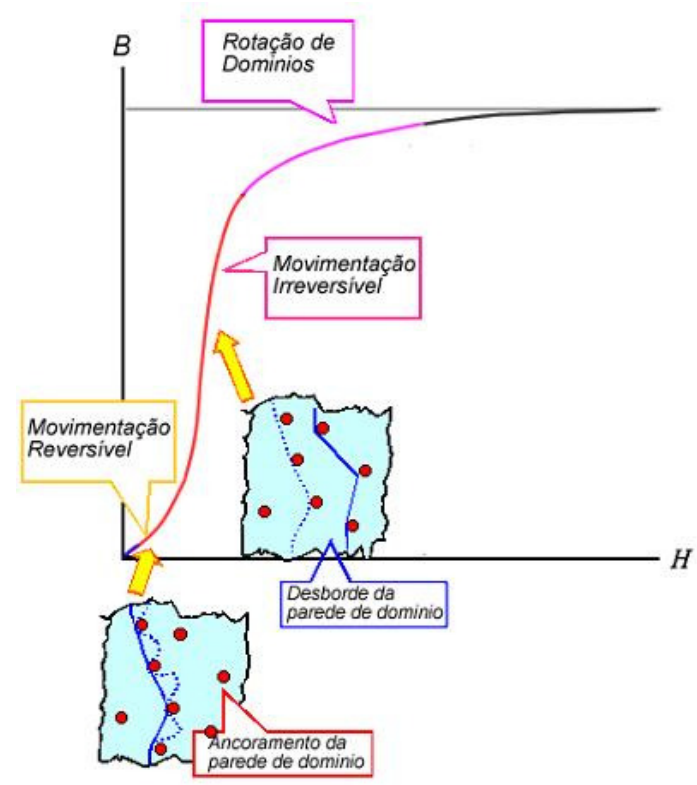

Figura 15 - Esquema de movimentação de paredes de domínio na curva de magnetização. Adaptação de (FOLL,2009)

A Figura 16 apresenta a curva de magnetização para um material ferromagnético. A curva inicia no estado desmagnetizado $(B=H=0)$, com 0 aumento do campo $H$, a indução magnética do material $(B)$ aumenta ao longo da curva $O A B C$ até atingir a magnetização de saturação. Na região $A O$, o processo de magnetização é reversível, isto é, a magnetização volta para zero uma tirado o campo $H$ (CHIKAZUMI,1997) e, envolve movimento das paredes de domínio (OHANDLEY,2000), como mostrado na Figura 16 . Após essa região o processo de magnetização não é mais reversível e também está associado com a movimentação das paredes. O fenômeno predominante para a magnetização na região $B C$ é rotação de domínios, e tem como característica que, com incrementos bem maiores do campo $\mathrm{H}$, se tem aumento muito pequeno de $B$ ou $M$ (CULLITY,2008).

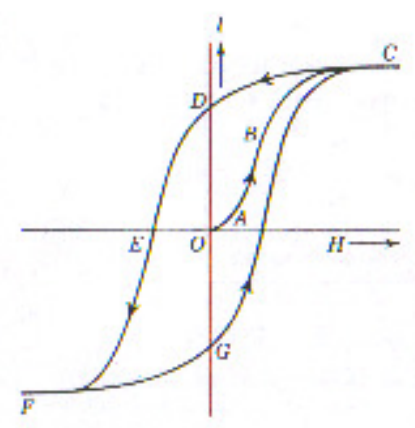

Figura 16 - Curva de magnetização para uma liga Fe-Si 3\% (CHIH,1986) 


\subsection{RMB e Tensões Mecânicas}

Estudos realizados por diversos autores (PEREZ-BENITEZ,2003), (PEREZBENITEZ,2007), (CAPO-SANCHEZ,2007), (ANGLADA-RIVERA,2001), (MANDACHE,2007), (KRAUSE, 1995), (KRAUSE,1996), (JILES,1989) sobre o RMB, e o efeito produzido neste pela aplicação de tensão uniaxial, de forma geral, mostraram que as tensões de tração alinham os domínios magnéticos no sentido da tensão aplicada, e, favorecem o aumento na intensidade do sinal $R M B$; enquanto as tensões de compressão alinham os domínios magnéticos em direção perpendicular a tensão aplicada, gerando níveis de RMB de menor intensidade. A Figura 17 representa esquematicamente 0 efeito de tensões de tração na estrutura de domínios.
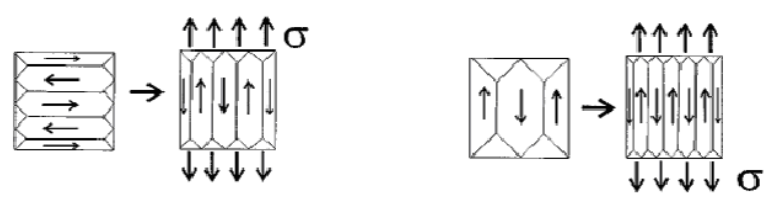

Figura 17 - Reorientação de Domínios produzida por tensão mecânica (KRAUSE,1996)

No entanto, há casos onde a tendência do alinhamento de domínios é inversa à mostrada anteriormente. Blaow (BLAOW,2005) mostrou que aços de baixa liga têm comportamentos diferentes do RMB. Os picos altos do envelope do $R M B$ aumentaram com a tensão de tração, enquanto, tensões de compressão mostraram um comportamento mais complexo; inicialmente foi observado um decréscimo dos picos altos, e com tensões maiores, os valores de $R M B$ começaram a aumentar, gerando um segundo pico. Este comportamento foi explicado como um favorecimento do movimento das paredes de domínios de $90^{\circ}$, devido à tensões de compressão e a composição e tratamento térmico do material (MOORTHY,2004), (MOORTHY,2005), (MOORTHY,2006). 


\subsection{RMB e microestrutura}

O RMB tem mostrado ser sensível a muitas propriedades do material, assim como suas propriedades mecânicas (PEREZ-BENITEZ,2003), (MOORTHY,1998), (SAQUET,1999). Mudanças na microestrutura influenciam consideravelmente a movimentação das paredes de domínios magnéticos e, consequentemente, as características do sinal RMB. Assim, o RMB depende de características do material como tamanho de grão (RANJAN,1987a), (JILES,2000); conteúdo de carbono (KAMEDA,1987), (CAPO-SANCHEZ,2004); e estado de tensões (SIPAHI,1994), (ANGLADA-RIVERA,2001); lacunas, inclusões e impurezas (SANTI,2006), (DURIN,2000), (SANTI,2001); discordâncias (ESTEFANITA,2000), (BIRKETT,1989), (HWANG,1988).

Irregularidades presentes na rede cristalina, e nas propriedades anteriormente descritas, atuam como pontos de ancoragem ou obstáculos, que oferecem uma resistência à movimentação das paredes de domínio e, dependendo do tipo e intensidade destas irregularidades, assim como da área afetada (DOBMAN,1997), há um incremento ou diminuição na quantidade e magnitude dos saltos de Barkhausen (JILES,2000). Devido a esse fato, o RMB tem sido utilizado como técnica de $E N D$, na avaliação de mudanças microestruturais em materiais ferromagnéticos (JAGADISH,1990), (BUTTLE, 1986), (RANJAN,1987), (RANJAN,1987a), (SUNDSTROM,1979).

Baseados na sensibilidade do $R M B$ com a microestrutura dos materiais ferromagnéticos, diversos estudos tem sido desenvolvidos para diferentes casos. Exemplo destes são pesquisas referentes a $R M B$ e diversas fases de formação dos materiais (MITRA,1995), (NORMANDO,2010), (Padovese,2010), (O'SULLIVAN,2004); tamanho de grão e tensão (KRAUSE,1996); dureza (MAASS,2000); tratamentos térmicos e encruamento (O'SULLIVAN,2004), deformação plástica e elástica (PIOTROWSKI,2008), (ESTEFANITA,2000); decarbonetação (SILVA,2006); espessura (SANTI,2006); tensão residual e fadiga (MOORTHY,1998) dentre outros. 


\subsection{ANÁLISE DO SINAL RMB}

A análise feita do sinal $R M B$ é baseada no estudo de diferentes parâmetros calculados a partir dela. Esses parâmetros são então relacionados, com ajuda de modelos matemáticos, às propriedades ou características que se procuram medir no material.

A seguir são citados alguns desses parâmetros, que são objeto deste estudo.

\subsubsection{Valor rms (root mean square) do sinal}

O valor rms representa a raiz quadrada do valor quadrático médio, medido em volts do sinal Barkhausen, para cada ponto observado no domínio do tempo, como definido a seguir:

$$
R M B_{r m s}=\sqrt{\frac{\sum_{i=1}^{n}\left(V_{i}-V_{m}\right)^{2}}{n-1}}
$$

onde:

$V_{i}=$ da voltagem medida para a $i$-ésima observação;

$V_{m} \quad=$ valor médio do sinal;

$n$ = número de observações ou pontos (tempo) do sinal.

Como o sinal de $R M B$ é centrado em amplitude, o seja, tem média zero, o valor rms é equivalente ao desvio padrão e, portanto, representa uma medida do tamanho médio das flutuações ao redor da média. 


\subsubsection{Energia do sinal}

A energia liberada pelo sinal de Barkhausen é definida segundo a equação ((35). $\mathrm{Na}$ fórmula, a área entre o eixo do tempo, e o quadrado do sinal de voltagem, é calculada para cada evento e, somado sobre todos os eventos medidos.

$$
R M B_{\text {energia }}=\sum_{i=1}^{n} V_{i}^{2} \Delta t
$$

Onde:

$V_{i}=$ valor da voltagem medida em um determinando instante;

$\Delta t=$ intervalo de tempo entre os pontos do sinal. Neste caso o inverso da frequência de amostragem.

\subsubsection{Envelope do sinal}

Trata-se da envoltória do sinal temporal. A Figura 18 mostra um exemplo do envelope do sinal de $R M B$.

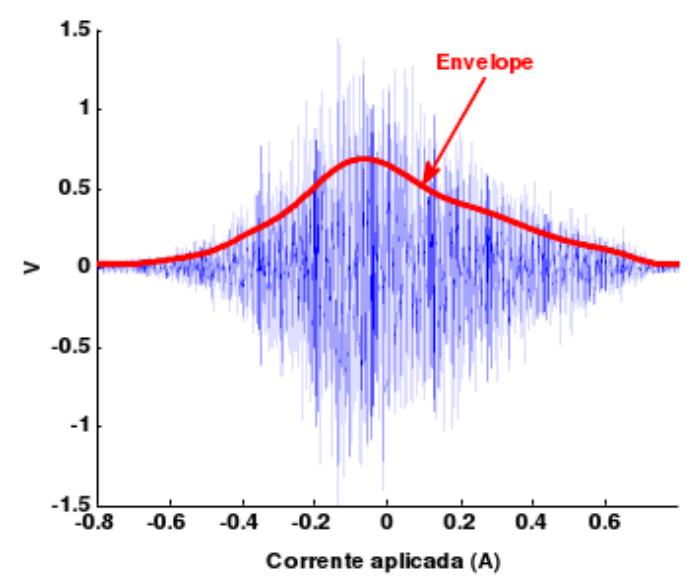

Figura 18 - Exemplo do envelope do sinal RMB (FRANCO,2010)

A maneira tradicional de se calcular o envelope é por meio do sinal analítico do sinal. O sinal analítico é o sinal $S_{+}(t)$ que contém unicamente as frequências 
positivas de $S(t)$. Assim, o sinal $S_{+}(t)$ é associado ao sinal $S(t)$, cuja Transformada de Fourier é expressa por $S(v)$ é definido como:

$$
S_{+}=\left|\operatorname{TFI}\left(Z_{s}(v)\right)\right|
$$

onde:

$$
Z_{s}(v)=\left\{\begin{array}{ccc}
2 S(v) & \text { para } & v \geq 0 \\
0 & \text { para } & v<0
\end{array}\right.
$$

Após calcular o envelope, é necessário utilizar um filtro passa baixa (utilizando uma certa taxa de decimação), para eliminar as frequências altas do envelope e, dessa forma, recuperar um envelope mais liso.

Do gráfico do envelope são calculados principalmente dois parâmetros: Amplitude do pico, relativo ao valor máximo do envelope, e; Posição do pico, relativo à localização do valor máximo, em relação à corrente, ou campo aplicado.

\subsubsection{Número de eventos}

Um evento Barkhausen é definido como uma porção do sinal que, inicia com o cruzamento do sinal com o eixo do tempo, com inclinação positiva (ponto a da Figura 19), e termina também com o cruzamento do sinal com o eixo horizontal, mas com pendente negativa (ponto b da mesma Figura). Assim, a contagem sucessiva dos eventos é o parâmetro Número de eventos. 


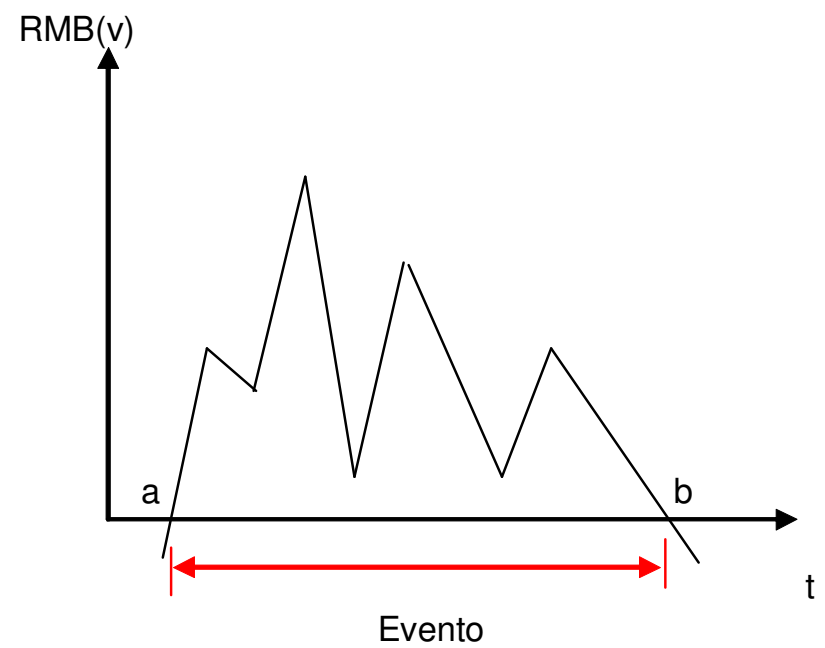

Figura 19 - Representação gráfica de um evento Barkhausen

\subsubsection{Análise do sinal de $R M B$ no domínio da frequência - Espectro do sinal}

Indica como a potência do sinal aleatório está distribuída no domínio da frequência. É definida pela transformada de Fourier, da função de autocorrelação do sinal:

$$
S(f)=\int_{-\tau_{0}}^{\tau_{0}} R(\tau) e^{-\pi f \tau} d t
$$

onde $R(\tau)$ é a função de autocorrelação. Com esta metodologia, consegue-se determinar a participação de diferentes bandas de frequência do sinal, no valor total do $R M B$. 


\section{ANÁLISE DE CASO I: INTEGRIDADE ESTRUTURAL DE RISER}

O objetivo deste experimento é, por meio da análise de diferentes parâmetros do sinal $R M B$ medidos na camada externa dos arames de tração de um riser flexível da indústria petrolífera, identificar o estado estrutural do conjunto arames que a compõem. Para isto, analisando os parâmetros obtidos do sinal RMB com uso de técnicas de estatística multivariada como Componentes Principais e Análise de Agrupamentos.

Os risers flexíveis são estruturas complexas utilizadas na indústria do petróleo para conduzir fluidos do fundo do mar para uma unidade flutuante de produção (navios ou plataformas marítimas). A estrutura do riser está formada por uma montagem de camadas alternadas de materiais metálicos e termoplásticos que oferecem uma alta resistência a carregamentos tais como tração, torção e pressão e possuem também uma baixa resistência ao dobramento (MARTINS,2008).

\subsection{MATERIAIS E MÉTODOS}

Neste capítulo são descritos os materiais empregados para a realização do experimento, montagens e métodos experimentais para a preparação das amostras, equipamentos de medição do $R M B$, e a metodologia empregada para a análise estatística. $O$ experimento foi conduzido e realizado pelo engenheiro Fredy Armando Franco Grijalba como parte das suas atividades do curso de doutorado, a análise feita neste capítulo tomou como base os bancos de dados obtidos desse experimento.

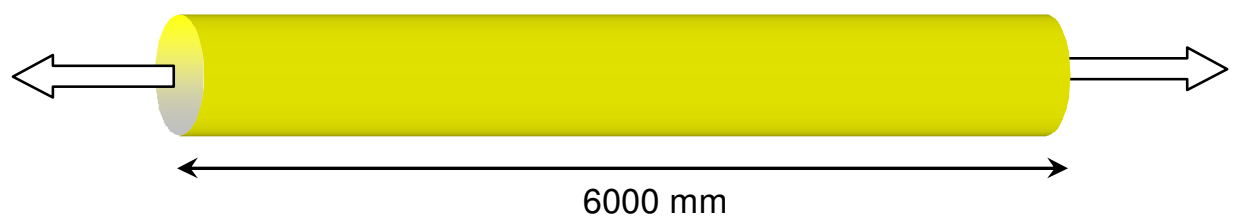

Figura 20 Esquema da amostra e direção dos carregamentos 
Nesse experimento, uma seção de um riser foi preparada. Foi aberta uma janela na camada externa de polímero e 9 dos 37 armes que compõem a camada de tração foram quebrados de forma aleatória (Desta forma tem-se dois conjuntos de arames, arames que vão operar em estado de falha - quebrados -, e arames que vão estar em condições normais de operação). O Dispositivo de excitação e leitura foi posicionado numa secção do riser longe da janela aberta anteriormente onde todas as camadas do riser se mantiveram intactas. O riser foi então submetido a três diferentes níveis de carregamento axial como indicado no diagrama da Figura 20, a montagem final pode ser apreciada na fotografia apresentada na Figura 21.

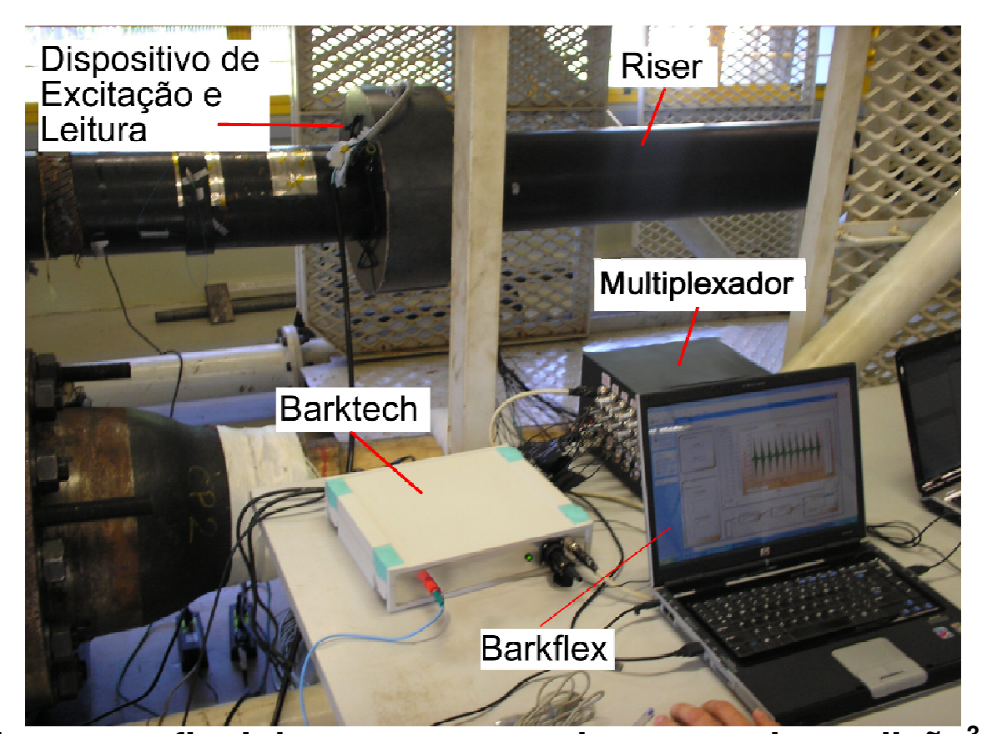

Figura 21 - Montagem final da amostra e equipamento de medição ${ }^{3}$

Para cada nível de carregamento foram feitas as medições do sinal $R M B$ e salvados os dados no computador, o experimento foi repetido segundo 0 planejamento experimental da Tabela 1. Em total foram 5,328 arquivos salvados no banco de dados ( 4 ciclos $\times 3$ níveis de carregamento $\times 12$ leituras $\times 37$ sensores $=$ 5,328 arquivos). No Anexo $C$ há uma descrição detalhada desse processo, para o caso de um sensor.

${ }^{3}$ Montagem feita com a colaboração do Laboratório de Metalurgia Física - LAMEF. Escola de Engenharia da Universidade Federal do Rio Grande do Sul. 
Tabela 1 - Desenho experimental de medições

\begin{tabular}{cccc}
\hline Ciclos de Medição & Carregamento $(T)$ & Leituras individuais & No. de sondas \\
\hline 4 & 80 & 12 & 37 \\
4 & 150 & 12 & 37 \\
4 & 220 & 12 & 37 \\
\hline
\end{tabular}

\subsubsection{Risers - Características}

Como descrito anteriormente, os risers são dutos flexíveis de estruturas que se compõem de múltiplas camadas e de diversos materiais (Figura 22). Uma descrição detalhada dos componentes pode ser encontrada no trabalho feito por (MARTINS,2008). A seguir são citados alguns desses componentes e sua função específica:

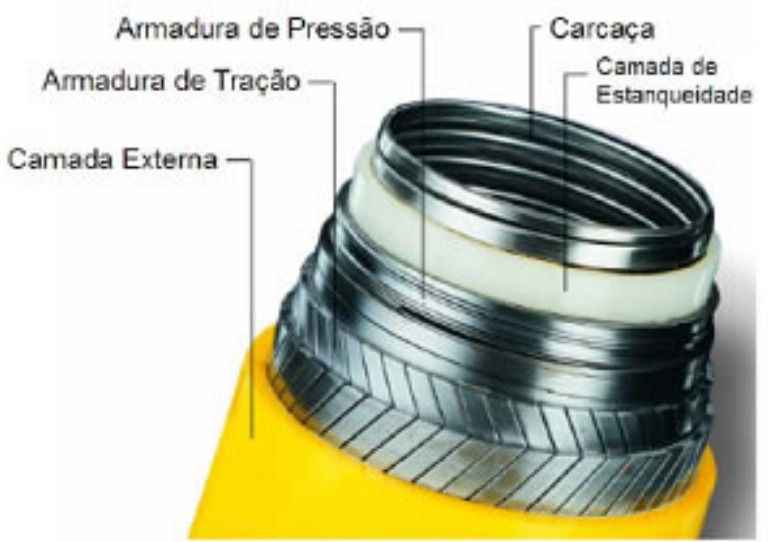

Figura 22 - Configuração típica de um duto flexível do tipo Unbounded (MARTINS,2008)

Carcaça - Tem a função de resistir a pressão interna e suportar os esforços causados pela inércia do componente. Geralmente é composta de aços inoxidáveis.

Camada de Estanqueidade - Tem a função de impedir a permeabilidade de gases para as camadas posteriores. É formada por polímeros variados, dependendo da temperatura de aplicação do duto.

Armadura de Pressão - Têm a função de suportar as tensões de topo, induzidas pela pressão interna no tubo. A armadura de pressão se compõe de duas camadas de tiras de aço, as quais dependendo da natureza do carregamento, podem ter a 
forma de um perfil plano ou de um perfil em C. Geralmente esta camada é confeccionada em aço carbono de alta resistência do tipo ABNT 1060.

Armadura de Tração - Tem a função de resistir aos esforços axiais aos quais o duto está sujeito. Funciona também para o balanceamento e torção, apresentando camadas de arames helicoidalmente distribuídas aos pares. Normalmente é confeccionada por aço carbono de alta resistência mecânica do tipo ABNT 1060 encruado.

Camada Externa - Têm a função de garantir resistência a corrosão e abrasão da armadura de tração. É formada de material polimérico, apresentando espessura variável segundo a aplicação.

\subsubsection{Descrição da amostra}

Para a amostra foi utilizada uma seção de um riser de aproximadamente 6 metros de comprimento e $152,40 \mathrm{~mm}$ de diâmetro externo.

A preparação e montagem da amostra foi feita com a colaboração da a equipe do Laboratório de Metalurgia Física - LAMEF, da Centenária Escola de Engenharia da Universidade Federal do Rio Grande do Sul, que dispõe de equipamentos especialmente desenhados para este tipo de teste.

\subsubsection{Sistema de medição}

Para as medições do sinal RMB foi usado o equipamento denominado "Barktech" desenvolvido no Laboratório de Dinâmica e Instrumentação (LADIM) da Escola Politécnica da Universidade de São Paulo. Este equipamento realiza uma variedade de operações, sendo estas necessárias para a medição do fenômeno do $R M B$ e são descritas a seguir: 


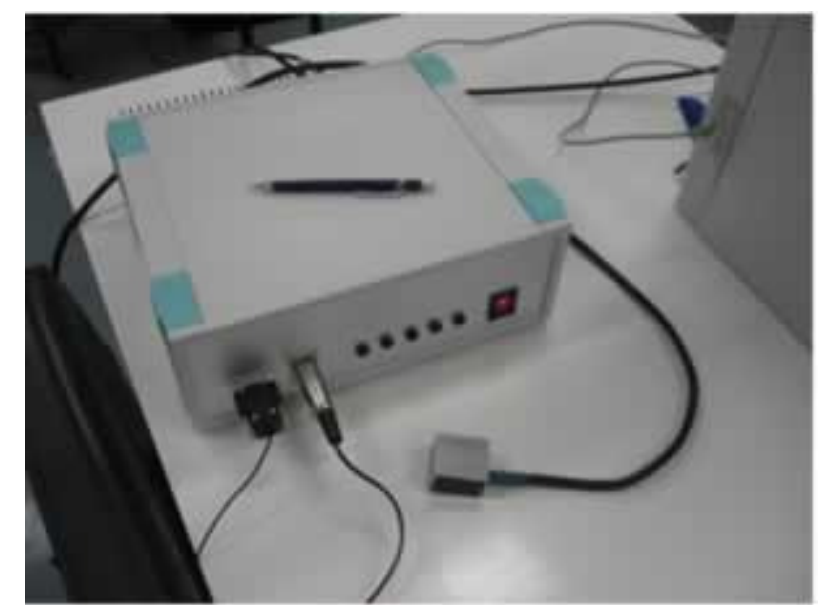

Figura 23 - Equipamento de medições do Ruído Magnético de Barkhausen, Barktech.

Geração e controle da corrente de excitação. O Barktech permite gerar, correntes de excitação com frequências de 0,4 a $100 \mathrm{~Hz}$, e amplitudes de 0 4A.

Aquisição e filtragem dos sinais obtidos pelo sensor $R M B$. O equipamento permite adquirir os sinais com diferentes faixas de frequência, assim como valores de amplificação e ganhos de diferentes magnitudes, todas estas controladas por computador ligado ao Barktech.
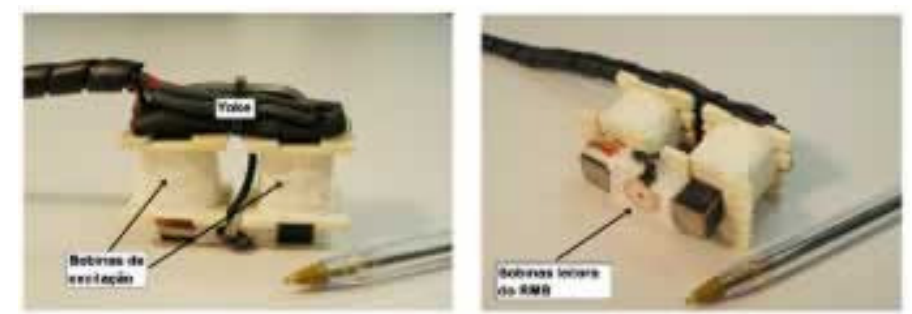

Figura 24 - Fotografia de Sonda RMB para ensaios de flexão (FRANCO,2010)

Quando a medição do $R M B$ é feita numa amostra simples, utiliza-se uma sonda como a apresentada na Figura 24. No entanto, e devido ás características dimensionais e estruturais do riser, foi necessário projetar um arranjo de 37 bobinas de leitura (uma para cada arame da camada externa da armadura de tração) como apresentado no esquema da Figura 25. 


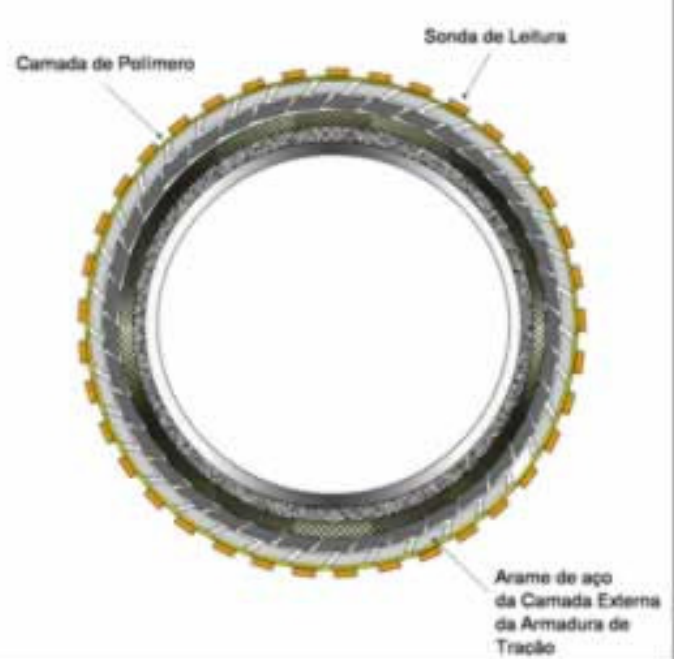

Figura 25 - Esquema do posicionamento das sondas de leitura para o Riser, corte transversal

O sistema de excitação foi também projetado especialmente para esta aplicação como ilustrado na Figura 26. Este é controlado pelo Barktech que controla a corrente responsável pela geração do campo de excitação no riser. $O$ arranjo de sensores fica alocado ao lado da bobina geradora.

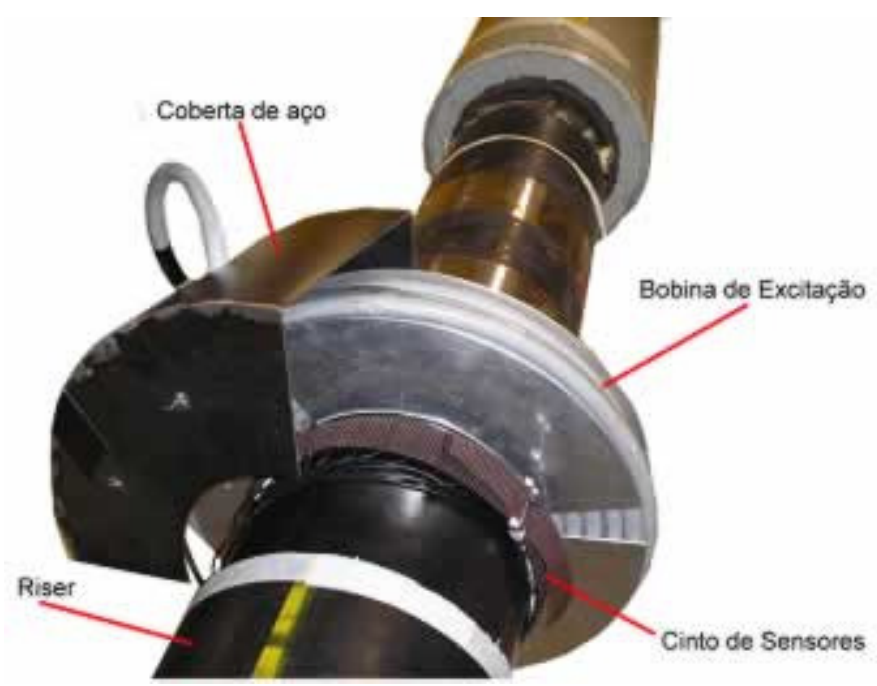

Figura 26 - Montagem do sistema de excitação, leitura e amostra 
Aquisição do sinal: Cada medida se compõe de sinais $R M B$ gerados para um ciclo completo de magnetização (Figura 27). A taxa de amostragem foi mantida em $200 \mathrm{kHz}$.

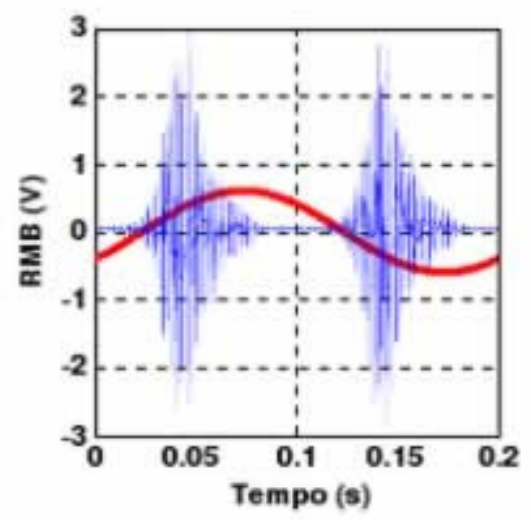

Figura 27 - Sinal RMB típico (linha azul) medido no riser e sinal de excitação (linha vermelha)

A visualização e gravação dos sinais foram feitas através de um programa desenvolvido no Ladin, nomeado Barkflex Versão $1.0 \AA^{\circledR}$. A Figura 28 apresenta uma captura da tela da aplicação para os parâmetros de entrada e saída do aplicativo.

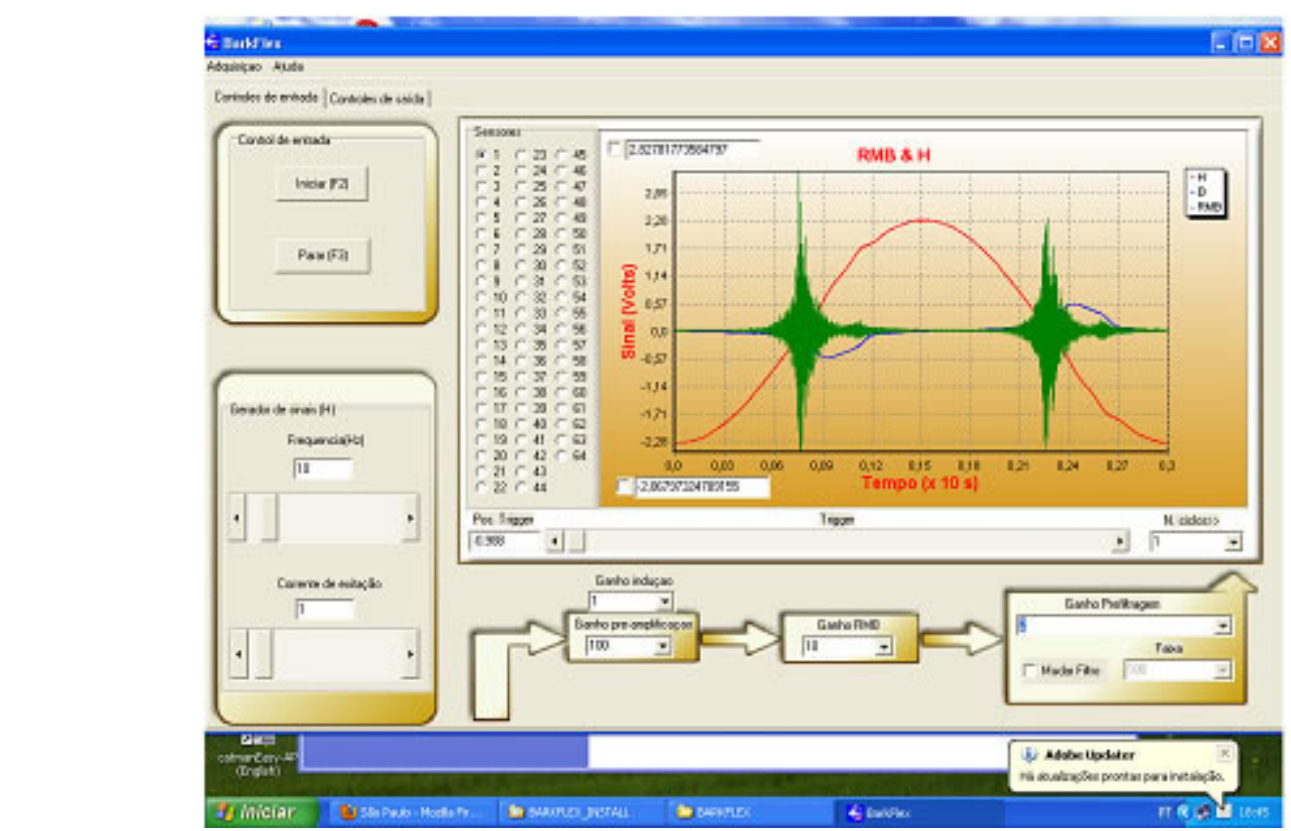

Figura 28 - Aplicativo Barkflex, software de aquisição de sinais RMB 


\subsection{METODOLOGIA DE ANÁLISE DOS DADOS}

O fluxograma mostrado na Figura 29 apresenta os métodos estatísticos empregados para a análise dos parâmetros calculados a partir dos sinais de $R M B$. Após os parâmetros terem sido calculados foi avaliada a qualidade da informação, isto mediante as técnicas explicadas revisão bibliográfica. Logo depois foi feita a ACP como etapa previa para a classificação não supervisionada com a AA.

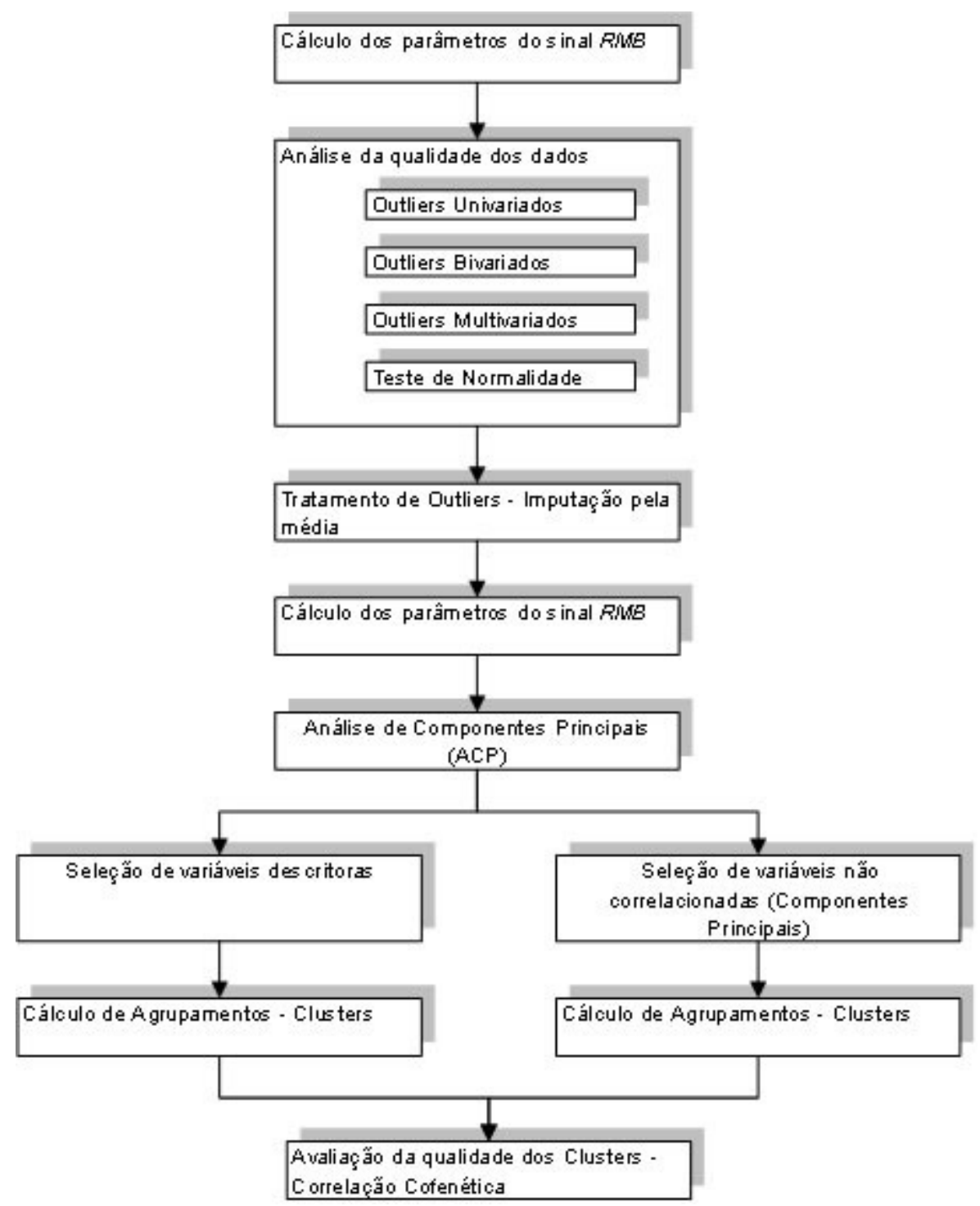

Figura 29 - Fluxograma dos métodos empregados para a análise dos sinais $R M B$ para o riser.

$\mathrm{Na}$ mesma figura são apresentadas as duas abordagens que foram avaliadas após o da ACP, onde no primeiro caso foi usada como técnica para seleção das 
variáveis mais representativas (de maior poder explicativo) e, no segundo caso para seleção das componentes de maior valor (maior variância).

Para um melhor entendimento dos procedimentos estatísticos empregados na etapa de avaliação da qualidade dos dados, o diagrama da Figura 30 apresenta uma pequena descrição da atividade e das ferramentas estatísticas utilizadas.

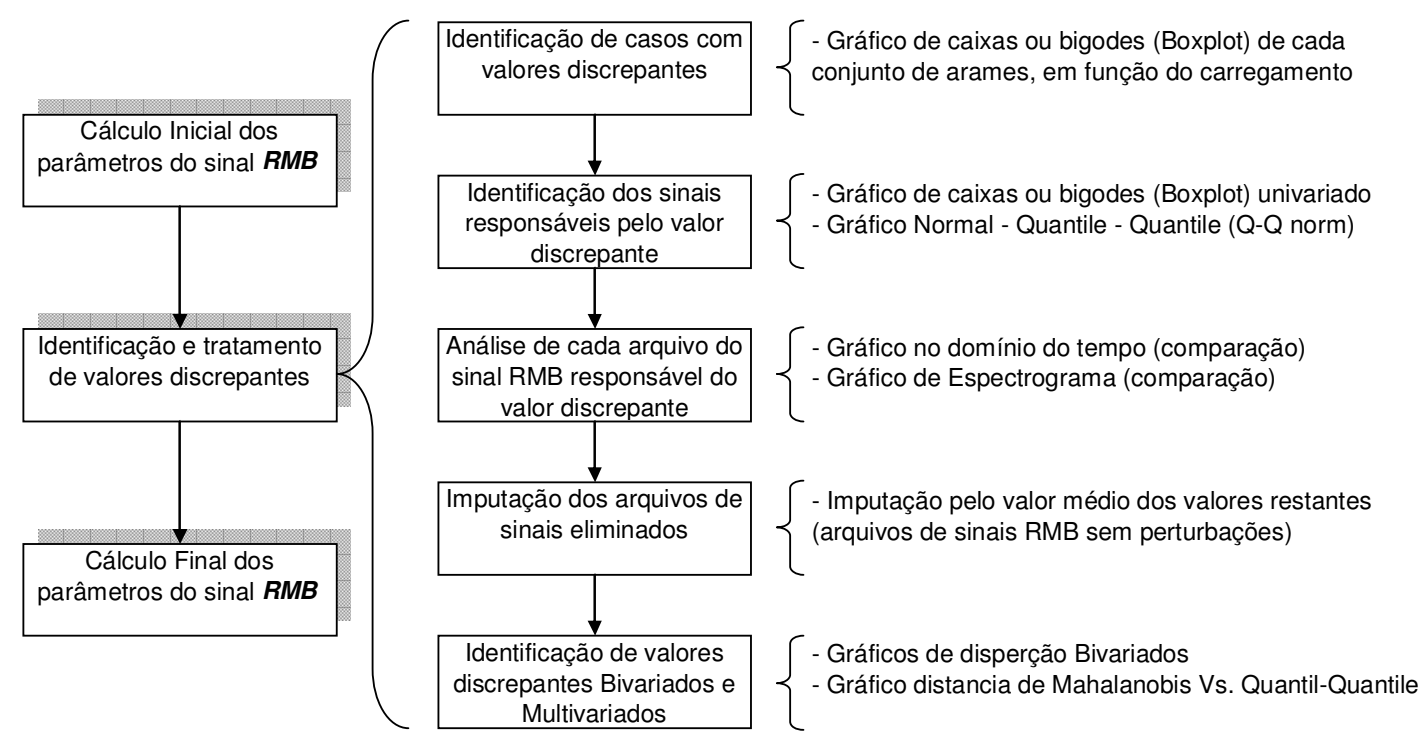

Figura 30 - Diagrama de blocos dos passos para identificação e tratamento dos valores discrepantes

A seguir são apresentados os cálculos feitos a partir dos arquivos de sinais $R M B$ conforme ao anterior diagrama, no item correspondente com a identificação da medição (arquivo) responsável por um valor discrepante (outlier) será apresentado apenas um caso a maneira explicativa pelo fato de uma tarefa iterativa ou repetitiva.

\subsubsection{Cálculo dos parâmetros do sinal}

Foram calculados diferentes parâmetros dos sinais medidos: Posição pico do envelope (Ppico), Amplitude do pico do envelope (Apico), $R M B_{r m s}, R M B_{\text {energia }}$, e Número de eventos (Neventos) para cada um dos carregamentos. Assim como os desvios padrão de parâmetro. No Anexo C são apresentados de forma detalhada os cálculos feitos para obter o valor médio de cada parâmetro em cada sensor. Os valores médios de esses parâmetros são apresentados na 
Tabela 2 e na Tabela 4.

Tabela 2 - Valores dos parâmetros calculados do sinal RMB - Carregamento de 80 toneladas

\begin{tabular}{|c|c|c|c|c|c|c|c|c|c|c|}
\hline Sensor & rms & energia & Neventos & Apico & Ppico & $\sigma_{r m s}$ & $\sigma_{\text {energia }}$ & $\sigma_{\text {Neventos }}$ & $\sigma_{\text {Apico }}$ & $\sigma_{\text {Ppico }}$ \\
\hline 1 & 0.1506 & 0.0228 & 852 & 0.7407 & 27,887 & 0.0087 & 0.0026 & 24.780 & 0.0650 & 16,280 \\
\hline 2 & 0.1533 & 0.0236 & 862 & 0.7424 & 24,325 & 0.0109 & 0.0034 & 21.643 & 0.0515 & 15,674 \\
\hline 3 & 0.1424 & 0.0204 & 800 & 0.7125 & 27,405 & 0.0093 & 0.0027 & 21.514 & 0.0622 & 16,205 \\
\hline 4 & 0.1431 & 0.0205 & 815 & 0.7051 & 26,326 & 0.0077 & 0.0022 & 19.428 & 0.0440 & 16,130 \\
\hline 5 & 0.1478 & 0.0219 & 832 & 0.7489 & 25,990 & 0.0080 & 0.0024 & 19.036 & 0.0543 & 16,014 \\
\hline 6 & 0.1529 & 0.0234 & 849 & 0.7476 & 23,550 & 0.0084 & 0.0026 & 20.198 & 0.0637 & 15,437 \\
\hline 7 & 0.1597 & 0.0256 & 862 & 0.8029 & 25,101 & 0.0089 & 0.0029 & 23.407 & 0.0634 & 16,012 \\
\hline 8 & 0.1754 & 0.0308 & 853 & 0.8522 & 24,724 & 0.0095 & 0.0033 & 16.717 & 0.0823 & 15,825 \\
\hline 9 & 0.1637 & 0.0269 & 875 & 0.7952 & 27,076 & 0.0088 & 0.0029 & 21.562 & 0.0644 & 16,504 \\
\hline 10 & 0.1805 & 0.0326 & 886 & 0.8503 & 19,464 & 0.0086 & 0.0031 & 20.207 & 0.0684 & 13,763 \\
\hline 11 & 0.2259 & 0.0512 & 922 & 1.0644 & 27,238 & 0.0135 & 0.0060 & 22.248 & 0.0994 & 16,367 \\
\hline 12 & 0.1725 & 0.0298 & 878 & 0.8089 & 21,601 & 0.0093 & 0.0033 & 20.243 & 0.0827 & 14,784 \\
\hline 13 & 0.1382 & 0.0191 & 865 & 0.6800 & 24,310 & 0.0062 & 0.0017 & 20.324 & 0.0523 & 15,591 \\
\hline 14 & 0.1150 & 0.0133 & 761 & 0.6031 & 23,887 & 0.0083 & 0.0019 & 22.161 & 0.0537 & 15,155 \\
\hline 15 & 0.1200 & 0.0145 & 809 & 0.6325 & 23,159 & 0.0091 & 0.0022 & 22.153 & 0.0591 & 14,723 \\
\hline 16 & 0.1811 & 0.0330 & 889 & 0.8566 & 23,232 & 0.0119 & 0.0044 & 17.404 & 0.0762 & 15,725 \\
\hline 17 & 0.1666 & 0.0278 & 854 & 0.8035 & 25,073 & 0.0094 & 0.0031 & 16.456 & 0.0711 & 16,142 \\
\hline 18 & 0.1785 & 0.0320 & 869 & 0.8651 & 26,290 & 0.0106 & 0.0038 & 23.575 & 0.0694 & 16,302 \\
\hline 19 & 0.1673 & 0.0281 & 872 & 0.8263 & 23,304 & 0.0094 & 0.0032 & 23.205 & 0.0728 & 15,351 \\
\hline 20 & 0.1551 & 0.0241 & 834 & 0.7651 & 24,951 & 0.0077 & 0.0024 & 19.033 & 0.0622 & 16,110 \\
\hline 21 & 0.1605 & 0.0258 & 860 & 0.7720 & 21,869 & 0.0066 & 0.0021 & 18.561 & 0.0528 & 14,698 \\
\hline 22 & 0.1277 & 0.0164 & 804 & 0.6495 & 25,187 & 0.0092 & 0.0024 & 20.935 & 0.0706 & 15,758 \\
\hline 23 & 0.1317 & 0.0174 & 817 & 0.6849 & 20,938 & 0.0075 & 0.0020 & 21.815 & 0.0620 & 14,197 \\
\hline 24 & 0.1640 & 0.0270 & 839 & 0.8426 & 21,725 & 0.0102 & 0.0034 & 20.517 & 0.0752 & 14,890 \\
\hline 25 & 0.1680 & 0.0283 & 789 & 0.8153 & 23,453 & 0.0099 & 0.0034 & 17.748 & 0.0791 & 15,271 \\
\hline 26 & 0.1567 & 0.0246 & 843 & 0.7919 & 24,718 & 0.0088 & 0.0027 & 19.903 & 0.0755 & 15,689 \\
\hline 27 & 0.1767 & 0.0313 & 909 & 0.8346 & 28,795 & 0.0093 & 0.0033 & 32.641 & 0.0789 & 16,150 \\
\hline 28 & 0.1807 & 0.0328 & 914 & 0.8561 & 24,397 & 0.0122 & 0.0045 & 23.415 & 0.0983 & 15,899 \\
\hline 29 & 0.1410 & 0.0199 & 814 & 0.6852 & 23,945 & 0.0065 & 0.0018 & 18.112 & 0.0588 & 15,630 \\
\hline 30 & 0.1727 & 0.0299 & 883 & 0.8286 & 27,655 & 0.0078 & 0.0027 & 20.739 & 0.0584 & 16,470 \\
\hline 31 & 0.1963 & 0.0386 & 870 & 0.9286 & 23,212 & 0.0107 & 0.0042 & 21.009 & 0.0778 & 15,594 \\
\hline 32 & 0.1709 & 0.0293 & 828 & 0.8407 & 25,875 & 0.0121 & 0.0041 & 21.746 & 0.0658 & 16,243 \\
\hline 33 & 0.1435 & 0.0207 & 800 & 0.7051 & 24,928 & 0.0092 & 0.0027 & 20.682 & 0.0714 & 16,053 \\
\hline 34 & 0.1473 & 0.0218 & 832 & 0.7145 & 21,123 & 0.0094 & 0.0028 & 22.139 & 0.0654 & 14,488 \\
\hline 35 & 0.1151 & 0.0133 & 766 & 0.6034 & 24,256 & 0.0055 & 0.0013 & 14.831 & 0.0568 & 15,629 \\
\hline 36 & 0.1321 & 0.0175 & 777 & 0.6739 & 25,759 & 0.0076 & 0.0020 & 21.637 & 0.0556 & 16,103 \\
\hline 37 & 0.1409 & 0.0199 & 831 & 0.7103 & 21,711 & 0.0101 & 0.0029 & 22.963 & 0.0545 & 14,895 \\
\hline
\end{tabular}


Tabela 3 - Valores dos parâmetros calculados do sinal RMB - Carregamento de 150 toneladas

\begin{tabular}{|c|c|c|c|c|c|c|c|c|c|c|}
\hline Sensor & $\mathrm{rms}$ & energia & Neventos & Apico & Ppico & $\sigma_{r m s}$ & $\sigma_{\text {energia }}$ & $\sigma_{\text {Neventos }}$ & $\sigma_{\text {Apico }}$ & $\sigma_{\text {Ppico }}$ \\
\hline 1 & 0.1347 & 0.0154 & 816 & 0.6854 & 23,444 & 0.0087 & 0.0021 & 17.581 & 0.0559 & 15,166 \\
\hline 2 & 0.1389 & 0.0175 & 830 & 0.6905 & 25,133 & 0.0098 & 0.0019 & 23.707 & 0.0588 & 15,716 \\
\hline 3 & 0.1285 & 0.0139 & 776 & 0.6809 & 25,184 & 0.0076 & 0.0016 & 19.853 & 0.0608 & 15,912 \\
\hline 4 & 0.1273 & 0.0133 & 782 & 0.6526 & 24,650 & 0.0068 & 0.0019 & 18.494 & 0.0452 & 15,622 \\
\hline 5 & 0.1283 & 0.0131 & 793 & 0.6519 & 22,343 & 0.0062 & 0.0016 & 18.784 & 0.0578 & 14,686 \\
\hline 6 & 0.1306 & 0.0137 & 809 & 0.6533 & 22,455 & 0.0061 & 0.0016 & 16.163 & 0.0535 & 14,718 \\
\hline 7 & 0.1396 & 0.0155 & 836 & 0.6996 & 24,280 & 0.0068 & 0.0021 & 20.797 & 0.0553 & 15,531 \\
\hline 8 & 0.1708 & 0.0296 & 844 & 0.8080 & 23,626 & 0.0110 & 0.0038 & 20.416 & 0.0715 & 15,190 \\
\hline 9 & 0.1459 & 0.0171 & 845 & 0.6988 & 25,460 & 0.0083 & 0.0019 & 23.966 & 0.0735 & 16,006 \\
\hline 10 & 0.1625 & 0.0202 & 855 & 0.7876 & 24,107 & 0.0085 & 0.0024 & 20.940 & 0.0713 & 15,927 \\
\hline 11 & 0.2176 & 0.0484 & 919 & 1.0364 & 21,901 & 0.0098 & 0.0053 & 17.637 & 0.0984 & 15,601 \\
\hline 12 & 0.1556 & 0.0204 & 855 & 0.7451 & 22,476 & 0.0096 & 0.0023 & 19.630 & 0.0571 & 15,229 \\
\hline 13 & 0.1205 & 0.0119 & 831 & 0.6221 & 22,934 & 0.0078 & 0.0015 & 20.817 & 0.0523 & 15,047 \\
\hline 14 & 0.0980 & 0.0074 & 717 & 0.5257 & 20,852 & 0.0058 & 0.0010 & 22.882 & 0.0526 & 13,310 \\
\hline 15 & 0.1053 & 0.0086 & 778 & 0.5543 & 21,446 & 0.0071 & 0.0008 & 19.610 & 0.0511 & 13,380 \\
\hline 16 & 0.1775 & 0.0321 & 885 & 0.8357 & 20,519 & 0.0096 & 0.0033 & 22.414 & 0.0741 & 14,576 \\
\hline 17 & 0.1493 & 0.0179 & 817 & 0.7425 & 19,778 & 0.0075 & 0.0020 & 20.683 & 0.0539 & 13,753 \\
\hline 18 & 0.1727 & 0.0299 & 856 & 0.8192 & 21,844 & 0.0106 & 0.0034 & 20.929 & 0.0775 & 14,749 \\
\hline 19 & 0.1436 & 0.0153 & 833 & 0.6923 & 23,339 & 0.0072 & 0.0016 & 17.604 & 0.0511 & 15,421 \\
\hline 20 & 0.1272 & 0.0114 & 786 & 0.6552 & 20,729 & 0.0077 & 0.0013 & 24.499 & 0.0544 & 13,974 \\
\hline 21 & 0.1347 & 0.0124 & 808 & 0.6753 & 25,052 & 0.0076 & 0.0014 & 22.821 & 0.0562 & 15,725 \\
\hline 22 & 0.1052 & 0.0075 & 748 & 0.5711 & 22,432 & 0.0045 & 0.0011 & 22.503 & 0.0423 & 14,327 \\
\hline 23 & 0.1299 & 0.0172 & 817 & 0.6645 & 19,850 & 0.0091 & 0.0025 & 20.570 & 0.0628 & 13,272 \\
\hline 24 & 0.1665 & 0.0293 & 839 & 0.8276 & 25,905 & 0.0095 & 0.0036 & 19.004 & 0.0822 & 16,120 \\
\hline 25 & 0.1655 & 0.0283 & 795 & 0.8308 & 24,751 & 0.0110 & 0.0037 & 20.211 & 0.0720 & 15,730 \\
\hline 26 & 0.1334 & 0.0122 & 798 & 0.6825 & 21,875 & 0.0073 & 0.0018 & 23.318 & 0.0585 & 14,491 \\
\hline 27 & 0.1530 & 0.0173 & 862 & 0.7383 & 23,669 & 0.0072 & 0.0020 & 19.943 & 0.0605 & 15,336 \\
\hline 28 & 0.1562 & 0.0181 & 862 & 0.7552 & 24,105 & 0.0091 & 0.0020 & 23.453 & 0.0675 & 15,594 \\
\hline 29 & 0.1232 & 0.0104 & 770 & 0.6265 & 20,397 & 0.0071 & 0.0015 & 22.409 & 0.0550 & 13,551 \\
\hline 30 & 0.1597 & 0.0211 & 862 & 0.7679 & 24,428 & 0.0082 & 0.0027 & 22.928 & 0.0647 & 15,923 \\
\hline 31 & 0.1906 & 0.0356 & 855 & 0.9155 & 21,229 & 0.0083 & 0.0045 & 14.873 & 0.0735 & 14,982 \\
\hline 32 & 0.1536 & 0.0183 & 802 & 0.7679 & 20,631 & 0.0095 & 0.0024 & 18.507 & 0.0700 & 14,619 \\
\hline 33 & 0.1279 & 0.0130 & 770 & 0.6482 & 23,781 & 0.0084 & 0.0016 & 20.348 & 0.0581 & 15,632 \\
\hline 34 & 0.1370 & 0.0171 & 809 & 0.6706 & 25,413 & 0.0065 & 0.0023 & 21.742 & 0.0482 & 15,939 \\
\hline 35 & 0.1080 & 0.0103 & 737 & 0.5817 & 26,086 & 0.0055 & 0.0012 & 17.388 & 0.0477 & 15,686 \\
\hline 36 & 0.1137 & 0.0102 & 743 & 0.5962 & 24,716 & 0.0076 & 0.0013 & 21.753 & 0.0536 & 15,500 \\
\hline 37 & 0.1232 & 0.0112 & 795 & 0.6284 & 18,700 & 0.0089 & 0.0015 & 27.818 & 0.0550 & 12,809 \\
\hline
\end{tabular}


Tabela 4 - Valores dos parâmetros calculados do sinal RMB - Carregamento de 220 toneladas

\begin{tabular}{|c|c|c|c|c|c|c|c|c|c|c|}
\hline Sensor & rms & energia & Neventos & Apico & Ppico & $\sigma_{r m s}$ & $\sigma_{\text {energia }}$ & $\sigma_{\text {Neventos }}$ & $\sigma_{\text {Apico }}$ & $\sigma_{\text {Ppico }}$ \\
\hline 1 & 0.1240 & 0.0154 & 789 & 0.6360 & 0.6360 & 0.0086 & 0.0021 & 21.102 & 0.0729 & 14,112 \\
\hline 2 & 0.1321 & 0.0175 & 804 & 0.6666 & 0.6666 & 0.0071 & 0.0019 & 22.530 & 0.0520 & 15,362 \\
\hline 3 & 0.1178 & 0.0139 & 745 & 0.6146 & 0.6146 & 0.0067 & 0.0016 & 24.017 & 0.0506 & 15,097 \\
\hline 4 & 0.1150 & 0.0133 & 758 & 0.5993 & 0.5993 & 0.0081 & 0.0019 & 18.547 & 0.0432 & 15,381 \\
\hline 5 & 0.1143 & 0.0131 & 749 & 0.5936 & 0.5936 & 0.0071 & 0.0016 & 17.179 & 0.0432 & 16,013 \\
\hline 6 & 0.1169 & 0.0137 & 770 & 0.6097 & 0.6097 & 0.0067 & 0.0016 & 17.684 & 0.0528 & 13,968 \\
\hline 7 & 0.1243 & 0.0155 & 795 & 0.6336 & 0.6336 & 0.0084 & 0.0021 & 18.607 & 0.0599 & 15,525 \\
\hline 8 & 0.1716 & 0.0296 & 844 & 0.8201 & 0.8201 & 0.0111 & 0.0038 & 21.417 & 0.0643 & 14,555 \\
\hline 9 & 0.1306 & 0.0171 & 818 & 0.6623 & 0.6623 & 0.0074 & 0.0019 & 21.496 & 0.0607 & 15,673 \\
\hline 10 & 0.1420 & 0.0202 & 836 & 0.7043 & 0.7043 & 0.0085 & 0.0024 & 18.759 & 0.0596 & 15,923 \\
\hline 11 & 0.2197 & 0.0484 & 916 & 1.0488 & 1.0488 & 0.0121 & 0.0053 & 23.465 & 0.0961 & 16,201 \\
\hline 12 & 0.1425 & 0.0204 & 829 & 0.6898 & 0.6898 & 0.0080 & 0.0023 & 23.390 & 0.0473 & 15,631 \\
\hline 13 & 0.1087 & 0.0119 & 804 & 0.5559 & 0.5559 & 0.0067 & 0.0015 & 21.010 & 0.0454 & 14,427 \\
\hline 14 & 0.0859 & 0.0074 & 680 & 0.4858 & 0.4858 & 0.0060 & 0.0010 & 25.153 & 0.0354 & 15,300 \\
\hline 15 & 0.0924 & 0.0086 & 736 & 0.4934 & 0.4934 & 0.0045 & 0.0008 & 20.485 & 0.0463 & 13,518 \\
\hline 16 & 0.1789 & 0.0321 & 887 & 0.8513 & 0.8513 & 0.0093 & 0.0033 & 16.760 & 0.0736 & 15,174 \\
\hline 17 & 0.1336 & 0.0179 & 793 & & & & & & 0.0611 & 14,664 \\
\hline 18 & 0.1728 & 0.0299 & 854 & 0.8256 & 0.8256 & 0.0098 & 0.0034 & 23.751 & 0.0812 & 16,289 \\
\hline 19 & 0.1236 & 0.0153 & 798 & 0.6345 & 0.6345 & 0.0065 & 0.0016 & 20.835 & 0.0449 & 15,319 \\
\hline 20 & 0.1065 & 0.0114 & 741 & 0.5724 & 0.5724 & 0.0063 & 0.0013 & 23.533 & 0.0502 & 14,908 \\
\hline 21 & 0.1111 & 0.0124 & 751 & & & 0.0063 & & 20.033 & 0.0476 & 14,838 \\
\hline 22 & & 0.0075 & 686 & & & & & & 0.0434 & 14,474 \\
\hline 23 & 0.1310 & 0.0172 & 811 & 0.6655 & 0.6655 & 0.0093 & 0.0025 & 22.758 & 0.0713 & 16,196 \\
\hline 24 & 0.1707 & 0.0293 & 842 & 0.8416 & 0.8416 & 0.0102 & 0.0036 & 19.487 & 0.0871 & 13,656 \\
\hline 25 & 0.1679 & 0.0283 & 789 & 0.8255 & 0.8255 & 0.0110 & 0.0037 & 23.269 & 0.0659 & 15,745 \\
\hline 26 & 0.1101 & 0.0122 & 739 & & & 0.0079 & & & 0.0525 & 14,752 \\
\hline 27 & 0.1312 & 0.0173 & 811 & 0.6635 & 0.6635 & 0.0078 & 0.0020 & 21.334 & 0.0498 & 15,731 \\
\hline 28 & 0.1342 & 0.0181 & 823 & 0.6723 & 0.6723 & 0.0073 & 0.0020 & 19.408 & 0.0492 & 14,529 \\
\hline 29 & 0.1018 & 0.0104 & 740 & 0.5574 & 0.5574 & 0.0073 & 0.0015 & 90.049 & 0.0463 & 15,732 \\
\hline 30 & 0.1449 & 0.0211 & 833 & 0.7192 & 0.7192 & 0.0092 & 0.0027 & 22.038 & 0.0682 & 14,427 \\
\hline 31 & 0.1882 & 0.0356 & 847 & 0.9097 & 0.9097 & 0.0121 & 0.0045 & 20.448 & 0.0917 & 16,350 \\
\hline 32 & 0.1349 & 0.0183 & 763 & 0.6969 & 0.6969 & 0.0088 & 0.0024 & 22.734 & 0.0669 & 16,302 \\
\hline 33 & 0.1136 & 0.0130 & 728 & 0.6139 & 0.6139 & 0.0072 & 0.0016 & 22.179 & 0.0527 & 16,093 \\
\hline 34 & 0.1306 & 0.0171 & 796 & 0.6531 & 0.6531 & 0.0086 & 0.0023 & 21.150 & 0.0592 & 16,063 \\
\hline 35 & 0.1015 & 0.0103 & 720 & 0.5464 & 0.5464 & 0.0059 & 0.0012 & 21.458 & 0.0528 & 14,174 \\
\hline 36 & 0.1010 & 0.0102 & 701 & 0.5485 & 0.5485 & 0.0065 & 0.0013 & 20.582 & 0.0473 & 15,427 \\
\hline 37 & 0.1056 & 0.0112 & 750 & 0.5589 & 0.5589 & 0.0071 & 0.0015 & 24.129 & 0.0512 & 15,406 \\
\hline
\end{tabular}

\subsubsection{Identificação e tratamento dos valores discrepantes}

Como descrito na Figura 30, após ter calculado os parâmetros para cada sinal RMB (dados a partir dos quais foram calculados os valores apresentados na (

Tabela 2 a Tabela 4), foi empregado o gráfico de caixas para cada conjunto de arames, segundo o carregamento aplicado. Da Figura 31 a Figura 33 são 
apresentados os resultados obtidos no caso da variável $R M B_{r m s}$ para os três níveis de carregamento aplicados ao riser.

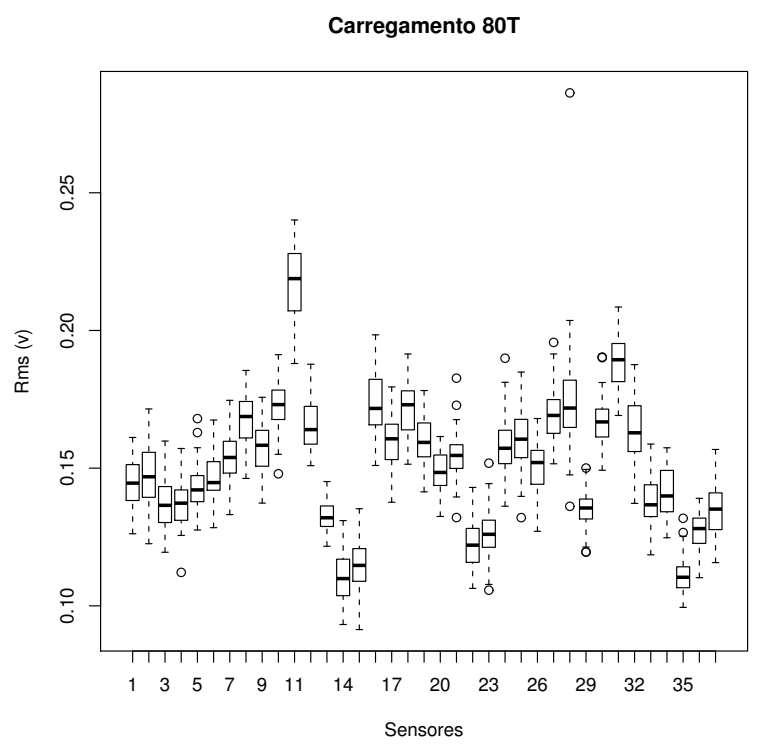

Figura 31 - Diagrama de caixas (Box-plot) para a o parâmetro $R M B_{r m s}$ quando o carregamento aplicado é 80 toneladas

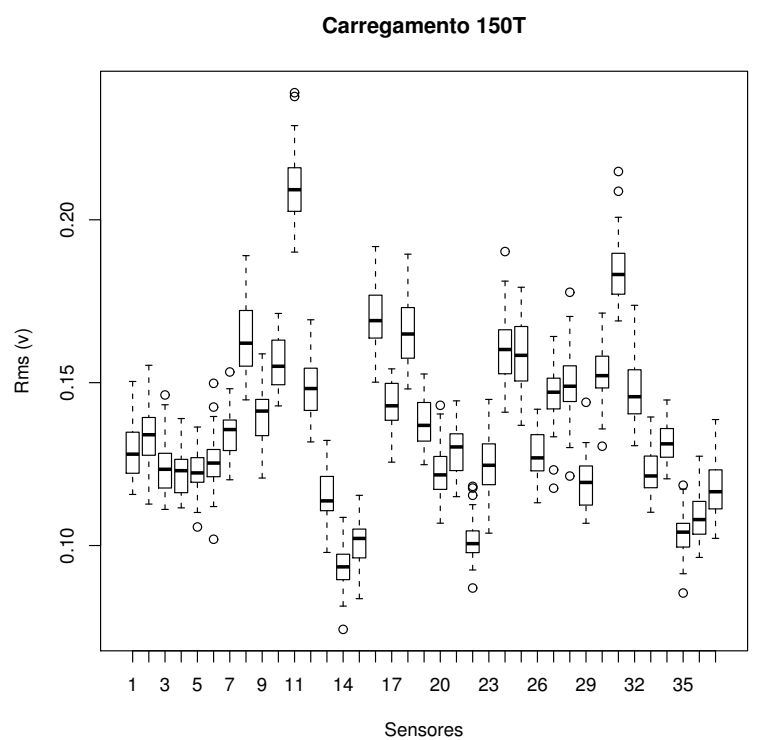

Figura 32 - Diagrama de caixas (Box-plot) para a o parâmetro $R M B_{r m s}$ quando o carregamento aplicado é 150 toneladas 


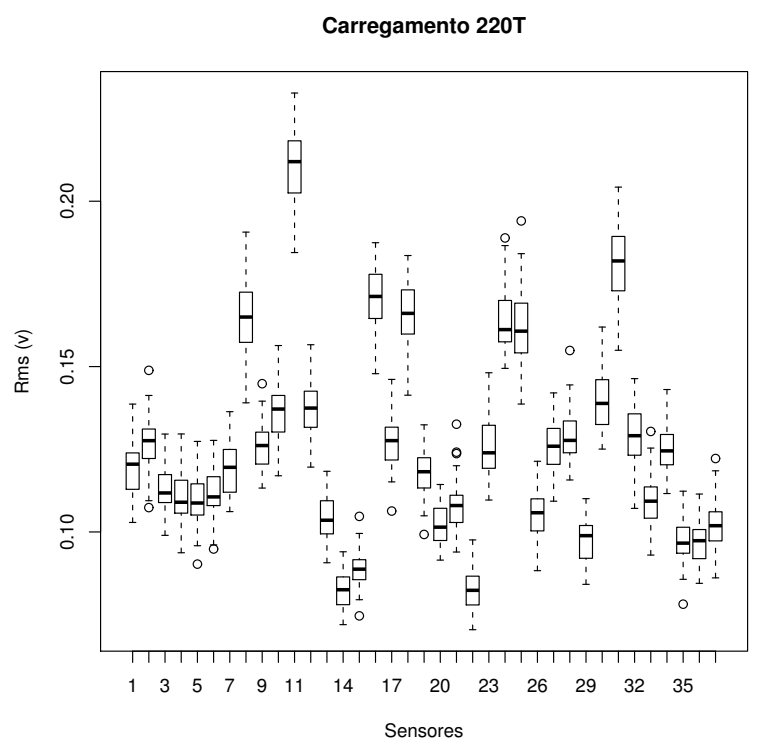

Figura 33 - Diagrama de caixas (Box-plot) para a o parâmetro $R M B_{r m s}$ quando o carregamento aplicado é 220 toneladas

A partir da visualização dos gráficos de caixas, pode-se observar a existência de vários valores discrepantes, para alguns sensores. Também é observado que, segundo os valores das medianas, existem elementos bem diferenciados uns dos outros, como é o caso dos sensores números 11 e 31 , o que sugere que estes elementos apresentam alguma anomalia respeito dos restantes arames ou, algo relacionado com o desempenho dos sensores (maior sensibilidade ou erros na montagem experimental).

Após ter sido feita a anterior análise, foram identificados 64 arquivos que apresentaram valores estranhos ou possíveis outliers. Na Tabela 5, é apresentado um resumo que contem o registro do número de arquivos identificados como valores discrepantes segundo o nível de carregamento aplicado. Em total foram 64 valores discrepantes (1.20\% do total dos arquivos de sinais)

Tabela 5 - Resumo de valores discrepantes segundo carregamento.

\begin{tabular}{cc}
\hline Carregamento (toneladas) & Número de arquivos com valores discrepantes \\
\hline 80 & 21 \\
150 & 25 \\
220 & 18 \\
Total & 64 \\
\hline
\end{tabular}




\subsubsection{Identificação dos sinais responsáveis pelos valores discrepantes}

Com a anterior informação são identificados os sensores aos quais pertencem os arquivos identificados como outliers, para posteriormente serem avaliados na procura da causa desse valor. A quantidade de valores discrepantes, segundo 0 sensor, para cada carregamento é detalhado na Tabela 6 à Tabela 8.

Tabela 6 - Número de valores discrepantes em função do sensor, para carregamento de 80 toneladas

\begin{tabular}{cc}
\hline Sensor & Número de valores Discrepantes \\
\hline 4 & 1 \\
5 & 2 \\
10 & 1 \\
21 & 3 \\
23 & 2 \\
24 & 1 \\
25 & 1 \\
27 & 1 \\
28 & 2 \\
29 & 3 \\
30 & 2 \\
35 & 2 \\
Total & 18 \\
\hline
\end{tabular}

Tabela 7 - Número de valores discrepantes em função do sensor, para carregamento de $\mathbf{1 5 0}$ toneladas

\begin{tabular}{cc}
\hline Sensor & Número de valores Discrepantes \\
\hline 3 & 1 \\
5 & 1 \\
6 & 3 \\
7 & 1 \\
11 & 2 \\
14 & 1 \\
20 & 1 \\
22 & 4 \\
24 & 1 \\
27 & 2 \\
28 & 2 \\
29 & 1 \\
30 & 1 \\
31 & 2 \\
35 & 2 \\
Total & 25 \\
\hline
\end{tabular}


Tabela 8 - Número de valores discrepantes em função do sensor, para carregamento de 220 toneladas

\begin{tabular}{cc}
\hline Sensor & Número de valores Discrepantes \\
\hline 2 & 2 \\
5 & 1 \\
6 & 1 \\
9 & 1 \\
15 & 2 \\
17 & 1 \\
19 & 1 \\
21 & 3 \\
24 & 1 \\
25 & 1 \\
28 & 1 \\
33 & 1 \\
35 & 1 \\
37 & 1 \\
Total & 18 \\
\hline
\end{tabular}

A título de exemplo, e devido à quantidade de arquivos a serem processados (64 arquivos), é apresentada a análise para o caso do sensor número 28 , quando 0 carregamento aplicado foi de 80 toneladas, inicialmente com o gráfico de caixas (Figura 34) e posteriormente com o gráfico q-q normal (Figura 35).

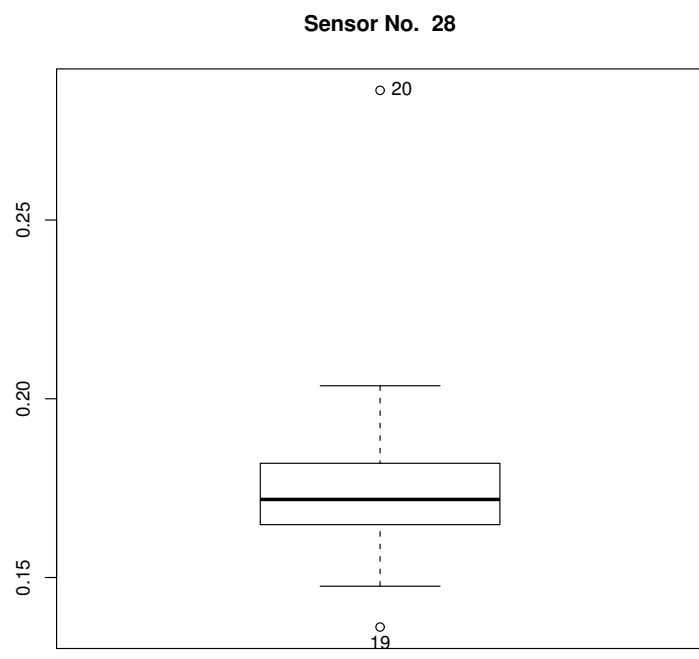

RMS

Figura 34 - Gráfico de caixa para a variável $R M B_{r m s}$, do sensor número 28 , quando o carregamento é de 80 toneladas. 
Normal Q-Qplot RMS - Bobina No. 28

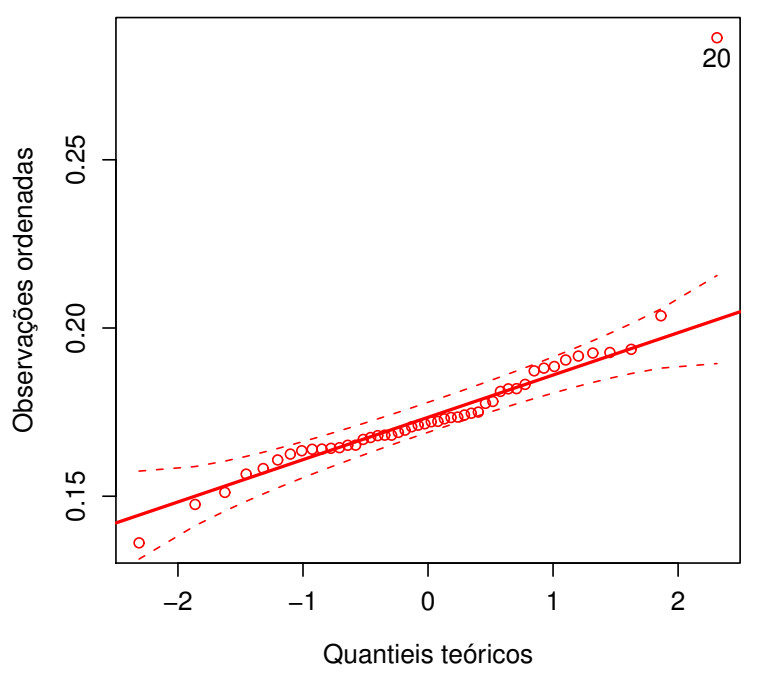

Figura 35 - Gráfico $Q-Q$ normal, para a variável $R M B_{r m s}$, do sensor número 28 , quando o carregamento é de 80 toneladas.

De acordo com as informações apresentadas na Figura 34 e na Figura 35, os arquivos responsáveis pelos valores discrepantes correspondem com os arquivos números 18 e 20. Esse procedimento foi repetido para cada um dos casos identificados (Tabela 6 a Tabela 8).

\subsubsection{Avaliação dos possíveis "Outliers"}

Depois identificar os arquivos de sinais responsáveis pelos valores de parâmetros estranhos, foi avaliado cada caso mediante os gráficos no domínio do tempo e do espectro do sinal. A seguir e a maneira de exemplo é apresentada a análise do sensor número 28 , quando o carregamento aplicado é de 80 toneladas e. 


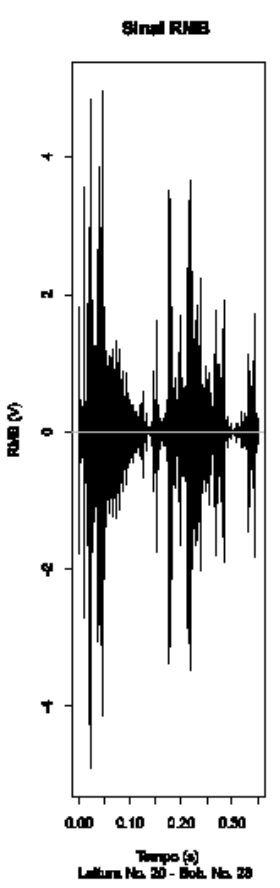

(a)

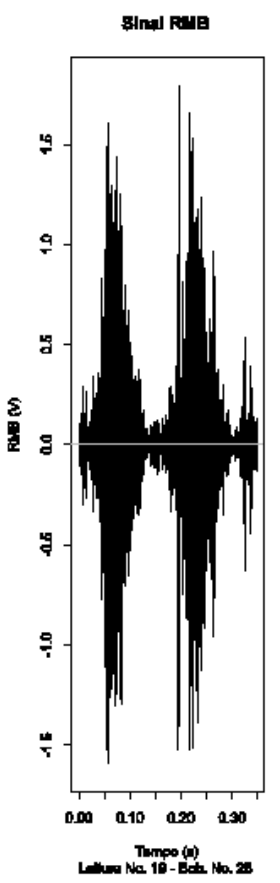

(b)

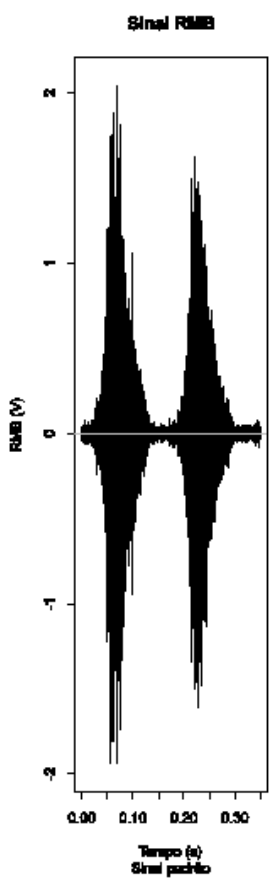

(c)

Figura 36 - Gráfico do sinal RMB, para as observações número 18 e 20, e comparação como um sinal padrão. Sinal arquivo No. 18 (a), sinal arquivo No. 20 (b), sinal de referência (c).

Na Figura 36, é possível observar que há perturbações no formato dos sinais, para os arquivos de sinais 18 e 20, quando comparados com um sinal padrão de referência. A Figura 37 confirma a anterior afirmação, pois os espectrogramas, para os mesmos arquivos, denotam a presença de distorções nos sinais, ou aparição de ruídos estranhos.

Esse mesmo procedimento foi feito para cada um dos arquivos identificados como possíveis outliers. Após a análise, foi comprovado que todos esses arquivos possuíam alterações relacionadas provavelmente com sinais mal medidos ou degradações por ruído externo, por tanto, e como sugerido por Hair (HAIR et all., 1999) eliminados e imputados pela valor médio dos sinais válidos. 


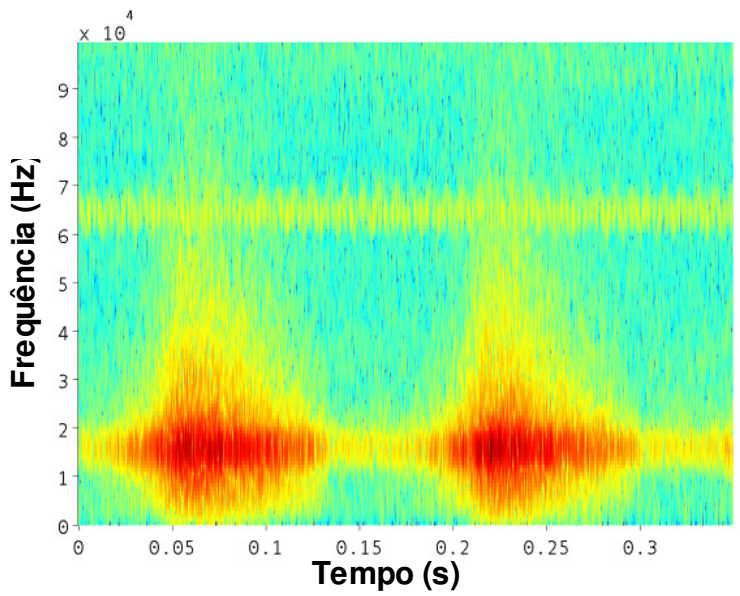

(a)

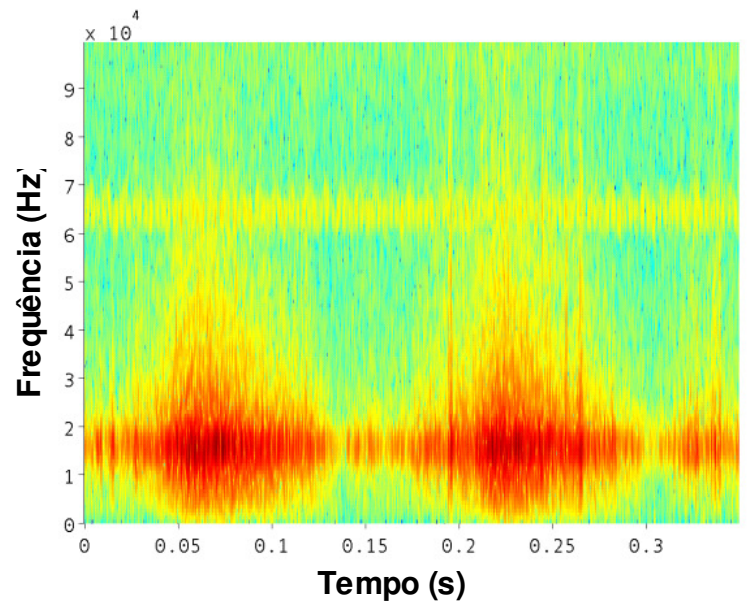

(b)

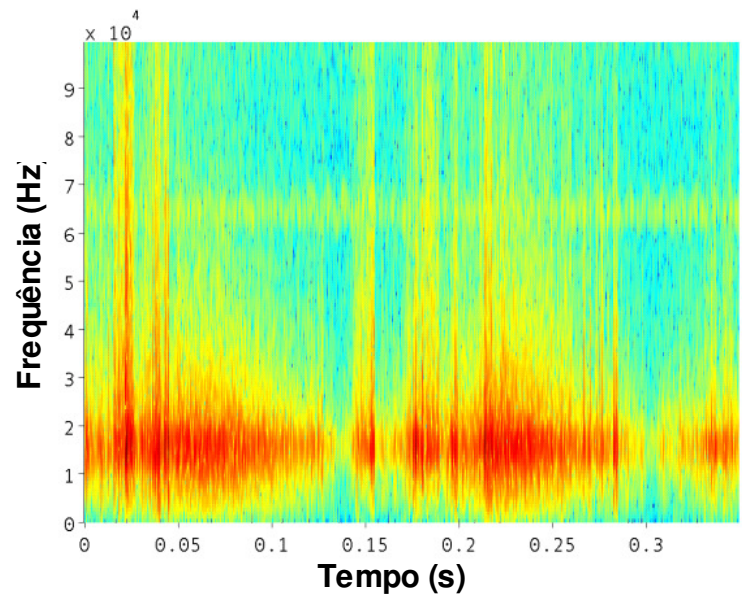

(c)

Figura 37 - Comparativo dos espectrogramas de um sinal padrão (a), e os sinais dos arquivos número 18 (b) e 20 (c), responsáveis pelos valores discrepantes do sensor número 28, quando o carregamento é de 80 toneladas. 


\subsubsection{Identificação de valores discrepantes bivariados e multivariados}

Após a retirada dos valores discrepantes univariados, foram avaliados os dados na procura de casos bivariados. Para este propósito, foram analisados os gráficos de dispersão bivariados de cada combinação possível das variáveis, para cada um dos carregamentos. A Figura 38 apresenta a matriz de gráficos de dispersão dos parâmetros do sinal $R M B$, para carregamento de 80 toneladas.

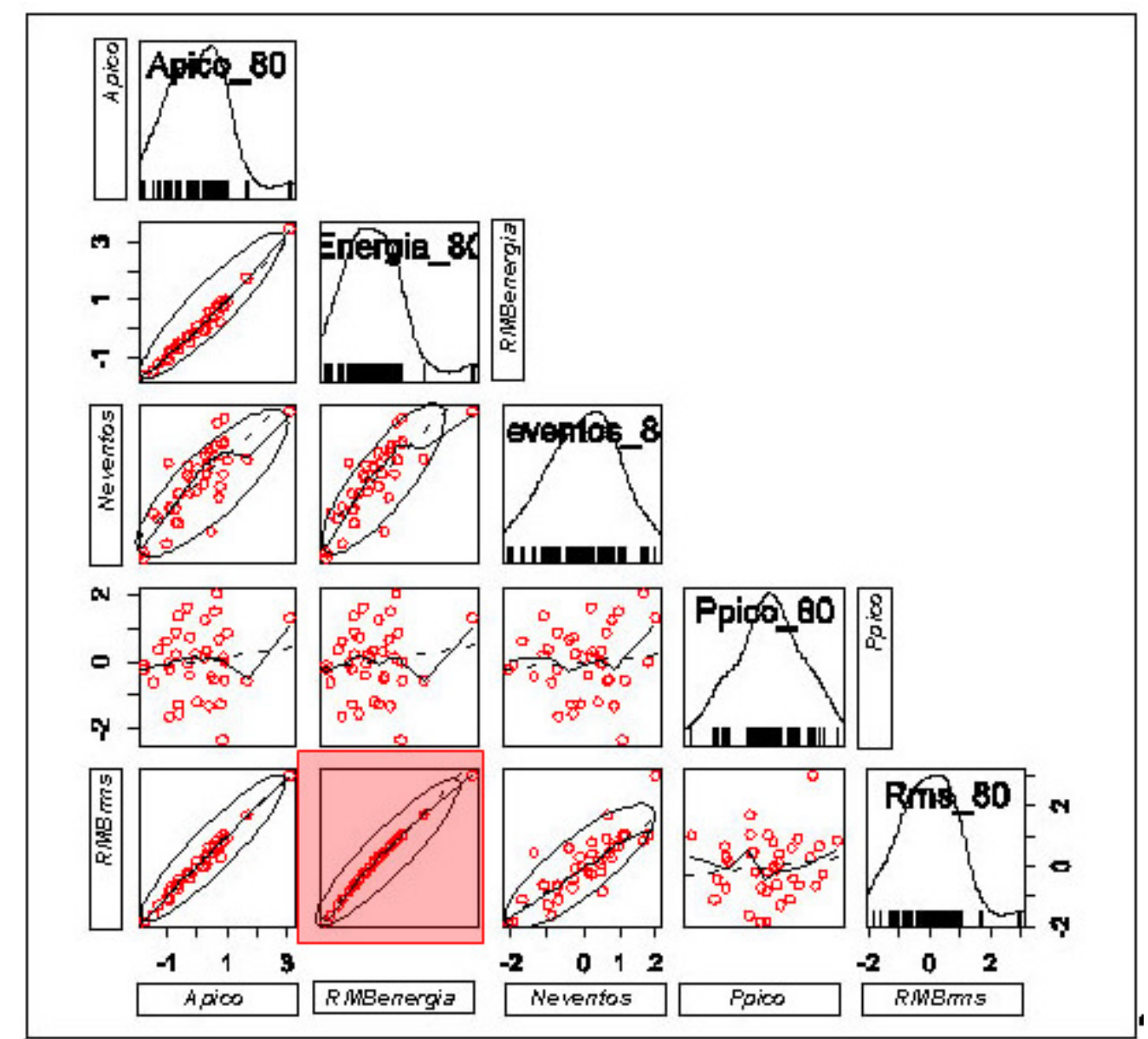

Figura 38 - Gráficos de dispersão entre as variáveis amplitude de pico, energia, número de eventos, posição do pico e RMS para o carregamento de 80 toneladas.

Neste gráfico de matriz de dispersão é também possível observar que a variável de menor correlação e de menor grau de normalidade é a Posição do pico do envelope, pois não estão próximos de uma reta, ou dito de outra forma, estão muito dispersos ao ser comparados com os restantes parâmetros. 
A partir da matriz de dispersão da Figura 38 se observa que a sonda número 11 é um possível valor discrepante multivariado (Ver ampliação do par $R M B_{\text {energia }} \mathrm{e}$ $R M B_{r m s}$ - em vermelho - na Figura 39), pois aparece como valor extremo nos gráficos de caixas alocados nos eixos $x$ e $y$.

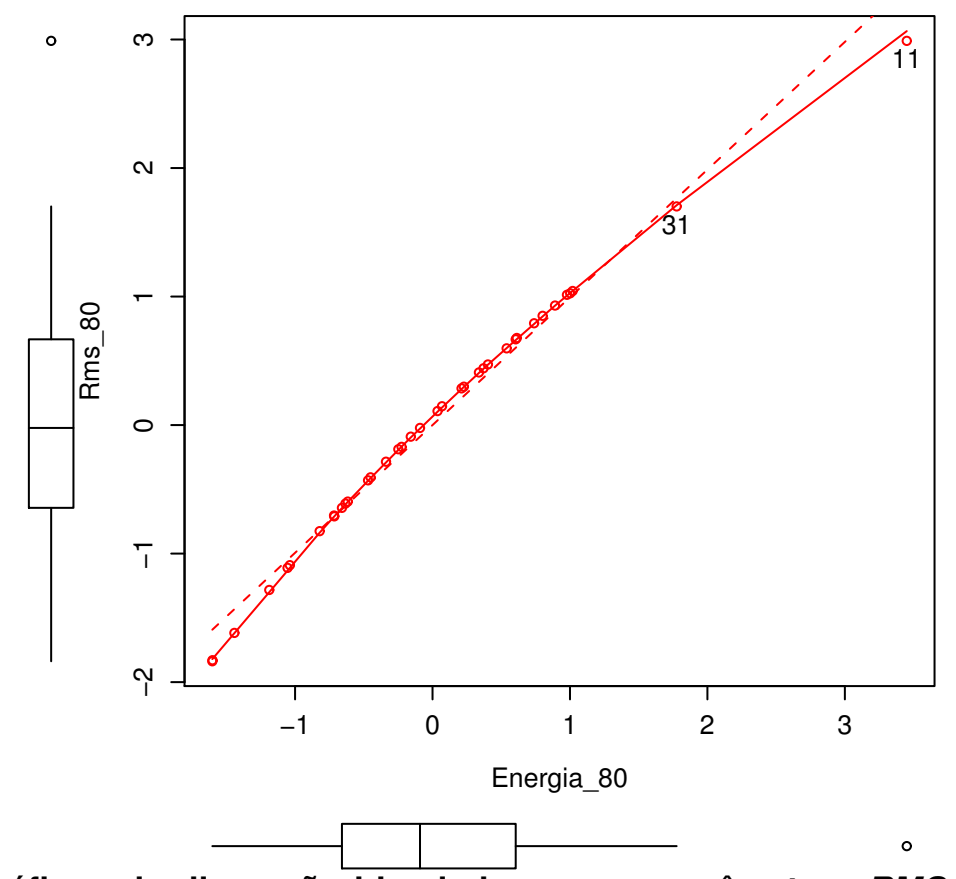

Figura 39 - Gráficos de dispersão bivariado para os parâmetros RMS e energia, quando o carregamento é de 80 toneladas (Ampliação do quadrante vermelho na Figura 38).

Esse mesmo procedimento foi empregado em cada um dos carregamentos, e para cada par possível de variáveis. O resultado indicou que, tanto o sensor 11 quanto o 31 tem chances de ser valores discrepantes bivariados. No entanto, após uma revisão dos arquivos dos sinais para cada caso, segundo o procedimento empregado para os casos univariados (espectrogramas e gráficos da amplitude do sinal), não foi detectada nenhuma anomalia que nos sinais que justificase a sua retirada do banco de dados. Acredita-se que essa discrepância esteja relacionada com a uma maior sensibilidade da sonda, ou seu posicionamento errado na superfície do Riser no momento da coleta dos dados.

Finalmente, e para avaliar a existência de valores discrepantes multivariados, foi calculada a distância $D_{j}^{2}$ (Tabela 9). Observando os valores obtidos, não houve 
indícios da existência de valores discrepantes multivariados, pois todos estão dentro da mesma ordem de grandeza numérica e muito próximos uns dos outros. No gráfico destes valores Figura 40, a presunção de normalidade é forte, pois estes ficam próximos da linha de regressão.

Tabela 9 - Distâncias de Mahalanobis D2j, da matriz de dados padronizados, para carregamento de 80 toneladas.

\begin{tabular}{cc|cc|cc}
\hline Sensor & D2 & Sensor & D2 & Sensor & D2 \\
\hline 1 & 33,00 & 14 & 25,98 & 27 & 30,41 \\
2 & 32,60 & 15 & 32,78 & 28 & 29,21 \\
3 & 25,08 & 16 & 30,06 & 29 & 34,82 \\
4 & 31,30 & 17 & 24,17 & 30 & 31,63 \\
5 & 29,28 & 18 & 27,92 & 31 & 30,69 \\
6 & 30,44 & 19 & 31,96 & 32 & 30,35 \\
7 & 27,71 & 20 & 23,80 & 33 & 28,12 \\
8 & 27,43 & 21 & 25,84 & 34 & 33,46 \\
9 & 26,50 & 22 & 32,04 & 35 & 31,59 \\
10 & 29,95 & 23 & 30,95 & 36 & 23,28 \\
11 & 33,82 & 24 & 29,95 & 37 & 30,05 \\
12 & 22,85 & 25 & 29,59 & & \\
13 & 27,73 & 26 & 23,66 & & \\
\hline
\end{tabular}

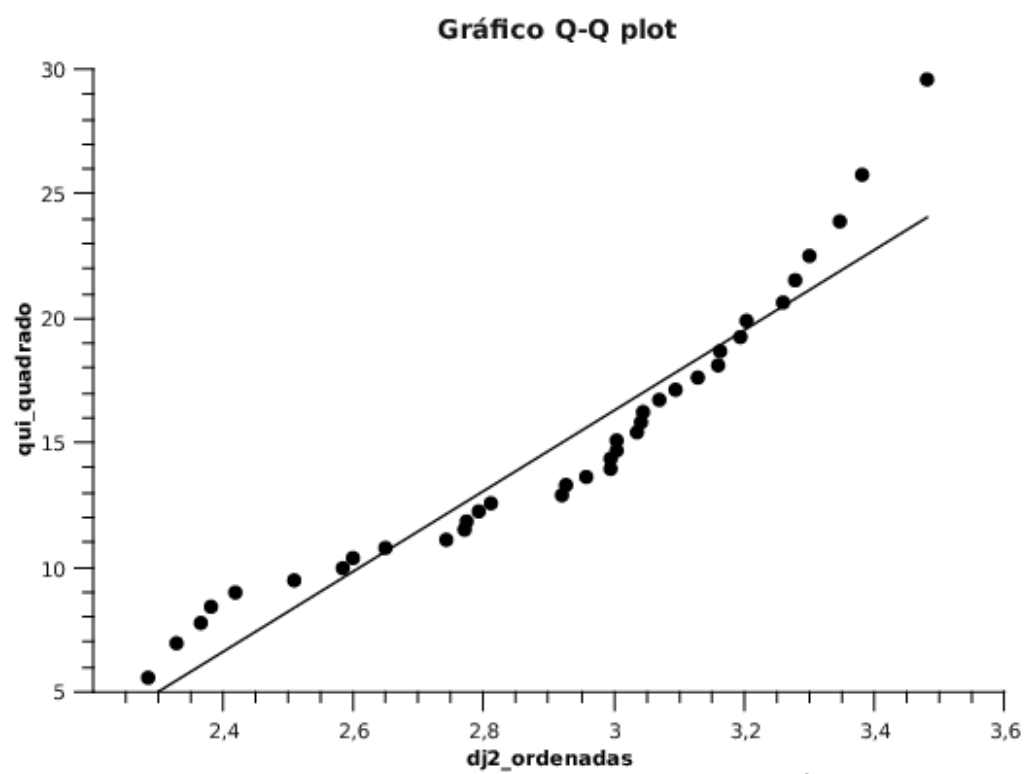

Figura 40 - Gráfico qui-quadrado (Q-Q plot) das distâncias $D_{j}^{2}$ para os parâmetros do sinal $R M B$, dos 37 sensores e os três carregamentos de 80,150 e 220 toneladas. 


\subsubsection{Análise das Componentes Principais - ACP}

Após a análise exploratória dos dados, e antes de começar com a ACP, foi feita a transformação das variáveis originais mediante padronização pela média e desvio padrão, com o objetivo de evitar o efeito da escala da grandeza numérica de unidades, dos dados originais, nos resultados da $A C P$. Esses valores padronizados são mostrados na Tabela 10 a Tabela 12.

Tabela 10 - Valores padronizados dos parâmetros calculados do sinal RMB - Carregamento de $80 \mathrm{~T}$

\begin{tabular}{|c|c|c|c|c|c|c|c|c|c|c|}
\hline Sensor & rms & energia & Neventos & Apico & Ppico & $\sigma_{R M B_{r m s}}$ & $\sigma_{R M B_{\text {energia }}}$ & $\sigma_{\text {Neventos }}$ & $\sigma_{\text {Apico }}$ & $\sigma_{\text {Ppico }}$ \\
\hline & Z1 & Z2 & Z3 & Z4 & Z5 & Z6 & $\mathrm{Z7}$ & Z8 & Z9 & Z10 \\
\hline 1 & $-0,29$ & $-0,34$ & 0,21 & $-0,33$ & 1,60 & $-0,23$ & $-0,32$ & 1,30 & $-0,15$ & 0,99 \\
\hline 2 & $-0,17$ & $-0,23$ & 0,47 & $-0,31$ & $-0,06$ & 1,07 & 0,47 & 0,24 & $-1,25$ & 0,09 \\
\hline 3 & $-0,64$ & $-0,66$ & $-1,10$ & $-0,63$ & 1,38 & 0,12 & $-0,27$ & 0,20 & $-0,38$ & 0,88 \\
\hline 4 & $-0,61$ & $-0,63$ & $-0,72$ & $-0,70$ & 0,88 & $-0,85$ & $-0,77$ & $-0,51$ & $-1,86$ & 0,77 \\
\hline 5 & $-0,41$ & $-0,45$ & $-0,30$ & $-0,24$ & 0,72 & $-0,66$ & $-0,60$ & $-0,64$ & $-1,02$ & 0,59 \\
\hline 6 & $-0,19$ & $-0,25$ & 0,13 & $-0,25$ & $-0,42$ & $-0,40$ & $-0,36$ & $-0,25$ & $-0,26$ & $-0,26$ \\
\hline 7 & 0,11 & 0,04 & 0,47 & 0,33 & 0,31 & $-0,09$ & $-0,07$ & 0,84 & $-0,28$ & 0,59 \\
\hline 8 & 0,79 & 0,74 & 0,23 & 0,86 & 0,13 & 0,25 & 0,46 & $-1,43$ & 1,26 & 0,31 \\
\hline 9 & 0,29 & 0,21 & 0,79 & 0,25 & 1,23 & $-0,15$ & $-0,04$ & 0,21 & $-0,20$ & 1,32 \\
\hline 10 & 1,01 & 0,98 & 1,06 & 0,84 & $-2,32$ & $-0,29$ & 0,20 & $-0,25$ & 0,12 & $-2,76$ \\
\hline 11 & 2,99 & 3,45 & 1,98 & 3,11 & 1,30 & 2,59 & 3,40 & 0,44 & 2,64 & 1,12 \\
\hline 12 & 0,67 & 0,61 & 0,85 & 0,40 & $-1,32$ & 0,13 & 0,37 & $-0,24$ & 1,28 & $-1,24$ \\
\hline 13 & $-0,83$ & $-0,82$ & 0,54 & $-0,97$ & $-0,06$ & $-1,72$ & $-1,31$ & $-0,21$ & $-1,19$ & $-0,03$ \\
\hline 14 & $-1,84$ & $-1,60$ & $-2,07$ & $-1,79$ & $-0,26$ & $-0,47$ & $-1,08$ & 0,41 & $-1,08$ & $-0,68$ \\
\hline 15 & $-1,62$ & $-1,44$ & $-0,87$ & $-1,48$ & $-0,60$ & $-0,03$ & $-0,80$ & 0,41 & $-0,64$ & $-1,33$ \\
\hline 16 & 1,04 & 1,02 & 1,15 & 0,91 & $-0,57$ & 1,64 & 1,57 & $-1,20$ & 0,75 & 0,16 \\
\hline 17 & 0,41 & 0,34 & 0,25 & 0,34 & 0,29 & 0,17 & 0,21 & $-1,52$ & 0,34 & 0,78 \\
\hline 18 & 0,93 & 0,89 & 0,63 & 1,00 & 0,86 & 0,90 & 0,95 & 0,89 & 0,21 & 1,02 \\
\hline 19 & 0,44 & 0,37 & 0,72 & 0,58 & $-0,53$ & 0,18 & 0,27 & 0,77 & 0,48 & $-0,39$ \\
\hline 20 & $-0,09$ & $-0,16$ & $-0,23$ & $-0,07$ & 0,24 & $-0,83$ & $-0,60$ & $-0,65$ & $-0,38$ & 0,74 \\
\hline 21 & 0,15 & 0,07 & 0,40 & 0,01 & $-1,20$ & $-1,44$ & $-0,86$ & $-0,81$ & $-1,14$ & $-1,36$ \\
\hline 22 & $-1,28$ & $-1,19$ & $-0,99$ & $-1,30$ & 0,35 & 0,04 & $-0,60$ & 0,00 & 0,30 & 0,21 \\
\hline 23 & $-1,11$ & $-1,05$ & $-0,68$ & $-0,92$ & $-1,63$ & $-0,92$ & $-1,02$ & 0,30 & $-0,40$ & $-2,11$ \\
\hline 24 & 0,30 & 0,23 & $-0,11$ & 0,76 & $-1,27$ & 0,65 & 0,50 & $-0,14$ & 0,67 & $-1,08$ \\
\hline 25 & 0,47 & 0,40 & $-1,37$ & 0,47 & $-0,46$ & 0,49 & 0,51 & $-1,08$ & 0,99 & $-0,51$ \\
\hline 26 & $-0,02$ & $-0,09$ & $-0,02$ & 0,22 & 0,13 & $-0,20$ & $-0,23$ & $-0,35$ & 0,70 & 0,11 \\
\hline 27 & 0,85 & 0,80 & 1,65 & 0,67 & 2,03 & 0,10 & 0,42 & 3,96 & 0,98 & 0,80 \\
\hline 28 & 1,03 & 1,00 & 1,78 & 0,90 & $-0,02$ & 1,79 & 1,68 & 0,84 & 2,55 & 0,42 \\
\hline 29 & $-0,70$ & $-0,72$ & $-0,74$ & $-0,92$ & $-0,23$ & $-1,52$ & $-1,18$ & $-0,96$ & $-0,66$ & 0,02 \\
\hline 30 & 0,68 & 0,61 & 0,98 & 0,61 & 1,50 & $-0,75$ & $-0,24$ & $-0,07$ & $-0,69$ & 1,27 \\
\hline 31 & 1,70 & 1,78 & 0,66 & 1,67 & $-0,57$ & 0,91 & 1,37 & 0,02 & 0,88 & $-0,03$ \\
\hline 32 & 0,60 & 0,54 & $-0,41$ & 0,74 & 0,67 & 1,72 & 1,31 & 0,27 & $-0,08$ & 0,94 \\
\hline 33 & $-0,60$ & $-0,62$ & $-1,10$ & $-0,70$ & 0,23 & 0,05 & $-0,28$ & $-0,09$ & 0,37 & 0,65 \\
\hline 34 & $-0,43$ & $-0,47$ & $-0,30$ & $-0,60$ & $-1,55$ & 0,18 & $-0,15$ & 0,41 & $-0,12$ & $-1,68$ \\
\hline 35 & $-1,83$ & $-1,60$ & $-1,95$ & $-1,79$ & $-0,09$ & $-2,12$ & $-1,80$ & $-2,07$ & $-0,82$ & 0,02 \\
\hline 36 & $-1,09$ & $-1,04$ & $-1,68$ & $-1,04$ & 0,61 & $-0,90$ & $-1,04$ & 0,24 & $-0,91$ & 0,73 \\
\hline 37 & $-0,71$ & $-0,71$ & $-0,31$ & $-0,65$ & $-1,27$ & 0,58 & $-0,07$ & 0,69 & $-1,01$ & $-1,07$ \\
\hline
\end{tabular}


Tabela 11 - Valores Padronizados dos parâmetros calculados do sinal RMB - Carregamento de 150T

\begin{tabular}{|c|c|c|c|c|c|c|c|c|c|c|}
\hline \multirow[t]{2}{*}{ Sensor } & rms & energia & Neventos & Apico & Ppico & $\sigma_{R M B_{r m s}}$ & $\sigma_{R M B_{\text {energia }}}$ & $\sigma_{\text {Neventos }}$ & $\sigma_{\text {Apico }}$ & $\sigma_{\text {Ppico }}$ \\
\hline & Z11 & Z12 & Z13 & Z14 & Z15 & Z16 & Z17 & Z18 & Z19 & Z20 \\
\hline 1 & $-0,29$ & $-0,34$ & 0,04 & $-0,22$ & 0,25 & 0,42 & 0,04 & $-1,22$ & $-0,43$ & 0,19 \\
\hline 2 & $-0,12$ & $-0,19$ & 0,37 & $-0,17$ & 1,11 & 1,15 & 0,44 & 1,15 & $-0,18$ & 0,80 \\
\hline 3 & $-0,54$ & $-0,56$ & $-0,88$ & $-0,26$ & 1,14 & $-0,29$ & $-0,47$ & $-0,34$ & $-0,01$ & 1,02 \\
\hline 4 & $-0,58$ & $-0,60$ & $-0,73$ & $-0,53$ & 0,86 & $-0,85$ & $-0,79$ & $-0,87$ & $-1,37$ & 0,70 \\
\hline 5 & $-0,55$ & $-0,57$ & $-0,49$ & $-0,54$ & $-0,32$ & $-1,21$ & $-0,96$ & $-0,75$ & $-0,27$ & $-0,34$ \\
\hline 6 & $-0,45$ & $-0,49$ & $-0,13$ & $-0,53$ & $-0,26$ & $-1,24$ & $-0,94$ & $-1,77$ & $-0,64$ & $-0,30$ \\
\hline 7 & $-0,10$ & $-0,17$ & 0,48 & $-0,08$ & 0,67 & $-0,81$ & $-0,58$ & 0,03 & $-0,49$ & 0,59 \\
\hline 8 & 1,14 & 1,10 & 0,67 & 0,97 & 0,34 & 1,94 & 1,87 & $-0,12$ & 0,92 & 0,22 \\
\hline 9 & 0,15 & 0,06 & 0,70 & $-0,09$ & 1,28 & 0,17 & 0,08 & 1,26 & 1,09 & 1,12 \\
\hline 10 & 0,81 & 0,73 & 0,94 & 0,77 & 0,59 & 0,30 & 0,53 & 0,08 & 0,90 & 1,03 \\
\hline 11 & 2,99 & 3,45 & 2,40 & 3,18 & $-0,54$ & 1,12 & 2,43 & $-1,20$ & 3,26 & 0,67 \\
\hline 12 & 0,53 & 0,44 & 0.93 & 0.36 & $-0,25$ & 0.98 & 0,81 & $-0,43$ & -0.33 & 0,26 \\
\hline 13 & $-0,85$ & $-0,82$ & 0,38 & $-0,83$ & $-0,01$ & $-0,16$ & $-0,57$ & 0,03 & $-0,75$ & 0,06 \\
\hline 14 & $-1,74$ & $-1,46$ & $-2,23$ & $-1,76$ & $-1,08$ & $-1,49$ & $-1,53$ & 0,83 & $-0,72$ & $-1,86$ \\
\hline 15 & $-1,45$ & $-1,26$ & $-0,85$ & $-1,48$ & $-0,77$ & $-0,61$ & $-1,09$ & $-0,43$ & $-0,85$ & $-1,78$ \\
\hline 16 & 1,41 & 1,40 & 1,61 & 1,24 & $-1,25$ & 1,00 & 1,33 & 0,65 & 1,15 & $-0,46$ \\
\hline 17 & 0,29 & 0,19 & 0,05 & 0,34 & $-1,63$ & $-0,33$ & $-0,15$ & $-0,02$ & $-0,61$ & $-1,37$ \\
\hline 18 & 1,22 & 1,18 & 0,96 & 1,08 & $-0,57$ & 1,68 & 1,72 & 0,08 & 1,44 & $-0,27$ \\
\hline 19 & 0,06 & $-0,03$ & 0,42 & $-0,15$ & 0,19 & $-0,54$ & $-0,35$ & $-1,21$ & $-0,86$ & 0,47 \\
\hline 20 & $-0,59$ & $-0,60$ & $-0,65$ & $-0,51$ & $-1,14$ & $-0,22$ & $-0,48$ & 1,46 & $-0,57$ & $-1,13$ \\
\hline 21 & $-0,29$ & $-0,35$ & $-0,15$ & $-0,31$ & 1,07 & $-0,28$ & $-0,38$ & 0,81 & $-0,41$ & 0,81 \\
\hline 22 & $-1,46$ & $-1,27$ & $-1,53$ & $-1,32$ & $-0,27$ & $-2,30$ & $-1,76$ & 0,69 & $-1,62$ & $-0,74$ \\
\hline 23 & $-0,48$ & $-0,51$ & 0,07 & $-0,42$ & $\begin{array}{r}-1,59 \\
\end{array}$ & 0,69 & $-0,01$ & $-0,06$ & 0,17 & $-1,90$ \\
\hline 24 & 0,97 & 0,90 & 0,56 & 1,16 & 1,51 & 0,95 & 1,04 & $-0,67$ & 1,85 & 1,25 \\
\hline 25 & 0,93 & 0,86 & $-0,45$ & 1,19 & 0,92 & 1,92 & 1,63 & $-0,20$ & 0,96 & 0,81 \\
\hline 26 & $-0,34$ & $-0,39$ & $-0,38$ & $-0,24$ & $-0,55$ & $-0,46$ & $-0,51$ & 1,00 & $-0,21$ & $-0,56$ \\
\hline 27 & 0,43 & 0,34 & 1,10 & 0,30 & 0,36 & $-0,56$ & $-0,19$ & $-0,31$ & $-0,03$ & 0,38 \\
\hline 28 & 0,56 & 0,47 & 1,10 & 0,46 & 0,59 & 0,69 & 0,64 & 1,06 & 0,57 & 0,66 \\
\hline 29 & $-0,74$ & $-0,73$ & $-1,01$ & $-0,78$ & $-1,31$ & $-0,62$ & $-0,77$ & 0,65 & $-0,51$ & $-1,60$ \\
\hline 30 & 0,70 & 0,61 & 1,08 & 0,58 & 0,75 & 0,12 & 0,37 & 0,85 & 0,33 & 1,03 \\
\hline 31 & 1,92 & 2,02 & 0,93 & 2,01 & $-0,88$ & 0,19 & 1,07 & $-2,27$ & 1,09 & $-0,01$ \\
\hline 32 & 0,46 & 0,37 & $-0,30$ & 0,58 & $-1,19$ & 0,94 & 0,80 & $-0,86$ & 0,79 & $-0,41$ \\
\hline 33 & $-0,56$ & $-0,58$ & $-1,03$ & $-0,58$ & 0,42 & 0,24 & $-0,20$ & $-0,15$ & $-0,24$ & 0,71 \\
\hline 34 & $-0,20$ & $-0,27$ & $-0,12$ & $-0,36$ & 1,25 & $-1,04$ & $-0,73$ & 0,39 & $-1,11$ & 1,05 \\
\hline 35 & $\begin{array}{r}-1,35 \\
\end{array}$ & $-1,19$ & $-1,77$ & $-1,22$ & 1,60 & $-1,68$ & $-1,48$ & $-1,30$ & $-1,14$ & 0,77 \\
\hline 36 & $-1,12$ & $-1,02$ & $-1,64$ & $-1,08$ & 0,90 & $-0,32$ & $-0,75$ & 0,40 & $-0,64$ & 0,56 \\
\hline 37 & $-0,75$ & $-0,73$ & $-0,45$ & $-0,77$ & $-2,18$ & 0,53 & $-0,15$ & 2,75 & $-0,52$ & $-2,42$ \\
\hline
\end{tabular}


Tabela 12 - Valores Padronizados dos parâmetros calculados do sinal RMB - Carregamento de $220 \mathrm{~T}$

\begin{tabular}{|c|c|c|c|c|c|c|c|c|c|c|}
\hline \multirow[t]{2}{*}{ Sensor } & rms & energia & Neventos & Apico & Ppico & $\sigma_{R M B_{r m s}}$ & $\sigma_{R M B_{\text {energia }}}$ & $\sigma_{\text {Neventos }}$ & $\sigma_{\text {Apico }}$ & $\sigma_{\text {Ppico }}$ \\
\hline & Z21 & Z22 & Z23 & Z24 & Z25 & Z26 & Z27 & Z28 & Z29 & Z30 \\
\hline S01 & $-0,21$ & $-0,28$ & 0,06 & $-0,22$ & $-1,36$ & 0,33 & $-0,06$ & $-0,17$ & 1,04 & $-1,40$ \\
\hline S02 & 0,06 & $-0,04$ & 0,33 & 0,03 & 0,11 & $-0,50$ & $-0,31$ & $-0,05$ & $-0,41$ & 0,19 \\
\hline S03 & $-0,41$ & $-0,45$ & $-0,75$ & $-0,39$ & $-0,10$ & $-0,73$ & $-0,59$ & 0,08 & $-0,51$ & $-0,15$ \\
\hline S04 & $-0,51$ & $-0,52$ & $-0,51$ & $-0,51$ & 0,49 & 0,06 & $-0,30$ & $-0,40$ & $-1,02$ & 0,21 \\
\hline S05 & $-0,53$ & $-0,55$ & $-0,69$ & $-0,56$ & 1,52 & $-0,49$ & $-0,54$ & $-0,52$ & $-1,02$ & 1,02 \\
\hline S06 & $-0,45$ & $-0,48$ & $-0,29$ & $-0,43$ & $-1,14$ & $-0,74$ & $-0,60$ & $-0,47$ & $-0,36$ & $-1,58$ \\
\hline S07 & $-0,20$ & $-0,27$ & 0,18 & $-0,24$ & 0,16 & 0,22 & $-0,08$ & $-0,39$ & 0,13 & 0,39 \\
\hline S08 & 1,38 & 1,33 & 1,08 & 1,28 & $-1,17$ & 1,78 & 1,62 & $-0,15$ & 0,44 & $-0,84$ \\
\hline S09 & 0,01 & $-0,09$ & 0,60 & 0,00 & 0,33 & $-0,32$ & $-0,24$ & $-0,14$ & 0,19 & 0,58 \\
\hline S10 & 0,39 & 0,27 & 0,92 & 0,34 & 0,76 & 0,27 & 0,23 & $-0,38$ & 0,12 & 0,90 \\
\hline S11 & 2,99 & 3,48 & 2,41 & 3,13 & 0,25 & 2,34 & 3,11 & 0,03 & 2,64 & 1,25 \\
\hline S12 & 0,41 & 0,28 & 0,80 & 0,22 & 0,38 & 0,03 & 0,10 & 0,02 & $-0,74$ & 0,53 \\
\hline S13 & $-0,72$ & $-0,69$ & 0,33 & $-0,87$ & $-0,79$ & $-0,74$ & $-0,71$ & $-0,18$ & $-0,87$ & $-1,00$ \\
\hline S14 & $-1,48$ & $-1,19$ & $-1,96$ & $-1,43$ & 0,84 & $-1,16$ & $-1,15$ & 0,18 & $-1,56$ & 0,11 \\
\hline S15 & $-1,26$ & $-1,06$ & $-0,92$ & $-1,37$ & $-1,11$ & $-1,99$ & $-1,34$ & $-0,23$ & $-0,81$ & $-2,16$ \\
\hline S16 & 1,63 & 1,62 & 1,87 & 1,53 & $-0,88$ & 0,76 & 1,15 & $-0,55$ & 1,09 & $-0,05$ \\
\hline S17 & 0,11 & 0,00 & 0,13 & 0,02 & $-0,91$ & $-0,36$ & $-0,19$ & $-0,26$ & 0,22 & $-0,70$ \\
\hline S18 & 1,42 & 1,37 & 1,26 & 1,32 & 1,20 & 1,06 & 1,20 & 0,06 & 1,61 & 1,37 \\
\hline S19 & $-0,22$ & $-0,29$ & 0,22 & $-0,23$ & $-0,20$ & $-0,84$ & $-0,56$ & $-0,20$ & $-0,91$ & 0,13 \\
\hline S20 & $-0,79$ & $-0,74$ & $-0,83$ & $-0,73$ & $-0,40$ & $-0,95$ & $-0,83$ & 0,04 & $-0,53$ & $-0,39$ \\
\hline S21 & $-0,64$ & $-0,63$ & $-0,64$ & $-0,55$ & $-0,71$ & $-0,95$ & $-0,78$ & $-0,27$ & $-0,71$ & $-0,48$ \\
\hline S22 & $-1,47$ & $-1,19$ & $-1,84$ & $-1,38$ & $-0,71$ & $-0,90$ & $-1,05$ & $-0,04$ & $-1,01$ & $-0,94$ \\
\hline S23 & 0,03 & $-0,07$ & 0,46 & 0,02 & 1,76 & 0,76 & 0,32 & $-0,03$ & 0,93 & 1,25 \\
\hline S24 & 1,35 & 1,29 & 1,03 & 1,45 & $-1,89$ & 1,25 & 1,38 & $-0,32$ & 2,02 & $-1,98$ \\
\hline S25 & 1,26 & 1,19 & 0,06 & 1,32 & 0,43 & 1,73 & 1,52 & 0,01 & 0,55 & 0,67 \\
\hline S26 & $-0,67$ & $-0,65$ & $-0,87$ & $-0,54$ & $-0,55$ & $-0,03$ & $-0,42$ & $-0,13$ & $-0,38$ & $-0,59$ \\
\hline S27 & 0.03 & -0.07 & 0,46 & 0.01 & 0.19 & -0.09 & -0.14 & $-0,15$ & $-0,56$ & 0.66 \\
\hline S28 & 0,13 & 0,02 & 0,70 & 0,08 & $-0,65$ & $-0,36$ & $-0,18$ & $-0,32$ & $-0,60$ & $-0,87$ \\
\hline S29 & $-0,95$ & $-0,85$ & $-0,85$ & $-0,85$ & 0,48 & $-0,39$ & $-0,69$ & 5,83 & $-0,81$ & 0,66 \\
\hline S30 & 0,49 & 0,36 & 0,88 & 0,46 & $-1,27$ & 0,70 & 0,53 & $-0,09$ & 0,71 & $-1,00$ \\
\hline S31 & 1,93 & 2,01 & 1,13 & 2,00 & 1,01 & 2,37 & 2,34 & $-0,23$ & 2,34 & 1,44 \\
\hline S32 & 0,16 & 0,04 & $-0,42$ & 0,28 & 2,58 & 0,49 & 0,18 & $-0,03$ & 0,62 & 1,38 \\
\hline S33 & $-0,55$ & $-0,56$ & $-1,07$ & $-0,40$ & 0,66 & $-0,45$ & $-0,54$ & $-0,08$ & $-0,37$ & 1,12 \\
\hline S34 & 0,01 & $-0,09$ & 0,19 & $-0,08$ & 1,36 & 0,34 & 0,10 & $-0,17$ & 0,09 & 1,08 \\
\hline S35 & $-0,96$ & $-0,86$ & $-1,21$ & $-0,94$ & $-1,20$ & $-1,17$ & $-0,96$ & $-0,14$ & $-0,36$ & $-1,32$ \\
\hline S36 & $-0,98$ & $-0,87$ & $-1,57$ & $-0,93$ & 0,53 & $-0,86$ & $-0,87$ & $-0,22$ & $-0,73$ & 0,27 \\
\hline S37 & $-0,82$ & $-0,76$ & $-0,66$ & $-0,84$ & $-0,02$ & $-0,49$ & $-0,68$ & 0,09 & $-0,47$ & 0,24 \\
\hline
\end{tabular}


Tabela 13 - Valores da matriz de covariâncias $\mathrm{S}$ dos valores padronizados dos parâmetros do sinal RMB

\begin{tabular}{|c|c|c|c|c|c|c|c|c|c|c|c|c|c|c|c|}
\hline Variável & Z1 & $\mathrm{Z2}$ & Z3 & Z4 & Z5 & Z6 & $\mathrm{Z7}$ & Z8 & Z9 & $\mathrm{Z10}$ & $\mathrm{Z} 11$ & $\mathrm{Z12}$ & $\mathrm{Z13}$ & $\mathrm{Z14}$ & Z15 \\
\hline Z1 & 1 & & & & & & & & & & & & & & \\
\hline Z2 & 0,99 & 1 & & & & & & & & & & & & & \\
\hline Z3 & 0,81 & 0,79 & 1 & & & & & & & & & & & & \\
\hline Z4 & 0,99 & 0,99 & 0,78 & 1 & & & & & & & & & & & \\
\hline Z5 & 0,12 & 0,13 & 0,10 & 0,13 & 1 & & & & & & & & & & \\
\hline Z6 & 0,67 & 0,68 & 0,47 & 0,69 & 0,08 & 1 & & & & & & & & & \\
\hline $\mathrm{Z7}$ & 0,88 & 0,90 & 0,67 & 0,89 & 0,12 & 0,93 & 1 & & & & & & & & \\
\hline Z8 & 0,14 & 0,14 & 0,35 & 0,14 & 0,32 & 0,28 & 0,22 & 1 & & & & & & & \\
\hline Z9 & 0,71 & 0,73 & 0,53 & 0,72 & 0,03 & 0,68 & 0,77 & 0,16 & 1 & & & & & & \\
\hline Z10 & 0,21 & 0,21 & 0,13 & 0,21 & 0,92 & 0,17 & 0,22 & 0,11 & 0,09 & 1 & & & & & \\
\hline Z11 & 0,96 & 0,96 & 0,70 & 0,96 & 0,06 & 0,68 & 0,88 & 0,05 & 0,71 & 0,14 & 1 & & & & \\
\hline Z12 & 0,94 & 0,96 & 0,68 & 0,95 & 0,07 & 0,69 & 0,89 & 0,05 & 0,71 & 0,15 & 0,99 & 1 & & & \\
\hline Z13 & 0,87 & 0,86 & 0,93 & 0,86 & 0,04 & 0,56 & 0,76 & 0,25 & 0,59 & 0,07 & 0,86 & 0,84 & 1 & & \\
\hline Z14 & 0,94 & 0,94 & 0,65 & 0,95 & 0,07 & 0,68 & 0,88 & 0,03 & 0,70 & 0,15 & 0,99 & 0,99 & 0,82 & 1 & \\
\hline Z15 & $-0,02$ & $-0,04$ & $-0,02$ & $-0,03$ & 0,13 & $-0,18$ & $-0,12$ & 0,02 & $-0,05$ & 0,06 & 0,00 & $-0,03$ & 0,01 & 0,00 & 1 \\
\hline Z16 & 0,59 & 0,57 & 0,39 & 0,60 & $-0,07$ & 0,55 & 0,61 & $-0,01$ & 0,45 & 0,02 & 0,69 & 0,66 & 0,59 & 0,68 & $-0,04$ \\
\hline Z17 & 0,83 & 0,83 & 0,56 & 0,84 & 0,01 & 0,68 & 0,82 & 0,00 & 0,64 & 0,10 & 0,91 & 0,90 & 0,76 & 0,91 & $-0,03$ \\
\hline Z18 & $-0,20$ & $-0,23$ & $-0,01$ & $-0,23$ & $-0,11$ & $-0,05$ & $-0,16$ & 0,01 & $-0,20$ & $-0,07$ & $-0,27$ & $-0,29$ & $-0,12$ & $-0,30$ & $-0,15$ \\
\hline Z19 & 0,78 & 0,80 & 0,50 & 0,81 & 0,08 & 0,65 & 0,78 & 0,05 & 0,61 & 0,13 & 0,86 & 0,88 & 0,70 & 0,87 & $-0,01$ \\
\hline Z20 & 0,37 & 0,35 & 0,28 & 0,35 & 0,19 & 0,09 & 0,23 & 0,04 & 0,21 & 0,18 & 0,37 & 0,34 & 0,33 & 0,37 & 0,89 \\
\hline Z21 & 0,86 & 0,87 & 0,58 & 0,88 & 0,02 & 0,66 & 0,83 & $-0,01$ & 0,65 & 0,11 & 0,97 & 0,97 & 0,80 & 0,97 & 0,02 \\
\hline Z22 & 0,84 & 0,87 & 0,54 & 0,86 & 0,03 & 0,67 & 0,84 & $-0,02$ & 0,66 & 0,12 & 0,95 & 0,97 & 0,76 & 0,96 & $-0,01$ \\
\hline Z23 & 0,83 & 0,83 & 0,80 & 0,82 & $-0,03$ & 0,55 & 0,74 & 0,11 & 0,58 & 0,02 & 0,90 & 0,88 & 0,96 & 0,86 & 0,03 \\
\hline Z24 & 0,86 & 0,88 & 0,55 & 0,88 & 0,03 & 0,67 & 0,84 & $-0,02$ & 0,66 & 0,12 & 0,97 & 0,97 & 0,77 & 0,97 & 0,02 \\
\hline Z25 & 0,06 & 0,06 & $-0,13$ & 0,05 & $-0,06$ & 0,16 & 0,12 & 0,21 & $-0,09$ & $-0,08$ & 0,06 & 0,06 & $-0,07$ & 0,06 & $-0,23$ \\
\hline Z26 & 0,73 & 0,73 & 0,39 & 0,75 & 0,02 & 0,52 & 0,67 & $-0,01$ & 0,55 & 0,08 & 0,86 & 0,86 & 0,63 & 0,87 & $-0,02$ \\
\hline Z27 & 0,80 & 0,82 & 0,47 & 0,82 & 0,02 & 0,61 & 0,77 & $-0,03$ & 0,63 & 0,09 & 0,93 & 0,94 & 0,70 & 0,94 & $-0,01$ \\
\hline Z28 & $-0,14$ & $-0,13$ & $-0,17$ & $-0,17$ & $-0,02$ & $-0,24$ & $-0,20$ & $-0,13$ & $-0,10$ & 0,01 & $-0,14$ & $-0,13$ & $-0,21$ & $-0,14$ & $-0,25$ \\
\hline Z29 & 0,66 & 0,68 & 0,39 & 0,70 & 0,04 & 0,53 & 0,66 & 0,01 & 0,48 & 0,11 & 0,80 & 0,81 & 0,62 & 0,83 & $-0,06$ \\
\hline Z30 & 0,33 & 0,34 & 0,10 & 0,31 & $-0,01$ & 0,27 & 0,33 & 0,20 & 0,11 & 0,01 & 0,34 & 0,33 & 0,18 & 0,32 & $-0,19$ \\
\hline
\end{tabular}


Continuação

\begin{tabular}{|c|c|c|c|c|c|c|c|c|c|c|c|c|c|c|c|}
\hline $\begin{array}{c}\text { Variáve } \\
\text { I }\end{array}$ & Z16 & Z17 & Z18 & Z19 & Z20 & Z21 & Z22 & Z23 & Z24 & Z25 & Z26 & Z27 & Z28 & Z29 & Z30 \\
\hline \multicolumn{16}{|l|}{ Z1 } \\
\hline \multicolumn{16}{|l|}{ Z2 } \\
\hline \multicolumn{16}{|l|}{ Z3 } \\
\hline \multicolumn{16}{|l|}{ Z4 } \\
\hline \multicolumn{16}{|l|}{ Z5 } \\
\hline \multicolumn{16}{|l|}{ Z6 } \\
\hline \multicolumn{16}{|l|}{ Z7 } \\
\hline \multicolumn{16}{|l|}{ Z8 } \\
\hline \multicolumn{16}{|l|}{ Z9 } \\
\hline \multicolumn{16}{|l|}{ Z10 } \\
\hline \multicolumn{16}{|l|}{ Z11 } \\
\hline \multicolumn{16}{|l|}{ Z12 } \\
\hline \multicolumn{16}{|l|}{ Z13 } \\
\hline \multicolumn{16}{|l|}{ Z14 } \\
\hline \multicolumn{16}{|l|}{ Z15 } \\
\hline Z16 & 1 & & & & & & & & & & & & & & \\
\hline Z17 & 0,91 & 1 & & & & & & & & & & & & & \\
\hline Z18 & 0,06 & $-0,12$ & 1 & & & & & & & & & & & & \\
\hline Z19 & 0,73 & 0,88 & $-0,14$ & 1 & & & & & & & & & & & \\
\hline Z20 & 0,17 & 0,28 & $-0,27$ & 0,27 & 1 & & & & & & & & & & \\
\hline Z21 & 0,72 & 0,93 & $-0,32$ & 0,87 & 0,35 & 1 & & & & & & & & & \\
\hline Z22 & 0,68 & 0,90 & $-0,32$ & 0,88 & 0,31 & 0,99 & 1 & & & & & & & & \\
\hline Z23 & 0,67 & 0,83 & $-0,20$ & 0,76 & 0,34 & 0,89 & 0,86 & 1 & & & & & & & \\
\hline Z24 & 0,71 & 0,92 & $-0,33$ & 0,89 & 0,36 & 1,00 & 0,99 & 0,87 & 1 & & & & & & \\
\hline Z25 & 0,08 & 0,07 & $-0,05$ & 0,10 & $-0,11$ & 0,06 & 0,05 & $-0,05$ & 0,07 & 1 & & & & & \\
\hline Z26 & 0,65 & 0,83 & $-0,30$ & 0,76 & 0,27 & 0,90 & 0,89 & 0,74 & 0,91 & 0,18 & 1 & & & & \\
\hline Z27 & 0,67 & 0,88 & $-0,34$ & 0,85 & 0,29 & 0,97 & 0,98 & 0,81 & 0,98 & 0,10 & 0,96 & 1 & & & \\
\hline Z28 & $-0,07$ & $-0,11$ & 0,16 & $-0,08$ & $-0,30$ & $-0,17$ & $-0,14$ & $-0,17$ & $-0,15$ & 0,12 & $-0,06$ & $-0,11$ & 1 & & \\
\hline Z29 & 0,59 & 0,76 & $-0,34$ & 0,80 & 0,21 & 0,86 & 0,86 & 0,74 & 0,87 & 0,02 & 0,85 & 0,88 & $-0,13$ & 1 & \\
\hline Z30 & 0,24 & 0,30 & $-0,01$ & 0,30 & 0,03 & 0,31 & 0,30 & 0,20 & 0,32 & 0,90 & 0,39 & 0,33 & 0,15 & 0,20 & 1 \\
\hline
\end{tabular}


A partir dos parâmetros padronizados, foi calculada a matriz de covariâncias $\mathbf{S}$ (Tabela 13), e calculadas as componentes principais, o que é equivalente a realizar a análise de componentes com a matriz de correlações $\boldsymbol{R}$, das variáveis originais. $\mathrm{Na}$ matriz $\boldsymbol{S}$ pode-se observar que os coeficientes são na grande maioria positivos e superiores a 0.5 , indicando um relacionamento linear positivo destas variáveis (como já tinha sido evidenciado no gráfico de matriz de dispersão da Figura 38). Somente algumas variáveis apresentaram um coeficiente de correlação negativo ou muito próximo de zero, sendo a maioria delas relacionadas com o parâmetro Posição do Pico do Envelope e, os desvios padrão das variáveis relacionadas com o Número de eventos do sinal, confirmando-se a informação obtida na matriz de dispersão bivariada (Figura 38), onde estas variáveis foram as de maior grau de correlação linear.

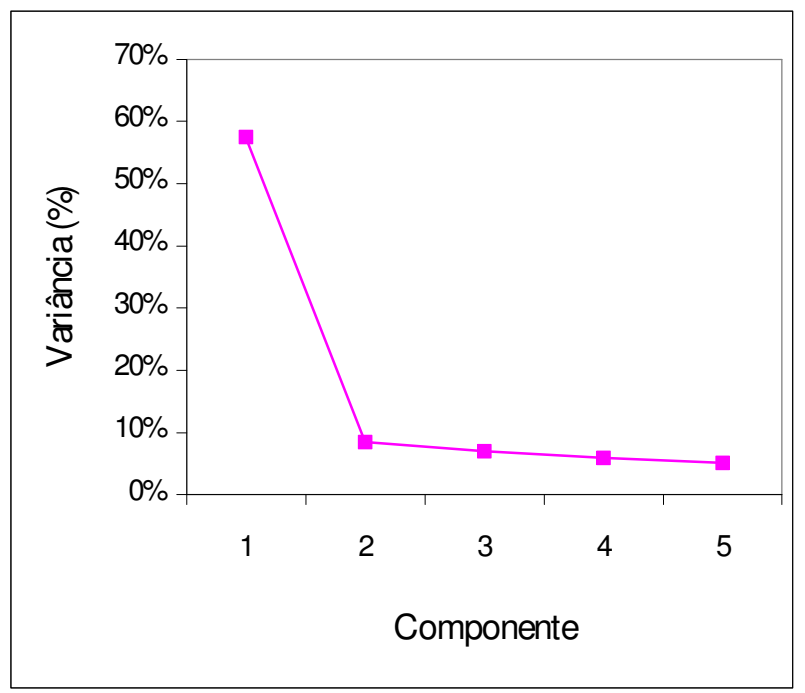

Figura 41 - Scree-plot das 5 primeiras componentes principais

Foi feito então o cálculo das ACP a partir da matriz de covariâncias dos valores padronizados. Observou-se que a variância total explicada pelas cinco (5) primeiras componentes principais foram $57.40 \%, 8.46 \%, 7.02 \%, 5.92 \%$, e $5.08 \%$ e juntas sumarizam o 83.89\% (Figura 41). Desta forma, com apenas as primeiras componentes, é possível explicar a maior parte da variância total dos dados. Ou seja, se o interesse da pesquisa fosse a redução de variáveis, essas cinco componentes poderiam substituir as variáveis originais em análises subsequentes. Mas, sendo o objetivo deste caso a seleção das variáveis mais importantes, foram escolhidas aquelas que apresentaram o maior valor absoluto do coeficiente na 
primeira CP (Tabela 14). Resulta interessante também o fato da segunda a quarta componente principal estar fortemente influenciadas pelo parâmetro Posição do Pico do Envelope (valores absolutos dos coeficientes maiores). Assim, as variáveis Altura do Pico do Envelope, rms, energia, e Número de eventos, são os parâmetros de entrada na análise de agrupamentos.

Tabela 14 - Fatores de carga das primeiras cinco (5) componentes principais para todos os parâmetros considerados na análise.

\begin{tabular}{|c|c|c|c|c|c|c|}
\hline Variável & Carregamento & Comp.1 & Comp.2 & Comp.3 & Comp.4 & Comp.5 \\
\hline & 80 & -0.2288 & -0.0405 & -0.0765 & -0.0724 & -0.0324 \\
\hline \multirow[t]{2}{*}{ Apico } & 150 & -0.2378 & -0.0017 & 0.0308 & 0.0427 & 0.0362 \\
\hline & 220 & -0.2345 & 0.0193 & 0.0863 & 0.1026 & 0.0664 \\
\hline & 80 & -0.2281 & -0.0338 & -0.0883 & -0.0753 & -0.0411 \\
\hline \multirow[t]{2}{*}{$R M B_{\text {energia }}$} & 150 & -0.2384 & 0.0071 & 0.0162 & 0.0150 & 0.0308 \\
\hline & 220 & -0.2319 & 0.0275 & 0.0863 & 0.0809 & 0.0913 \\
\hline & 80 & -0.1681 & -0.1383 & -0.1269 & -0.3598 & -0.2099 \\
\hline \multirow[t]{2}{*}{ Neventos } & 150 & -0.2078 & -0.0829 & -0.0169 & -0.2308 & -0.1583 \\
\hline & 220 & -0.2169 & -0.0386 & 0.0883 & -0.1173 & -0.0873 \\
\hline & 80 & -0.0187 & -0.3182 & -0.4890 & 0.1598 & 0.3072 \\
\hline \multirow[t]{2}{*}{ Ppico } & 150 & 0.0018 & -0.4547 & 0.1750 & 0.2924 & -0.3004 \\
\hline & 220 & -0.0179 & 0.3911 & -0.2790 & 0.3711 & -0.3205 \\
\hline & 80 & -0.2266 & -0.0429 & -0.0865 & -0.0847 & -0.0613 \\
\hline \multirow[t]{3}{*}{$R M B_{r m s}$} & 150 & -0.2391 & -0.0031 & 0.0201 & 0.0070 & -0.0004 \\
\hline & 220 & -0.2347 & 0.0152 & 0.0951 & 0.0804 & 0.0503 \\
\hline & 80 & -0.1752 & -0.0320 & -0.0324 & -0.1755 & 0.0201 \\
\hline \multirow[t]{3}{*}{$\sigma_{\text {Apico }}$} & 150 & -0.2142 & 0.0478 & 0.0222 & 0.0460 & 0.0762 \\
\hline & 220 & -0.1986 & 0.0407 & 0.1102 & 0.1261 & 0.1722 \\
\hline & 80 & -0.2182 & 0.0236 & -0.1445 & -0.1127 & -0.0219 \\
\hline \multirow[t]{3}{*}{$\sigma_{R M B e n e r g i a}$} & 150 & -0.2244 & 0.0637 & 0.0679 & 0.0020 & 0.0539 \\
\hline & 220 & -0.2253 & 0.0580 & 0.1030 & 0.1475 & 0.1043 \\
\hline & 80 & -0.0255 & -0.0705 & -0.4234 & -0.1347 & -0.3555 \\
\hline \multirow[t]{3}{*}{$\sigma_{\text {Neventos }}$} & 150 & 0.0629 & 0.1350 & -0.0890 & -0.3451 & -0.0547 \\
\hline & 220 & 0.0407 & 0.2438 & -0.0783 & 0.0448 & 0.2704 \\
\hline & 80 & -0.0381 & -0.2799 & -0.4487 & 0.1477 & 0.3991 \\
\hline \multirow[t]{3}{*}{$\sigma_{\text {Ppico }}$} & 150 & -0.0855 & -0.4261 & 0.1037 & 0.2939 & -0.3151 \\
\hline & 220 & -0.0804 & 0.3499 & -0.2803 & 0.3382 & -0.3009 \\
\hline & 80 & -0.1763 & 0.0718 & -0.1762 & -0.1446 & -0.0262 \\
\hline \multirow[t]{2}{*}{$\sigma_{R M B r m s}$} & 150 & -0.1739 & 0.1157 & 0.0961 & -0.0303 & 0.0384 \\
\hline & 220 & -0.2081 & 0.0953 & 0.0867 & 0.2103 & 0.0892 \\
\hline
\end{tabular}




\subsubsection{Análise de Agrupamentos}

Realiza se agora a penúltima etapa da análise de dados, conforme o fluxograma da Figura 29, a análise de agrupamentos.

\subsubsection{Agrupamentos a partir da seleção das variáveis com maior poder explicativo}

Segundo a análise previa (ACP) as variáveis com maior poder explicativo são Altura do Pico do Envelope, $R M B_{r m s}, R M B_{\text {energia }}$, e Número de eventos. Esses parâmetros são tomados como variáveis de entrada para a análise de de agrupamentos apresentado neste capítulo.

Foram utilizados os métodos hierárquicos aglomerativos: ligação simples (single linkage), ligação completa (complet linkage), média das distâncias (average linkage), mediana das distâncias (median linkage), método do centroide, e método de McQuitty, todos eles tratados no item 2.2.4. Para cada um desses métodos foram avaliadas as matrizes de distâncias: euclidiana, euclidiana quadrática e Manhattan (item 2.2.3).

Tabela 15 - Correlação cofenética dos resultados dos agrupamentos

\begin{tabular}{cccc}
\hline \multirow{2}{*}{ Método de Agrupamento } & & \multicolumn{2}{c}{ Seleção de variáveis } \\
& Eistância & Correlação cofenética & Grupos \\
\cline { 2 - 4 } Ligação simples & Euclidiana & 0.8194012 & 4 \\
& Manhattan & 0.8121303 & 4 \\
& E. Quatrática & 0.8063474 & 4 \\
\hline \multirow{2}{*}{ Ligação completa } & Euclidiana & 0.7096628 & 2 \\
& Manhattan & 0.6285557 & 3 \\
& E. Quatrática & 0.5892533 & 2 \\
\hline \multirow{2}{*}{ Ligação média } & Euclidiana & 0.8379014 & 3 \\
& Manhattan & 0.8379014 & 3 \\
& E. Quatrática & 0.8100593 & 3 \\
\hline \multirow{2}{*}{ Centróides } & Euclidiana & 0.810271 & 3 \\
& Manhattan & 0.8155021 & 3 \\
& E. Quatrática & 0.8081532 & 3 \\
\hline \multirow{2}{*}{ McQuitty } & Euclidiana & 0.7151194 & 2 \\
& Manhattan & 0.7139382 & 2 \\
& E. Quatrática & 0.5897927 & 2 \\
\hline \multirow{2}{*}{ Ligação da mediana } & Euclidiana & 0.7086481 & 2 \\
& Manhattan & 0.6852537 & 2 \\
& E. Quatrática & 0.5878541 & 2 \\
\hline
\end{tabular}


Como expressado no item 2.2.6.3, a correlação cofenética é uma medida da qualidade dos resultados obtidos pelos modelos de agrupamentos ou conglomerados (clusters). Os valores desse cálculo aparecem na Tabela 15, nessa tabela pode-se apreciar que os modelos com o maior grau de correlação foram o de Ligação simples, Ligação média e Centroides, no entanto, e considerando que o número de classes ou grupos definidos no desenho experimental é de dois (arames ruins e arames bons), assim, os modelos mais acertados para a classificação em dois grupos são o de McQuitty e Ligação da mediana.

Na Figura 42 e na Figura 43 são apresentados os resultados dos métodos McQuitty e Ligação da mediana e, em cada um deles, o dendograma conforme a matriz de distâncias (item 2.2.3) calculada para a comparação entre os arames. Pode-se apreciar que os grupos formados estão bem diferenciados um do outro (Dissimilaridade entre grupos) e composto pelos mesmos arames. Os dendogramas para os restantes métodos são apresentados nos Anexo E ao Anexo $\mathrm{H}$. 
Ligação da mediana das distâncias

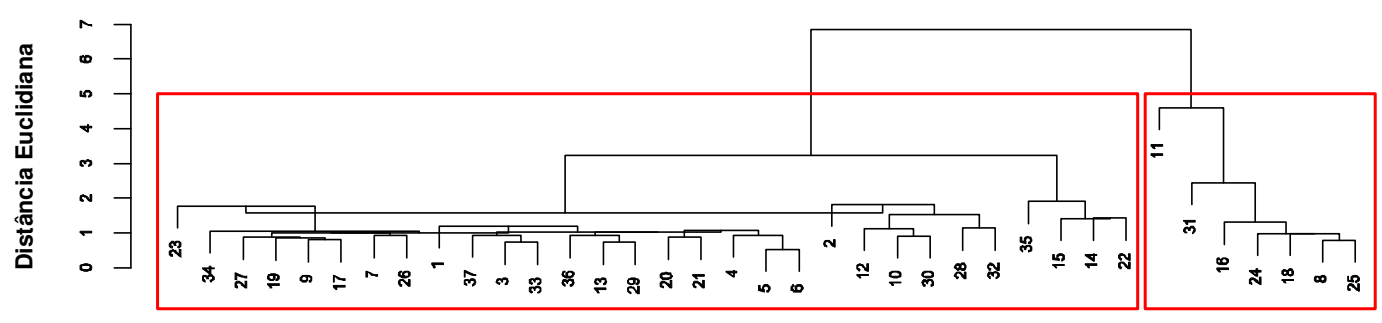

Sensores

Ligação da mediana das distâncias

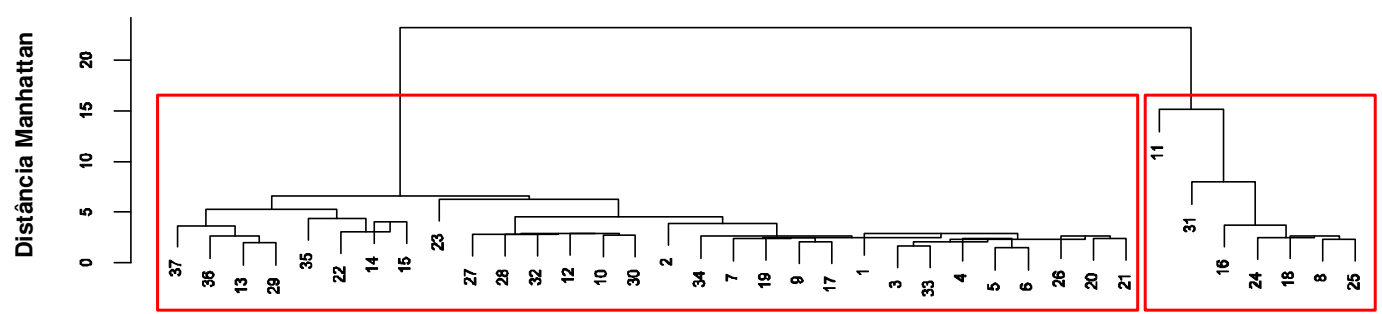

Sensores

Ligação da mediana das distâncias

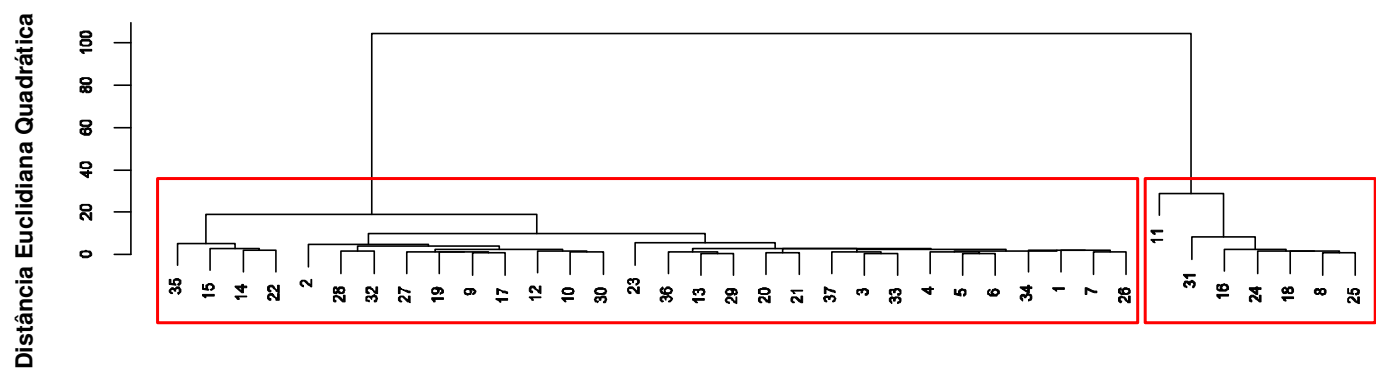

Sensores

Figura 42 - Dendograma Método Mediana das distâncias 

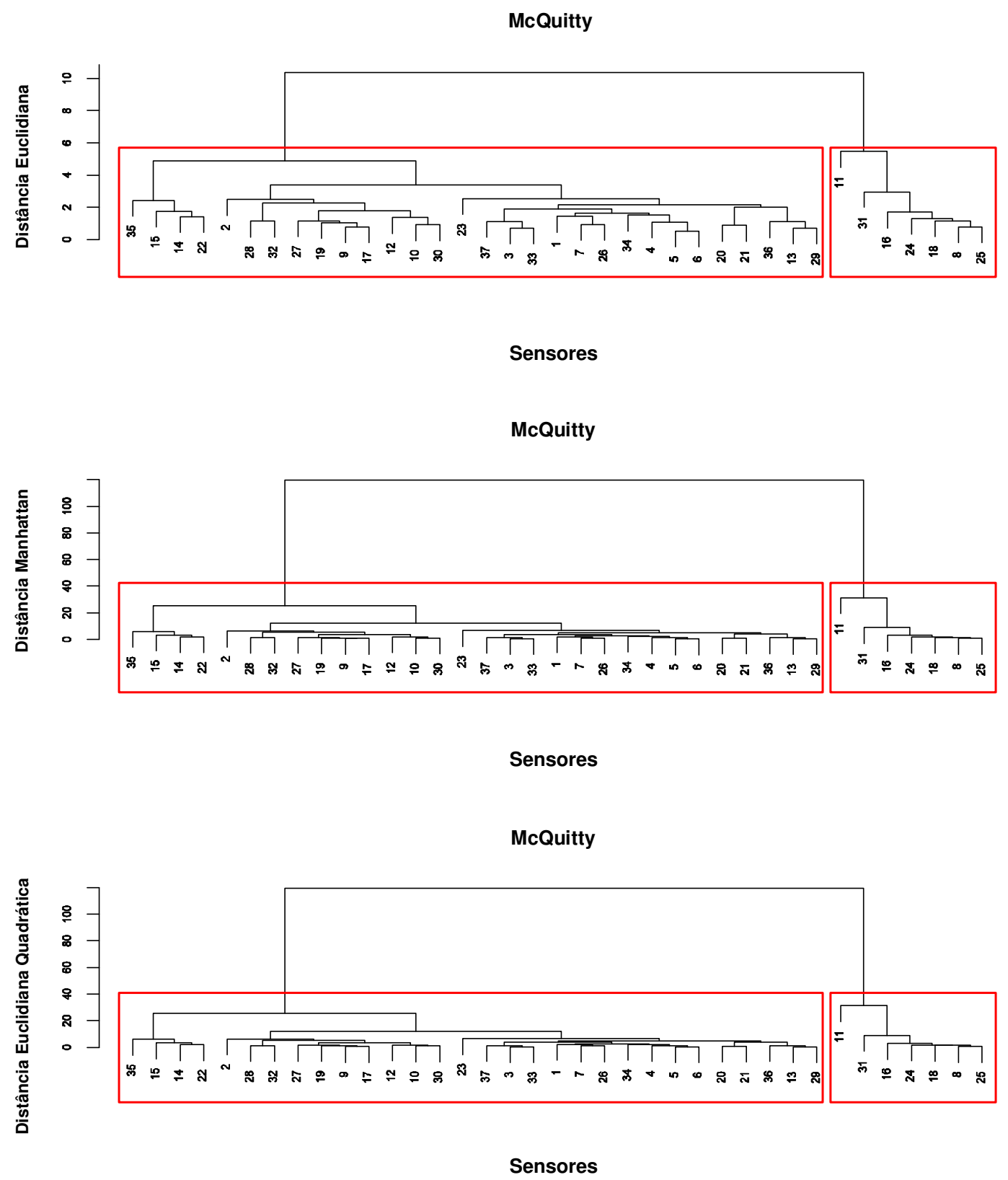

Figura 43 - Dendograma Método McQuitty

\subsubsection{Agrupamentos a partir das componentes principais}

Nesta abordagem, as variáveis de entrada para a análise de agrupamentos são as componentes principais calculadas no inicio do item 4.2.6, e cujos resultados são apresentados na Tabela 14 para as primeiras 5 componentes. Assim, os grupos serão obtidos com variáveis que, quando consecutivas $\left(C P_{1}-C P_{2}, C P_{2}-C P_{3}, \ldots\right.$, $\left.C P_{k-1}-C P_{k}\right)$ não apresentam correlação entre si, devido à propriedade de ortogonalidade apresentada pelas componentes principais. 
A análise de agrupamentos é então feita com as 7 primeiras componentes principais segundo os resultados na análise previa de ACP.

As correlações cofenéticas calculadas para cada solução obtida com a Análise de Agrupamentos mostraram um desempenho mais pobre com relação a os valores obtidos na abordagem do item 4.2.7.1. Além do acima exposto, os grupos conformados foram mais heterogêneos e nenhum deles se conseguiu uma classificação com um número de grupos acorde ao desenho experimental. $O$ resultado mais próximo foi o da Ligação média das distâncias (Tabela 16), no entanto o número de grupos foi maior ao esperado. Na Figura 44 é apresentado o dendograma para essa solução, pode-se apreciar que para cada uma das distâncias avaliadas (euclidiana, euclidiana quadrática e City-Block) apareceram pelo menos uma classe unitária (um sensor isolado dos grupos). As restantes soluções são apresentadas nos Anexos I a M.

Tabela 16 - Correlação cofenética dos resultados dos agrupamentos

\begin{tabular}{cccc}
\hline \multirow{2}{*}{ Método de Agrupamento } & \multicolumn{3}{c}{ Componentes Principais } \\
\cline { 2 - 4 } & Distância & $\begin{array}{c}\text { Correlação } \\
\text { cofenética }\end{array}$ & Grupos \\
\hline \multirow{2}{*}{ Ligação simples } & Euclidiana & 0.7636742 & $6^{*}$ \\
& Manhattan & 0.7379548 & $6^{*}$ \\
& E. Quatrática & 0.7448218 & $6^{*}$ \\
\hline \multirow{2}{*}{ Ligação completa } & Euclidiana & 0.5512651 & $4^{*}$ \\
& Manhattan & 0.5294854 & $4^{*}$ \\
& E. Quatrática & 0.4475784 & $4^{*}$ \\
\hline \multirow{2}{*}{ Ligação média } & Euclidiana & 0.7983285 & $3^{*}$ \\
& Manhattan & 0.7670253 & $3^{*}$ \\
& E. Quatrática & 0.7845438 & $3^{*}$ \\
\hline \multirow{2}{*}{ Centróides } & Euclidiana & 0.6797433 & $>6^{*}$ \\
& Manhattan & 0.6469222 & $>6^{*}$ \\
& E. Quatrática & 0.7015829 & $>6^{*}$ \\
\hline \multirow{2}{*}{ McQuitty } & Euclidiana & 0.6797433 & $4^{*}$ \\
& Manhattan & 0.6469222 & $4^{*}$ \\
& E. Quatrática & 0.7015829 & $4^{*}$ \\
\hline \multirow{2}{*}{ Ligação da mediana } & Euclidiana & 0.6797433 & $4^{*}$ \\
& Manhattan & 0.6469222 & $4^{*}$ \\
& E. Quatrática & 0.7015829 & $4^{*}$ \\
\hline
\end{tabular}




\section{Distância Euclidiana}

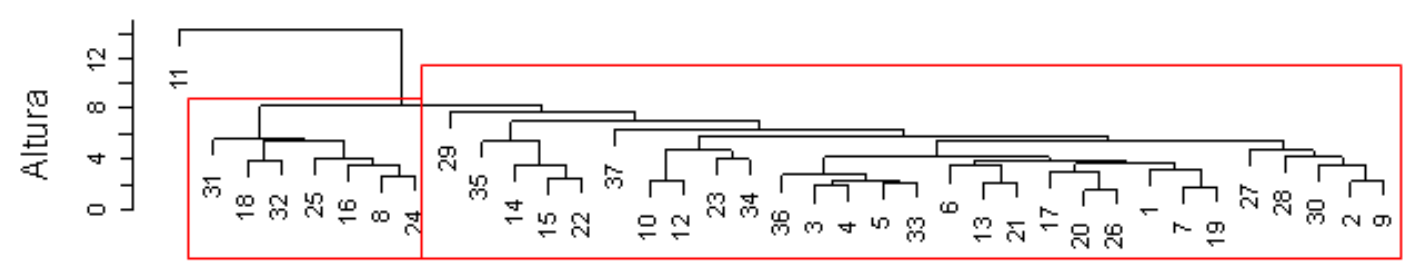

Sensores

\section{Distância Euclidiana Quadrática}

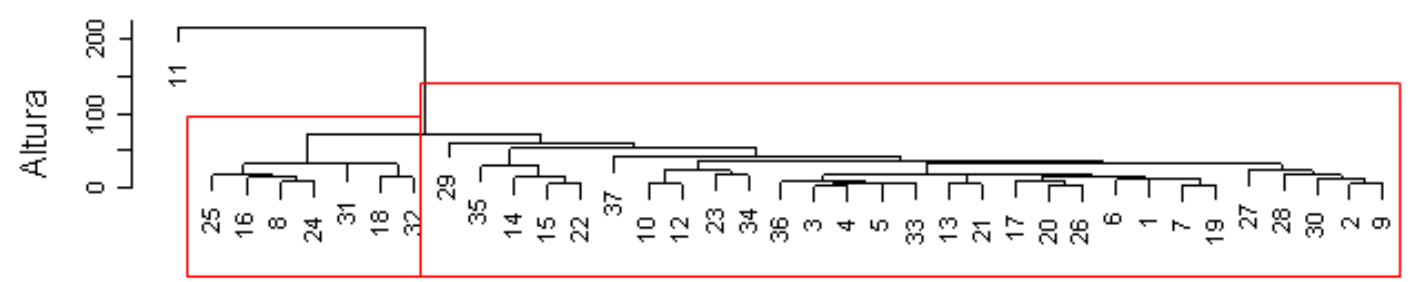

Sensores

\section{Distância City-block}

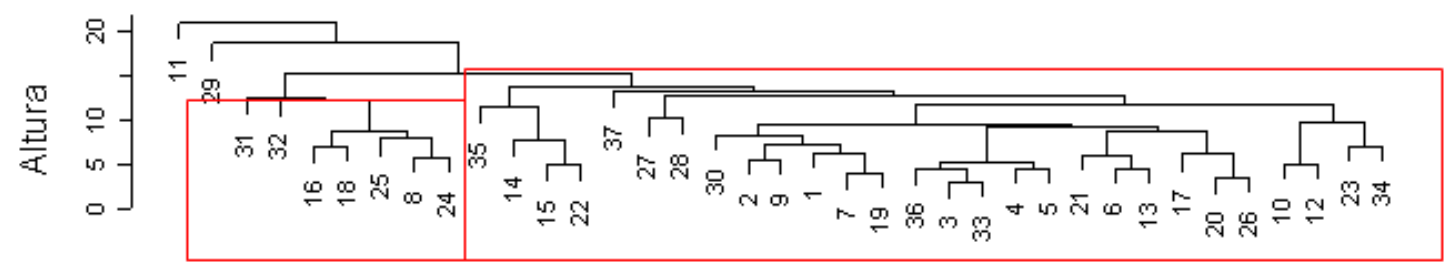

Sensores

Figura 44 - Dendograma método da ligação média

\subsection{RESULTADOS E DISCUSSÃO}

Os resultados obtidos no cálculo das correlações cofenéticas ( Tabela 15 e Tabela 16) sugerem a abordagem de seleção de variáveis a partir dos coeficientes de maior valor (absoluto) da primeira componente como a de melhor desempenho (coeficientes de correlação maiores). Além disso, observando nas figuras dos dendrogramas fica evidente que os resultados obtidos nesta mesma abordagem são os mais homogêneos e de melhor separação entre grupos (clusters).

Avaliando os resultados apresentados nos gráficos dos dendogramas de cada combinação, os métodos que forneceram uma melhor solução, em termos de 
número de classes ou grupos, foram a mediana das distâncias, e o McQuitty, (Figura 42 e Figura 43). Estes métodos conseguiram agrupar os dados em duas classes $(K=2)$ como feitos no desenho experimental (Item 4.1.).

As demais combinações, embora consigam agrupações similares, também reportam, pelo menos uma classe adicional $(K \geq 3)$, composta por agrupações unitárias. Estes métodos em especial, apresentaram maior sensibilidade com os casos de valores discrepantes bivariados identificados na avaliação da qualidade dos dados.

Finalmente, e dado que o número de arames quebrados, assim como o sensor correspondente com cada arame foram variáveis controladas no experimento, é possível testar o grau de sucesso dos métodos de agrupamento com solução para k=2. A Tabela 17, apresenta o comparativo dos arames identificados como quebrados e os classes obtidas com a análise de clusters.

Tabela 17 - Comparação dos resultados obtidos com métodos McQuitty (M1) e, Ligação da mediana (M2), respeito à inspeção visual.

\begin{tabular}{|c|c|c|c|c|c|c|c|}
\hline \multirow{2}{*}{ Sensor } & \multirow{2}{*}{$\begin{array}{l}\text { Inspeção } \\
\text { Visual }\end{array}$} & \multicolumn{2}{|c|}{ Método } & \multirow{2}{*}{ Sensor } & \multirow{2}{*}{ Inspeção Visual } & \multicolumn{2}{|c|}{ Método } \\
\hline & & M1 & M2 & & & M1 & M2 \\
\hline 8 & 1 & 1 & 1 & 13 & 2 & 2 & 2 \\
\hline 11 & 1 & 1 & 1 & 14 & 2 & 2 & 2 \\
\hline 16 & 1 & 1 & 1 & 15 & 2 & 2 & 2 \\
\hline 18 & 1 & 1 & 1 & 17 & 2 & 2 & 2 \\
\hline 23 & 1 & 2 & 2 & 19 & 2 & 2 & 2 \\
\hline 24 & 1 & 1 & 1 & 20 & 2 & 2 & 2 \\
\hline 25 & 1 & 1 & 1 & 21 & 2 & 2 & 2 \\
\hline 31 & 1 & 1 & 1 & 22 & 2 & 2 & 2 \\
\hline 35 & 1 & 2 & 2 & 26 & 2 & 2 & 2 \\
\hline 1 & 2 & 2 & 2 & 27 & 2 & 2 & 2 \\
\hline 2 & 2 & 2 & 2 & 28 & 2 & 2 & 2 \\
\hline 3 & 2 & 2 & 2 & 29 & 2 & 2 & 2 \\
\hline 4 & 2 & 2 & 2 & 30 & 2 & 2 & 2 \\
\hline 5 & 2 & 2 & 2 & 32 & 2 & 2 & 2 \\
\hline 6 & 2 & 2 & 2 & 33 & 2 & 2 & 2 \\
\hline 7 & 2 & 2 & 2 & 34 & 2 & 2 & 2 \\
\hline 9 & 2 & 2 & 2 & 36 & 2 & 2 & 2 \\
\hline 10 & 2 & 2 & 2 & 37 & 2 & 2 & 2 \\
\hline 12 & 2 & 2 & 2 & & & & \\
\hline
\end{tabular}

Pode-se observar que 0 análise de clusters foi capaz de diferenciar as duas classes com uma porcentagem de sucesso de $94.60 \%$ ao conseguir classificar de forma correta 35 dos 37 arames. 


\section{CASO II - CLASSIFICAÇÃO DE TRATAMENTOS TÉRMICOS}

O objetivo deste experimento é, por meio da análise de diferentes parâmetros do sinal RMB, medidos num grupo de amostras de aço AISI 420, submetidos a tratamentos térmicos de têmpera e revenimento a diferentes temperaturas, obter uma ou varias regras (modelos matemáticos) de classificação que permitam identificar, numa amostra nova, a que tipo de tratamento foi submetida e, de forma indireta, qual o seu nível de dureza.

\subsection{MATERIAIS E MÉTODOS}

Neste capítulo são descritos os materiais empregados para a realização do experimento, montagens e métodos experimentais para a preparação das amostras, equipamentos de medição do $\mathrm{RMB}$, e a metodologia empregada para a análise estatística.

O experimento foi conduzido e realizado pelo engenheiro Rufino Medina como parte das suas atividades do curso de Mestrado na Universidade de Antioquia (Colômbia), sob a orientação da engenheira Dra. Claudia Patrícia Serna Giraldo do Laboratório de Materialografía da Universidade de Antioquia (Colômbia). Os testes de END foram realizados no Laboratório de Dinâmica e Instrumentação - Ladin. A análise feita neste capítulo tomou como base os bancos de dados obtidos desse experimento.

Para o experimento foi analisado um aço AISI 420 que é um material geralmente utilizado na fabricação de peças tais como moldes de injeção de plásticos, instrumentos cirúrgicos, válvulas para água e vapor, turbinas a gás, engrenagens, eixos, cutelaria , réguas; medidores, ; rolamentos de esferas; bolas de milho; disco 
de freio, etc., peças que requerem características especiais de resistência mecânica, ductilidade e resistência a corrosão.

Segundo a norma AISI, o aço 420 pertence ao tipo martensítico, que são ligas com elevados teores de carbono, tendo sua grande utilização no estado temperado revenido. Podem ser considerados equivalentes aos aços para têmpera e revenimento com a diferença principal do elevado teor de cromo (Tabela 18) que aumentam sua temperabilidade e resistência ao amolecimento no revenido.

Tabela 18 - Composição química do aço 420 conforme norma AISI

\begin{tabular}{ccccccc}
\hline ABNT/AISI & C mín. & Mn máx. & P máx. & S máx. & Si máx. & $\mathrm{Cr}$ \\
\hline 420 & 0,15 & 1,00 & 0,040 & 0,030 & 1,00 & $12,00-14,00$ \\
\hline
\end{tabular}

com o intuito de conferir o tipo de aço utilizado para o experimento, foi feita uma análise por espectrometria de emissão óptica a qual permitiu conhecer a composição química do material (Tabela 19). Ao serem comparados os valores obtidos na medição com os valores apresentados na Tabela 18 se observa que de fato trata-se de um AISI 420.

Tabela 19 - Resultados da análise de espectrometria de emissão óptica

\begin{tabular}{ccccc}
\hline Elemento & $\mathrm{Fe}$ & $\mathrm{C}$ & $\mathrm{Ni}$ & $\mathrm{Cr}$ \\
\hline Concentrações & $85,760 \%$ & $0,214 \%$ & $0,504 \%$ & $12,235 \%$ \\
\hline
\end{tabular}

A seguir são apresentadas algumas características do aço AISI 420 (FAVORIT,2010):

- Aço ligado ao cromo

- Inoxidável

- Martensítico

- Temperável

- Magnético

- Boa resistência mecânica até a temperatura de $550{ }^{\circ} \mathrm{C}$

- Boa resistência à oxidação até a temperatura de $630{ }^{\circ} \mathrm{C}$.

- No estado temperado e revenido, apresenta maior resistência à corrosão, podendo alcançar dureza de até $50 \mathrm{HRc}$. 
- Não apresenta boa conformabilidade a frio, sendo necessário um preaquecimento entre 200 e $400{ }^{\circ} \mathrm{C}$.

- A característica inoxidável pode ser melhorada mediante a utilização de superfícies limpas e polidas, sendo necessário portanto, a remoção de carepas formadas nas operações de soldagens, tratamentos térmicos, ou conformações a quente.

- Deve-se evitar revenimento na faixa de temperatura entre 425 e $525^{\circ} \mathrm{C}$, onde ocorre a fragilização do material.

\subsubsection{Experimento}

Foram usinadas 14 amostras de aço AISI 420 com as dimensões apresentadas na Figura 45. Posteriormente, as amostras foram submetidas a tratamento de têmpera e revenido a diferentes temperaturas como indicado na Tabela 20.

Tabela 20 - Codificação de Amostras e tratamentos térmicos aplicados

\begin{tabular}{cccc}
\hline Codificação & Tratamento & Tratamento & Temperatura (graus celcius) \\
\hline T00 & NA $^{*}$ & NA & NA \\
T01 & Recozimento & NA & NA \\
T10 & Têmpera & Revenimento & NA \\
T11 & Têmpera & Revenimento & $200^{\circ} \mathrm{C}$ \\
T12 & Têmpera & Revenimento & $300^{\circ} \mathrm{C}$ \\
T13 & Têmpera & Revenimento & $500^{\circ} \mathrm{C}$ \\
T14 & Têmpera & Revenimento & $600^{\circ} \mathrm{C}$ \\
\hline
\end{tabular}

* Não há dado ou não aplica (NA) 


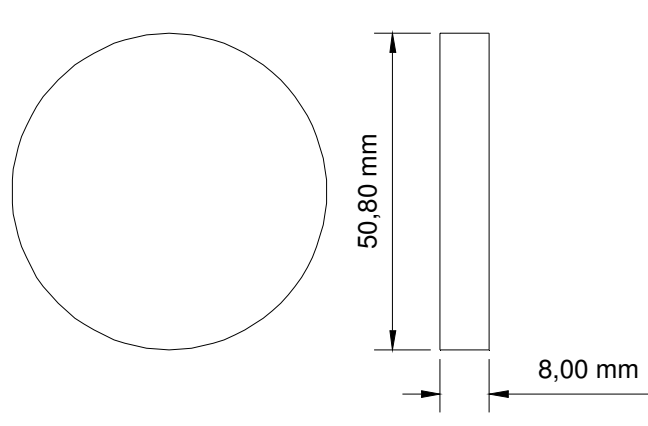

(a)

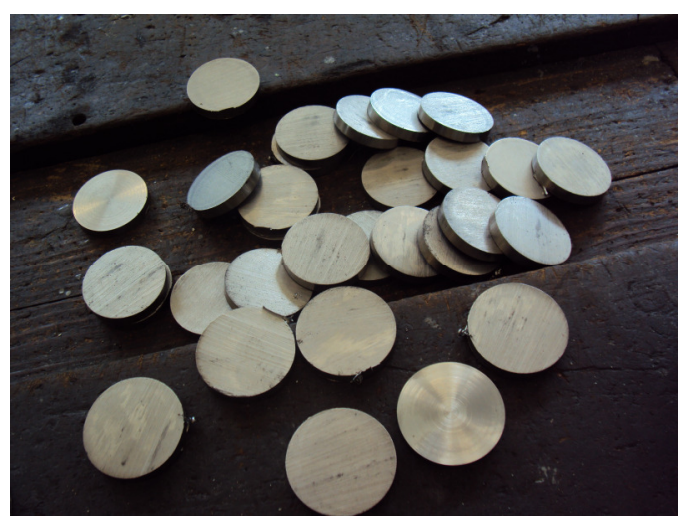

(b)

Figura 45 Características dimensionais das amostras de aço (a), amostras antes do tratamento térmico

A codificação indica os diferentes estados de tratamento térmico, sendo o T00 o estado inicial do material no momento da compra, T01 o tratamento de recozido inicial para homogeneização das amostras e T10 para têmpera a $1020^{\circ} \mathrm{C}$. Para os tratamentos de revenido, a Tabela 20 oferece os detalhes das temperaturas usadas.

Essas temperaturas foram escolhidas com o intuito de modificar de forma significativa o tamanho de grão [YAKAMURA, 2001], a dureza e a microestrutura do material [CAPÓ-SANCHEZ, 2002]. Na Figura 46 é apresentada a curva do comportamento da dureza para este aço quando submetido a tratamento de tempera de revenido.

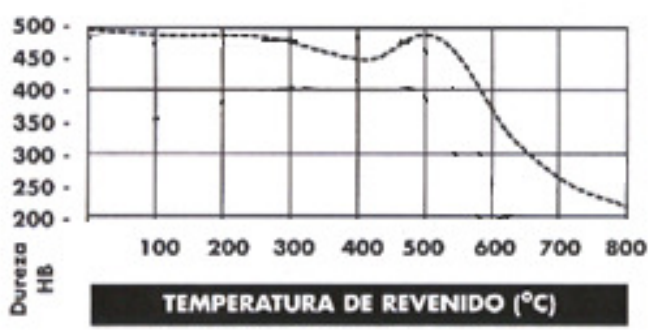

OBS.: Propriedades mecánicas médias previstas, podendo variar com a composiçăo química especifica do material e parámetros inerentes ao processo de deformaçás.

Figura 46 - Características Mecânicas x Temperatura Revenimento, tomado de Favorit (FAVORIT, 2010) 


\subsubsection{Condições iniciais do material}

Uma vez realizados os tratamentos de têmpera e revenido nas amostras, foram estabelecidas as macro e micro durezas para cada uma delas, na Tabela 21 são apresentados os resultados. Com esses dados é construído o gráfico (Figura 47) com as curvas de macro e micro-dureza das amostras.

Tabela 21 - Macro e Microdurezas das medidas nas amostras de aço AISI 420

\begin{tabular}{ccccc}
\hline Tratamento & $\begin{array}{c}\text { Macrodureza } \\
\text { (Valor médio HV) }\end{array}$ & $\begin{array}{c}\text { Desvio } \\
\text { padrão }\end{array}$ & $\begin{array}{c}\text { Microdureza } \\
\text { (Valor médio HV) }\end{array}$ & $\begin{array}{c}\text { Desvio } \\
\text { padrão }\end{array}$ \\
\hline T00 & 194,832 & 4,15441 & 231,68000 & 11,59146 \\
T01 & 189,464 & 3,38140 & 191,66667 & 12,14303 \\
T10 & 432,286 & 9,13990 & 460,27500 & 12,22112 \\
T11 & 412,219 & 8,57977 & 408,73333 & 5,06491 \\
T12 & 408,497 & 10,55318 & 463,66670 & 10,71510 \\
T13 & 419,563 & 6,40236 & 449,40000 & 12,34666 \\
T14 & 314,131 & 5,55228 & 343,23330 & 12,54804 \\
\hline
\end{tabular}

Na Figura 47 é observado que a dureza das amostras com os tratamentos T10, T11, T12, T13 e T14 apresentam um comportamento muito próximo do esperado para aços AISI 420 (Figura 46) para as condições de temperatura de revenido de menos de 100, 200, 300, 500 e 600 graus Celsius respectivamente, o que permite que sejam utilizadas como parâmetro de comparação para avaliar o grau de correlação entre os parâmetros do sinal RMB e a dureza do material. 


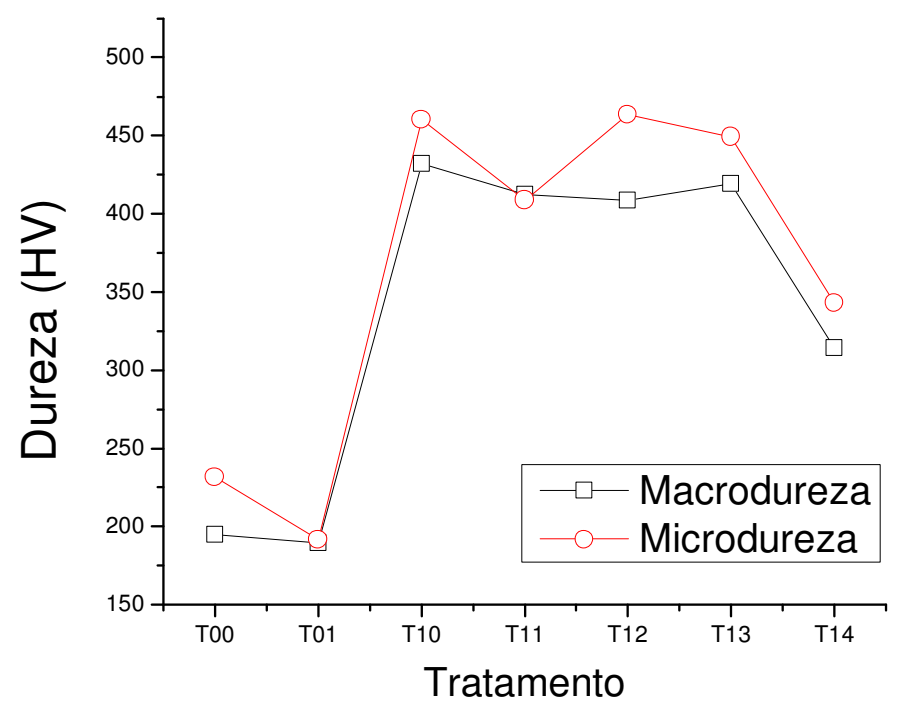

Figura 47 - Comportamento da Macro e Microdureza para as amostras de aço AISI 420 , segundo o tratamento de têmpera e/ou revenido empregada.

\subsubsection{Leitura dos sinais RMB}

Para as medições do sinal $R M B$ neste experimento foi usado o equipamento Barktech, o mesmo indicado no item 4.1.3. As características do equipamento estão indicadas no mesmo item. Para a leitura do sinal foi empregada uma sonda como a mostrada na Figura 48.
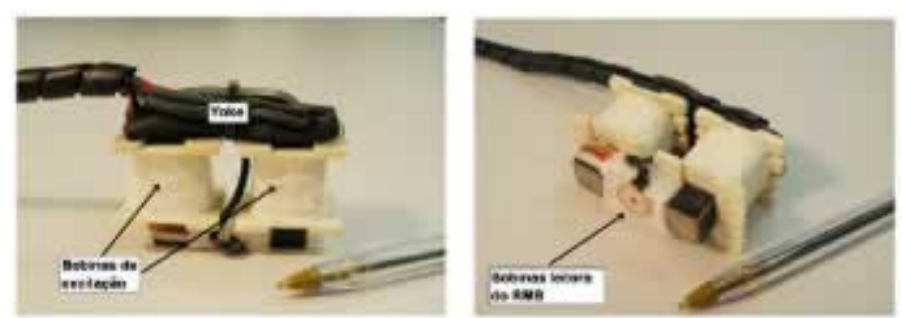

Figura 48 - Fotografia de Sonda RMB para ensaios de flexão (FRANCO,2010)

Para cada amostra foram feitas medições em duas direções, girando a sonda 90 graus respeito da primeira medição, esse procedimento foi repetido 3 vezes e por cada repetição foi feita a leitura de 10 arquivos de sinal $R M B$. Com tudo foram feitas 420 medições que conformaram o banco de dados para a análise (Tabela 22). 
Tabela 22 - Desenho experimental das medições

\begin{tabular}{ccccc}
\hline No. de amostras & Direção de medição & Repetições & No. Leituras & Total Arquivos \\
\hline
\end{tabular}
$\begin{array}{lll}7 & 2 & 3\end{array}$ 10 420

\subsection{METODOLOGIA DE ANÁLISE DOS DADOS}

O fluxograma apresentado na Figura 49 corresponde com os métodos estatísticos empregados nesta análise. Após a análise da qualidade dos dados, foram rejeitados alguns arquivos de sinais, o problema destes arquivos obedeceu a medições com mau posicionamento da sonda por parte do pesquisador. Assim, o tamanho final do banco de dados foi de 372 arquivos. Na Tabela 23 é apresentado o número de observações válidas por cada sonda ou amostra.

Tabela 23 - Numero de observações do banco de dados para análise discriminante, segundo tratamento térmico

\begin{tabular}{cccccccc}
\hline Tratamentos & T00 & T01 & T10 & T11 & T12 & T13 & T14 \\
\hline Observações & 60 & 60 & 40 & 48 & 44 & 60 & 60 \\
\hline
\end{tabular}




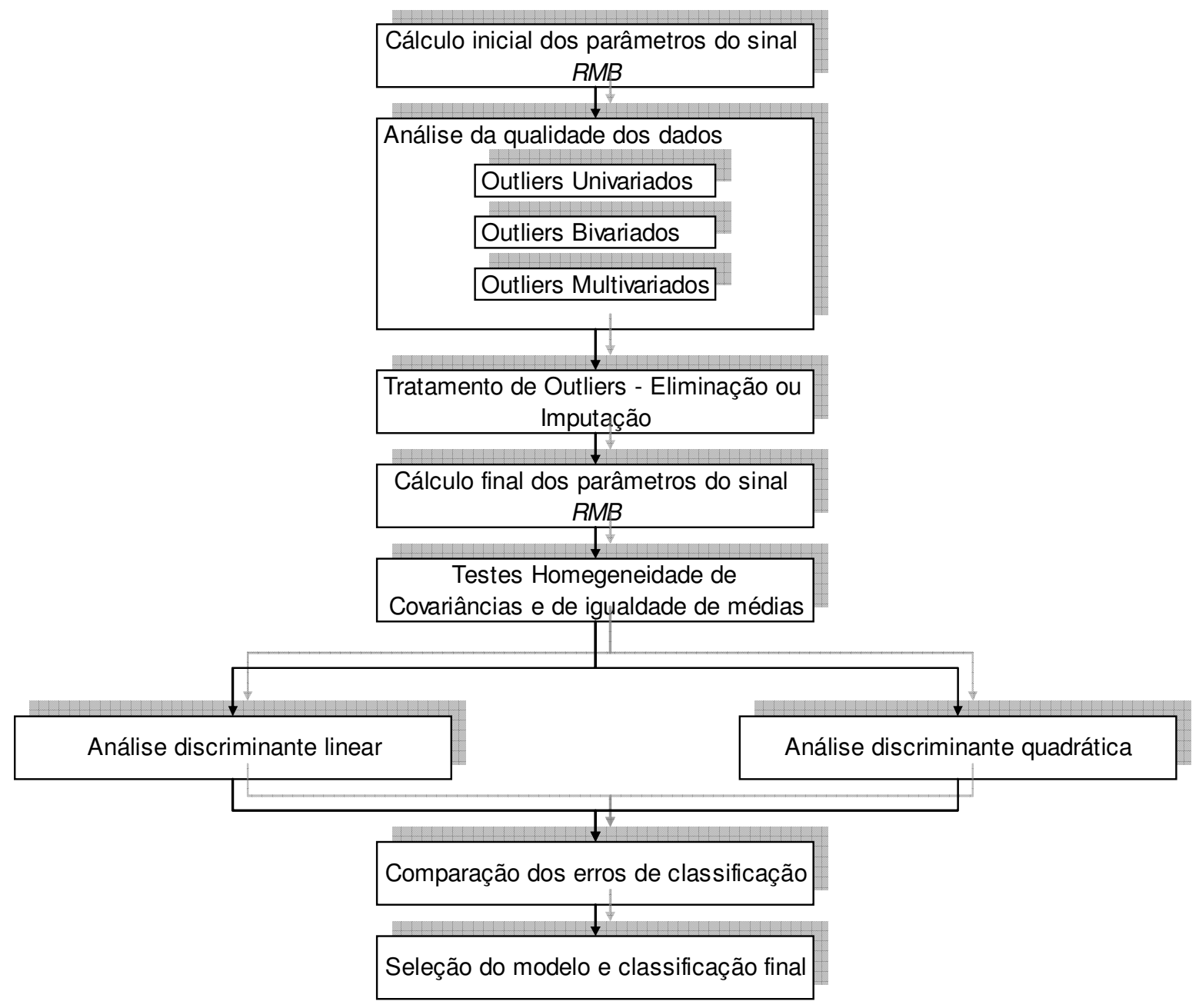

Figura 49 - Fluxograma dos métodos empregados para a análise dos sinais $R M B$ para na análise discriminante.

Após ter sido depurado o banco de dados foi feita uma avaliação dos gráficos dos sinais $R M B$ para cada uma das amostras. Fica evidente que, apesar dos dados virem de sete amostras com características de dureza e tratamento térmico diferentes, os sinais para determinados casos são bem "semelhantes" (Figura 50, Figura 51 e Figura 52), fato o que dificulta fazer uma classificação ótima baseados unicamente na inspeção visual da forma do sinal. Esta agrupação visual inicial mostra que os valores de dureza para cada grupo são muito próximos entre si (Figura 47 e Tabela 21) e que a força do sinal RMB é direitamente proporcional com o grau de dureza das amostras. 


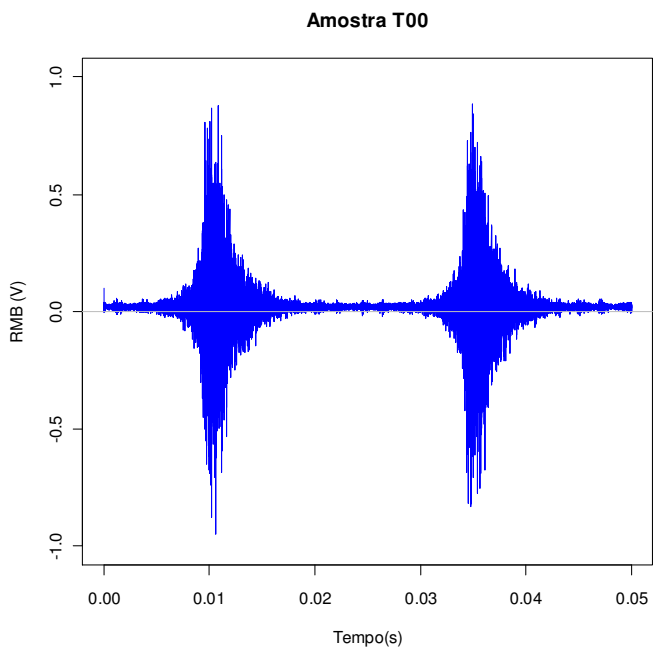

(a)

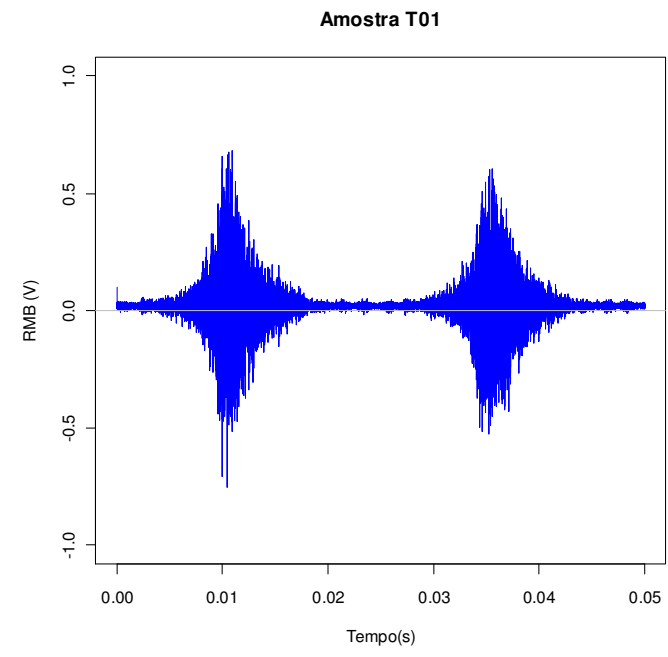

(b)

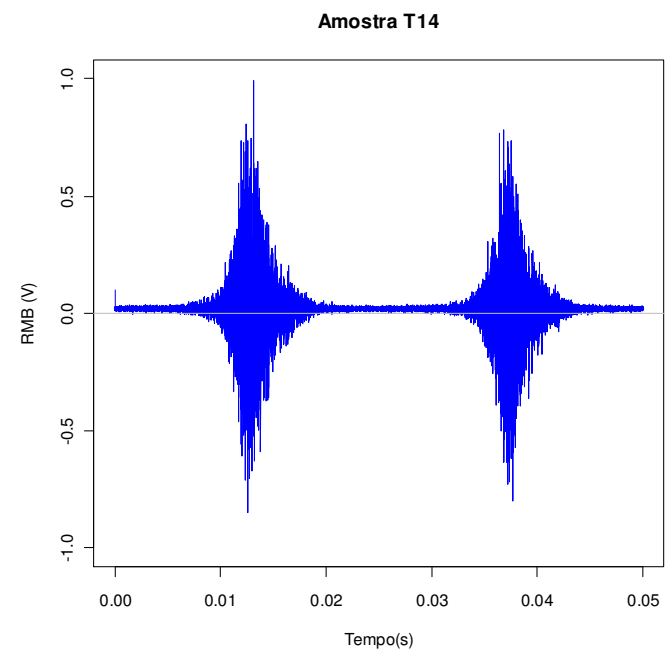

(c)

Figura 50 - Sinal RMB típica para as amostras T00 (a), T01 (b) e T14 (c). 


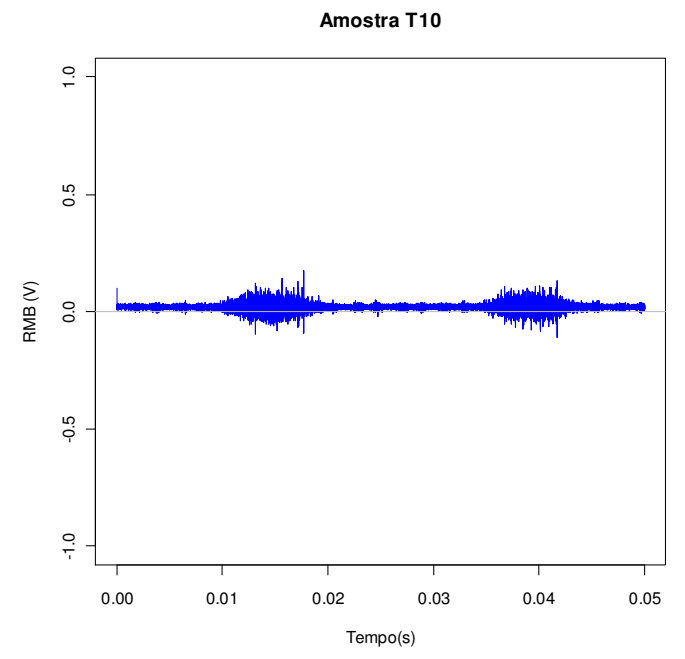

(a)

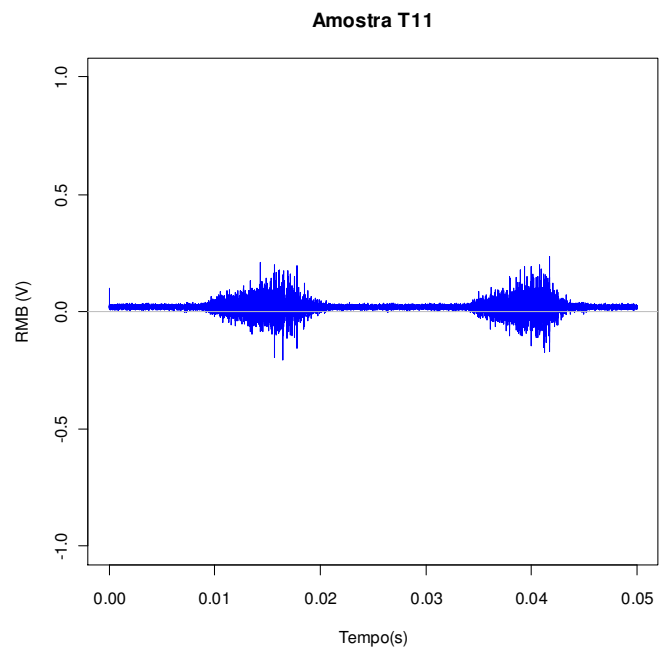

(b)

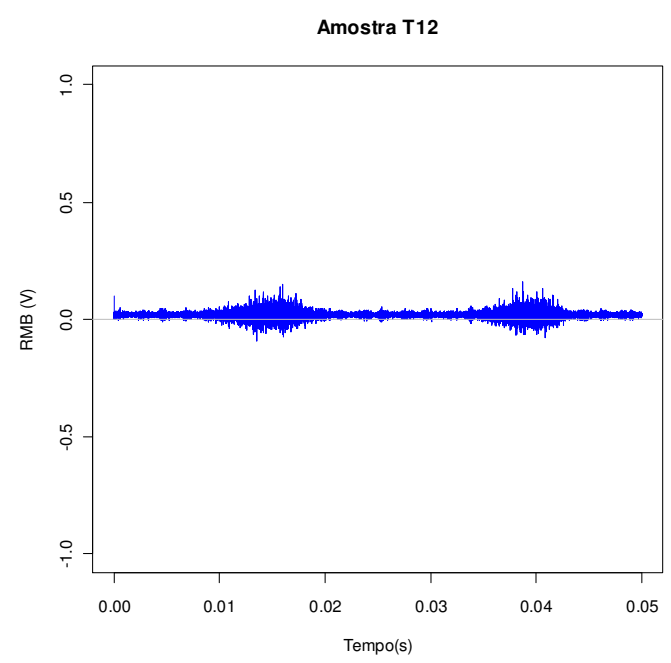

(c)

Figura 51 - - Sinal RMB típica para as amostras T10 (a), T11 (b) e T12 (c).

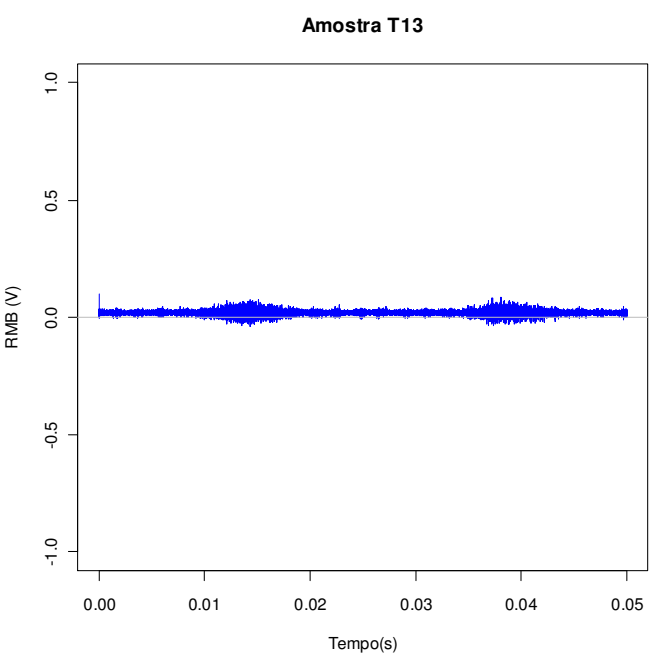

Figura 52 - Sinal RMB típica para as amostras T13 


\subsubsection{Cálculo dos Parâmetros do sinal}

Foram calculados diferentes parâmetros dos sinais medidos: Posição pico do envelope (Ppico), Amplitude do pico do envelope (Apico), $R M B_{r m s}, R M B_{\text {energia }}$, e Número de eventos (Neventos) para cada um dos carregamentos. Os valores médios de esses parâmetros são apresentados na Tabela 24 a seguir:

Tabela 24 - Valores médios dos parâmetros calculados do sinal RMB segundo tratamento térmico

\begin{tabular}{cccccc}
\hline Tratamento & $\overline{r m s}$ & $\overline{\text { energia }}$ & $\overline{\text { eventos }}$ & $\overline{\text { apico }}$ & $\overline{\text { ppico }}$ \\
\hline T00 & 0.0867455227 & 0.0075289866 & 2,674 & 0.5345070506 & 0.1018375 \\
T01 & 0.0706362312 & 0.0050115788 & 3,081 & 0.3784628791 & 0.10628333 \\
T10 & 0.0096985903 & 0.0000944472 & 1,561 & 0.0721885608 & 0.15132083 \\
T11 & 0.0105703313 & 0.0001120712 & 1,635 & 0.0754597467 & 0.14426625 \\
T12 & 0.0082219303 & 0.0000676561 & 1,684 & 0.0672748857 & 0.1429025 \\
T13 & 0.0040920976 & 0.0000168567 & 1,024 & 0.0571386182 & 0.14118625 \\
T14 & 0.0797956288 & 0.0063690604 & 2,439 & 0.4923722084 & 0.12896917 \\
\hline
\end{tabular}

Os parâmetros do sinal foram então grafados (Figura 53 e Figura 54) junto com os valores observados de dureza (ensaio destrutivo) com o intuito de observar e avaliar o grau de correlação entre esses parâmetros e Macrodureza do material.

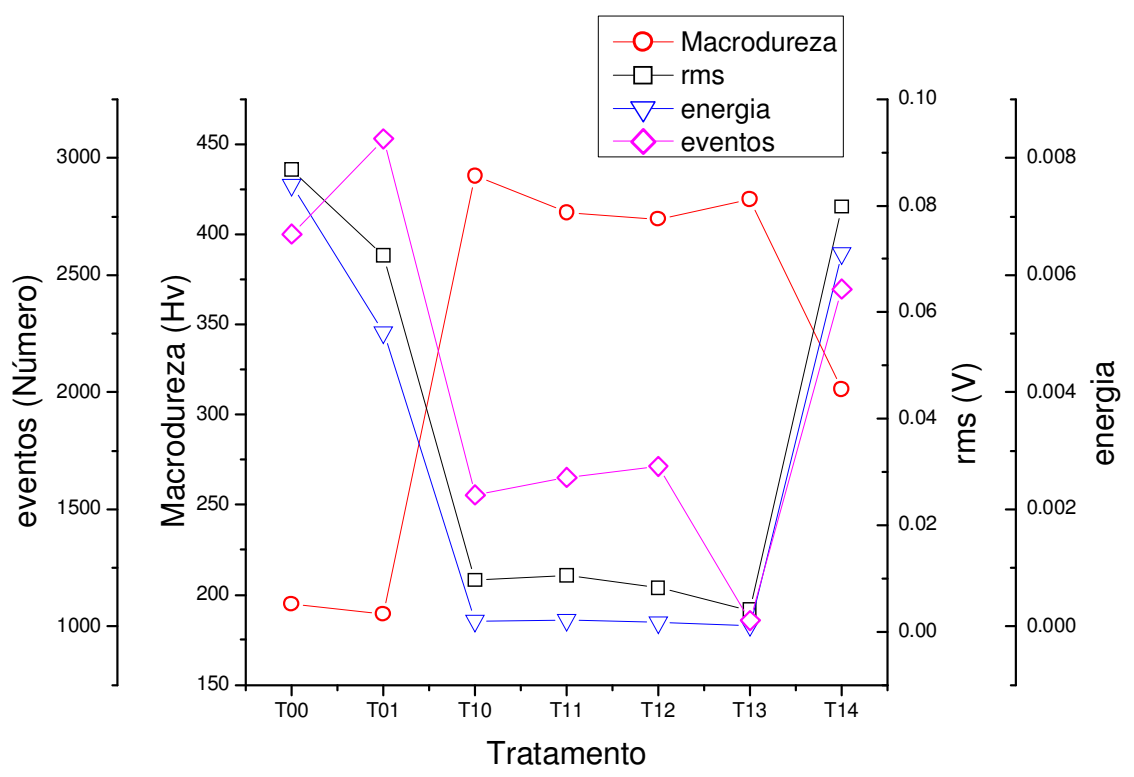

Figura 53 - Parâmetros rms, energia e numero de eventos do sinal RMB Vs. Macrodureza do material, segundo tratamento térmico. 


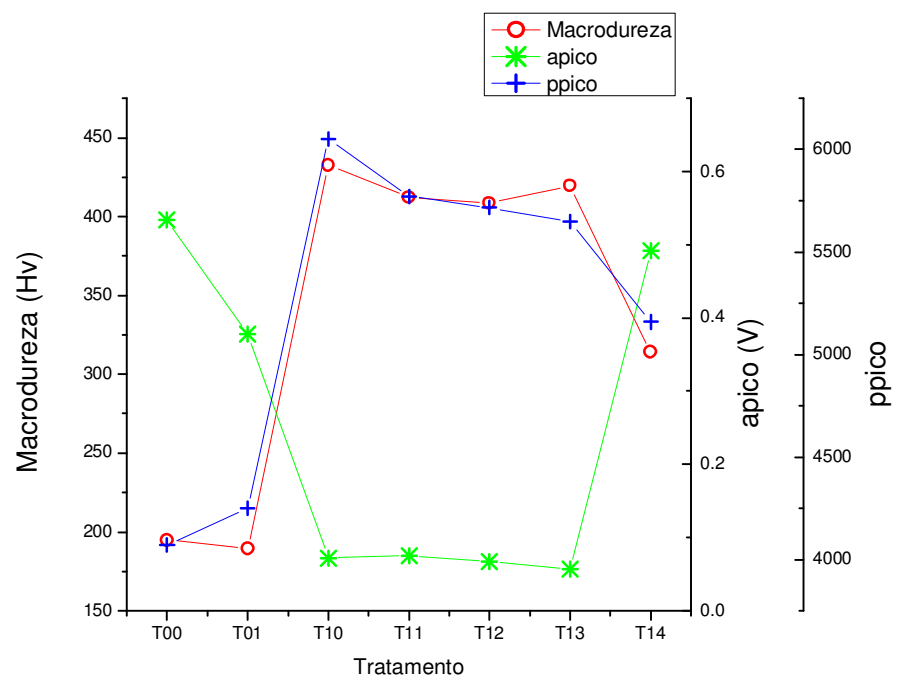

Figura 54 - Parâmetros apico e ppico do sinal RMB Vs. Macrodureza do material, segundo tratamento térmico.

$\mathrm{Na}$ Figura 53 e na Figura 54 fica claro que todos os parâmetros do $R M B$ acompanham, de forma inversa e proporcional, a variável macrodureza. Somente o parâmetro Posição do pico do envelope tem o mesmo sentido (correlação positiva) com a macrodureza. Este fato é um bom indicador do poder discriminante que possuem os parâmetros do $R M B$ para serem usados como variáveis de entrada para modelos de reconhecimento de padrões supervisionado como a Análise Discriminante e, da capacidade para inferir a dureza do material a partir deles. $\mathrm{Na}$ Tabela 25 são apresentados os cálculos de correlação de cada um dos parâmetros do $R M B$ com a Macrodureza do material, os valores confirmam as informações apresentadas na Figura 53 e na Figura 54.

Tabela 25 - Correlações entre os parâmetros do sinal RMB e as medições de Macro-dureza Micro-dureza

\begin{tabular}{cc}
\hline $\begin{array}{c}\text { Parâmetro do sinal } \\
R M B\end{array}$ & $\begin{array}{c}\text { Macro- } \\
\text { dureza }\end{array}$ \\
\hline$\overline{r m s}$ & -0.8804 \\
$\overline{\text { energia }}$ & -0.8556 \\
$\overline{\text { eventos }}$ & -0.9290 \\
$\overline{\text { apico }}$ & -0.8400 \\
$\overline{\text { ppico }}$ & 0.9647 \\
\hline
\end{tabular}




\subsubsection{Análise exploratória}

Antes de começar a análise discriminante propriamente dita, é preciso testar a igualdade dos vetores de médias dos parâmetros ou variáveis (item 2.2.6.2) nos grupos o classes existentes no conjunto de observações, e a igualdade ou similaridade das matrizes de variância-covariâncias desses dados e a normalidade dos dados que compõem a amostra. Uma vez feito isso, e feita uma análise linear, quadrática ou, se necessário, as duas análises e posterior avaliação dos erros de classificação. Na Tabela 26 são apresentados os valores médios (vetores de médias) para cada um dos parâmetros.

Tabela 26 - Médias das variáveis e número das observações segundo grupo de tratamento térmico

\begin{tabular}{ccccccc}
\hline Tratamento & $\mathrm{V} 1$ & $\mathrm{~V} 2$ & $\mathrm{~V} 3$ & $\mathrm{~V} 5$ & $\mathrm{~V} 5$ & $\mathrm{~N}$ \\
\hline T00 & 0.086745523 & 0.00752898658 & 2673.667 & 0.53450705 & 4073.500 & 60 \\
T01 & 0.070636231 & 0.00501157878 & 3081.200 & 0.37846288 & 4251.333 & 60 \\
T10 & 0.009277824 & 0.00008610610 & 1550.750 & 0.07160202 & 6002.775 & 40 \\
T11 & 0.010355856 & 0.00010703996 & 1629.146 & 0.07570322 & 5697.083 & 48 \\
T12 & 0.008102411 & 0.00006574311 & 1710.545 & 0.06692757 & 5688.182 & 44 \\
T13 & 0.004092098 & 0.00001685850 & 1024.267 & 0.05713862 & 5647.450 & 60 \\
T14 & 0.079795629 & 0.00636906050 & 2439.383 & 0.49237221 & 5158.767 & 60 \\
\hline
\end{tabular}

Para a análise discriminante são adotadas para cada parâmetro do sinal as convenções a seguir:

V1 $\overline{r m s}$ - Valor médio de valor RMS do sinal

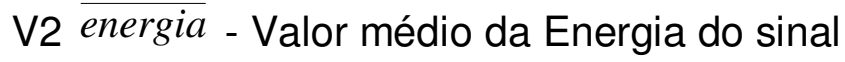

V3 $\overline{\text { eventos }}$ - Valor médio de Eventos do sinal

V4 $\overline{\text { apico }}$ - Valor médio de Amplitude do Pico do envelope

V5 $\overline{\text { ppico }}$ - Valor médio de Posição Pico do sinal

\subsubsection{Igualdade dos vetores de médias}

Para testar a hipótese de igualdade dos vetores de médias apresentados na Tabela 26, foram feitos 4 diferentes testes (item 2.2.6.2) assim como testes para 
cada combinação possível entre os diferentes grupos, estes testes são apresentados na Tabela 27 e Tabela 28 respectivamente.

Tabela 27 - Tabela de teste de hipótese de igualdade dos vetores de médias (cálculos anova)

\begin{tabular}{ccc}
\hline Teste & Statístico & $\mathrm{Pr}$ \\
\hline Wilks Lambda & 0.0 & 0 \\
Pillai Trace & 3.2 & 0 \\
Hotelling-Lawley Trace & 3488.2 & 0 \\
Roy Greatest Root & 3461.3 & 0 \\
\hline
\end{tabular}

O valor do parâmetro $\operatorname{Pr}(p$-value) indica a significância estatística para igualdade dos vetores de médias multivariados, pode-se observar que o valor foi inferior ao 0,05 nos casos (Tabela 27), o que indica que as médias dos grupos não são iguais (hipótese rejeitada), desta forma, uma das hipóteses para a análise discriminante é satisfeito.

Adicionalmente, e como sugerido por Mlngoti (MINGOTI,2005) foi testada a igualdade entre médias das variáveis para cada combinação das diferentes classes (tratamentos térmicos) segundo o teste de Hotelling. OS resultados confirmam a rejeição hipótese de igualdade de médias (parâmetro $\operatorname{Pr}<0,05$ ), como requerido pelos modelos de análise discriminante (Tabela 28). 
Tabela 28 - Teste de Hotelling para diferença de médias entre grupos

\begin{tabular}{ccc}
\hline Tratamentos & $\mathrm{F}$ & $\mathrm{Pr}$ \\
\hline T00-T01 & 1927.9 & 0 \\
T00-T10 & 66844.2 & 0 \\
T00-T11 & 70993.9 & 0 \\
T00-T12 & 74204.8 & 0 \\
T00-T13 & 101758.4 & 0 \\
T00-T14 & 412.2 & 0 \\
T01-T10 & 52284.3 & 0 \\
T01-T11 & 55101.8 & 0 \\
T01-T12 & 58188.6 & 0 \\
T01-T13 & 82414.6 & 0 \\
T01-T14 & 1442.1 & 0 \\
T10-T11 & 41.7 & 0 \\
T10-T12 & 80.0 & 0 \\
T10-T13 & 972.2 & 0 \\
T10-T14 & 61080.1 & 0 \\
T11-T12 & 162.7 & 0 \\
T11-T13 & 1505.8 & 0 \\
T11-T14 & 64809.1 & 0 \\
T12-T13 & 896.3 & 0 \\
T12-T14 & 68125.7 & 0 \\
T13-T14 & 93856.6 & 0 \\
\hline
\end{tabular}

No entanto, e apesar dos testes apresentados anteriormente, uma análise gráfica das funções de densidade de probabilidade de cada um dos parâmetros, segundo o tipo de tratamento térmico (Figura 55 a Figura 59), mostrou que para alguns tratamentos os parâmetros de forma individual não garantem uma boa classificação ou diferenciação entre grupos na tentativa de escolher só um parâmetro como classificador único. Assim o critério multivariado prevalece e a abordagem sugerida por [SUELI, 2005] de uma análise linear e outra quadrática serão exploradas. 
Função Densidade de Probabilidade

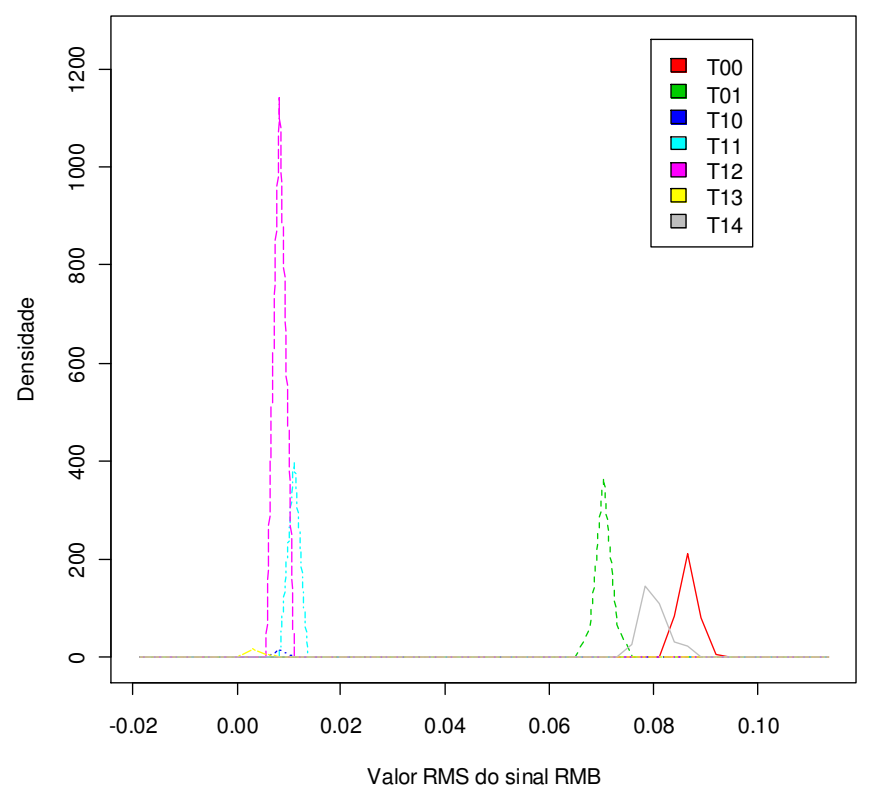

Figura 55 - Funções de densidade de probabilidade para o parâmetro RMS dos sinais RMB, segundo o tipo de tratamento térmico.

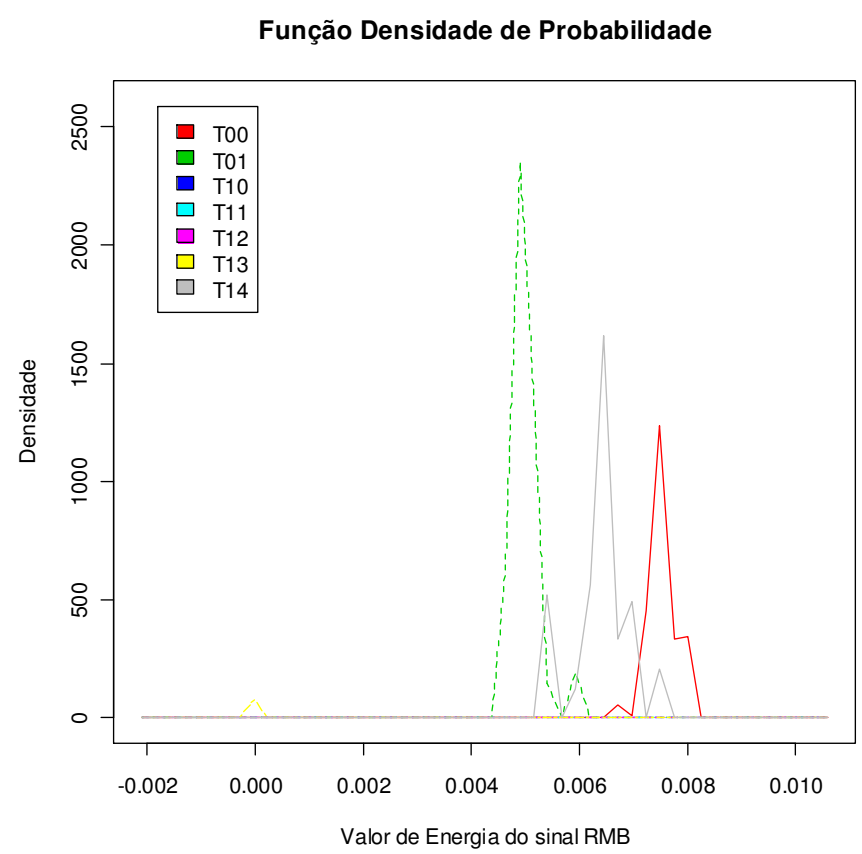

Figura 56 - Funções de densidade de probabilidade para o parâmetro Energia dos sinais RMB, segundo o tipo de tratamento térmico. 


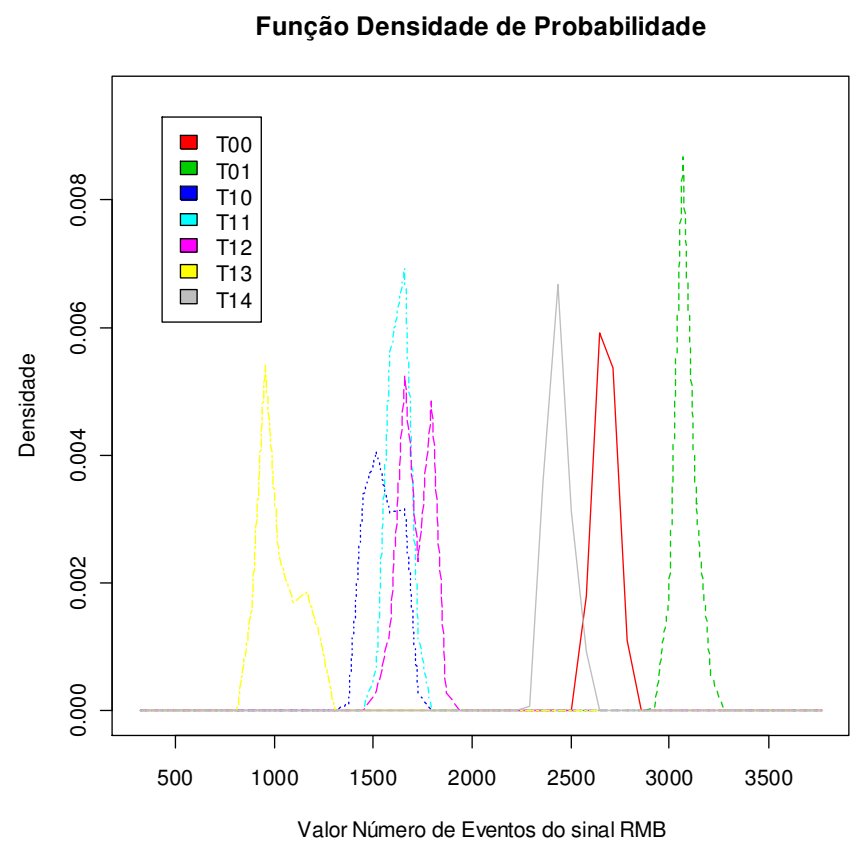

Figura 57 - Funções de densidade de probabilidade para o parâmetro Número de Eventos dos sinais RMB, segundo o tipo de tratamento térmico.

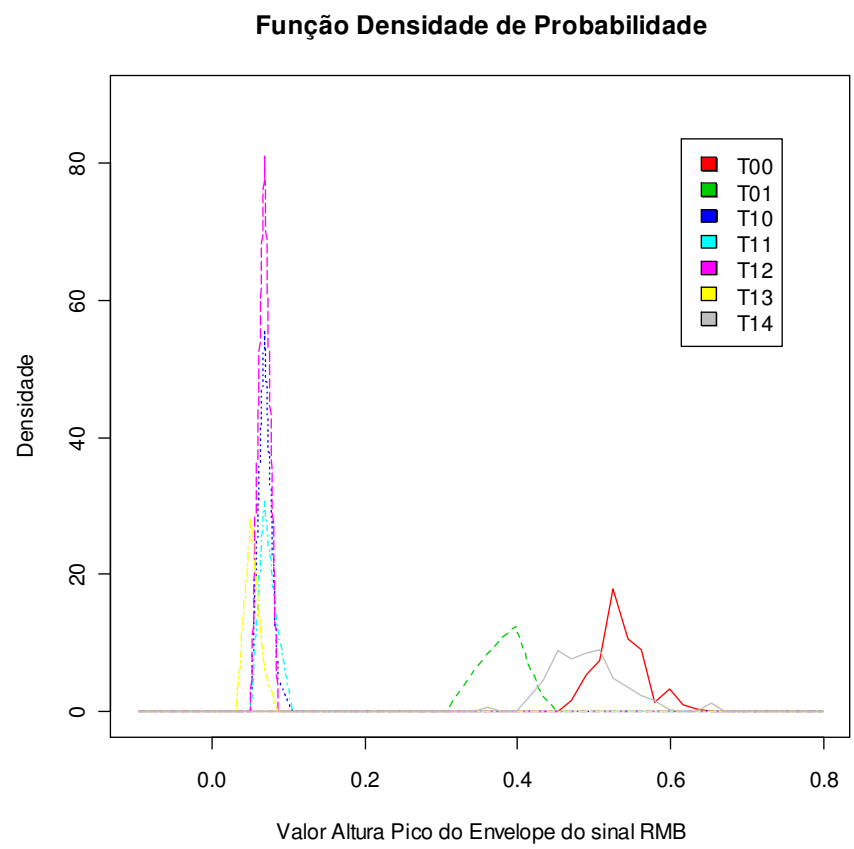

Figura 58 - Funções de densidade de probabilidade para o parâmetro Amplitude do Pico do Envelope dos sinais RMB, segundo o tipo de tratamento térmico. 


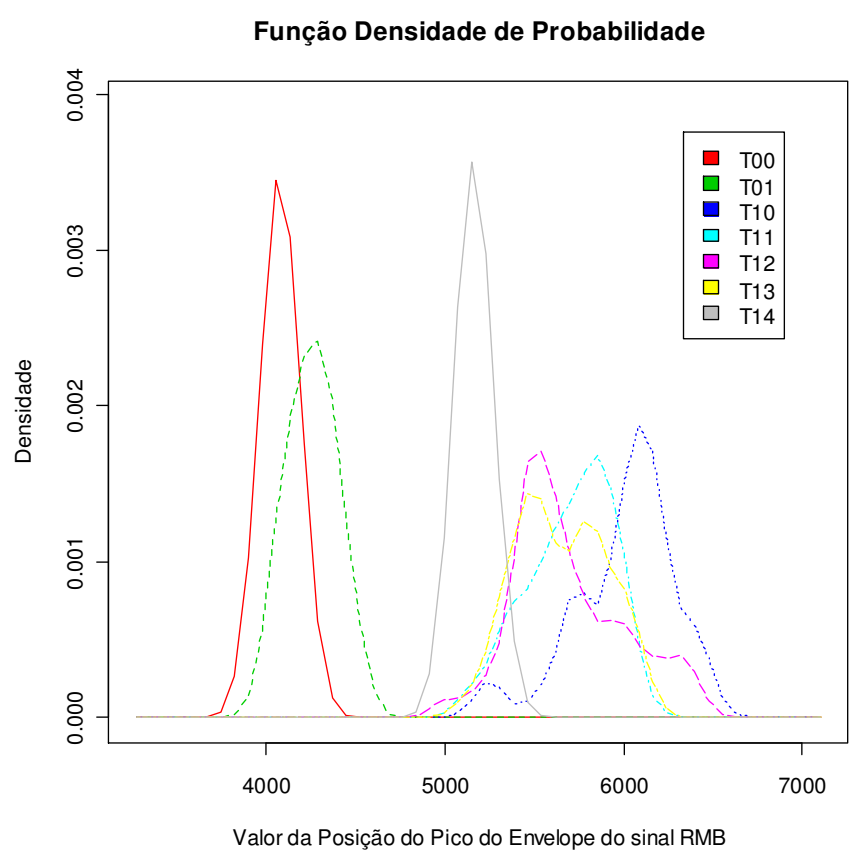

Figura 59 - Funções de densidade de probabilidade para o parâmetro Posição do Pico do Envelope dos sinais RMB, segundo o tipo de tratamento térmico.

\subsubsection{Homogeneidade das Covariâncias}

Nos testes feitos para avaliar a homogeneidade das matrizes de covariâncias (item 2.2.6.2), o valor obtido para o parâmetro $\operatorname{Pr}$ ( $p$-value) no teste de Box. M. e $M$. Ajustado (Tabela 29) foi inferior a 0,05 para os dois casos. O resultado indica que as matrizes de covariâncias não são iguais e a hipótese de homogeneidade requerida para a análise discriminante de tipo linear não é satisfeito. Assim, e como sugerido por [MINGOTI, 2005], serão feitos os cálculos para o modelo linear e o quadrático e logo depois avaliados os erros de classificação dos resultados e, finalmente feita a escolha da melhor abordagem (linear ou quadrática).

Tabela 29 - Testes para homogeneidade das matrizes de covariâncias dos grupos de tratamentos térmicos

\begin{tabular}{|c|c|c|c|}
\hline Teste & Vr. do teste & Graus de liberdade & $\mathrm{Pr}$ \\
\hline Box. M & 3275.964 & 90 & 0 \\
\hline adj.M & 3144.702 & 90 & 0 \\
\hline
\end{tabular}




\subsection{ANÁLISE DISCRIMINANTE}

A seguir são apresentados os resultados para a Análise Discriminante. Uma análise exploratória prévia dos dados evidencia o maior poder discriminante de algumas variáveis ou combinação de variáveis como apreciado na Figura 60, onde são privilegiadas as variáveis Número de eventos .e Posição do pico do envelope.

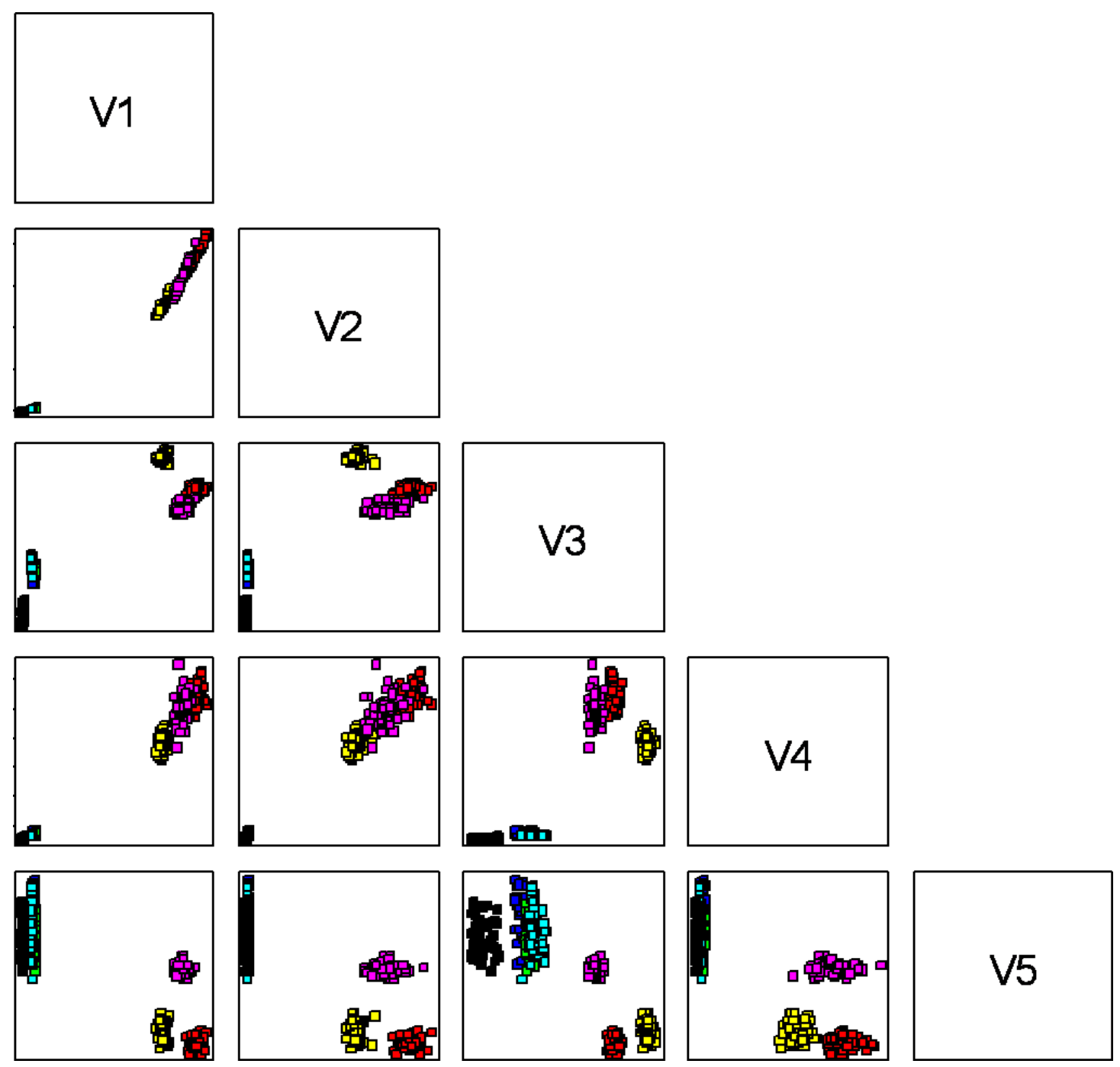

Figura 60 - Diagramas de dispersão multivariado V1 (rms), V2 (energia), V3 (Número de eventos), V4 (Altura do pico) e V5 (Posição do Pico).

Devido ao fato de ter sido rejeitada a hipótese de homogeneidade das matrizes de covariâncias (item 5.2.2.2), é feito o calculo tanto do modelo lineal como do modelo quadrático da Análise Discriminante, assim como indicado no fluxograma da Figura 49. 


\subsubsection{Abordagem 1 - Análise Discriminante linear [ADL]}

Nesta abordagem, o resultado do cálculo da matriz de distâncias de Mahalanobis para os diferentes tratamentos (item 2.1.3.2), apresentadas na Tabela 30, dão evidencia da proximidade (ou similaridade) existente entre tratamentos T10, T11 e T12 ao ser os que apresentam os valores menores da tabela. Este fato confirma a informação obtida dos gráficos de densidade de probabilidade (Figura 55 a Figura 59) onde, pare esses mesmos tratamentos, as curvas são muito próximas (igualdade de médias) ou se sobrepõem umas acima das outras.

Tabela 30 - Distância de Mahalanobis

\begin{tabular}{cccccccc}
\hline & T00 & T01 & T10 & T11 & T12 & T13 & T14 \\
\hline T00 & 0.00 & 324.88 & 14080.17 & 13458.85 & 14778.04 & 17147.65 & 69.46 \\
T01 & & 0.00 & 11013.25 & 10446.07 & 11588.39 & 13887.97 & 243.02 \\
T10 & & & 0.00 & 9.67 & 19.29 & 204.79 & 12866.01 \\
T11 & & & & 0.00 & 35.83 & 285.47 & 12286.35 \\
T12 & & & & & 0.00 & 178.49 & 13567.38 \\
T13 & & & & & & 0.00 & 15816.09 \\
T14 & & & & & & & 0.00 \\
\hline
\end{tabular}

A seguir são então feitos os cálculos dos erros de classificação pelo método Plug-in e Validação cruzada (item 2.2.6.3). Os resultados são apresentados na Tabela 31 e Tabela 32 respectivamente. Em ambos os casos, o erro de classificação foi o mesmo, 2 observações da classe T10 foram classificadas erroneamente como da classe T11 e, 1 observação da classe T11 foi classificada erroneamente como da classe T10.

Tabela 31 - Tabela de Classificação tipo Plug-in Análise Linear de Fisher segundo tratamentos térmicos.

\begin{tabular}{|c|c|c|c|c|c|c|c|c|}
\hline Tratamentos & T00 & T01 & $\mathrm{T} 10$ & T11 & T12 & $\mathrm{T} 13$ & T14 & Erro \\
\hline T00 & 60 & & & & & & & 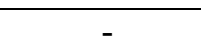 \\
\hline T01 & - & 60 & - & - & - & - & - & - \\
\hline T10 & - & - & 38 & 2 & - & - & - & 0.0500000 \\
\hline T11 & - & - & 1 & 47 & & - & - & 0.0208333 \\
\hline T12 & - & - & - & - & 44 & & - & - \\
\hline T13 & - & - & - & - & - & 60 & - & - \\
\hline \multirow[t]{2}{*}{ T14 } & - & - & - & - & - & & 60 & \\
\hline & & & 0 Tot & & & & & 0.0708333 \\
\hline
\end{tabular}


Tabela 32 - Tabela de Classificação de Validação Cruzada

\begin{tabular}{ccccccccc}
\hline $\begin{array}{c}\text { Tratamento } \\
\text { s }\end{array}$ & T00 & T01 & T10 & T11 & T12 & T13 & T14 & Erro \\
\hline T00 & 60 & - & - & - & - & - & - & - \\
T01 & - & 60 & - & - & - & - & - & - \\
T10 & - & - & 38 & 2 & - & - & - & 0.0500000 \\
T11 & - & - & 1 & 47 & - & - & - & 0.0208333 \\
T12 & - & - & - & - & 44 & - & - & - \\
T13 & - & - & - & - & - & 60 & - & - \\
T14 & - & - & - & - & - & 60 & - \\
\hline \multicolumn{7}{c}{ Erro total } \\
\hline
\end{tabular}

Segundo os anteriores resultados, o erro de classificação do modelo linear é do $5 \%$ (2/40) para a classe T10 e de 2,08\% (1/48) para a classe T11. Com tudo, a percentagem total de erro pode ser calculada como 3 falhas em 328 observações (3/328), equivalente a um erro total $0,91 \%$ com a abordagem linear.

\subsubsection{Abordagem 2 - Análise Discriminante Quadrático}

$\mathrm{Na}$ análise discriminante quadrática, assim como foi feito na análise linear, é calculada a matriz de distâncias de Mahalanobis (Tabela 30 e Tabela 33), para avaliar a similiradidade ou proximidade das classes envolvidas na análise. Os resultados confirmam o achado no modelo linear, e dizer, há forte evidencia da proximidade (ou similaridade) existente entre tratamentos T10, T11 e T12 ao ser os que apresentam os valores menores da distância (células em amarelo na Tabela 33).

Tabela 33 - Distância de Mahalanobis

\begin{tabular}{cccccccc}
\hline Tratamentos & T00 & T01 & T10 & T11 & T12 & T13 & T14 \\
\hline T00 & - & 300.49 & 19700000 & 3386659.9 & 1,120000000 & 14261206.8 & 288.31 \\
T01 & 570.27 & - & 7650000.0 & 1279183.1 & 457000000 & 6198298.0 & 489.51 \\
T10 & 123870.5 & 5666.7 & - & 29.35 & 247.00 & 938.10 & 18167.8 \\
T11 & 117237.1 & 5308.1 & 31.50 & 0.00 & 1780.00 & 1567.13 & 17312.6 \\
T12 & 130466.2 & 5773.0 & 64.70 & 108.74 & - & 581.16 & 18886.7 \\
T13 & 159502.5 & 7552.7 & 1950.00 & 1299.79 & 4150.00 & - & 22904.2 \\
T14 & 261.01 & 396.81 & 13400000. & 2279299.6 & 777000000 & 10100109 & - \\
\hline
\end{tabular}

Os resultados do cálculo do erro de classificação segundo os métodos de Plug-in e validação cruzada (Tabela 34 e Tabela 35 ) oferecem respostas um tanto diferentes para uma das classes, no primeiro caso (Tabela 34), a classe ou 
tratamento T11 apresenta um erro na classificação (erro de 2,08\% respeito da classe - 1/47) enquanto que na validação cruzada (Tabela 35), tanto o tratamento T10 quanto o T11 apresentam um erro de classificação em cada um dos casos. Os tratamentos com erros de classificação são iluminados em cor amarelo.

Tabela 34 - Tabela de Classificação tipo Plug-in Análise Linear de Fisher segundo tratamentos térmicos.

\begin{tabular}{ccccccccc}
\hline $\begin{array}{c}\text { Tratamento } \\
\text { s }\end{array}$ & T00 & T01 & T10 & T11 & T12 & T13 & T14 & Erro \\
\hline T00 & 60 & - & - & - & - & - & - & - \\
T01 & - & 60 & - & - & - & - & - & - \\
T10 & - & - & 40 & - & - & - & - & - \\
T11 & - & - & 1 & 47 & - & - & - & 0.0208333 \\
T12 & - & - & - & - & 44 & - & - & - \\
T13 & - & - & - & - & - & 60 & - & - \\
T14 & - & - & - & - & - & - & 60 & - \\
\hline \multicolumn{7}{c}{ Erro total } \\
\hline
\end{tabular}

Tabela 35 - Tabela de Classificação de Validação Cruzada

\begin{tabular}{|c|c|c|c|c|c|c|c|c|}
\hline & T00 & T01 & T10 & T11 & $\mathrm{T} 12$ & $\overline{T 13}$ & T14 & Erro \\
\hline T00 & 60 & & 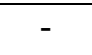 & & - & & - & \\
\hline T01 & - & 60 & - & & - & - & - & \\
\hline T10 & - & - & 39 & 1 & - & - & - & 0.0250000 \\
\hline $\mathrm{T} 11$ & - & - & 1 & 47 & - & - & - & 0.0208333 \\
\hline $\mathrm{T} 12$ & - & - & - & 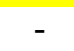 & 44 & & - & 0.0000000 \\
\hline $\mathrm{T} 13$ & - & - & - & - & - & 60 & - & - \\
\hline $\mathrm{T} 14$ & - & - & - & - & - & - & 60 & - \\
\hline
\end{tabular}

\subsection{RESULTADOS E DISCUSSÃO}

Os resultados obtidos a partir das análises linear e quadráticas estão resumidos na Tabela 36. Observando os erros de classificação para cada um dos métodos de cálculo do erro, fica claro que o modelo quadrático oferece a melhor solução para o problema de classificação das amostras. 
Tabela 36 - Comparação dos erros de classificação segundo o modelo linear de Fisher e o modelo quadrático.

\begin{tabular}{cccc}
\hline Modelo & Tipo de Validação & $\begin{array}{c}\text { Observações classificadas } \\
\text { de forma errada }\end{array}$ & Erro global \\
\hline Modelo Linear & Validação Plug-in & $3 / 328$ & $0,9146 \%$ \\
& Validação Cruzada & $3 / 328$ & $0,9146 \%$ \\
\hline Modelo Quadrático & Validação Plug-in & $1 / 328$ & $0,3049 \%$ \\
& Validação Cruzada & $2 / 328$ & $0,6097 \%$ \\
\hline
\end{tabular}

Tomando como base os erros de maior valor calculados (três erros no modelo linear e quatro erros no modelo quadrático), a percentagem de acerto global de cada abordagem fica assim:

$$
\begin{gathered}
\text { Modelo quadrático }=(1-2 / 328) * 100=99,39 \% \\
\text { Modelo linear }=(1-3 / 328) * 100=99,09 \%
\end{gathered}
$$

Segundo os resultados do erro global (Fórmulas (1) e (2)), o modelo a ser escolhido é o quadrático por ter apresentado o menor erro de classificação. Esse modelo consegue classificar os 7 tratamentos com um percentagem de êxito de $99,39 \%$.

Com relação aos dados que causaram os erros de classificação, as duas análises (linear e quadrática) identificaram os tratamentos como responsáveis pelo erro ( $\mathrm{T} 10$ e T11), isto corrobora a dificuldade expressada inicialmente quando foram analisadas as matrizes de distâncias (Tabela 30 e Tabela 33) e os gráficos das funções de densidade de probabilidade (Figura 55 a Figura 59) dos diferentes tratamentos térmicos.

É de ressaltar que foi possível diferenciar e classificar amostras de aço AISI 420 submetidas tratamentos térmicos, através da análise multivariada dos parâmetros do sinal RMB com níveis de erro bastante aceitáveis para dois dos tratamentos térmicos $(1 / 40=2,5 \%$ para $\mathrm{T} 10$ e $1 / 48=2,08 \%$ para $\mathrm{T} 11)$ e $0 \%$ de erro nos restantes tratamentos (T00, T01, T12, T13, T14). 


\section{CONCLUSÕES}

\subsection{CASO I: INTEGRIDADE ESTRUTURAL DE RISER}

A aplicação de técnicas de avaliação da qualidade dos dados (univariadas, bivariadas e multivariadas) mostrou ser eficiente na identificação de sinais com problemas (sinais estranhos, aparição de ruídos, problemas próprios da medição etc.). Isso possibilitou melhorar a qualidade das posteriores análises. Essas técnicas automatizaram a identificação de "outliers", evitando a análise visual de um banco de sinais enorme.

Com a utilização conjunta das técnicas de Componentes Principais e Análise de Agrupamentos (prévia avaliação da qualidade dos dados), foi possível obter de forma direta uma representação gráfica (dendrograma) de dois grupos de arames, os quais correspondem com os arames quebrados e aqueles que estão operando em condições normais.

A análise das componentes principais mostrou que as variáveis de maior valor discriminante são $R M B_{\text {rms }}, R M B_{\text {energia }}$, Neventos e Apico.

Finalmente, com a metodologia empregada nesta análise, foi possível identificar dois grupos bem diferenciados que correspondem com "Arames bons" e "Arames quebrados". Ao serem comparados esses resultados com o planejamento experimental, a percentagem global de êxito foi de $(94,60 \%)$, sendo que somente dois arames foram mal classificados.

Confirma-se o potencial e a capacidade do uso do RMB como técnica END para a identificação arames quebrados, através da medição de tensão mecânica, sobre a camada de polímero em risers.

\subsection{Caso II: Classificação de tratamentos térmicos}

Os parâmetros do sinal RMB mostraram ser ótimas variáveis para a discriminação e classificação de peças de aço AISI 420 provenientes de grupos com 
diferentes tratamentos térmicos, já que os erros de classificação foram inferiores a 1\% (proporção global de acerto superior ao 99\%, com uma significância estatística de $0,05 \%)$.

Devido à similaridade dos valores dos parâmetros do sinal para alguns dos tratamentos térmicos, a análise discriminante quadrática é a melhor opção para classificar as amostras.

Por tratar-se de um modelo de reconhecimento de padrões supervisionado, os níveis de eficiência na classificação podem melhorar com a inclusão de novas observações (aprendizado).

Finalmente, fica comprovado com um critério estatístico e probabilístico que o $R M B$ pode ser usado como uma técnica de controle de qualidade ou como técnica de END para casos de classificação de amostras ferromagnéticas com diferentes tratamentos térmicos ou níveis de dureza, neste caso, o aço AISI 420. 


\section{REFERÊNCIAS}

Favorit Aços Especiais. Aços inoxidáveis, Aço AISI 420. http://www.favorit.com.br/produtos/categoria/acos-inoxidaveis/aco-aisi-420. Novembro 2010.

ANDERSON, T. W.; DARLING, D. A. Asymptotic theory of certatin "goodnes of fit" criteria based on stochastic processes. The annals of Mathematical Statistics, v. 23, p. 193-212, 1952.

JAIN, A. K.; DUIN, R. P. W.; MAO, J.; Statistical Pattern Recongnition: A Review; IEEE Transactions on Pattern Analysis and Machine Intelligence; V. 22 (1); p.4-37, 2000.

ANGLADA-RIVERA, J.; PADOVESE, L. R. \& CAPO-SANCHEZ, J. Magnetic Barkhausen Noise and hysteresis loop in commercial carbon steel: influence of applied tensile stress and grain size Journal Of Magnetism And Magnetic Materials, v. 231, p. 299-306, 2001

BLAOW, M. Magnetic Barkhausen noise: the influence of microstructure and deformation in bending. Acta Materialia, v. 53 (2), p. 279-287, 2005

BRADY, G. S.; CLAUSER, H. R. \& VACCARI, J. A. MCCOMBS, K. (ed.) MATERIALS HANDBOOK McGraw Hill, 2002

BIRKETT, A. J.; CORNER, W. D.; TANNER, B. K. \& THOMPSON, S. M. Influence Of Plastic-Deformation On Barkhausen Power Spectra In Steels Journal Of Physics D-Applied Physics, v. 22, p. 1240-1242, 1989.

BINFENG, Y.; FEILU, L.; DAN, H. Research on the identification of a defect using pulsed eddy current based on principal component analysis. NDT\&E International, v. 40, p. 294-299, 2007. 
BUTTLE, D. J.; BRIGGS, G. A. D.; JAKUBOVICS, J. P.; LITTLE, E. A. \& SCRUBY, C. B. Magnetoacoustic And Barkhausen Emission In Ferromagnetic Materials Philosophical Transactions Of The Royal Society Of London Series AMathematical Physical And Engineering Sciences, v. 320, p. 363-378, 1986.

CAPO-SANCHEZ, J.; PADOVESE L.R.; SERNA-GIRALDO, C.P., em II Congresso Nacional de Engenharia Mecânica., João Pessoa, Brasil 2002.

CAPO-SANCHEZ, J.; PEREZ-BENITEZ, J. A.; PADOVESE, L. R. \& SERNAGIRALDO, C. Dependence of the magnetic Barkhausen emission with carbon content in commercial steels Journal Of Materials Science, v. 39, p. 1367-1370, 2004.

CAPO-SANCHEZ, J.; CAMPOS, M. A. \& PADOVESE, L. R. Magnetic Barkhausen measurements for evaluating the formation of Luders bands in carbon steel Ndt \& E International, v. 40, p. 520-524, 2007.

CAPO-SANCHEZ, J.; PADOVESE, L. R. Magnetic Barkhausen noise measurement by resonant coil method. Journal Of Magnetism And Magnetic Materials, v. 321, p. L57-L62, 2009.

CALLISTER, W. D. WILEY, J. \& Sons, I. (ed.) Materials Science and Enginering An Introduction John Wiley and Sons, Inc., 2007.

CHIKAZUMI, S. \& CHARAP, S. H. Press, O. U. (ed.) Physics of ferromagnetism Oxford University Press, 1997.

CUNHA, D.M., Caractarização de tecidos mamários a través de modelos estatísticos utilizando espalhamento de raios-x, Tese (Mestrado). Faculdade de Filosofia Ciências e Letras de Ribe irão Preto - Universidade de São Paulo, 2006. 
CULLITY, B. D. \& GRAHAM, C. D. Wiley, J. \& Sons (ed.) Introduction to Magnetic Materials J Wiley and Sons, 2008.

DIRAISON, Y. L.; JOUBERT P.; PLACKO, D. Characterization of subsurface defects in aeronautical riveted lap-joints using multi-frequency eddy current immaging. NDT\&E International, V. 42, p. 133-140, 2009.

DOBMAN, G.; MEYENDORF, N. \& SCHNEIDER, E. Nondestructive characterization of materials - A growing demand for describing damage and servicelife-relevant aging processes in plant components Nuclear Engineering and Design, v. 171, p. 91-112, 1997.

DURIN, G. \& ZAPPERI, S. Scaling exponents for Barkhausen avalanches in polycrystalline and amorphous ferromagnets Physical Review Letters, v. 84, p. 47054708, 2000.

ESTefanitA, C. G.; ATHERTON, D. L. \& CLAPHAM, L. Plastic Versus Elastic Deformation Effects on Magnetic Barkhausen Noise in Steel Acta Materialia, v. 48, p. 3545-3551, 2000.

EWALD, H. \& SCHACHT, J. Surface condition monitoring of unalloyed steel sheet by measuring ferromagnetic properties and using multiparameter data analysis NDT\&E International, v. 27 (5), p. 249-253, 1994.

FARIAS, A. R. Caracterização do ruído magnético de barkhausen em materiais estruturais utilizando transformada wavelet. Dissertação (Mestrado) - Comissão Nacional de Energia Nuclear - Centro de Desenvolvimento da Tecnologia Nuclear, 2005.

FRANCO, F. A. Desenvolvimento de ensaio não destrutivo baseado no ruído magnético de barkhausen para caracterização de tensões elásticas e deformações plásticas em aços. Tese (Doutorado). Escola Politécnica - Universidade de São Paulo, 2010. 
GIRALDO, C. P. S. \& PADOVESE, L. R. El ruido magnético de Barkhausen: un método de END parra monitorear microestructuras en uniones soldadas, Scientia Et Technica, v. XIII - 36, p. 527-53, 2007.

HAIR, J. F. J.; ANDERSON, R. E.; TATHAM, R. L. \& BLACK, W. C. OTERO, A. Análisis Multivariante, Prentice Hall, 1999.

HOLGERSSON, M. The limited value of cophenetic correlation as a clustering criterion Pattern Recognition, v. 10, p. 287-295, 1978.

HWANG, D. G. \& KIM, H. C. The Influence Of Plastic-Deformation On Barkhausen Effects And Magnetic-Properties In Mild-Steel Journal Of Physics DApplied Physics, v. 21, p. 1807-1813, 1988.

HUANG, J. Y.; QUI, Y. B.; Guo, X. P. Cluster and discriminant analysis of electrochemical noise statistical parameters. Electrochimica Acta, v. 54, p. 22182223, 2009.

JAGADISH, C.; CLAPHAM, L.; ATHERTON, L. Influence of uniaxial elastic stress on power spectrum and pulse height distribution of surface Barkhausen noise in pipeline steel. IEE Transactions On Magnetics, v. 26 (3), p. 1160-1163, 1990.

JILES, D. C. The Effect Of Stress On Magnetic Barkhausen Activity In Ferromagnetic Steels leee Transactions On Magnetics, v. 25, p. 3455-3, 1989.

Dynamics of domain magnetization and the Barkhausen effect. Czechoslovak Journal Of Physics, v. 50 (8), p. 893-988, 2000.

W. Prentice Hall, 6a. (ed.) Applied Multivariate Statistical Analysis Prentice Hall, 2007.

JOHNSON, R. A. \& WICHERN, D. W. Prentice Hall, I. (ed.) Applied Multivariate Statistical Analysis Prentice Hall, 2001. 
KAMEDA, J. \& RANJAN, R. Nondestructive Evaluation Of Steels Using Acoustic And Magnetic Barkhausen Signals .1. Effect Of Carbide Precipitation And Hardness Acta Metallurgica, v. 35, p. 1515-1526, 1987

FOLL, H., Electronic Materials, University of Kiel, Faculty of Enginieering, 2009, Disponível em: http://www.tf.uni-kiel.de/matwis/amat/elmat_en/index.html

KRAUSE, T. W.; PATTANTYUS, A. \& ATHERTON, D. L. Investigation Of StrainDependent Magnetic Barkhausen Noise In Steel leee Transactions On Magnetics, v. 31, p. 3376-3378, 1995.

KRAUSE, T. W.; ClAPHAM, L.; PATTANTYUS, A. \& ATHERTON, D. L. Investigation of the stress-dependent magnetic easy axis in steel using magnetic Barkhausen noise Journal Of Applied Physics, v. 79, p. 4242-42, 1996.

MAASS, P. et al. Detection and classification of material attributes - a practical application of wavelet analysis. IEEE Transactions On Signal Processing, v. 48 (8), p. 2432-2438, 2000.

MARTINS, C. O. D. Desenvolvimento de Tecnologias de Inspeção e Monitoramento de Risers Flexíveis através de Técnicas Micromagnéticas de Análise de Tensões Escola de Engenharia - Universidade Federal de Rio Grande do Sul, 2008.

MAHALANOBIS, P. C. On the generalised distance in statistics Proceedings of the National Institute of Sciences of India, v. 2 (1), p. 49-55, 1936.

MANDACHE, C.; KRAUSE, T. W. \& CLAPHAM, L. Investigation of optimum field amplitude for stress dependence of magnetic barkhausen noise leee Transactions On Magnetics, v. 43, p. 3976-3983, 2007.

MINGOTI, S. A. UFMG, E. (ed.) Análise de dados através de métodos de Estatística Multivariada : Uma abordagem aplicada Universidade Federal de Minas Gerais, 2005 
MITRA, A.; GOVINDARAJU, M. \& JILES, D. Influence of microstructure on micromagnetic barkhausen emissions in aisi-4140 steel ieee transactions on magnetics, v. 31, p. 4053-40, 1995.

MOORTHY, V.; VAIDYANATHAN, S.; JAYAKUMAR, T. \& RAJ, B. On the influence of tempered microstructures on magnetic Barkhausen emission in ferritic steels Philosophical Magazine A-Physics Of Condensed Matter Structure Defects And Mechanical Properties, v. 77, p. 1499-151, 1998.

et al. Evaluation of applied and residual stresses in casecarburised En36 steel subjected to bending using the magnetic Barkhausen emission technique. Acta Materialia, v. 52, n. 7, p. 1927-1936, 2004.

. et al. Magnetic Barkhausen emission technique for detecting the overstressing during bending fatigue in case-carburised En36 steel. Ndt \& E International, v. 38, n. 2, p. 159-166, 2005.

et al. Magnetic Barkhausen emission technique for evaluation of residual stress alteration by grinding in case-carburised En36 steel. Acta Materialia, v. 53, n. 19, p. 4997-5006, 2005.

. et al. Surface and subsurface stress evaluation in case-carburised steel using high and low frequency magnetic Barkhausen emission measurements. Journal of Magnetism and Magnetic Materials, v. 299, n. 2, p. 362-375, 2006.

NORMANDO, P. G.; MOURA, E. P.; SOUZA, J. A.; TAVAREZ, S. M. \& PADOVESE, L. R. Ultrasound, eddy current and magnetic Barkhausen noise as tools for sigma phase detection on a UNS S31803 duplex stainless steel Materials Science And Engineering A-Structural Materials Properties Microstructure And Processing, v. 527, p. 2886-2891, 2010.

OKSANEN, J. Cluster Analisys: Tutorial with R, 2010, Disponível em: http://cc.oulu.fi/ jarioksa/opetus/metodi/sessio3.pdf 
OHANDLEY, R. C. WILEY, J. \& Sons (ed.) Modern magnetic materials: principles and applications J Wiley and Sons, 2000.

O'SULLIVAN, D.; COTTERELL, M.; TANNER, D. A. \& MÉSZAROS, I. Characterization of ferritic stainless steel by Barkhausen techniques NDT\&E International, v. 37, p. 489-496, 2004.

[PADOVESE,2009] Padovese, L. R.; Martin, N. \& Millioz, F. Time-frequency and time-scale analysis of Barkhausen noise signals. Proceedings Of The Institution Of Mechanical Engineers Part G-Journal Of Aerospace Engineering, v. 223, p. 577$588,2009$.

[PADOVESE,2010] PADOVESE, L. R.; DA SILVA, F. E.; MOURA, E. P. \& GONÇALVES, L. L. Characterization of Microestrutural Changes in Coarse FerriticPearlitic Stainless Steel Through the Statistical Fluctuation and Fractal Analisys of Barkhausen Noise. Review of Quantitative Nondestructive Evaluation, v. 29, p. 12931299, 2010.

PEREZ-BENITEZ, J. A.; PADOVESE, L. R.; CAPO-SANCHEZ, J. \& ANGLADARIVERA, J. Investigation of the magnetic Barkhausen noise using elementary signals parameters in 1000 commercial steel Journal Of Magnetism And Magnetic Materials, v. 263, p. 72-7, 2003.

PEREZ-BENITEZ, J. A.; CAPO-SANCHEZ, J. \& PADOVESE, L. R. Characterization of angular dependence of macroscopic magnetic properties in ASTM 36 steel using magnetic Barkhausen noise Ndt \& E International, v. 40, p. 284288, 2007.

[PIOTROWSKI,2008] PIOTROWSKI, L. et al. An in-depth study of the barkhausen emission signal properties of the plastically deformed $\mathrm{Fe}-2 \% \mathrm{Si}$ ally. IEEE TRANSANCTIONS ON MAGNETICS, v. 44, p. 3828-3831, 2008. 
RANJAN, R.; JILES, D. C.; BUCK, O. \& THOMPSON, R. B. Grain-Size Measurement Using Magnetic And Acoustic Barkhausen Noise Journal Of Applied Physics, v. 61, p. 3199-32, 1987.

RANJAN, R.; JILES, D. C. \& RASTOGI, P. K. Magnetic-Properties of Decarburized Steels - An Investigation Of The Effects Of Grain-Size And Carbon Content leee Transactions On Magnetics, v. 23, p. 1869-1876, 1987a.

[RODRIGUEZ,2008] Rodriguez, J. L.; Perez-Benitez, J. A.; Capo-Sanchez, J.; Padovese, L. R. \& Betancourt-Riera, R. Dependence of Barkhausen jump shape on microstructure in carbon steel. Revista Mexicana De Física, v. 54, 127-129, 2008.

SANTI, L.; VIEGAS, A. D. C.; DE-ANDRADE, A. M. H.; SOMMER, R. L.; GROSSINGER, R. \& TURTELLI, R. S. Barkhausen noise measurements in Finemet type materials Journal Of Magnetism And Magnetic Materials, v. 226, p. 1484-1486, 2001.

SANTI, L.; BOHN, F.; VIEGAS, A. D. C.; DURIN, G.; MAGNI, A.; BONIN, R.; ZAPPERI, S. \& SOMMER, R. L. Effects of thickness on the statistical properties of the Barkhausen noise in amorphous films Physica B-Condensed Matter, v. 384, p. 144-146, 2006.

SAQUET, O.; CHICOIS, J. \& VINCENT, A. Barkhausen noise from plain carbon steels: analysis of the influence of microstructure Materials Science And Engineering A-Structural Materials Properties Microstructure And Processing, v. 269, p. 73-8, 1999.

SAWADA, H. Statistical study of the Barkhausen effect part II, relation between domain size and internal stress. Journal of the Physical Society of Japan, v. 7, p. 571-574, 1952.

SNEATH, P.H.A., The evaluation of cluster methods, Numerical Taxonomy, London: Academic Press., 1957. 
DA SILVA, I. C.; DA SILVA, R. S.; REBELLO, J. M. A.; BRUNO, A. C. \& SILVEIRA, T. F. Characterization of carburization of HP steels by non destructive magnetic testing Ndt \& E International, v. 39, p. 569-577, 2006.

SHIZHAO, Arquivo: File:Boxplot vs PDF.png., 2006., em http://en.wikipedia.org/wiki/File:Boxplot_vs_PDF.png. Acesso em 01.12.2011.

SIPAHI, L. B. Overview Of Applications Of Micromagnetic Barkhausen Emissions As Noninvasive Material Characterization Technique Journal Of Applied Physics, v. 75, p. 6978, 1994.

SOPHIAN, A.; TIAN, G. Y.; TAYLOR, D.; RUDLIN, J. A feature extraction technique based on principal component analysis for pulsed Eddy current NDT. NDT\&E International, v. 36, p. 37-41, 2003.

SUNDSTROM, O. \& TORRONEN, K. Use Of Barkhausen Noise-Analysis In Nondestructive Testing Materials Evaluation, v. 37, p. 51-56, 1979.

TRIOLA, M. F. LTC (ed.) Introdução à Estatística, Ltc. Editores, 2005.

TSUCHIDA, Y.; ANDO, T.; ENOKIZONO, M. Stress evaluation of steel plates by chaos of Barkhausen noise, IEE Transactions On Magnetics, v. 38 (5), p. 3210-3212, 2002.

VIEIRA, Edson de O. et al . Avaliação da contaminação do carbofuran nos solos do Distrito de Irrigação do Gorutuba. Rev. bras. eng. agríc. ambient., Campina Grande, v. 13, n. 3, June 2009.

VILLARDON, J. L. V.; Análisis Discriminante: Introducción; Inspección de Matrices de Datos Multivariados, Curso de Doctorado 2008 - Universidad de Salamanca, Grupo de Estatística Aplicada; em:

http://biplot.usal.es/DOCTORADO/3CICLO/BIENIO-0608/MetodosClasicos/MetodosClasicos.php ; Accesso em janeiro 11 de 2011. 
YANG, D. X.; KANKOLENSKI, K. P.; HUA, S. Z.; SWARTZENDRUBER, L. J. \& CHOPRA, H. D. Evaluation of Mechanical Properties of Magnetic Materials Using Non-Destructive Method IEEE Transactions On Magnetics, v. 37, p. 2758-2760, 2001.

YAKAMURA, S.; FURYA, Y.; WATANABE, T., Acta Materialia, v. 49, p. 3019, 2001. 


\section{APÊNDICE A - Regra de discriminação para várias populações}

Os modelos matemáticos envolvidos no cálculo da função discriminante para o caso de várias populações é descrito de forma detalhada por (JOHNSON\&WICHERN,2001). Os autores desenvolvem inicialmente o equacionamento para o caso onde as matrizes de covariâncias das populações do grupo de treinamento são diferentes (gerando o modelo discriminante quadrático) e, posteriormente, com a hipótese de homocedasticidade (matrizes de covariâncias iguais), é obtido o modelo discriminante linear ao ser eliminados os componentes quadráticos do equacionamento inicial. A seguir é descrito o equacionamento para 0 modelo quadrático e linear respectivamente:

Alocar x para a classe $\pi_{k}$ se $\mathrm{O}$ escore quadrático

$$
\widehat{d}_{k}^{Q}(\mathbf{x})=\operatorname{máximo}\left(\widehat{d}_{1}^{Q}(\mathbf{x}), \widehat{d}_{2}^{Q}(\mathbf{x}), \ldots, \widehat{d}_{g}^{Q}(\mathbf{x}) \quad 3\right.
$$

Onde

$$
\hat{d}_{i}^{Q}(\mathbf{x})=-\frac{1}{2} \ln \left|S_{i}\right|-\frac{1}{2}\left(\mathbf{x}-\mathbf{x}_{i}\right) S_{i}^{-1}\left(\mathbf{x}-\mathbf{x}_{i}\right)+\ln p_{i}, i=1,2, \ldots \quad 4
$$

Uma simplificação é possível se as matrizes de covariâncias populacionais, $\Sigma_{i}$, são iguais. Quando $\Sigma_{i}=\Sigma$, para $i=1,2, \ldots, g$, o escore discriminante é definido como:

$$
d_{i}^{Q}(\mathbf{x})=-\frac{1}{2} \ln |\Sigma|-\frac{1}{2} \mathbf{x} \Sigma^{-1} \mathbf{x}+\mu_{i}^{\prime} \Sigma^{-1} \mathbf{x}-\frac{1}{2} \mu_{i}^{\prime} \Sigma^{-1} \mu_{i}+\ln p_{1} 4
$$

Os dois primeiros termos são os mesmos para $d_{1}^{Q}(\mathbf{x}), d_{2}^{Q}(\mathbf{x}), \ldots, d_{g}^{Q}(\mathbf{x})$, e, conseqüentemente, estes podem ser ignorados para propósitos de alocação. Os 
demais termos consistem de uma constante $C_{i}=\ln p_{i}-\frac{1}{2} \mu_{i} \Sigma^{-1} \mu_{i}$ e a combinação linear das componentes de $\mathbf{x}$.

A seguir é definido o escore discriminante linear:

$$
d_{i}(\mathrm{x})=\mu_{i} \Sigma^{-1} \mathrm{x}-\frac{1}{2} \mu_{i} \Sigma^{-1} \mu_{i}+\ln p_{i}, i=1,2, \ldots, \quad 4
$$

Uma estimativa $\hat{d}_{i}(\mathrm{x})$ do escore discriminante linear $d_{i}(\mathrm{x})$ é baseado na estimativa da matriz de covariâncias amostral combinada $\Sigma$.

$$
S_{p \times p}=\frac{\left(n_{1}-1\right) S_{1}+\left(n_{2}-1\right) S_{2}+\ldots+\left(n_{g}-1\right) !}{\left(n_{1}+n_{2}+\ldots+n_{g}\right)-g} \quad 4
$$




\section{APÊNDICE B - Passos a seguir na validação cruzada para erros de classificação aplicados em analises discriminantes}

Passo 1: retira-se um vetor de observações do conjunto de dados e utilizam-se (n-1) elementos amostrais restantes para construir a função de discriminação;

Passo 2: utiliza-se a regra de discriminação construída no passo 1 para classificar o elemento que ficou à parte da construção da regra de discriminação, verificando se a regra de discriminação conseguiu acertar na sua real procedência ou não;

Passo 3: retorna-se o elemento amostral que foi retirado no passo 1 à amostra original e retira-se um outro elemento amostral diferente do primeiro. Os passoss $1 \mathrm{e}$ 2 são repetidos.

Os passos 1, 2, e 3 devem ser repetidos para todos os elementos da amostra e os erros de do tipo 1 e 2 de classificações incorretas são estimadas respectivamente por:

$$
\hat{p}(2 \mid 1)=\frac{n_{12}}{n_{1}} \text { e } \hat{p}(1 \mid 2)=\frac{n_{21}}{n_{2}}
$$




\section{APÊNDICE C - Dendograma método de ligação completa}

Ligação completa

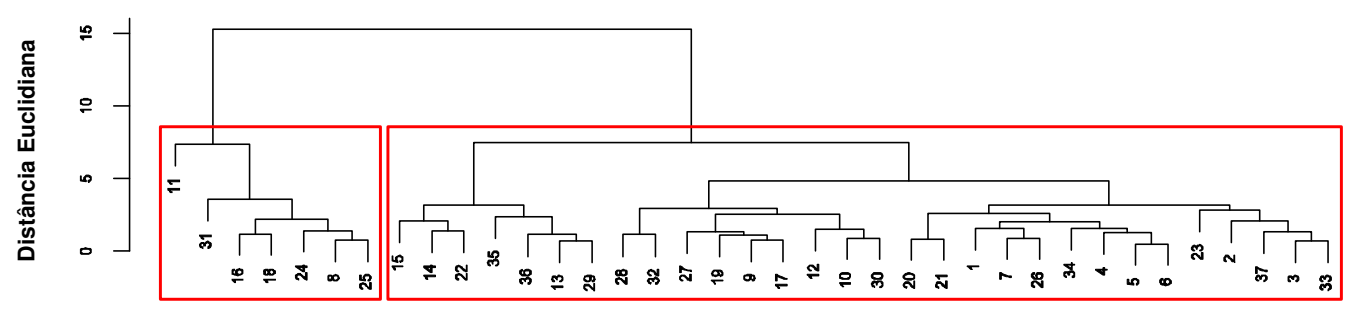

Sensores

Ligação completa

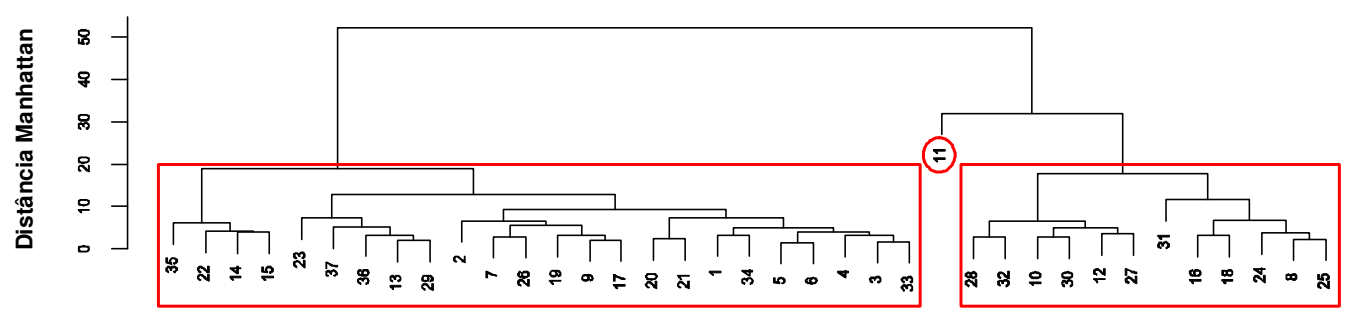

Sensores

Ligação completa

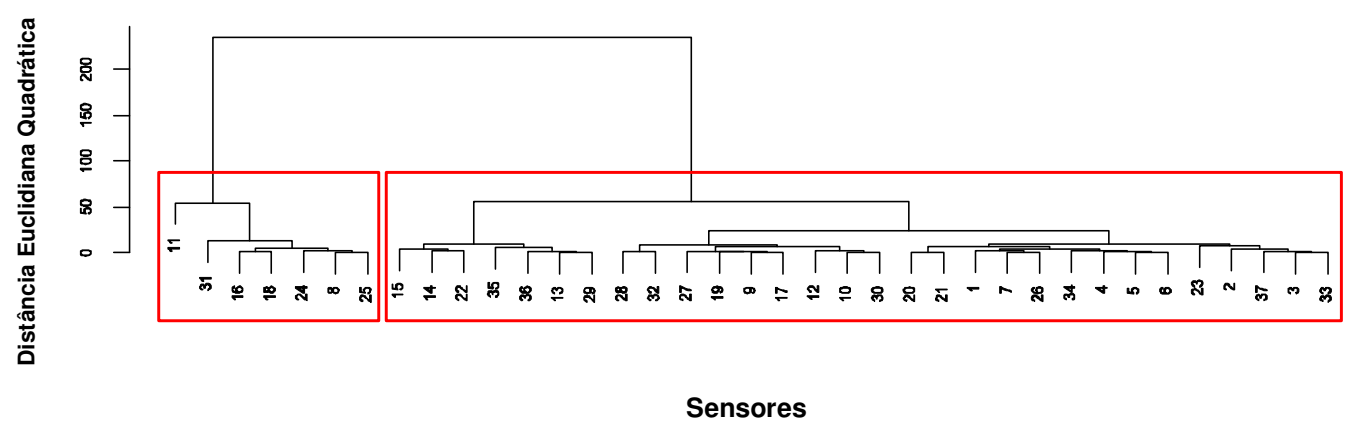


APÊNDICE D - Dendograma método de ligação simples

Ligação simples

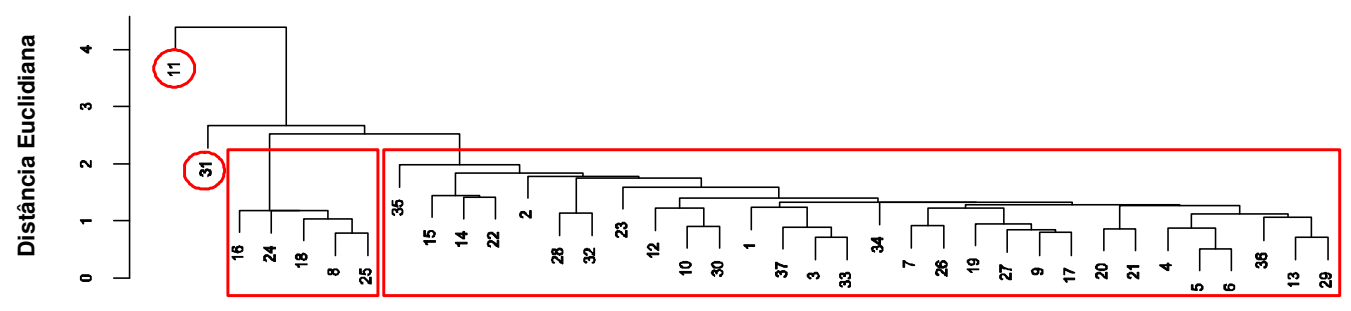

Sensores

Ligação simples

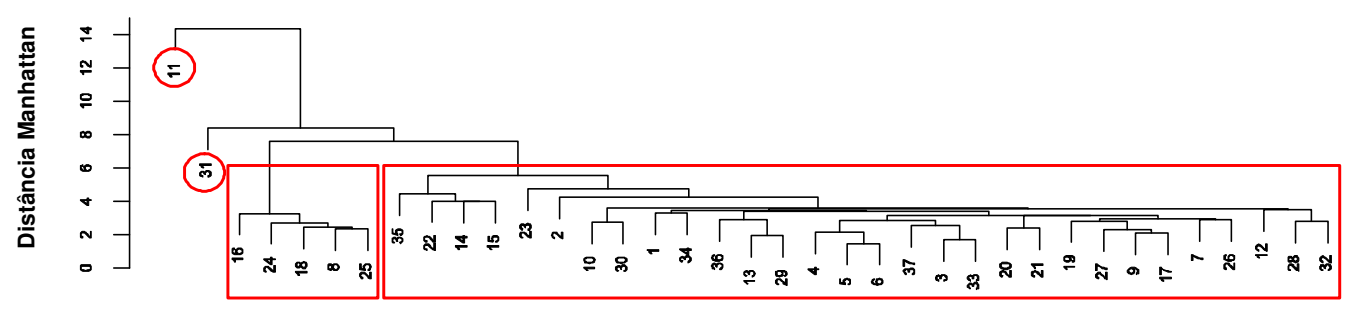

Sensores

Ligação simples

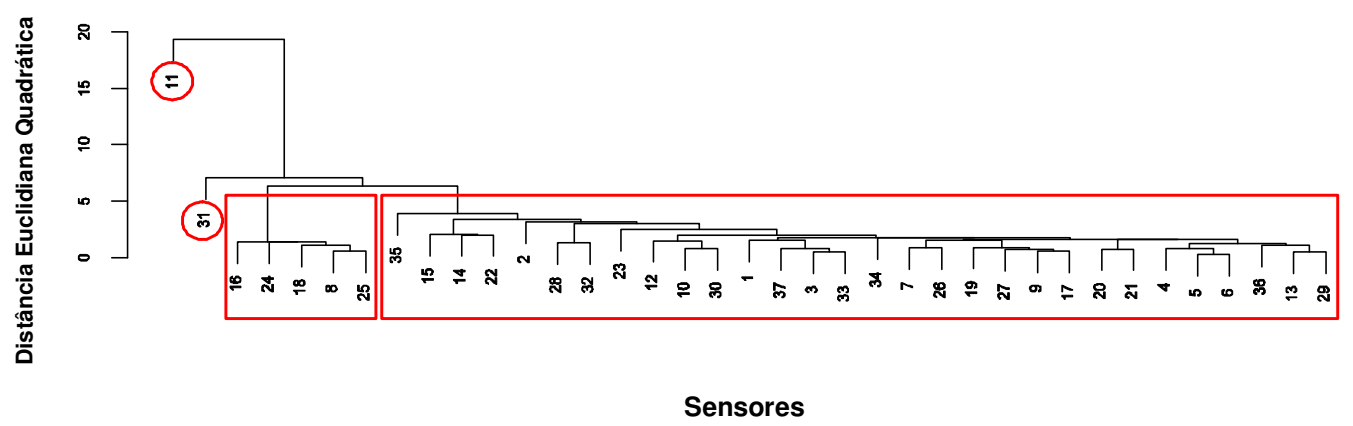




\section{APÊNDICE F - DENDOGRAMA MÉTODO DE LIGAÇÃO DA MEDIA DAS DISTÂNCIAS}

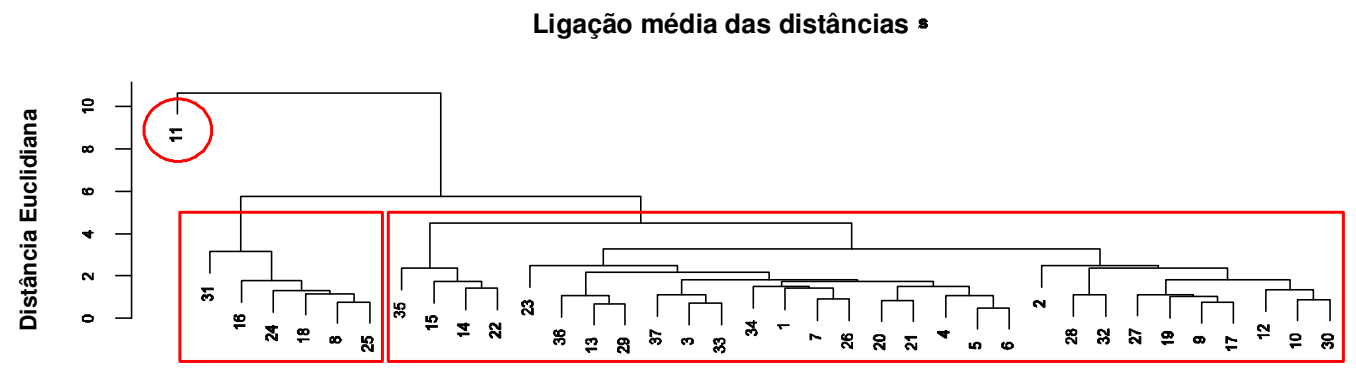

Sensores

Ligação média das distâncias .

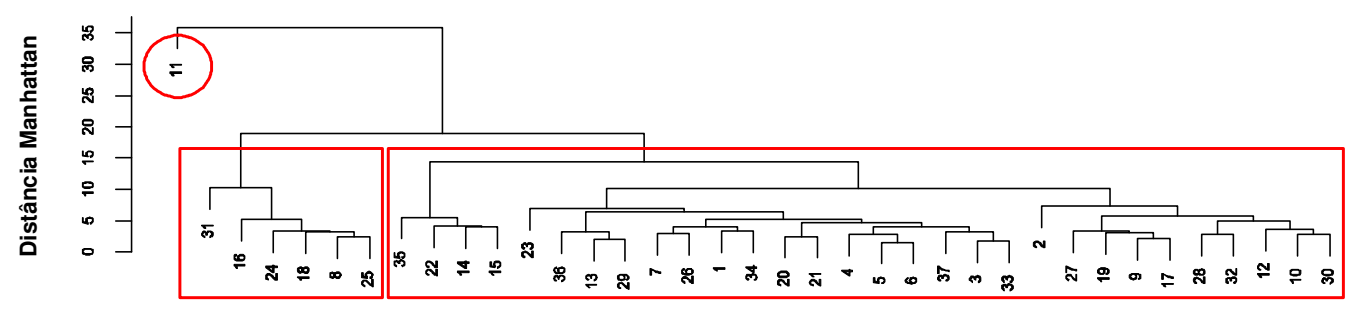

Sensores

Ligação média das distâncias '

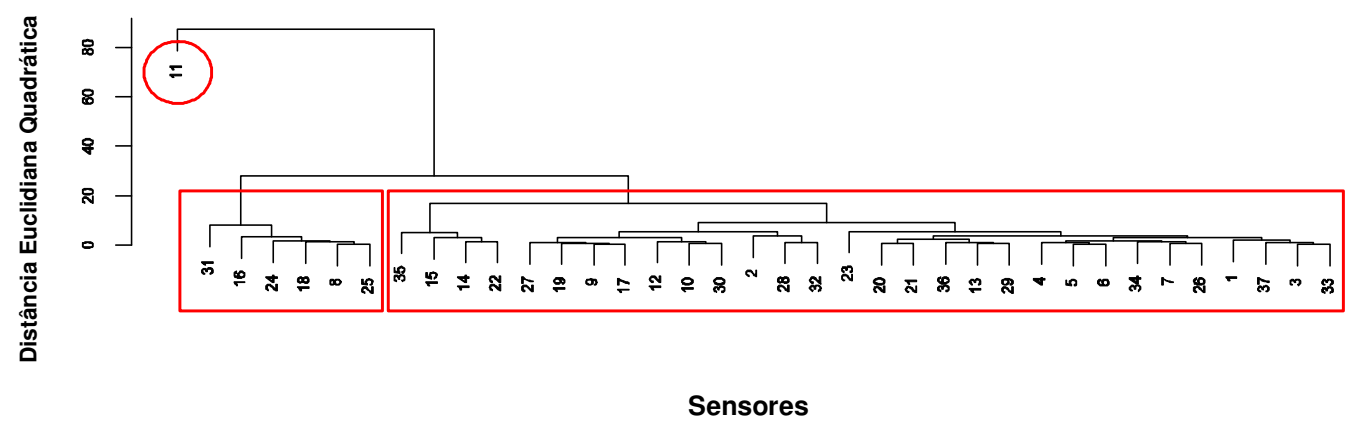


APÊNDICE G - Dendograma método dos centroides

Centróides

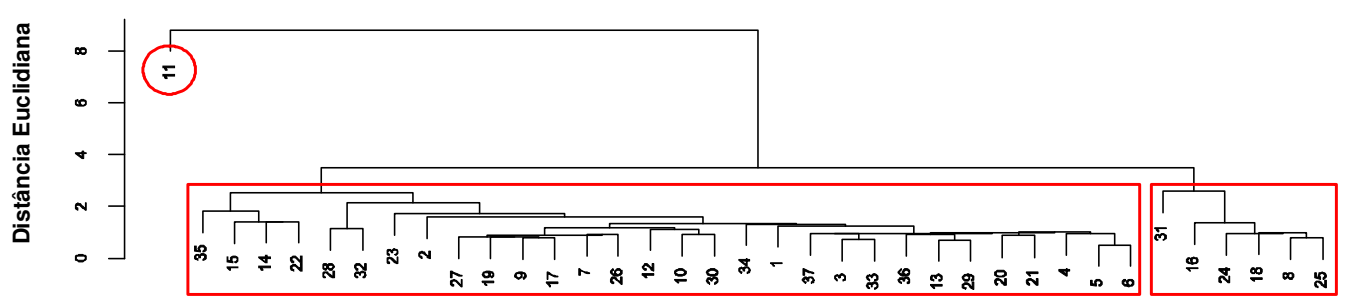

Sensores

Centróides

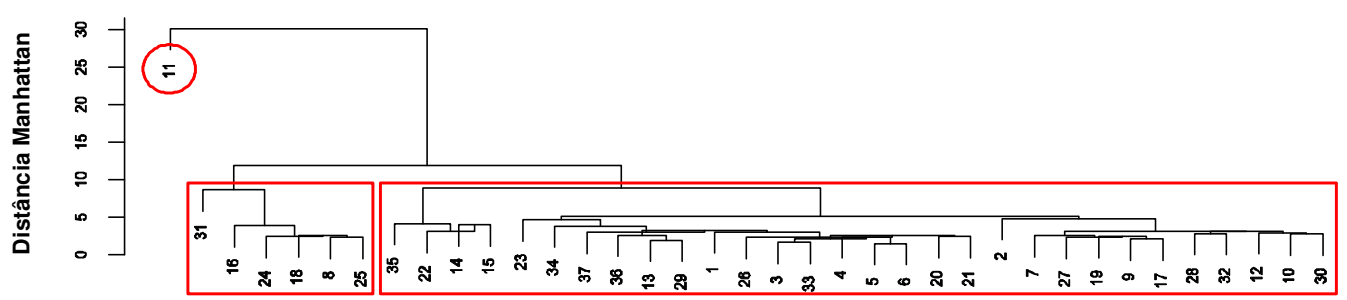

Sensores

Centróides

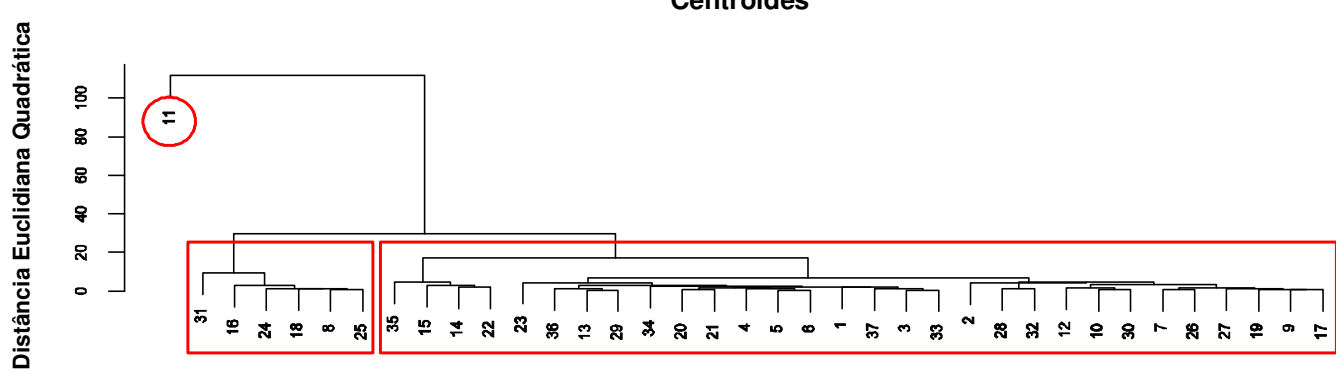

Sensores 
APÊNDICE H - Dendograma método da ligação simples

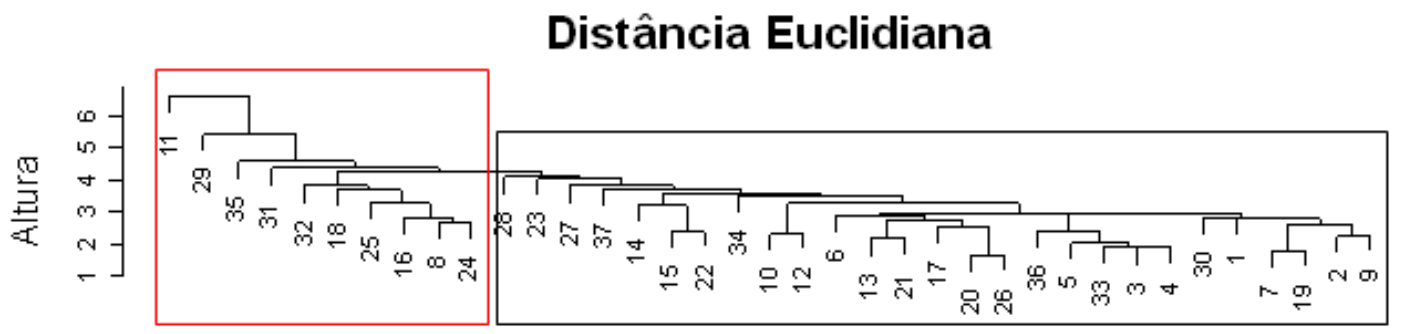

Sensores

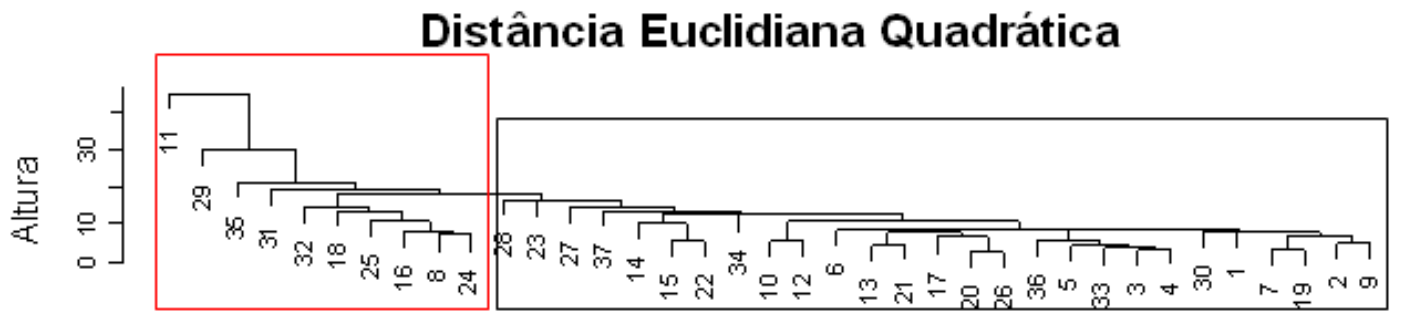

Sensores

\section{Distância City-block}

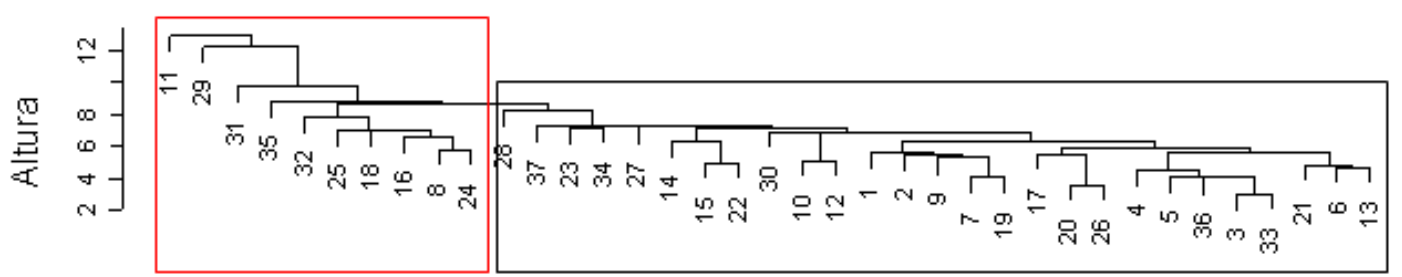




\section{APÊNDICE I - DENDOGRAMA MÉTODO DA LIGAÇÃO COMPLETA}

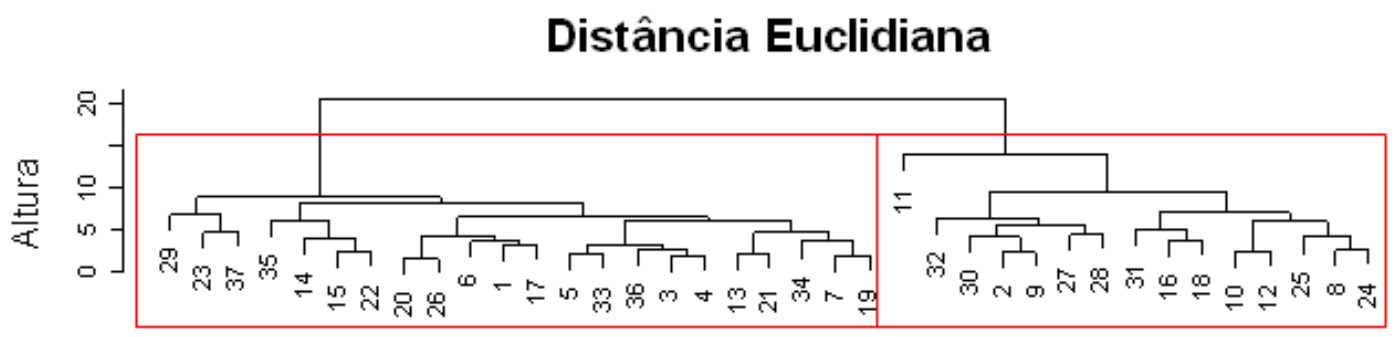

Sensores

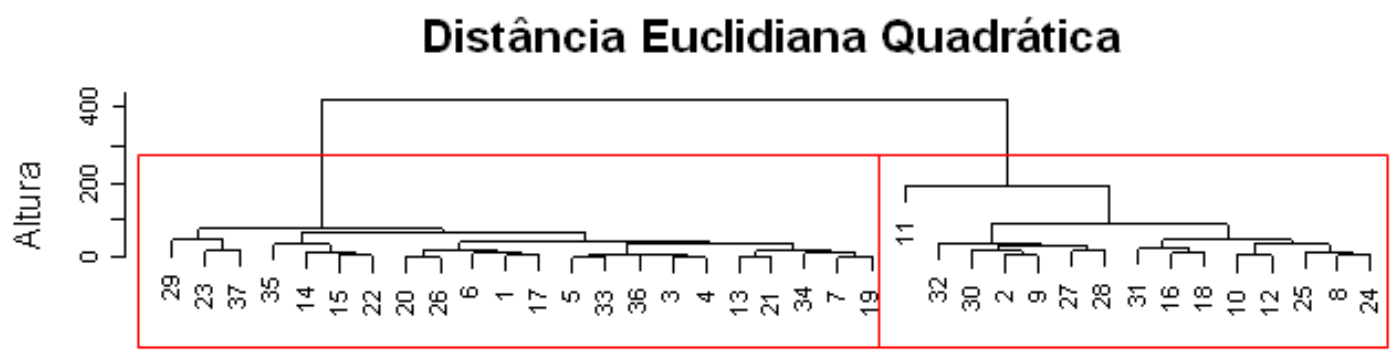

Sensores

\section{Distância City-block}

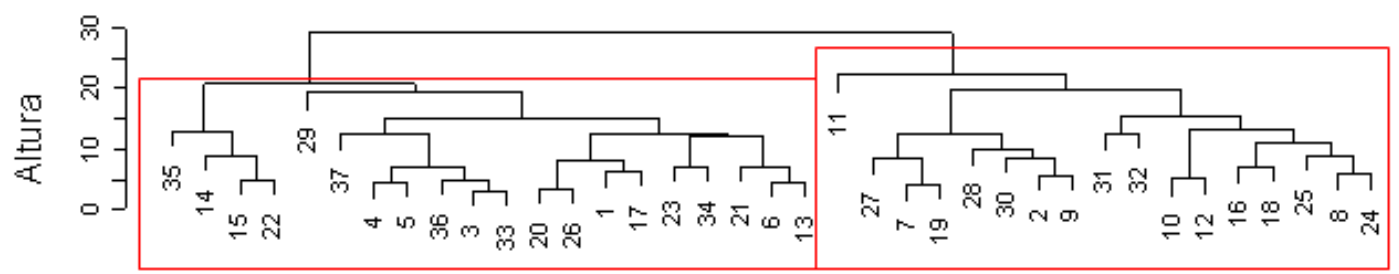




\section{APÊNDICE J - Dendograma método McQuitty}

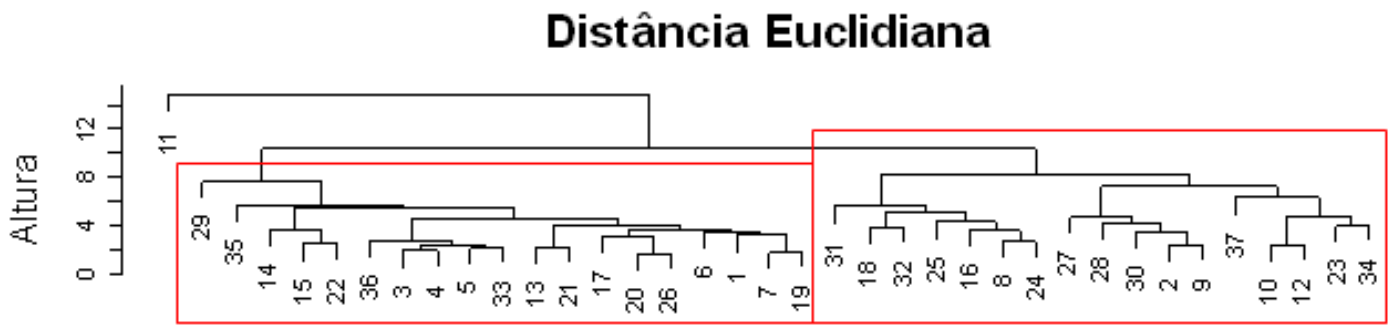

Sensores

Distância Euclidiana Quadrática

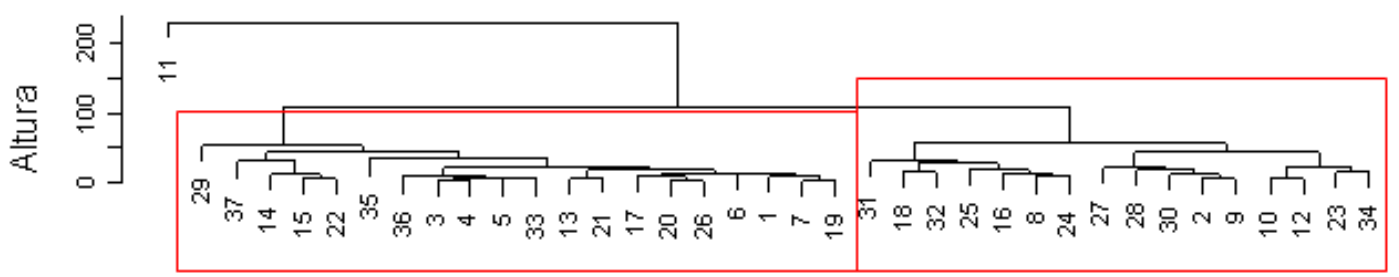

Sensores

\section{Distância City-block}

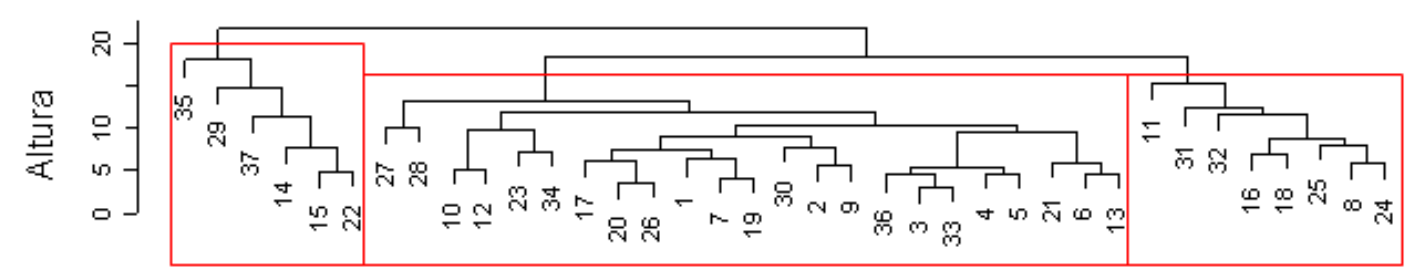




\section{APÊNDICE K - DENDOGRAMA MÉTODO DOS CENTROIDES}

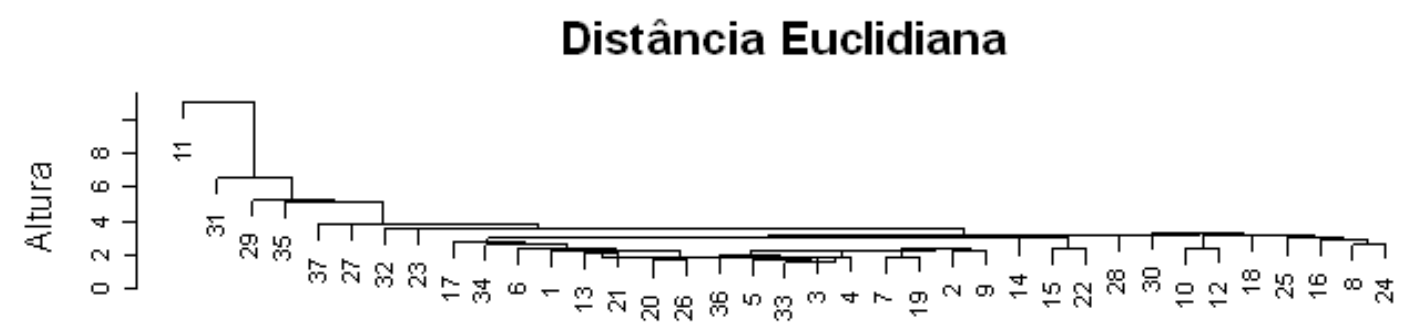

Sensores

Distância Euclidiana Quadrática

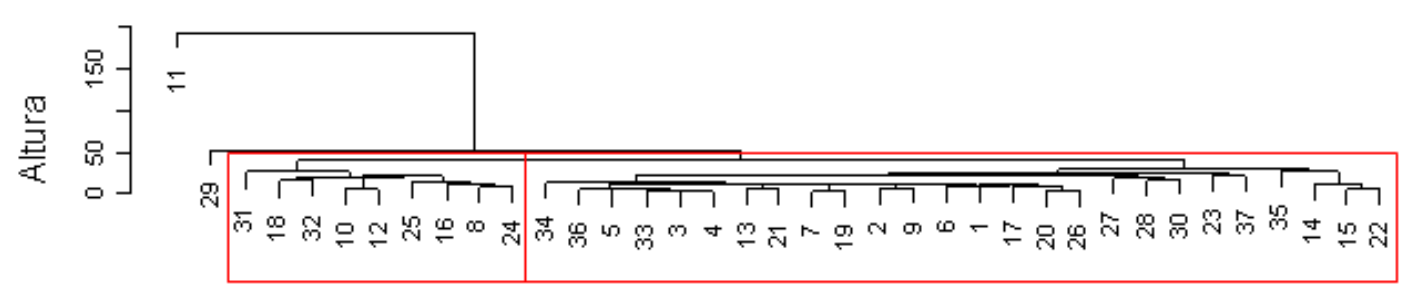

Sensores

Distância City-block

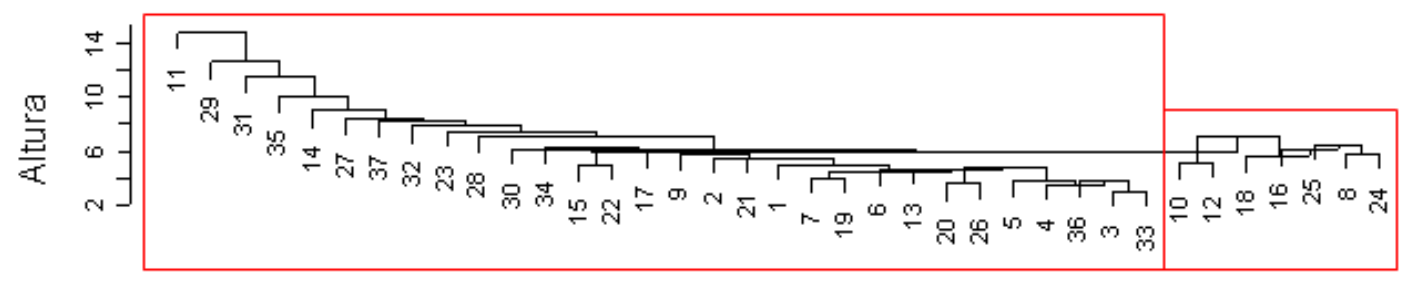




\section{APÊNDICE L - DENDOGRAMA MÉTODO DA LIGAÇÃO DAS MEDIANAS}

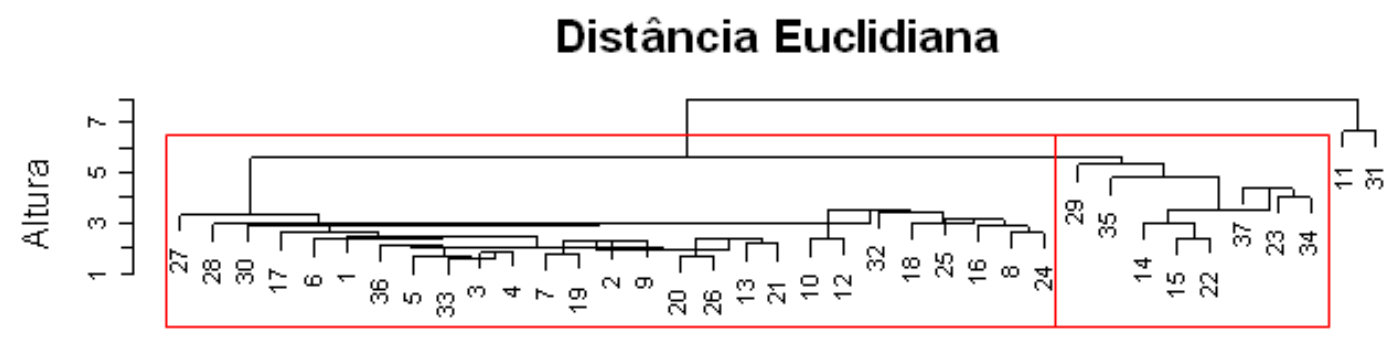

Sensores

Distância Euclidiana Quadrática

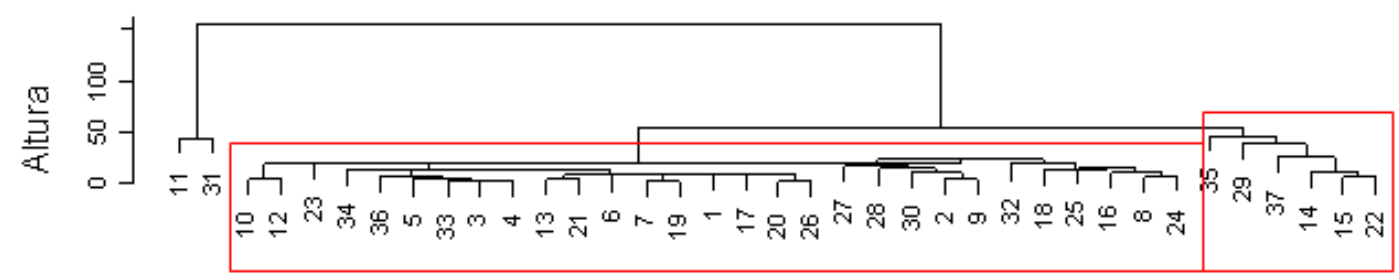

Sensores

Distância City-block

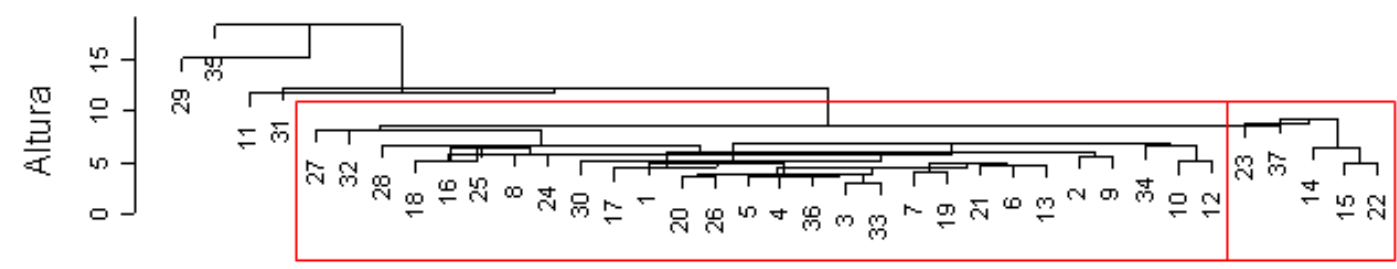

Sensores 


\section{ANEXO A - Teste Lambda de Wilks}

INFORMATION POINT:

Wilks' lambda

Further reading
Wilks' lambda is a test statistic used in multivariate analysis of variance (MANOVA) to test whether there are differences between the means of identified groups of subjects on a combination of dependent variables. For example, in the paper above, the authors test whether the mean score of two groups, graduates and diplomates, is the same across eight constructs simultaneously. Thus, they are considering eight dependent variables and comparing the mean of this combination for two groups.

Wilks' lambda performs, in the multivariate setting, with a combination of dependent variables, the same role as the $F$-test performs in one-way analysis of variance. Wilks' lambda is a direct measure of the proportion of variance in the combination of dependent variables that is unaccounted for by the independent variable (the grouping variable or factor). If a large proportion of the variance is accounted for by the independent variable then it suggests that there is an effect from the grouping variable and that the groups (in this case the graduates and diplomates) have different mean values.

Wilks' lambda statistic can be transformed (mathematically adjusted) to a statistic which has approximately an $F$ distribution. This makes it easier to calculate the $P$-value. Often authors will present the $F$-value and degrees of freedom, as in the above paper, rather than giving the actual value of Wilks' lambda.

There are a number of alternative statistics that can be calculated to perform a similar task to that of Wilks' lambda, such as Pillai's trace criterion and Roy's ger criterion; however, Wilks' lambda is the most widely used. Everitt \& Dunn (1991) and Polit (1996) provide more detail about the use and interpretation of Wilks' lambda.

Everitt B.S. \& Dunn G. (1991) Applied Multivariate Data Analysis. Edward Arnold. London. pp. 219-220.

Polit D.F. (1996) Data Analysis and Statistics for Nursing Research. Appleton and Lange, Stamford, Connecticut. pp. 320-321.

NICOLA CRICHTON

Versão original disponível em:

http://www.blackwellpublishing.com/specialarticles/jcn_9_381.pdf 


\section{Appendix 14: Box's M Test}

Box's $M$ statistic is used to test for homogeneity of covariance matrices. The $j$ th set of $r$ dependent variables in the ith cell are $y_{i j}^{\prime}=x_{i j}^{\prime} \mathbf{B}+e_{i j}^{\prime}$ where $e_{i j} \sim N_{r}\left(0, w_{i j}^{-1} \Sigma_{i}\right)$ for $i=1, \ldots, g$ and $i=1, \ldots, n_{i}$. The null hypothesis of the test for homogeneity of covariance matrices is $H_{a}: \Sigma_{1}=\cdots=\Sigma_{g}$. Box (1949) derived a test statistic based on the likelihood-ratio test. The test statistic is called Box's $M$ statistic. For moderate to small sample sizes, an $F$ approximation is used to compute its significance.

Box's $M$ statistic is not designed to be used in a linear model context; therefore the observed cell means are used in computing the statistic.

\section{Notation}

The following notation is used throughout this chapter, unless otherwise stated:

$g$ Number of cells with non-singular covariance matrices.

$n_{i} \quad$ Number of cases in the th cell.

$n$ Total sample size, $n=n_{1}+\cdots+n_{g}$.

$\mathbf{y}_{i j}$ The $j$ th set of dependent variables in the ith cell. A column vector of length $r$.

$w_{i j} \quad$ Regression weight associated with $\mathbf{y}_{i j}$. It is assumed $w_{i j}>0$.

\footnotetext{
'Although Anderson (1958, Section 10.2) mentioned that the population cell means can be expressed as linear combinations of parameters, he assumed that the combination coefficients are different for different cells, which is not the model assumed for GLM .
} 
2 Appendix 14

\section{Statistics}

Means

$$
\overline{\mathbf{y}}_{i}=\sum_{j=1}^{n_{i}} \mathbf{y}_{i j} / n_{i}
$$

Cell Covariance Matrix

$$
\mathbf{S}_{i}= \begin{cases}\sum_{j=1}^{n_{i}} w_{i j}\left(\mathbf{y}_{i j}-\overline{\mathbf{y}}_{i}\right)\left(\mathbf{y}_{i j}-\overline{\mathbf{y}}_{i}\right)^{\prime} /\left(n_{i}-1\right) & \text { if } n_{i}>1 \\ 0 & \text { if } n_{i} \leq 1\end{cases}
$$

\section{Pooled Covariance Matrix}

$$
\mathbf{S}= \begin{cases}\sum_{i=1}^{g}\left(n_{i}-1\right) \mathbf{S}_{i} /(n-g) & \text { if } n>g \\ 0 & \text { if } n \leq g\end{cases}
$$

Box's $M$ Statistic

$$
M= \begin{cases}(n-g) \log |\mathbf{S}|-\sum_{i=1}^{g}\left(n_{i}-1\right) \log \left|\mathbf{S}_{i}\right| & \text { if }|\mathbf{S}|>0 \\ \text { SYSMIS } & \text { if }|\mathbf{S}| \leq 0\end{cases}
$$




\section{Significance}

$1-\operatorname{CDF} . \mathrm{F}\left(\gamma M, f_{1}, f_{2}\right)$

where CDF.F is the SPSS function for the cumulative $F$ distribution and

$f_{1}=(g-1) r(r+1) / 2$

$\rho=1-\frac{2 r^{2}+3 r-1}{6(r+1)(g-1)}\left(\sum_{i=1}^{g} \frac{1}{\left(n_{i}-1\right)}-\frac{1}{(n-g)}\right)$

$\tau-\frac{(r-1)(r+2)}{6(g-1)}\left(\sum_{i=1}^{g} \frac{1}{\left(n_{i}-1\right)^{2}}-\frac{1}{(n-g)^{2}}\right)$

$f_{2}=\frac{f_{1}+2}{\left|\tau-(1-\rho)^{2}\right|}$

$\gamma=\frac{\left(\rho-f_{1} / f_{2}\right)}{f_{1}}$

The significance is a system-missing value whenever the denominator is zero in the above expression.

\section{References}

Anderson, T. W. 1958. Introduction to multivariate statistical analysis. New York: John Wiley \& Sons, Inc.

Box, G. E. P., 1949. A general distribution theory for a class of likelihood criteria. Biometrika, 36: 317-346.

Seber, G. A. F. 1984. Multivariate observations. New York: John Wiley \& Sons, Inc. (Section 9.2.6).

Versão original disponível em:

http://www.im.ufri.br/flavia/mad484/app14 boxs m.pdf 


\section{ANEXO C - Leitura de arquivos de sinais RMB e cálculo de parâmetros do sinal}

A Seguir é apresentada de forma esquemática a metodologia empregada para a leitura dos arquivos do sinal RMB.

No experimento do riser, foram feitos quatro ciclos de carregamento, para cada ciclo foram aplicados 3 diferentes níveis de carga (80, 150 e 220 toneladas) e, com cada carregamento foi então lido e salvado o arquivo RMB para cada um dos 37 sensores, como mostrado no código de programação apresentado a seguir:

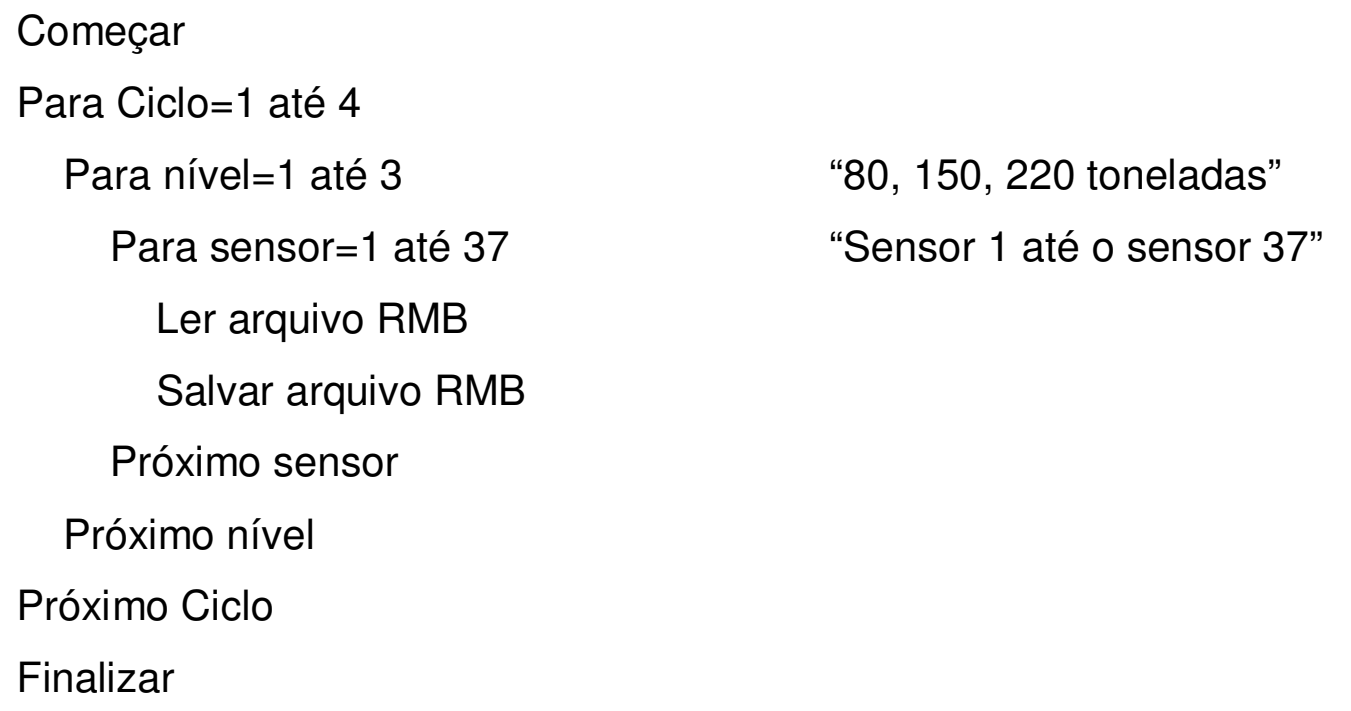

Dessa forma, por cada sensor são lidos e salvados 48 arquivos de sinal RMB. $O$ banco de dados final consta de 5,328 arquivos (1776 arquivos por nível de carregamento). Na Figura 61 é apresentado o esquema do processo de leitura dos arquivos para um sensor qualquer como sugerido no algoritmo descrito acima.

Na Tabela 38 são apresentados os cálculos dos parâmetros do sinal RMB para cada um dos arquivos de sinal lidos no sensor No. 1, assim como indicado no diagrama da Figura 61. A partir desses dados é calculado o valor médio de cada parâmetro como sugerido na fórmula a seguir: 
$\overline{\text { Parâmetro }}=\sum_{i=1}^{48}$ Parâmetro $_{i}$

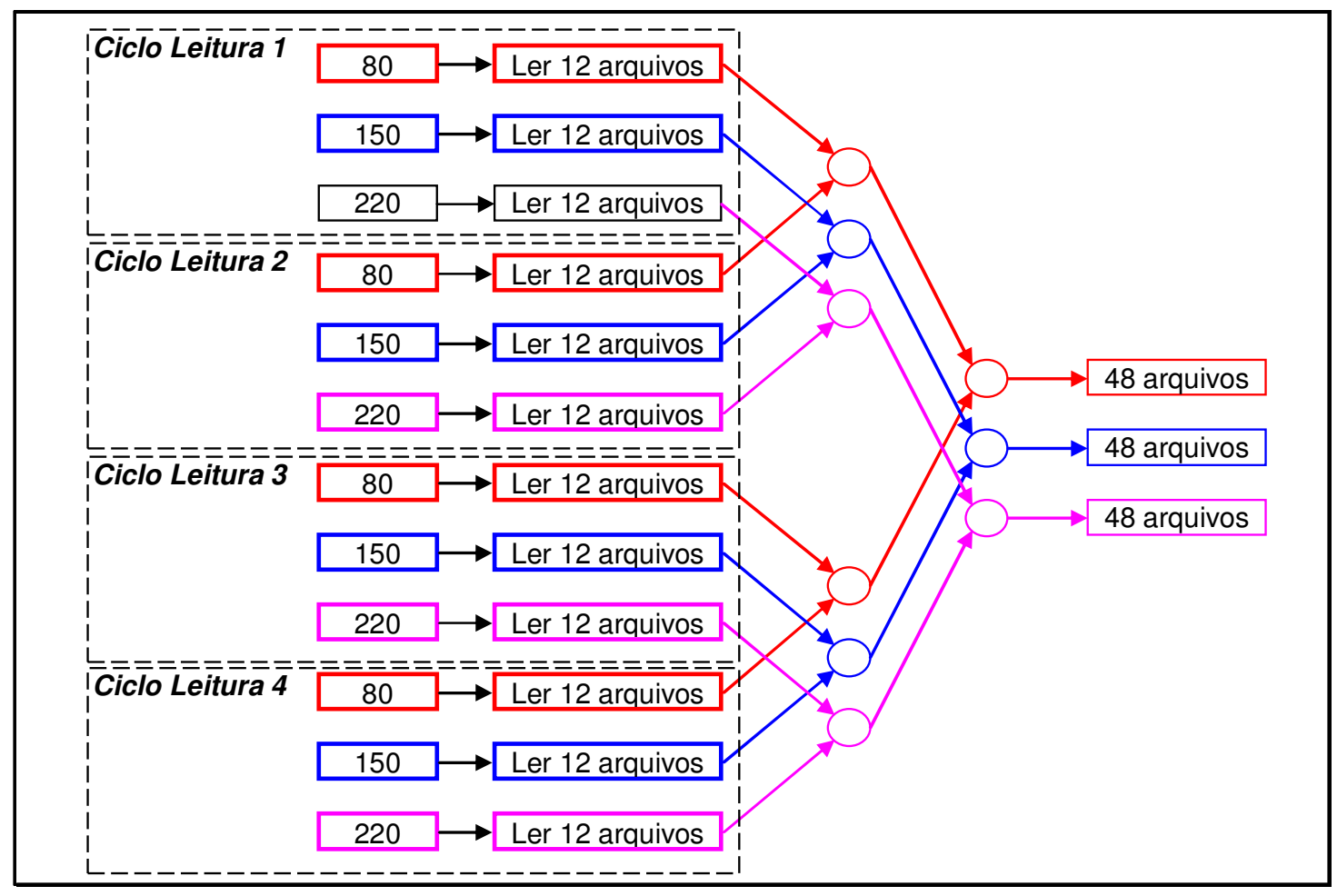

Figura 61 - Processo de leitura de arquivos por um sensor, segundo o planejamento experimental do riser (os valores de 80, 150 e 220 correspondem com os níveis de carregamento aplicados)

Dessa forma, os resultados para o caso da sonda No. 1 é resumido na tabela a seguir: 
Tabela 37 - Valores médios dos parâmetros para o sensor No. 1 (Carregamento 80T)

\begin{tabular}{cccccc}
\hline \multirow{2}{*}{ Sonda } & \multicolumn{5}{c}{ Valores médios } \\
\cline { 2 - 6 } & Rms & Energia & Eventos & Apico & Ppico \\
\hline 1 & 0.1506 & 0.0228 & 852 & 0.7407 & 27,887 \\
\hline
\end{tabular}

Esse mesmo procedimento foi feito para cada um dos sensores e para cada nível de carregamento. A partir dos dados dos sensores como os apresentados na Tabela 38, foram feitas as análises de qualidade dos dados como sugerido no item 2.1. Os valores médios para cada sensor foram apresentados nas Tabelas 2, 3, e 4, no item 4.2.1 
Tabela 38 - Cálculo dos parâmetros do sinal RMB para o sensor No. 1 (Carregamento 80T)

\begin{tabular}{|c|c|c|c|c|c|c|}
\hline Ciclo & Arquivo & Rms & Energia & Eventos & Apico & Ppico \\
\hline 1 & 1 & 0.147562455 & 0.021774678 & 848 & 0.74073 & 27887 \\
\hline 1 & 2 & 0.150976648 & 0.022793948 & 854 & 0.83706 & 12758 \\
\hline 1 & 3 & 0.157791004 & 0.024898001 & 858 & 0.74073 & 27887 \\
\hline 1 & 4 & 0.167333319 & 0.02800044 & 889 & 0.74084 & 13164 \\
\hline 1 & 5 & 0.142907805 & 0.020422641 & 836 & 0.67562 & 45018 \\
\hline 1 & 6 & 0.160890985 & 0.025885909 & 857 & 0.69749 & 11638 \\
\hline 1 & 7 & 0.14939267 & 0.02231817 & 893 & 0.7624 & 13020 \\
\hline 1 & 8 & 0.167736907 & 0.02813567 & 845 & 0.73858 & 44405 \\
\hline 1 & 9 & 0.16299565 & 0.026567582 & 879 & 0.7678 & 13508 \\
\hline 1 & 10 & 0.150192034 & 0.022557647 & 854 & 0.81257 & 12084 \\
\hline 1 & 11 & 0.137211629 & 0.018827031 & 814 & 0.63314 & 45211 \\
\hline 1 & 12 & 0.151104841 & 0.022832673 & 871 & 0.74073 & 27887 \\
\hline 2 & 1 & 0.138124038 & 0.01907825 & 833 & 0.73972 & 12499 \\
\hline 2 & 2 & 0.14776575 & 0.021834717 & 850 & 0.72798 & 45965 \\
\hline 2 & 3 & 0.149885262 & 0.022465592 & 840 & 0.7409 & 13706 \\
\hline 2 & 4 & 0.152061222 & 0.023122615 & 878 & 0.76317 & 46214 \\
\hline 2 & 5 & 0.156228174 & 0.024407242 & 864 & 0.80577 & 12398 \\
\hline 2 & 6 & 0.145304468 & 0.021113389 & 825 & 0.68238 & 13501 \\
\hline 2 & 7 & 0.141877013 & 0.020129087 & 887 & 0.75618 & 45020 \\
\hline 2 & 8 & 0.146069192 & 0.021336209 & 829 & 0.69075 & 45996 \\
\hline 2 & 9 & 0.131471109 & 0.017284652 & 857 & 0.74526 & 45460 \\
\hline 2 & 10 & 0.157732918 & 0.024879673 & 852 & 0.71921 & 14035 \\
\hline 2 & 11 & 0.142098269 & 0.020191918 & 829 & 0.695 & 13195 \\
\hline 2 & 12 & 0.14967936 & 0.022403911 & 828 & 0.75845 & 45080 \\
\hline 3 & 1 & 0.151884117 & 0.023068785 & 896 & 0.86089 & 44868 \\
\hline 3 & 2 & 0.143313717 & 0.020538821 & 853 & 0.67856 & 45774 \\
\hline 3 & 3 & 0.160526821 & 0.02576886 & 789 & 0.91606 & 12354 \\
\hline 3 & 4 & 0.153087821 & 0.023435881 & 849 & 0.71777 & 13208 \\
\hline 3 & 5 & 0.137819107 & 0.018994106 & 786 & 0.73742 & 11855 \\
\hline 3 & 6 & 0.133782553 & 0.017897771 & 880 & 0.56396 & 44109 \\
\hline 3 & 7 & 0.16021024 & 0.025667321 & 814 & 0.79636 & 13139 \\
\hline 3 & 8 & 0.147342955 & 0.021709946 & 839 & 0.78949 & 12000 \\
\hline 3 & 9 & 0.158134642 & 0.025006565 & 851 & 0.68161 & 12398 \\
\hline 3 & 10 & 0.144792257 & 0.020964798 & 836 & 0.62206 & 14080 \\
\hline 3 & 11 & 0.143227913 & 0.020514235 & 832 & 0.70228 & 13440 \\
\hline 3 & 12 & 0.148307038 & 0.021994978 & 818 & 0.78578 & 46088 \\
\hline 4 & 1 & 0.152219131 & 0.023170664 & 860 & 0.64347 & 44373 \\
\hline 4 & 2 & 0.16790892 & 0.028193406 & 840 & 0.79238 & 11826 \\
\hline 4 & 3 & 0.153816609 & 0.023659549 & 852 & 0.74089 & 45001 \\
\hline 4 & 4 & 0.152809244 & 0.023350665 & 880 & 0.66162 & 13342 \\
\hline 4 & 5 & 0.158247176 & 0.025042169 & 865 & 0.81112 & 45332 \\
\hline 4 & 6 & 0.155992107 & 0.024333537 & 866 & 0.7275 & 43647 \\
\hline 4 & 7 & 0.157537114 & 0.024817942 & 856 & 0.79608 & 12127 \\
\hline 4 & 8 & 0.150279222 & 0.022583845 & 878 & 0.73789 & 44976 \\
\hline 4 & 9 & 0.139256015 & 0.019392238 & 872 & 0.74695 & 44920 \\
\hline 4 & 10 & 0.161343157 & 0.026031614 & 875 & 0.79808 & 12949 \\
\hline 4 & 11 & 0.151036587 & 0.022812051 & 869 & 0.75755 & 44522 \\
\hline 4 & 12 & 0.142843023 & 0.020404129 & 866 & 0.77683 & 44721 \\
\hline
\end{tabular}

